\title{
Influence of Religion and Religiosity on Fertility and Contraceptive Use in Continental Sub-Saharan Africa: A Comprehensive Review
}

\author{
Nicola Turner \\ Master's thesis submitted in partial fulfilment [60 HEC] of the requirement for the degree of \\ Master of Atmosphere, Climate and Ecosystems [120 HEC] \\ Supervisor: Frank Götmark [BioEnv Sciences] \\ Examiner: Lennart Bornmalm [BioEnv and Marine Sciences]
}

June 2021 


\section{Signature Page}

I, Nicola Turner, declare to the University of Gothenburg Department of Biological and Environmental Sciences that this Thesis is my own original work and has not been nor is currently being submitted for a higher degree award at any other institution.

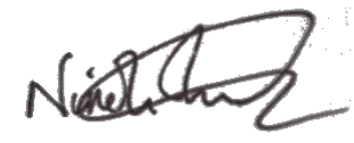

NICOLA TURNER $21^{\text {st }}$ May 2021

DATE 


\section{Acknowledgements}

Throughout the writing of this Thesis, I have received a great deal of support and assistance.

I would first like to thank my supervisor, Professor Frank Götmark, whose expertise and guidance from beginning to end pushed me to sharpen my thinking skills and brought my work to a higher level. I have learnt so much and am exceptionally grateful for your support.

I would like to acknowledge Åsa Arrhenius and Lennart Bornmalm for their continuous encouragement and advice, and ensuring my progress was kept on track.

I would also like to acknowledge the people of Africa that took part in the studies in this review for their contribution of invaluable information, their generosity with their time, and their honesty and courage in discussing potentially sensitive topics.

And finally, I would like to thank my mother for her love and support. 


\section{Abstract}

The global human population has been increasing at an alarming rate over the last 100 years and is projected by the United Nations (UN) to continue to increase and reach 10 billion by 2057, despite a declining growth rate. Although some countries and regions, primarily Japan and Europe, have stabilised or declining populations, Sub-Saharan Africa is dramatically growing at an annual rate of $2.7 \%$ as of 2019 , and is projected to sustain a rapid population growth up to 2100. Addressing the subject of population growth and overpopulation is an important but unfortunately neglected task. The consequences of a large, growing human population are already having distressing impacts on the planet, both on the natural environment and on humans, especially women and children. Until recently, there have been few studies on the effects of religion and religiosity on fertility and contraceptive use, and these factors are often overlooked as possible determinants. The aim of this review is to explore and seek to clarify the role of religion and religiosity on fertility and contraceptive use in continental Sub-Saharan African countries. The review of quantitative publications supported by insights and opinions from actual quotes of respondents from qualitative studies shows that followers of African Indigenous Religions and Islam have higher fertility rates than followers of Christianity. Across Christian denominations, Catholics generally had higher fertility than Protestants although the difference is small. Followers of the Apostolic Church exhibited the highest fertility among Christian groups. Focus group discussions and in-depth interviews from the qualitative studies found that religious beliefs were frequently cited as a barrier to contraceptive uptake. The findings clearly suggest that religion influences fertility and contraceptive use, although countries differ in this respect. Few studies mentioned religiosity; existing results show a positive relationship across Sub-Saharan Africa between degree of religiosity and fertility, and a negative relationship with contraceptive use. These relationships are stronger in Islamic and Indigenous religions compared with Christianity. Religious leaders across all religions were found to be highly influential and many participants were inclined to follow the recommendations of religious leaders regarding fertility and contraceptive use. The implication of this finding is that educating religious leaders about rights-based family planning and its benefits should be part of a comprehensive strategy to increase contraceptive uptake and reduce fertility. With knowledge of its benefits, religious leaders could spread accurate messages about family planning to their followers and promote higher contraceptive use and low fertility. In addition, other important socioeconomic and cultural factors influence fertility and contraceptive use. Education, economy and access to family planning have a negative relationship with religiosity, but the strength of this relationship varies depending on religion, residence and region, with Muslims generally reported as the most disadvantaged in terms of education and wealth across Sub-Saharan Africa. Polygyny, gender attitudes, social status and misconceptions about family planning were additional influences on fertility and contraceptive use mentioned in focus group discussions and in-depth interviews from the qualitative studies. Religion and religiosity have an important role to play in relation to fertility and contraceptive use, but they also depend on other factors, their interactions and their relative influences. They have variable relationships to education, economy, gender equality, residence (rural/urban) and access to family planning, due to the different levels of these factors among and within countries in Sub-Saharan Africa. The review suggests that with a more religiously open stance towards family planning, population policies can be more easily implemented. Religion and religiosity need to be considered in surveys and studies on fertility and contraceptive use to inform and help policymakers, economic planners, program managers, researchers and survey specialists. In addition, this has the potential to improve environmental conditions in Sub-Saharan Africa. 


\section{Table of Contents}

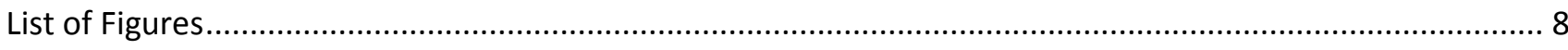

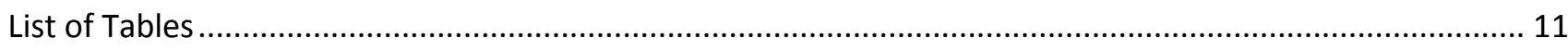

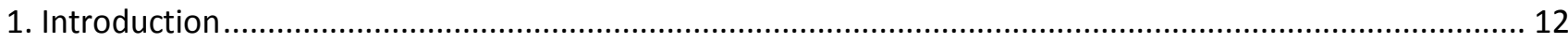

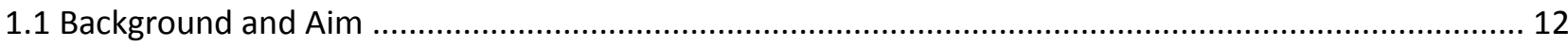

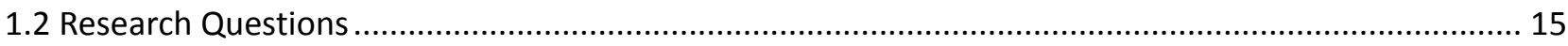

1.3 Religion, Religiosity and Religions in Sub-Saharan Africa............................................................ 16

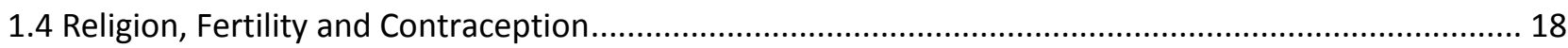

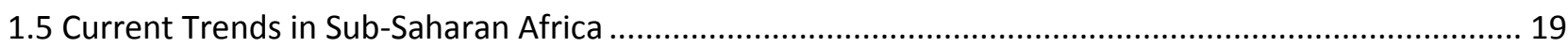

1.5.1 Total Fertility Rates and Contraceptive Prevalence Rates .......................................................... 19

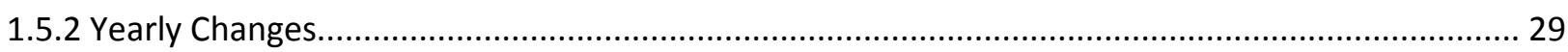

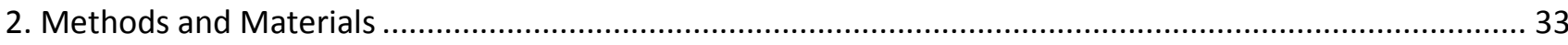

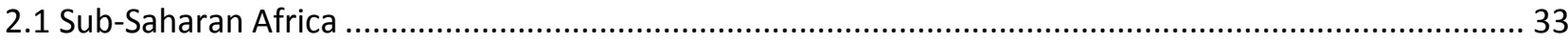

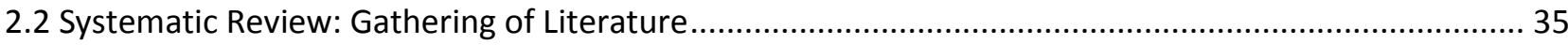

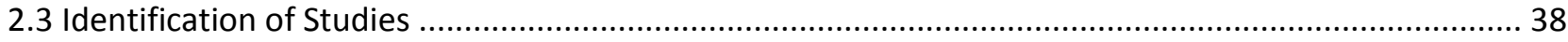

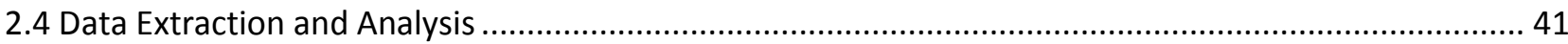

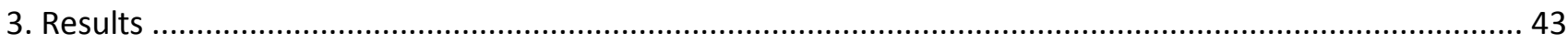

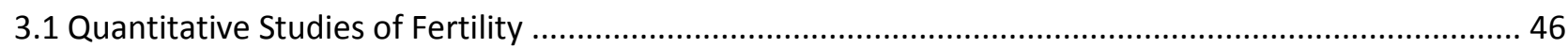

3.1.1 Achievement of Fertility Desires (in total 1 paper) …................................................................ 50

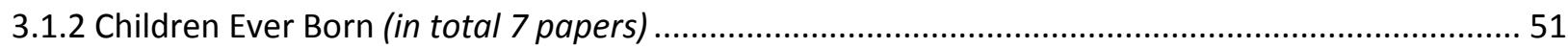

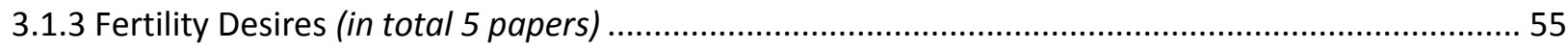

3.1.4 No. of Births in the Last Five Years (in total 3 papers) ................................................................ 61

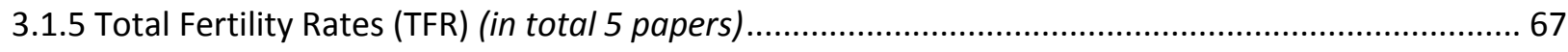

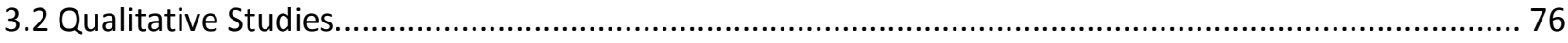

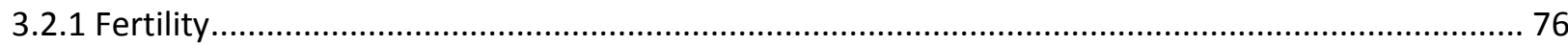

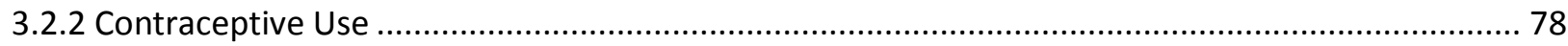

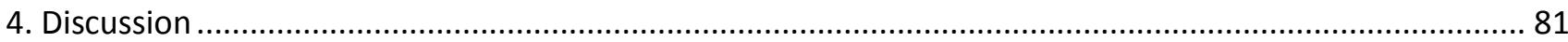

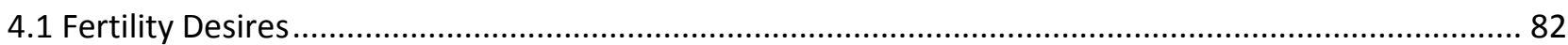

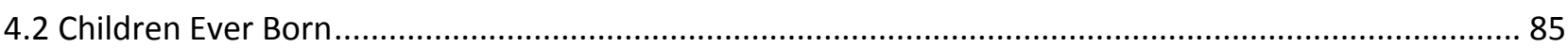

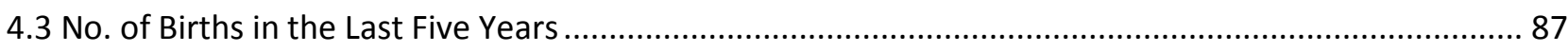

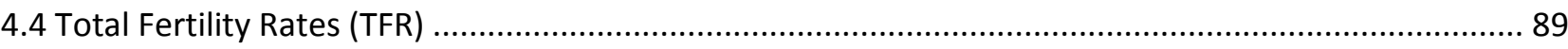

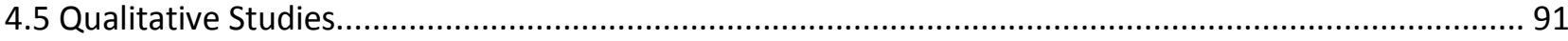

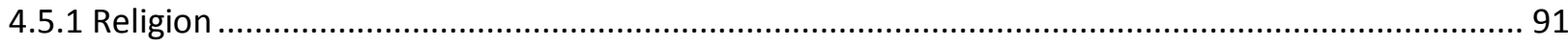

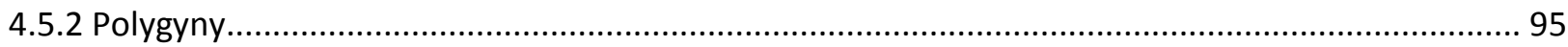




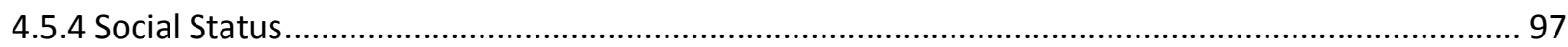

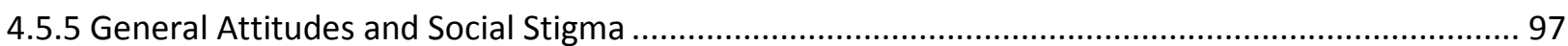

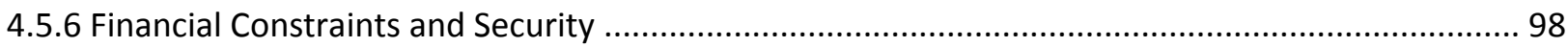

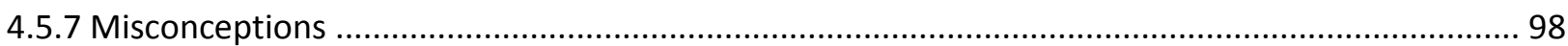

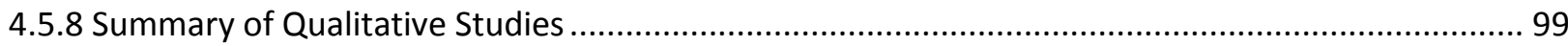

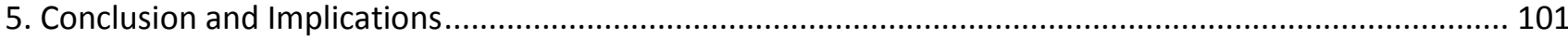

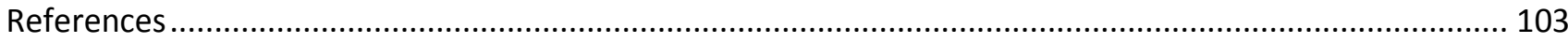

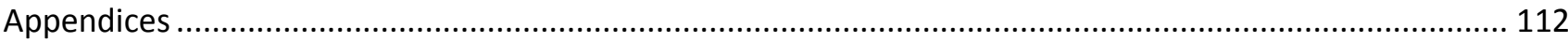

Appendix A: Distribution of Population by Denomination Across Sub-Saharan Africa.......................... 112

Appendix B: Statistical Data for Countries in Sub-Saharan Africa .................................................. 115

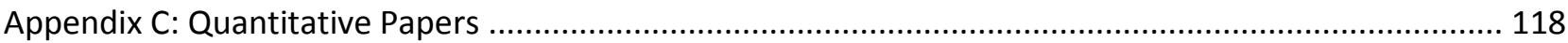

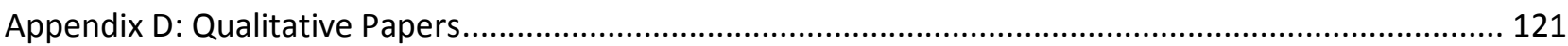

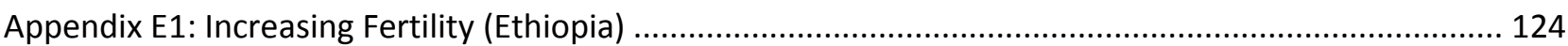

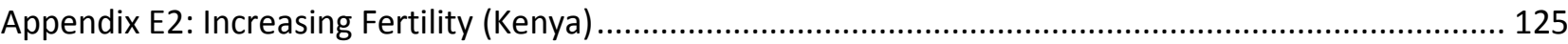

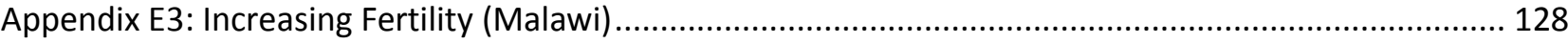

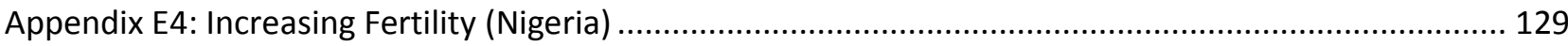

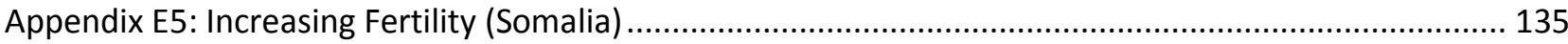

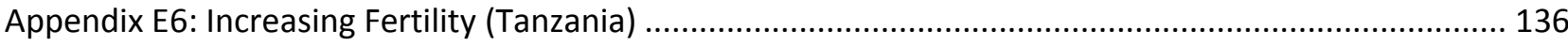

Appendix E7: Increasing Fertility (Uganda) ........................................................................... 138

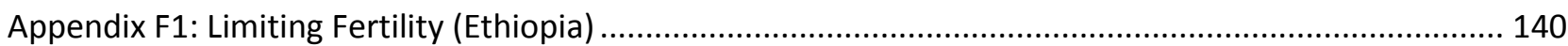

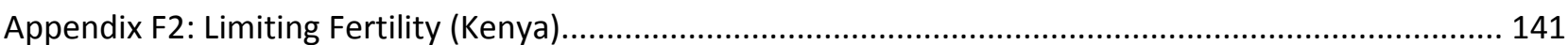

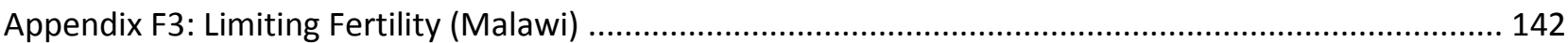

Appendix F4: Limiting Fertility (Nigeria) ............................................................................ 143

Appendix F5: Limiting Fertility (Tanzania) ......................................................................... 144

Appendix G1: Lower Acceptance of Family Planning (Ethiopia) ................................................ 146

Appendix G2: Lower Acceptance of Family Planning (Kenya) .................................................... 148

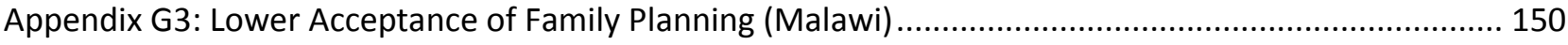

Appendix G4: Lower Acceptance of Family Planning (Nigeria) .................................................. 153

Appendix G5: Lower Acceptance of Family Planning (Somalia) .................................................. 161

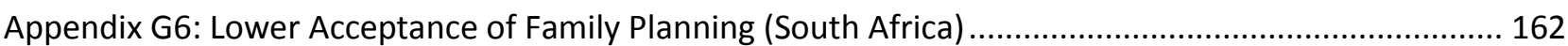

Appendix G7: Lower Acceptance of Family Planning (Tanzania) ................................................. 165

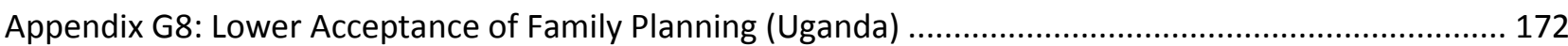

Appendix H1: Higher Acceptance of Family Planning (Ethiopia) ................................................ 175 
Appendix H2: Higher Acceptance of Family Planning (Kenya) ......................................................... 178

Appendix H3: Higher Acceptance of Family Planning (Malawi) .......................................................... 180

Appendix H4: Higher Acceptance of Family Planning (Nigeria) ............................................................. 182

Appendix H5: Higher Acceptance of Family Planning (Somalia) ......................................................... 188

Appendix H6: Higher Acceptance of Family Planning (South Africa) ....................................................... 189

Appendix H7: Higher Acceptance of Family Planning (Tanzania)............................................................ 191

Appendix H8: Higher Acceptance of Family Planning (Uganda)........................................................... 195 


\section{List of Figures}

FIGURE 1. TOTAL GLOBAL HUMAN POPULATION SIZE AND ANNUAL GROWTH RATE, WITH A MEDIUM-VARIANT PROJECTION WITH 95 PERCENT PREDICTION INTERVALS. POPULATION GROWTH IS PROJECTED TO CONTINUE EXPANDING AT THE GLOBAL LEVEL, BUT THE GROWTH RATE IS SLOWING, UNDER THE MODEL OF ASSUMPTION OF THE UN. THE POPULATION SIZE MIGHT REACH A PEAK BY THE END OF THE $21^{\text {ST }}$ CENTURY. [SOURCE: United NATIONS, 2020]...

Figure 2. PAST AND PROJECTED POPULATION BASED ON REGIONS FROM THE UNITED NATIONS SUSTAINABLE DEVELOPMENT GoALS, WITH A MEDIUM-VARIANT PROJECTION AND 95 PERCENT PREDICTION INTERVALS. OF THE EIGHT REGIONS, ONLY SUB-SAHARAN AFRICA IS PROJECTED TO SUSTAIN A RAPID POPULATION GROWTH UP TO YEAR 2100. [SOURCE: UNITED NATIONS, 2020]

Figure 3. Distribution of RELIGIONS ACROSS SUb-SAHARAN AfricA. GREY AREAS DENOTE NO dATA AVAILABLE. [DATA SOURCE: UNITED NATIONS, 2020]

FIgURE 4. TFR HAS A NEGATIVE RELATIONSHIP WITH CPR (\%) ACROSS SUB-SAHARAN AFRICA..................................................... 19

FIGURE 5. POPULATION SIZE HAS A POSITIVE RELATIONSHIP WITH TFR ACROSS SUB-SAHARAN AFRICA................................................20

Figure 6. PopUlation SIZE HAS A WEAK NEGATIVE RELATIONSHIP WITH CPR (\%) ACROSS SUB-SAHARAN AfRICA. ............................... 20

FIGURE 7. GDP PER CAPITA (US\$) HAS A NEGATIVE RELATIONSHIP WITH TFR (\%) ACROSS SUB-SAHARAN AfRICA ................................. 21

FIGURE 8. GDP PER CAPITA (US\$) HAS A POSITIVE RELATIONSHIP WITH CPR (\%) ACROSS SUB-SAHARAN AFRICA.................................. 21

FIgURE 9. TFR HAS A WEAK POSITIVE RELATIONSHIP WITH MUSLIM POPULATIONS (\%) ACROSS SUB-SAHARAN AfRICA............................. 23

FIGURE 10. CPR (\%) HAS A NEGATIVE RELATIONSHIP WITH MUSLIM POPULATIONS (\%) ACROSS SUB-SAHARAN AfRICA............................ 23

Figure 11. TFR haS A WEAK NEGATIVE RELATIONSHIP With Christian POPULATIONS (\%) ACROSS SUb-SAHARAN Africa....................... 24

Figure 12. CPR (\%) HAS A POSITIVE RELATIONSHIP WITH CHRISTIAN POPULATIONS (\%) ACROSS SUB-SAHARAN AfricA. ........................ 24

Figure 13. TFR haS A POSITIVE RELATIONSHIP WITH CATHOLIC POPULATIONS (\%) ACROSS SUb-SAHARAN AfRICA.................................. 25

FIGURE 14. CPR (\%) HAS A NEGATIVE RELATIONSHIP WITH CATHOLIC POPULATIONS (\%) ACROSS SUB-SAHARAN AfriCA .......................... 25

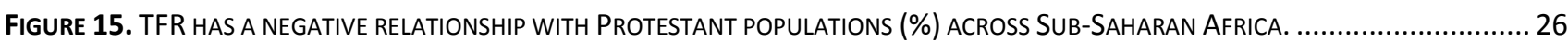

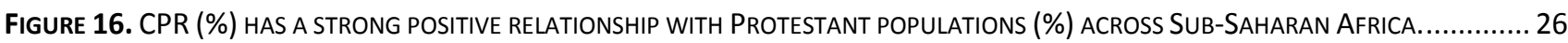

Figure 17. TFR haS A NEGATIVE RELATIONSHIP WITH INDIgENOUS ReligIONS POPULATIONS (\%) ACROSS SUb-SAHARAN AfRICA............... 27

FiguRE 18. CPR (\%) HAS A WEAK NEGATIVE RELATIONSHIP WITH INDIGENOUS RELIGION POPULATIONS (\%) ACROSS SUB-SAHARAN AFRICA. . 27

Figure 19. TFR hAS A NEGATIVE RELATIONSHIP WITH NO RELIGIOUS AFFILIATION POPULATIONS (\%) ACROSS SUB-SAHARAN AFRICA. ........... 28

Figure 20. CPR (\%) HAS A POSITIVE RELATIONSHIP WITH NO RELIGIOUS AFFILIATION POPULATIONS (\%) ACROSS SUB-SAHARAN AFRICA. ...... 28

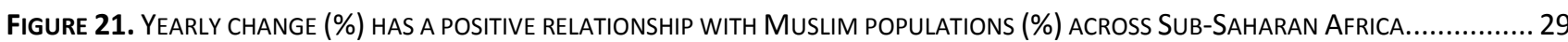

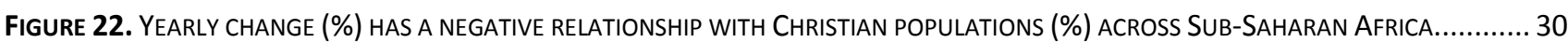

Figure 23. Yearly Change (\%) has a positive Relationship With Catholic Populations (\%) aCross Sub-Saharan Africa.............. 30

Figure 24. Yearly change (\%) has a negative Relationship With Protestant Populations (\%) across Sub-Saharan Africa. ....... 31

FigURE 25. YEARLY CHANGE (\%) HAS A NEGATIVE RELATIONSHIP WITH INDIGENOUS RELIGIONS POPULATIONS (\%) ACROSS SSA. ................ 31

Figure 26. YEARLY CHANGE (\%) HAS A NEGATIVE RELATIONSHIP WITH NO RELIGIOUS AFFILIATION POPULATIONS (\%) ACROSS SSA............... 32

Figure 27. SUb-SAHARAN AFRICA IS DEFINED BY THE UN AS ALL AFRICAN COUNTRIES THAT ARE FULLY OR PARTIALLY LOCATED SOUTH OF THE SAHARA DESERT. COUNTRIES SOUTH OF THE BLACK LINE ARE SUB-SAHARAN NATIONS THAT WERE INCLUDED IN THIS STUDY. [SOURCE: NATIONS ONLINE PROJECT, 2019].

Figure 28. VENN DIAGRAMS SHOWING THE PERCENTAGES OF PAPERS THAT WERE FOUND THROUGH WEB OF SCIENCE, SCOPUS, AND THE PERCENTAGES THAT OVERLAPPED FOR EACH DECADE BETWEEN 1990 AND 2020, AS WELL AS THE TOTAL......................................37

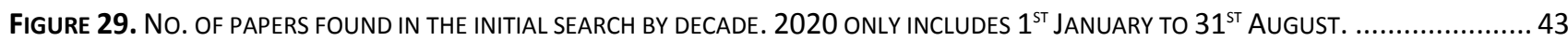

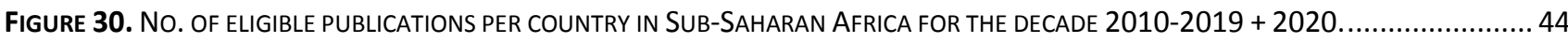

FIgURE 31. THE STUDIES EXAMINED COVER 35 COUNTRIES OUT OF THE 44 NATIONS THAT QUALIFY AS CONTINENTAL SUB-SAHARAN AFRICA. . 45

FIgURE 32. QUANTITATIVE STUDIES EXAMINED COVER 34 COUNTRIES ACROSS CONTINENTAL SUB-SAHARAN AfRICA...............................45

FIGURE 33. QUALITATIVE STUDIES EXAMINED COVER EIGHT COUNTRIES ACROSS CONTINENTAL SUB-SAHARAN AFRICA............................46

Figure 34. FERTILITY DISTRIBUTION BETWEEN CHRISTIANS AND AfRICAN INDIGENOUS RELIGIONS. AfricAN INDIGENOUS RELIGIONS HAD HIGHER FERTILITY THAN CHRISTIANS ACROSS ALL COUNTRIES. THE SIZE OF THE BAR INDICATES THE MAGNITUDE OF FERTILITY DIFFERENCE

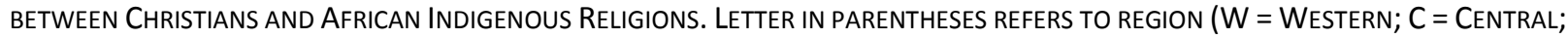
$\mathrm{E}=$ EASTERN; $\mathrm{S}=$ SOUTHERN). $[N=$ NO. OF PAPERS. $]$ 


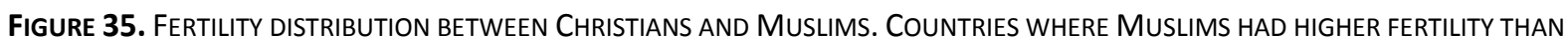
CHRISTIANS IS PRESENTED ON THE RIGHT; COUNTRIES WHERE CHRISTIANS HAD HIGHER FERTILITY THAN MUSLIMS IS PRESENTED ON THE LEFT. THE SIZE OF THE BAR INDICATES THE MAGNITUDE OF FERTILITY DIFFERENCE BETWEEN CHRISTIANS AND MUSLIMS. LETTER IN PARENTHESES REFERS TO REgION (W = Western; $C=$ Central; E = EASTERN; $S=$ SOUthern). [ $N=$ No. OF PAPERS.]

Figure 36. FERTILITY DISTRIBUTION BETWEEN MUSLIMS AND AfRICAN INDIGENOUS RELIGIONS. COUNTRIES WHERE AfRICAN INDIGENOUS RELIGIONS HAD HIGHER FERTILITY THAN MUSLIMS IS PRESENTED ON THE RIGHT; COUNTRIES WHERE MUSLIMS HAD HIGHER FERTILITY THAN AFRICAN INDIGENOUS RELIGIONS IS PRESENTED ON THE LEFT. THE SIZE OF THE BAR INDICATES THE MAGNITUDE OF FERTILITY DIFFERENCE

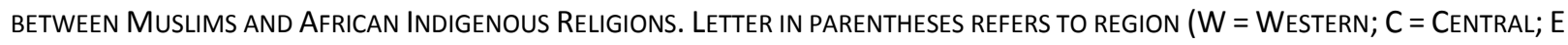
$=$ EASTERN; $S=$ SOUTHERN). [ $N=$ NO. OF PAPERS. $]$

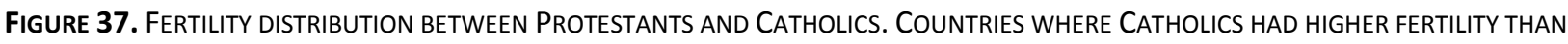
PROTESTANTS IS PRESENTED ON THE RIGHT; COUNTRIES WHERE PROTESTANTS HAD HIGHER FERTILITY THAN CATHOLICS IS PRESENTED ON THE LEFT. THE SIZE OF THE BAR INDICATES THE MAGNITUDE OF FERTILITY DIFFERENCE BETWEEN PROTESTANTS AND CATHOLICS. LETTER IN PARENTHESES REFERS TO REGION (W = WESTERN; C = CENTRAL; E = EASTERN; $S=$ SOUTHERN). [ $N=$ No. OF PAPERS.]

Figure 38. MEAN NUMBER OF CHILDREN EVER BORN (CEB) FOR ChRISTIANS, MUSLIMS, INDIGENOUS RELIGIONS AND NO RELIGIOUS AfFiliation. [ $N$ = SAMPle Size.] [DATA SOURCE: AgAdjanian \& YABIKU, 2014; CheMHAKA \& OdIMEgWU, 2020; NTOIMO \& Mutanda, 2017] [NB: For EsWatini And Mozambique, Christian (Total) WAs Calculated by taking the aVerage of AlL the CHRISTIAN RELIGIONS.]

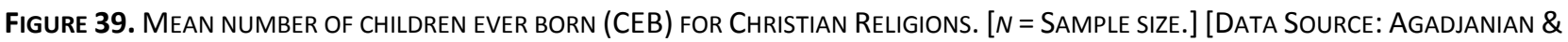
YABIKU, 2014; CHEMHAKA \& OdIMEgWU, 2020; NTOIMO \& MutANDA, 2017] [NB: For MozAMbIQUe, Other Christian WAS CAlCulated by taking the AVERAge of all the Christian Religions eXCEPt Catholic. NBB: For EsWatini, "Apostolic/Zion" IS Represented by "Apostolic", and "Pentecostal/Charismatic" is Represented by "Pentecostal".]

Figure 40. MEAN NUMBer OF CHILDREN EVER BORn (CEB) IN NIGERIA BETWEen 2003 AND 2013 FOR WOMEN AGED 15-49 YEARS. [DATA

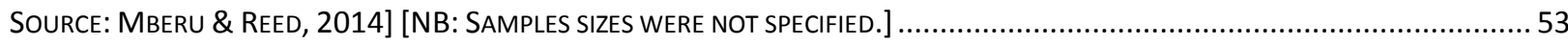

Figure 41. MEAN NUMBER OF CHILDREN EVER BORn (CEB) IN NIGERIA BETWEen 2003 AND 2013 FOR WOMEN AGED 40-49 YEARS. [DATA SOURCE: MBERU \& REED, 2014] [NB: SAMPLES SIZES WERE NOT SPECIFIED.]

Figure 42. MEAN NUMBER OF CHILDREN EVER BORN (CEB) FOR MIXED RELIGION COUPLES. [ $N$ = SAMPLE SIZE.] [DATA SOURCE: NTOIMO \& MUTANDA, 2017].

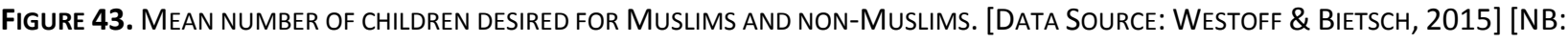
SAMPLES SIZES WERE NOT SPECIFIED.] [NBB: FOR MALAWI, AVERAGE OF ALL NON-MUSLIM RELIGIONS GENERATED THE NON-MUSLIM NUMBER FOR COMPARATIVE PURPOSES.]

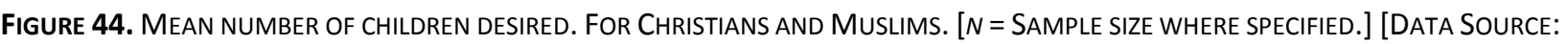
MUHOZA, ET AL., 2014; WESTOFF \& BIETSCH, 2015]

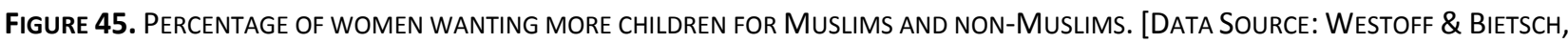
2015] [NB: SAMPLES SIZES WERE NOT SPECIFIED.] [NBB: For MALAWI, AVERAGE OF ALL NON-MUSLIM RELIGIONS GENERATED THE NON-MUSLIM NUMBER FOR COMPARATIVE PURPOSES.]

Figure 46. PerCentage of WOMEN WANTING MORE CHILDREN FOR IN MALAWI. [N = SAMPLE SIZE WHERE SPECIFIED.] [DATA SOURCE: Adebowale \& PalamulenI, 2015]

Figure 47. PeRCENTAGe of WOMEN OF EACH RELIGION WANTING 0-3 (TOP), 4-5 (CENTRE) AND 6+ (BOTTOM) CHILDREN IN RWANDA AND KenYA. [ $N$ = SAMPLE SIZE.] [DATA SOURCE: MUHOZA, 2019]

FIGURE 48. PERCENTAGE OF COUPLES WITH EQUAL FERTILITY DESIRES (TOP) AND WITH HUSBAND HAVING HIGHER FERTILITY DESIRES (BOTTOM) IN NIGERIA. [ $N$ = SAMPLE SIZE.] [DATA SOURCE: OdUSINA, ET AL., 2020].

Figure 49. MEAN NUMBER OF BIRTHS IN THE LAST FIVE YEARS FOR CHRISTIANS, MUSLIMS, OtHeR ReLIGIONS AND THOSE WITH NO RELIGIOUS

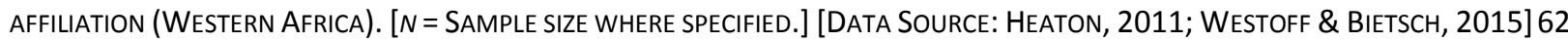

Figure 50. MEAN NUMBer of BIRTHS IN THE LAST FIVE YEARS FOR ChRISTIAN RELIGIONS (WESTERn AfricA). [ $N=$ SAMPLE SIZE WHERE SPECIFIED.] [DATA SOURCE: HEATON, 2011; WeSTOFF \& BIETSCH, 2015]

Figure 51. MEAN NUMBeR OF BIRTHS IN THE LAST FIVE YEARS FOR CHRISTIANS, MUSLIMS, Other ReLIGIONS AND thOSE WITH NO RELIGIOUS affiliation (CEntral Africa). [ $N$ = SAMple size Where SPECified.] [DATA SOURCe: Heaton, 2011; Westoff \& BietSCH, 2015]. 64

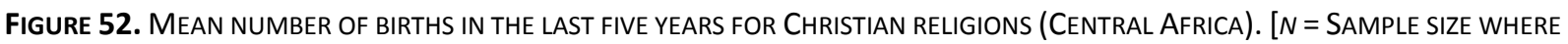
SPECIFIED.] [DATA SOURCE: HeATON, 2011; WeSTOFF \& BIETSCH, 2015] 
Figure 53. MEAN NUMBER OF BIRTHS IN THE LAST FIVE YEARS FOR CHRISTIANS, MUSLIMS, OtHeR RELIGIONS AND thOSE WITH NO RELIGIOUS

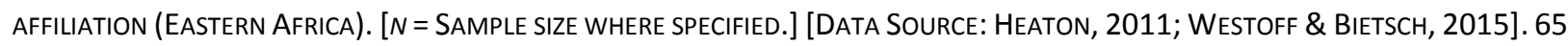

Figure 54. MEAN NUMBER OF BIRTHS IN THE LAST FIVE YEARS FOR CHRISTIAN RELIGIONS (EASTERN AFRICA). [ $N=$ SAMPLE SIZE WHERE SPECIFIED.] [DATA SOURCE: HEATON, 2011; WESTOFF \& BIETSCH, 2015]

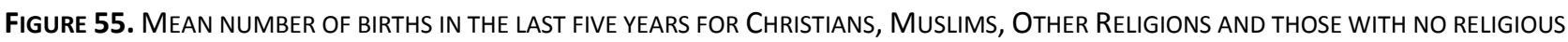

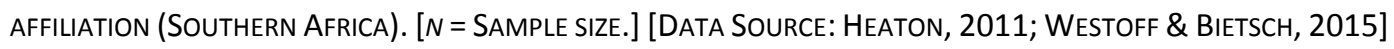

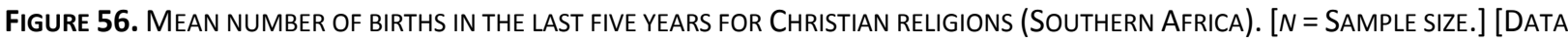
SOURCE: HEATON, 2011; WESTOFF \& BIETSCH, 2015]

Figure 57. TFR for Christian, Muslim and Indigenous / Other Religions (WeStern Africa). [Data SourCe: Nansubuga, et al., 2011; WESTOFF \& BIETSCH, 2015] [NB: SAMPLES SIZES WERE NOT SPECIFIED.]

Figure 58. TFR for Christian Religions (Western Africa). [DATA SOURCE: NANSUbuga, et al., 2011; WeStoff \& BietSCH, 2015] [NB: SAMPLES SIZES WERE NOT SPECIFIED; NBB: MAJOR ChRISTIAN RELIGION OF BENIN IS CELESTIAL ReVIVAL ChURCH.].

Figure 59. TFR for Christian, Muslim and Indigenous / Other Religions (CEntral Africa). [DATA SOURCE: NANSUbuga, et al., 2011; WESTOFF \& BIETSCH, 2015] [NB: SAMPLES SIZES WERE NOT SPECIFIED.]

Figure 60. TFR for Christian Religions (Central Africa). [Data Source: NAnsubuga, et al., 2011; Westoff \& BietsCh, 2015] [NB: SAMPLES SIZES WERE NOT SPECIFIED; NBB: MAJOR CHRISTIAN RELIGION OF CONGO IS UNSPECIFIED.]

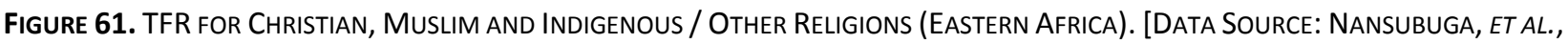
2011; WESTOFF \& BIETSCH, 2015] [NB: SAMPLES SIZES WERE NOT SPECIFIED.]

Figure 62. TFR for Christian Religions (EASTERn Africa). [DATA SOURCE: NANSUbuga, ET AL., 2011; Westoff \& BIETSCH, 2015] [NB: SAMPLES SIZES WERE NOT SPECIFIED; NBB: MAJOR CHRISTIAN RELIGION OF ETHIOPIA IS ORTHOdOX; MAJOR CHRISTIAN RELIGIONS OF MALAWI, MOZAMBIQUE AND ZIMBABWE ARE UNSPECIFIED.].

Figure 63. TFR for Christian, Muslim and Indigenous / Other Religions (SOUthern Africa). [Data SourCe: NANSUbuga, et al., 2011; WeSTOFF \& BIETSCH, 2015] [NB: SAMPLES SIZES WERE NOT SPECIFIED.]

Figure 64. TFR for Christian Religions (SOUthern Africa). [DATA SOURCE: NANSUBuga, et AL., 2011; WeStoff \& BietSCH, 2015] [NB: SAMPLES SIZES WERE NOT SPECIFIED; NBB: MAJOR CHRISTIAN RELIGIONS OF LESOTHO AND NAMIBIA ARE UNSPECIFIED.]

Figure 65. TFR for Christians ANd MusLims in SHARIA AND NON-SHARIA LAW StATES IN NIGERIA BETWEen 1990 AND 2013. [ $N=$ SAMPLE SIZE.] [DATA SOURCE: STONAWSKI, ET AL., 2016] [NB: BECAUSE OF THE SMALL NUMBER OF OBSERVATIONS, IT WAS NOT POSSIBLE TO CALCULATE TFR FOR CHRISTIANS IN SHARIA STATES IN 1990.]

Figure 66. TFR fOR CRL AND NON-CRL StATES In NIGERIA. [MCGOVERn, et AL., 2019] [NB: SAMPLES SIZES WERE NOT SPECIFIED.] ...... 75

FIGURE 67. FREQUENCY THE THEME OF RELIGION WAS MENTIONED AS A FACTOR FOR FERTILITY..................................................... 76

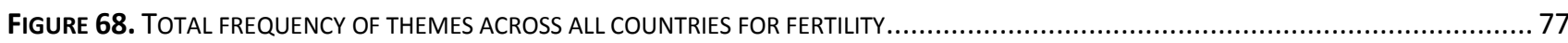

FIGURE 69. FREQUENCY THE THEME OF RELIGION WAS MENTIONED AS A FACTOR FOR ACCEPTANCE OF FAMILY PLANNING (FP).................. 78

FIGURE 70. TOTAL FREQUENCY OF THEMES ACROSS ALL COUNTRIES FOR ACCEPTANCE OF FAMILY PLANNING (FP) ................................. 


\section{List of Tables}

TABLE 1. TOtAL NUMBER OF PAPERS AND THEIR CORRESPONDING PERCENTAGES FOUND FOR EACH LITERATURE SOURCE.

TABLE 2. CRITERIA TO ESTABLISH THE STRENGTH OF FOCUS ON RELIGION AND RELIGIOSITY FROM CONCLUSIONS IN EXAMINED PAPERS............ 38

TABLE 3. CLASSIFICATION OF MODERN AND TRADITIONAL CONTRACEPTIVES AS DEFINED BY THE DHS PROGRAM. ...................................39

TABLE 4. LIST OF INCLUSION AND EXCLUSION CRITERIA. PAPERS THAT MET ALL THE INCLUSION CRITERIA WERE INCLUDED IN THE STUDY; PAPERS

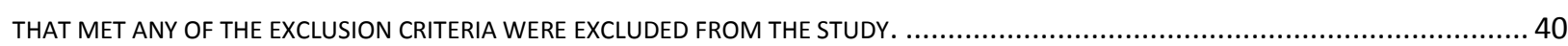

TABLE 5. NUMBER OF PAPERS REPRESENTED FOR EACH CLASSIFICATION. ............................................................................

TABle 6. NumBer Of PAPERS REPRESENTING EACH DEPENDENT VARIABLE RELATING TO FERTILITY FOR GENERAL POPULATION: ALL REPRODUCTIVE AGES (12-65 YEARS). 


\section{Introduction}

\subsection{Background and Aim}

The global human population has been increasing at an alarming rate over the last 200 years, from 1 billion in 1804 to 2 billion in 1930, doubling to 4 billion in 1974, 6 billion in 1999, and currently sits at 7.8 billion people. The population is projected by the United Nations (UN) to continue to increase substantially, to 10 billion by 2057 despite a declining growth rate (Figure 1). Although some countries and regions, such as Japan and parts of Europe, have stabilised or even declining populations, Sub-Saharan Africa has dramatic growth. In SubSaharan Africa, many countries have a young population; $40-50 \%$ of the populations are under 15 years of age, thereby contributing to further growth through population momentum (Week, 2015; United Nations, 2020). Among the eight regional groups from the UN Sustainable Development Goals (SDGs), only Sub-Saharan Africa is projected to sustain a rapid population growth up to 2100 , while the seven other regions either have started to decline, or are projected to stabilise, by 2100 (United Nations, 2020) (Figure 2). According to the UN Population Division, the population of Sub-Saharan Africa is growing at an annual rate of 2.7\%, as of 2019. At a rate of $2 \%$ annual increase, a country's population doubles in 35 years.

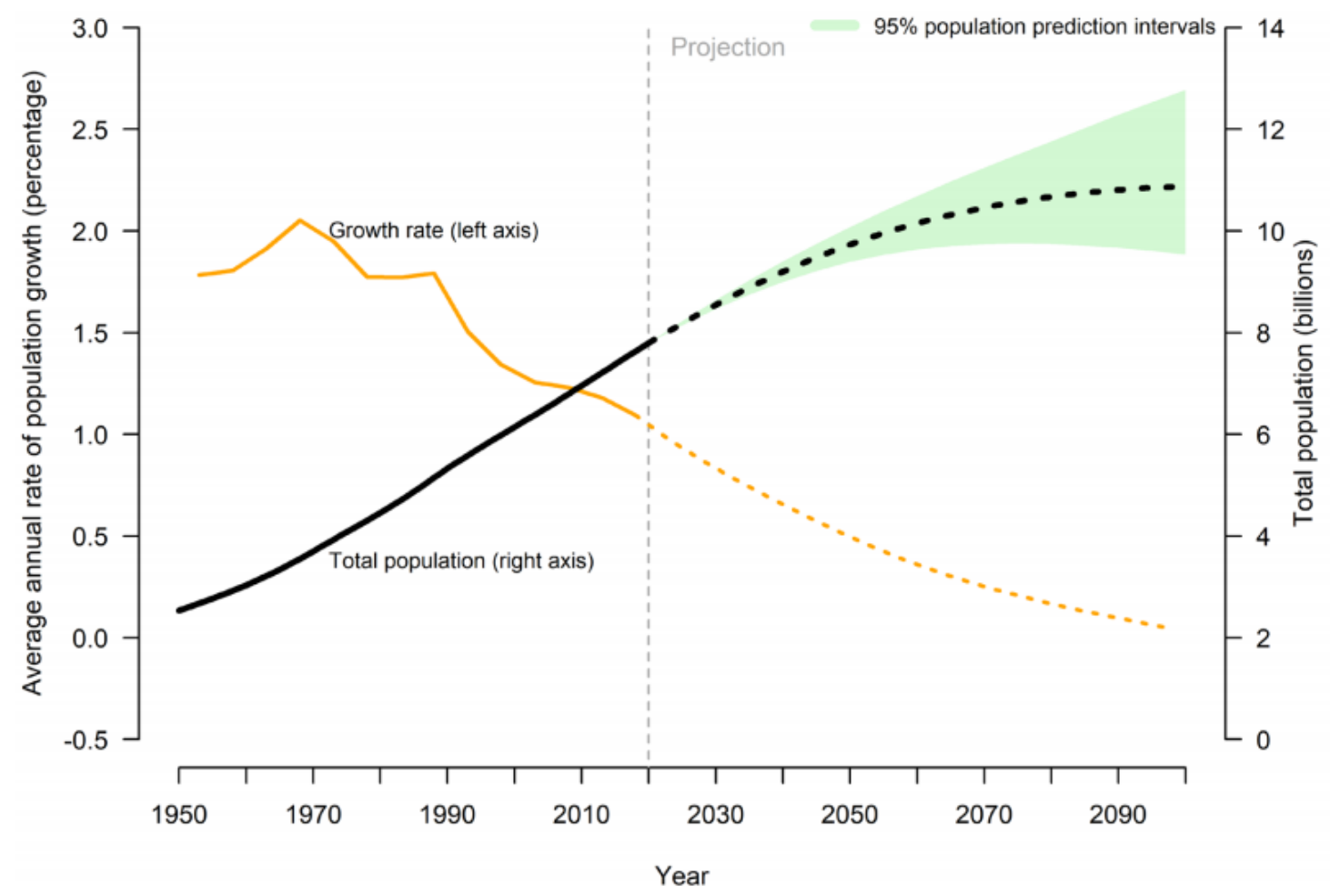

Figure 1. Total global human population size and annual growth rate, with a medium-variant projection with 95 percent prediction intervals. Population growth is projected to continue expanding at the global level, but the growth rate is slowing, under the model of assumption of the UN. The population size might reach a peak by the end of the $21^{\text {st }}$ Century. [Source: United Nations, 2020] 


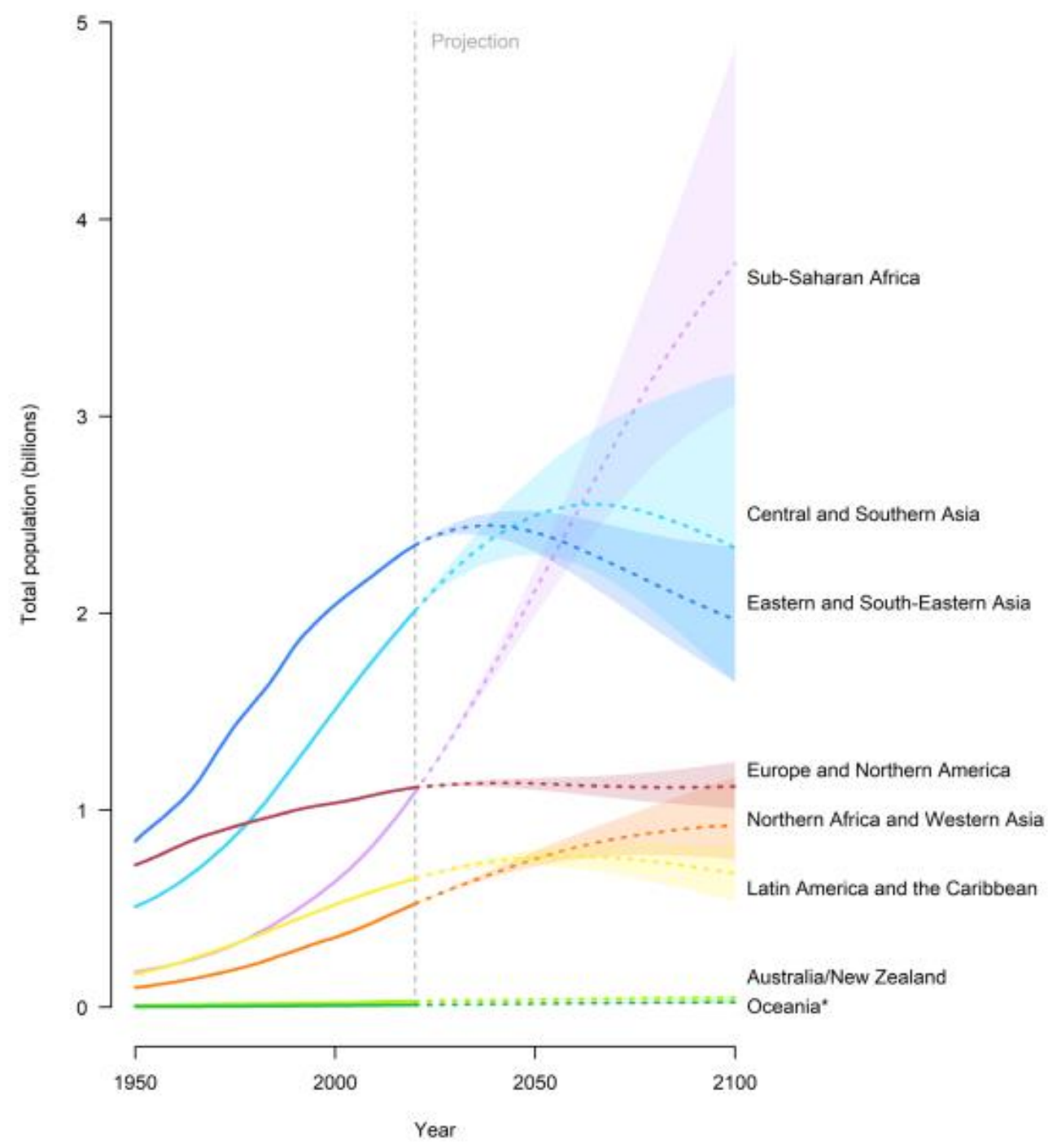

Figure 2. Past and projected population based on regions from the United Nations Sustainable Development Goals, with a medium-variant projection and 95 percent prediction intervals. Of the eight regions, only Sub-Saharan Africa is projected to sustain a rapid population growth up to year 2100. [Source: United Nations, 2020]

In this Thesis, I argue that addressing population growth and overpopulation is an important and neglected subject that deserves much more attention. The large human population has serious impacts on the planet, both on the natural environment and on humans. These include the destruction of many natural ecosystems, extinction of biodiversity and wild habitats, overexploitation of vast expanses of land and loss of land fertility, overconsumption and depletion of natural resources, hunger and starvation locally due to there being more people than can be fed, and cultural, economic and political turmoil contributing to poverty (Foreman and Carroll, 2014). These are issues often reported by scientists and in the media, and they need to be dealt with urgently. However, the role of population growth is rarely mentioned in the media, and this is also true regarding media reports from Africa.

The Total Fertility Rate (TFR) and Contraceptive Prevalence Rate (CPR) are major determinants of population growth. TFR is the average number of children women would bear, if they survive to the end of reproductive life and have the same probability of child-bearing in each age interval as currently prevails across the population (Week, 2015). A TFR of 2.1 children per woman is known as the Replacement Level Fertility. This is 
the average number of children a woman would need to have to replace herself and her partner to maintain a sustained, relatively stable population (World Health Organisation, 2006). This number takes into account infant and child mortality, and therefore the number is 2.1 rather than 2.0. CPR is the "proportion of women at reproductive age who are using, or whose partner is using, a contraceptive method at a given point in time" (World Health Organisation, 2006).

Studies show that TFR correlates negatively with level of education (i.e. number of years in school), female autonomy, gross domestic product (GDP) per capita and access to family planning services, and positively with religiosity in Sub-Saharan Africa, and across global regions (Götmark \& Andersson, 2020). However, until recently, few studies exist on the role of religion and religiosity for TFR and CPR, and these factors are often overlooked in published work. Many Sub-Saharan African countries lack detailed studies on the relationships between religion and religiosity and TFR and CPR; most studies thus far were conducted in Ethiopia, Ghana, Kenya and Nigeria.

Below, I review the scientific literature to explore and seek to clarify the role of religion and religiosity on fertility and contraceptive use in Sub-Saharan African countries. To judge the role of religion and religiosity, I examine other variables as well and their relationships to fertility and contraceptive use, including education, economy (GDP per capita), female autonomy, and access to family planning services. Because most studies in the review dealt with religion and few examined religiosity, the term "religion" (i.e. denomination, like Christianity or Catholicism) is used below unless the study, analysis or question comprise religiosity (degree of belief in God or supernatural agent). Furthermore, because not all studies specifically examined TFR and CPR as defined above, I use "fertility" to describe all measures related to the number of children being born, including children ever born, children born in the last five years, fertility desires and achievement, and TFR. "Contraceptive use" describes all measures related to current and ever contraceptive practices as well as future intentions for contraceptive use. Although most studies examined the uptake of modern contraceptives, this Thesis is not limited to modern methods. 


\subsection{Research Questions}

For the review of the literature, the following research questions were set:

1. Are there correlations between degree of religiosity and fertility/contraceptive use? If so, how strong are they?

2. Do religions differ with respect to levels of fertility/contraceptive use?

3. How do religion and religiosity relate to factors such as education, economy, gender equality and access to family planning? Do religions differ in these respects?

4. Taking into account religion and religiosity and these other factors overall, what is the relative importance of religion/religiosity for fertility/contraceptive use?

5. Do the relationships of religion and religiosity to factors such as education, economy, gender equality and access to family planning vary between countries and regions within Sub-Saharan Africa? What may cause this variation?

With respect to these questions and previous studies, I expect that:

1. There is a positive correlation between degree of religiosity and fertility, and a negative correlation for contraceptive use. These correlations are likely to be stronger in Islamic and African Indigenous Religions, but weaker Christian religions.

2. Islam and African Indigenous Religions have higher fertility and lower contraceptive use than Christianity. Within Christianity, Catholics have higher fertility and lower contraceptive use than Protestants.

3. Education, economy, gender equality and access to family planning have a negative correlation with religiosity, but this correlation may vary depending on religion and circumstances.

4. Religion/religiosity has an important role to play for fertility/contraceptive use, but it will also depend on other factors and their relative influences.

5. Religion and religiosity will have variable relationships to education, economy, gender equality and access to family planning, due to the different levels of these factors among and within countries in Sub-Saharan Africa.

Understanding the interlinking factors that affect fertility and contraceptive use and how they relate to population growth is essential for nations to implement population policies to combat the problems caused by overpopulation and to deal with population growth at macro levels (national and international levels). At a "micro" level, religion and religiosity relates to, and may influence decisions regarding family size, female empowerment and use of modern contraceptives, and hence fertility levels. The general aim of the Thesis is to improve the knowledge of these factors, given many published research reports during the last decades.

The following sub-section defines religion and religiosity, and presents the religions practiced in Sub-Saharan Africa (Section 1.3). Then follows a background on religious views on fertility and contraceptive use (Section 1.4). Section 1.5 presents current fertility and contraceptive trends in Sub-Saharan Africa as well as data on the yearly population growth. 


\subsection{Religion, Religiosity and Religions in Sub-Saharan Africa}

Many definitions of religions exist. Some definitions are shaped by Western religious traditions, in particular Christianity. Grillo, et al. (2019) redefines the concept of religion to one that encapsulates the common characteristics of all World religions and their purposes. This includes Indigenous religions and religions that have adapted their original practices to that of local customs, such as African Christianity.

"Religions are complex systems of thought and practice that convey foundational ideas in ways that allow adherents to experience them as a compelling ground of being. ...They reveal and engage the invisible sources of spiritual power; ... and they empower practitioners to act as self-conscious, ethical agents, allowing them to shape and transform their lives in conformity with ultimate values."

(Grillo, et al., 2019)

Other definitions emphasise that "religion is concerned with the supernatural; everything else is secondary", and "religion consists of two elements... a belief in powers greater than man and an attempt to propriate and please them" (Stark \& Finke, 2000).

Religious affiliation refers to the self-identified association of a person with a religion either by birth or religious conversion, whereas religiosity refers to the degree of religious commitment, including attitudes, behaviour and values (McAndrew, 2011). Demographic and Health Surveys (DHS), commonly used in scientific studies, include only one question about participants' religious affiliations. DHS does not reveal the degree of religiosity. The quantification of religiosity requires measurements such as weekly frequency of Church or Mosque attendance and strength of adherence to religious values (McAndrew, 2011; Stark, 2015).

The three main religions practiced throughout continental Sub-Saharan Africa are Christianity, Islam and African Indigenous Religions. Throughout the $20^{\text {th }}$ and $21^{\text {st }}$ Centuries, Christianity in Africa has grown considerably from 9\% in 1910 to 49\% in 2020, with almost all African Christians living in Sub-Saharan Africa (Grillo, et al., 2019; Stark, 2015). Some countries are almost entirely Christian with the top five countries with the highest percentage of Christians for 2020 being the Lesotho (96.2\%), Democratic Republic of Congo (95.9\%), Zambia (95.5\%), Rwanda (93.2\%) and Eswatini (90\%) (United Nations, 2020). Christian faiths in SubSaharan Africa, initially influenced by colonial powers and missionary work, developed to reflect the concerns and agendas of Africans in current socio-cultural contexts, and speak to the spiritual needs of many Africans (Grillo, et al., 2019; Stark, 2015; Walls, 2002).

The presence of Islam in Sub-Saharan Africa varies geographically, being stronger in Western and Eastern Africa with $50 \%$ and $34 \%$ of the population identifying as Muslims, respectively. Weaker adherences to Islam are observed in the Central and Southern regions, with $15 \%$ and $7 \%$ identifying as Muslims, respectively (Grillo, et al., 2019). The practice of Islam in Sub-Saharan Africa is not static and is constantly being shaped by social, economical and political influences among the countries (Robinson, 2004).

Long ago, before Christianity and Islam, Africans practiced only traditional religions, referred to below as African Indigenous Religions, which allude to the belief in a Supreme Being, known by different names in different ethnic groups, such as Nyame by the Akan, and Mawu by the Ewe. However, the Supreme Being is thought of as being remote and is therefore not directly worshipped, but rather worshipped through smaller Gods. These Gods take up residency in streams, rivers, trees and mountains (Berry, 1994; Beyers, 2010). The 
spiritual powers of dead ancestors or non-human spirits are also worshipped in African Indigenous Religions, and tend to border witchcraft tendencies, which are also currently present in forms of Christianity (Beyers, 2010). Much of present Christianity has elements of indigenous religions (Stark, 2015).

Figure 3 illustrates the distribution of religions throughout Sub-Saharan Africa. Christianity is strongest in Southern Africa and south of Eastern Africa while the presence of Islam is stronger in Western and north of Eastern Africa. African Indigenous Religions are still present in Western, Southern and parts of Eastern Africa, and is particularly prominent in Togo, Benin and Namibia. For a table of the distribution of population by denomination, see Appendix A.
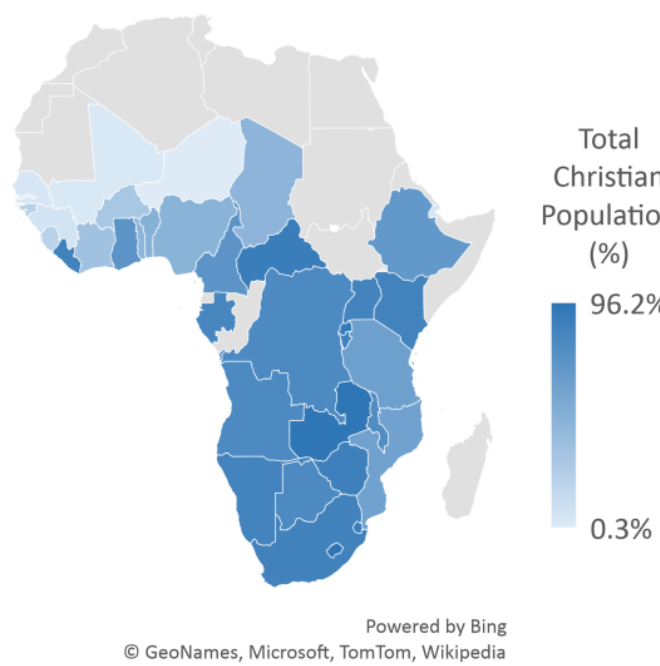

Population

(\%)

$96.2 \%$

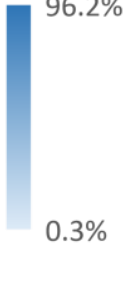

(c) GeoNames, Microsoft, Tom
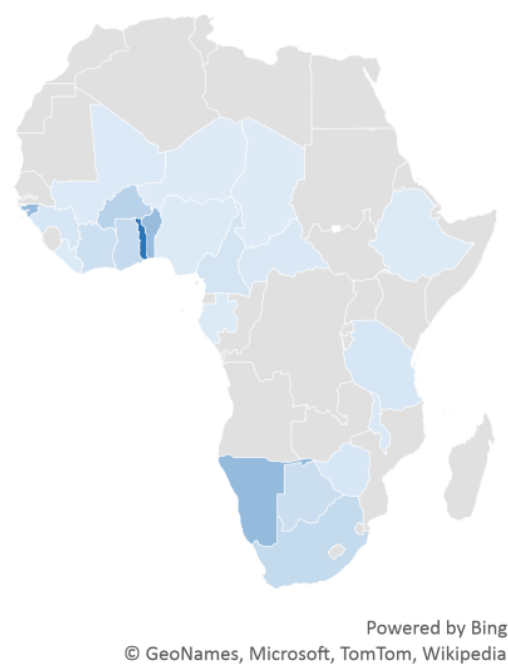

Figure 3. Distribution of religions across Sub-Saharan Africa. Grey areas denote no data available.

[Data Source: United Nations, 2020]

\section{African \\ Indigenous \\ Religions \\ Population}

(\%)

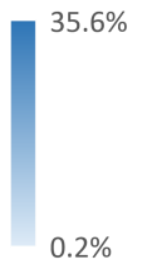

Powered by Bing (c) GeoNames, Microsoft, TomTom, Wikipedia
Muslim 


\subsection{Religion, Fertility and Contraception}

Christian ideas on contraception come from interpretations of Church teachings rather than scripture. Although little is explicitly mentioned regarding the use of contraception, the Bible mentions that children are a gift from God and that God's first words to Adam and Eve were, "Be fruitful and multiply and fill the Earth" [Genesis 1:28] (McKeown, 2014). Prior to the 20 $0^{\text {th }}$ Century, all Churches disapproved of contraceptive use, since limitation of children was against the main purpose of marriage (to procreate) (Goodson, 1997). In recent times, Protestant Churches have become more liberal in their teachings of family planning. The Evangelical Church was one of the few Protestant Churches that pioneered in the use of modern contraceptives (Sweet, 1994). By the mid-20 ${ }^{\text {th }}$ Century, nearly all Protestant denominations had approved the practice of contraception, so long as it did not promote promiscuous behaviour (Goodson, 1997). The Catholic Church (i.e. the Vatican and Pope) does not allow the use of artificial contraceptive methods as these methods are believed to promote promiscuity and adultery. Only "natural contraception" is permissible, i.e. breastfeeding, withdrawal (coitus interruptus) and calendar (rhythm) methods (Ignaciuk, 2020). In the 1960s, the contraceptive Pill was introduced and although this was not approved by the Church, many Catholic women had been using it (Bouvier, 1972). Despite the ban on artificial contraceptive methods, some Catholic Churches silently tolerate the practice (Kok, 2020).

Unlike Christianity, Islam has been aware of birth control for centuries and it is permitted in eight of the nine classic schools of Islamic Law (Sharia) (Musallam, 1981). However, Islam is strongly pro-family and regards children as a gift from God, therefore teachings of contraceptive use often refer to family planning for the purpose of birth spacing to preserve the health of the mother rather than for limiting children (Scrivani, 2018). Contraception may also be permitted if the mother's health is in danger from pregnancy, if there is a chance of a child being born with health complications, or if the parents are not financially ready to raise a child (Musallam, 1981). Acceptance of contraceptive methods has since evolved beyond coitus interruptus and most modern methods are permitted in Islam. However, abortion, permanent methods and emergency contraception are prohibited (Atighetchi, 1994; Scrivani, 2018). Although the Quran does not explicitly refer to contraception, several hadith ("sayings") refer to the Sunnah, which describes the practice of coitus interruptus by the Companions of the Prophet. When the Prophet was queried about it, he said, "Not out of all the semen a child is formed, and if Allah willed to create something, nothing would stop him from doing it" (Deuraseh, 2003). On the other hand, a minority of more conservative Muslims stand against family planning saying that it is an interference with God's plans (Deuraseh, 2003). Some Islamic jurists also state that the killing of semen is no different to the killing of children and quoted the Prophet's later hadith of coitus interruptus as hidden infanticide (Deuraseh, 2003). Sunni and Shia are two major sects of Islam. In two studies (Budhwani, et al., 2018; Scrivani, 2018), those who identified as Sunni were less likely to utilise contraception compared with those who identify as Shia.

African Indigenous Religions are embedded in lineage and descent systems as lineage is believed to have mystical significance between the living and departed ancestors (Adongo, et al., 1998). Ancestors are honoured and their spirits appeased through the bearing of children as descendants (Caldwell \& Caldwell, 1987). Therefore, the importance of having many children, particularly sons, is strongly conveyed in religious messages so that family lineages can grow, prosper and its spirits can flourish (Adongo, et al., 1998).

Adherence to and interpretations of the teachings of these religions vary across Sub-Saharan African and around the world, and is apparent in the studies from this review. 


\subsection{Current Trends in Sub-Saharan Africa}

\subsubsection{Total Fertility Rates and Contraceptive Prevalence Rates}

Recent data obtained from the UN show interesting trends in Sub-Saharan Africa. (For the UN data, see Appendix B.) Below, countries (dots in graphs) are used as statistical units. Figure 4 shows the negative relationship between TFR and CPR across the Sub-Saharan nations included in the review. The same trend is observed in Götmark \& Andersson (2020). In Figure 5, population size relates positively, though weakly with TFR. Population size hardly has any relationship with CPR (Figure 6). Figure 7 shows a strong negative relationship between TFR and GDP per capita (also observed in Götmark \& Andersson, 2020) while Figure 8 shows a strong positive relationship between CPR and GDP per capita.

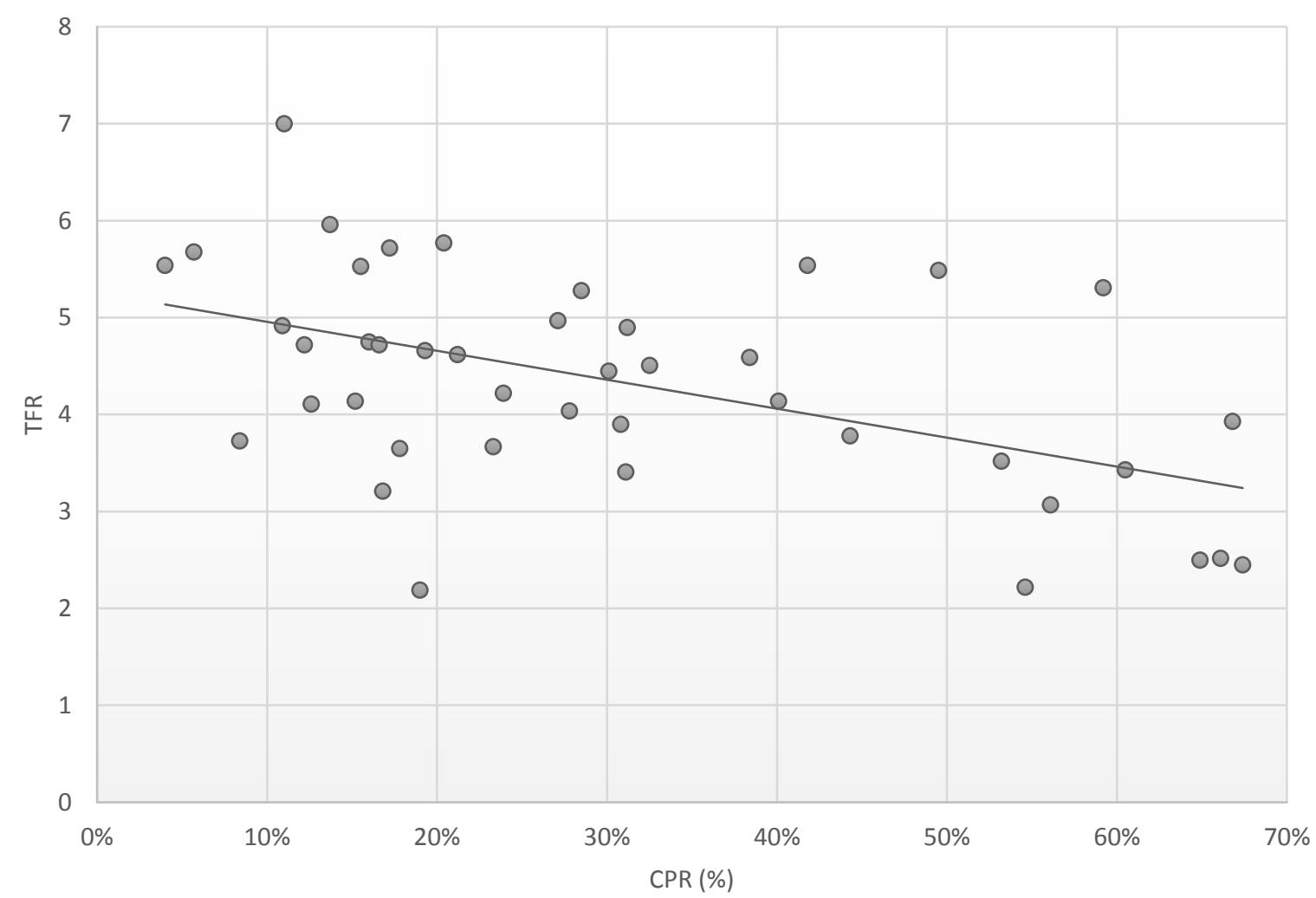

Figure 4. TFR has a negative relationship with CPR (\%) across Sub-Saharan Africa. 


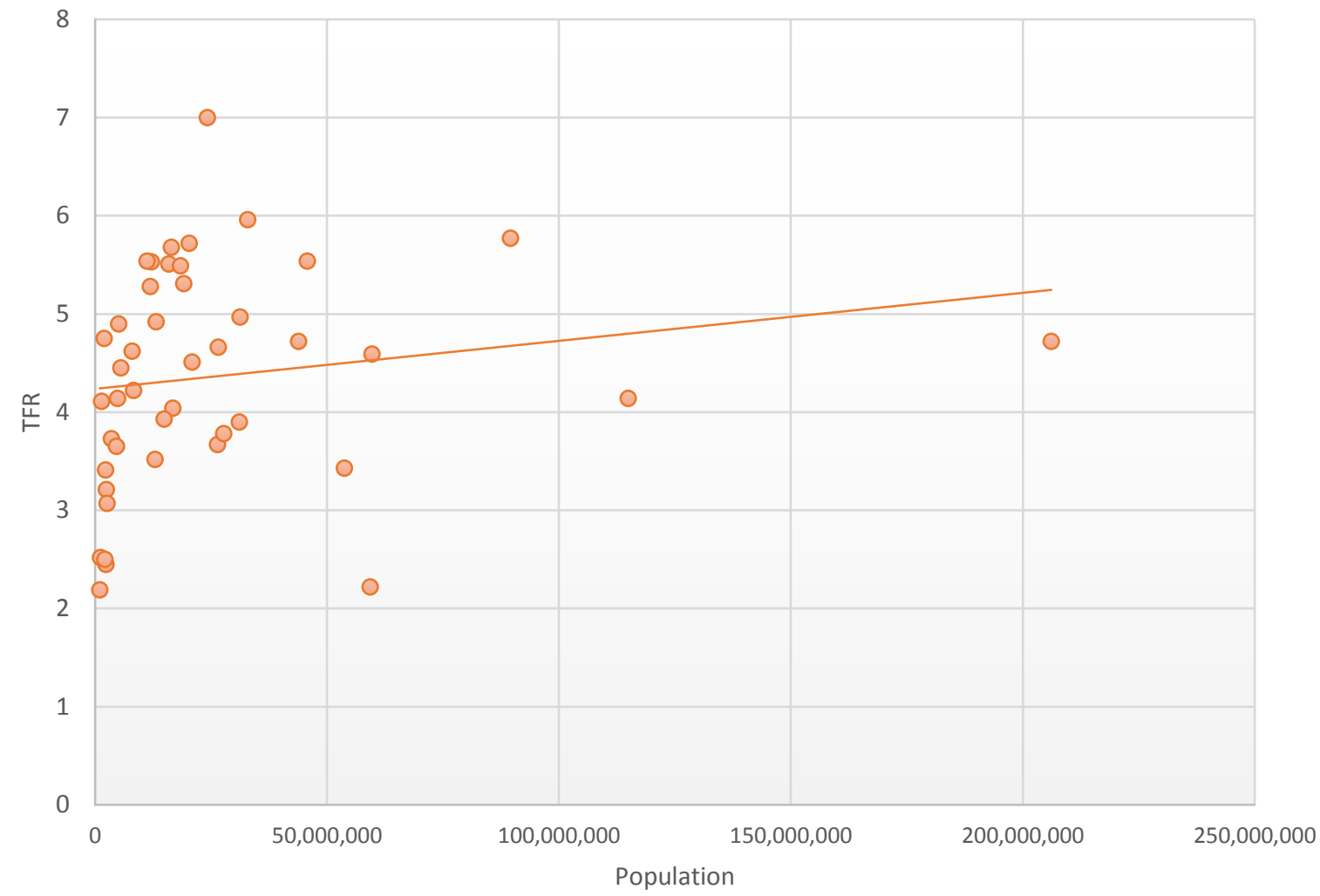

Figure 5. Population size has a positive relationship with TFR across Sub-Saharan Africa.

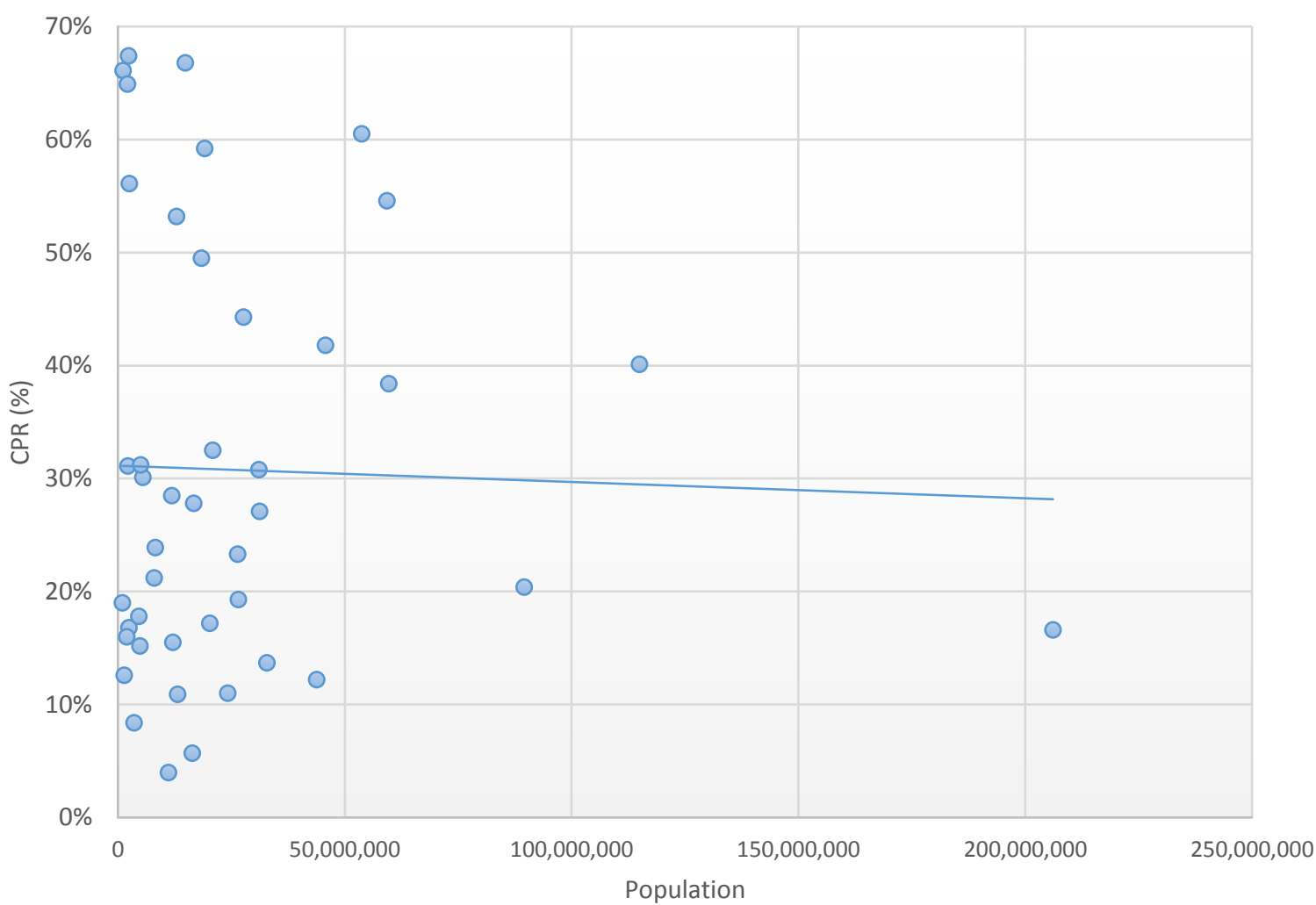

Figure 6. Population size has a weak negative relationship with CPR (\%) across Sub-Saharan Africa. 


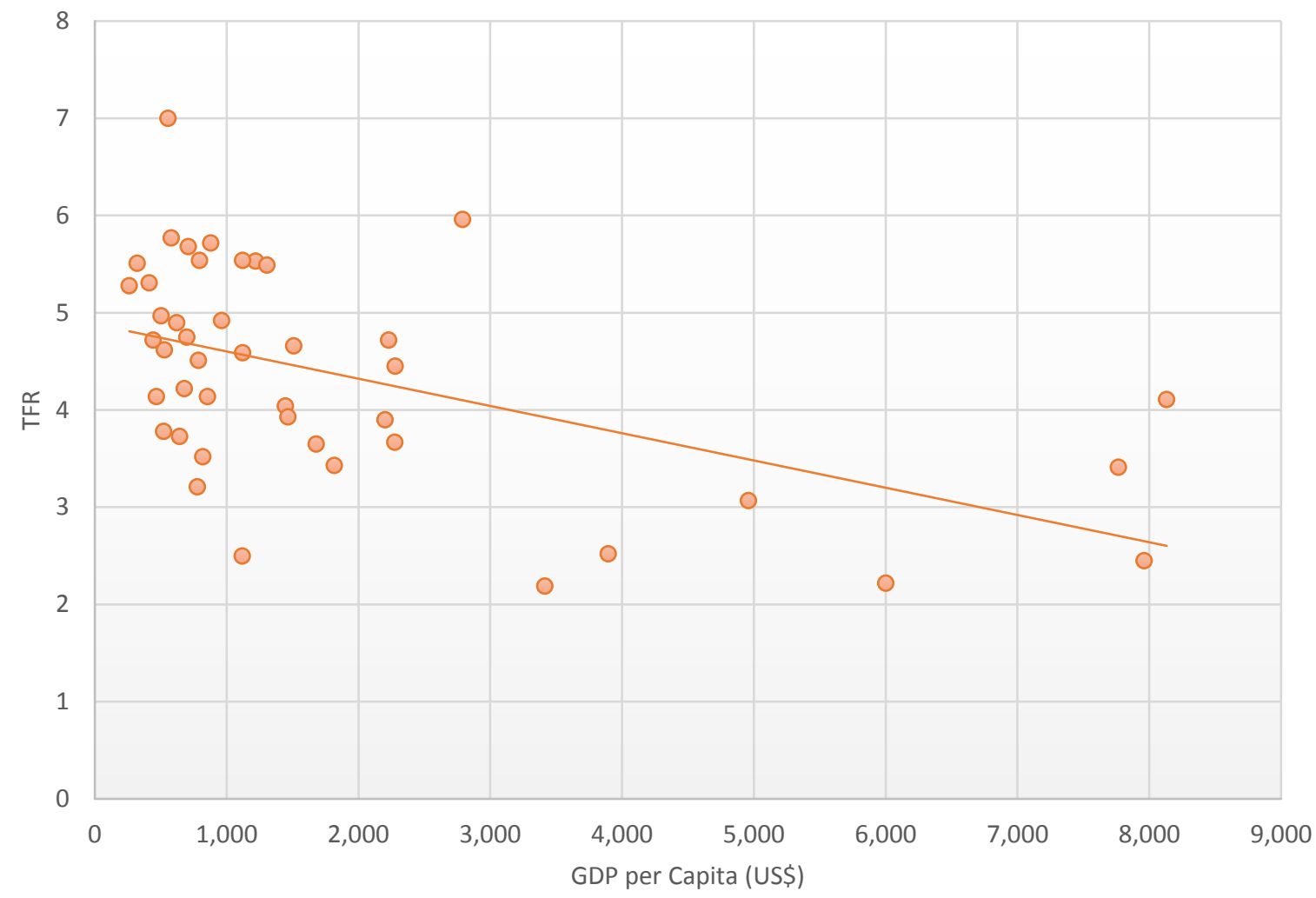

Figure 7. GDP per capita (US\$) has a negative relationship with TFR (\%) across Sub-Saharan Africa.

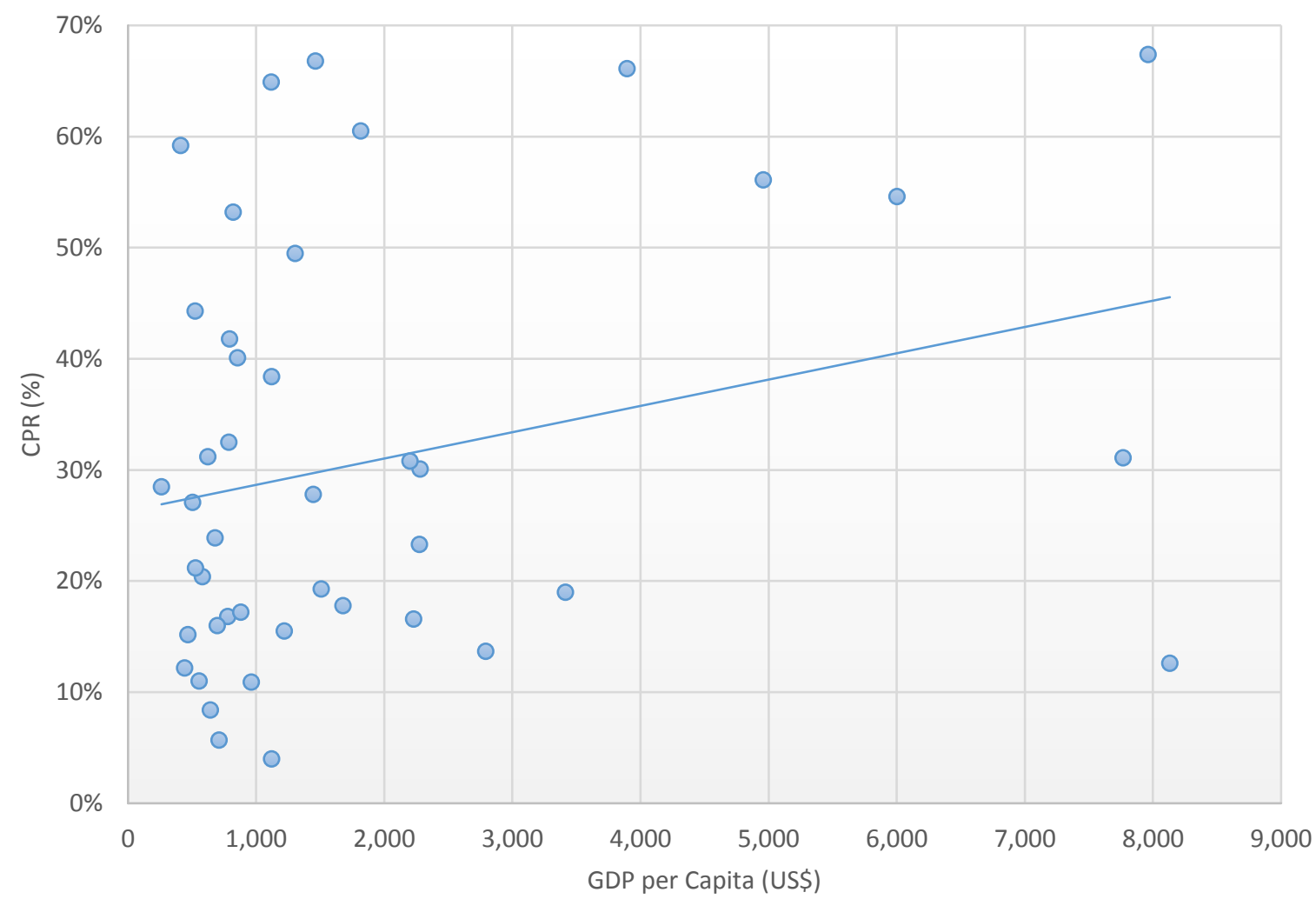

Figure 8. GDP per capita (US\$) has a positive relationship with CPR (\%) across Sub-Saharan Africa. 
The following figures show trends for TFR, CPR and religious denominations. Percentage of Muslim population has a weak but consistent positive relationship with TFR (Figure 9) and a clear negative relationship with CPR (Figure 10). On the other hand, the percentage of Christian population has the opposite relationship, with a weak negative relationship with TFR (Figure 11) and positive relationship with CPR (Figure 12). However, this trend is not consistent when data from the two largest Christian denominations are examined. Percentage of Catholic population is positively associated with TFR (Figure 13) and negatively associated with CPR (Figure 14), whereas the percentage of Protestant population demonstrates the opposite trend (Figure 15 and Figure 16), with the positive relationship with CPR being especially strong. TFR and CPR and percentage of the population that follows African Indigenous Religions illustrate slight negative relationships (Figure 17 and Figure 18). Finally, the percentage of the non-religious population is weakly negatively associated with TFR (Figure 19) and weakly positively associated with CPR (Figure 20). Using Gallup surveys from Stark (2015), Götmark \& Andersson (2020) studied TFR and its relation to religiosity and found that TFR increased with degree of religiosity in Sub-Saharan Africa. Stronger religiosity was also associated with lower education, CPR and GDP per capita. However, the authors did not distinguish between religions due to the global scale of the analyses, though there are likely differences. 


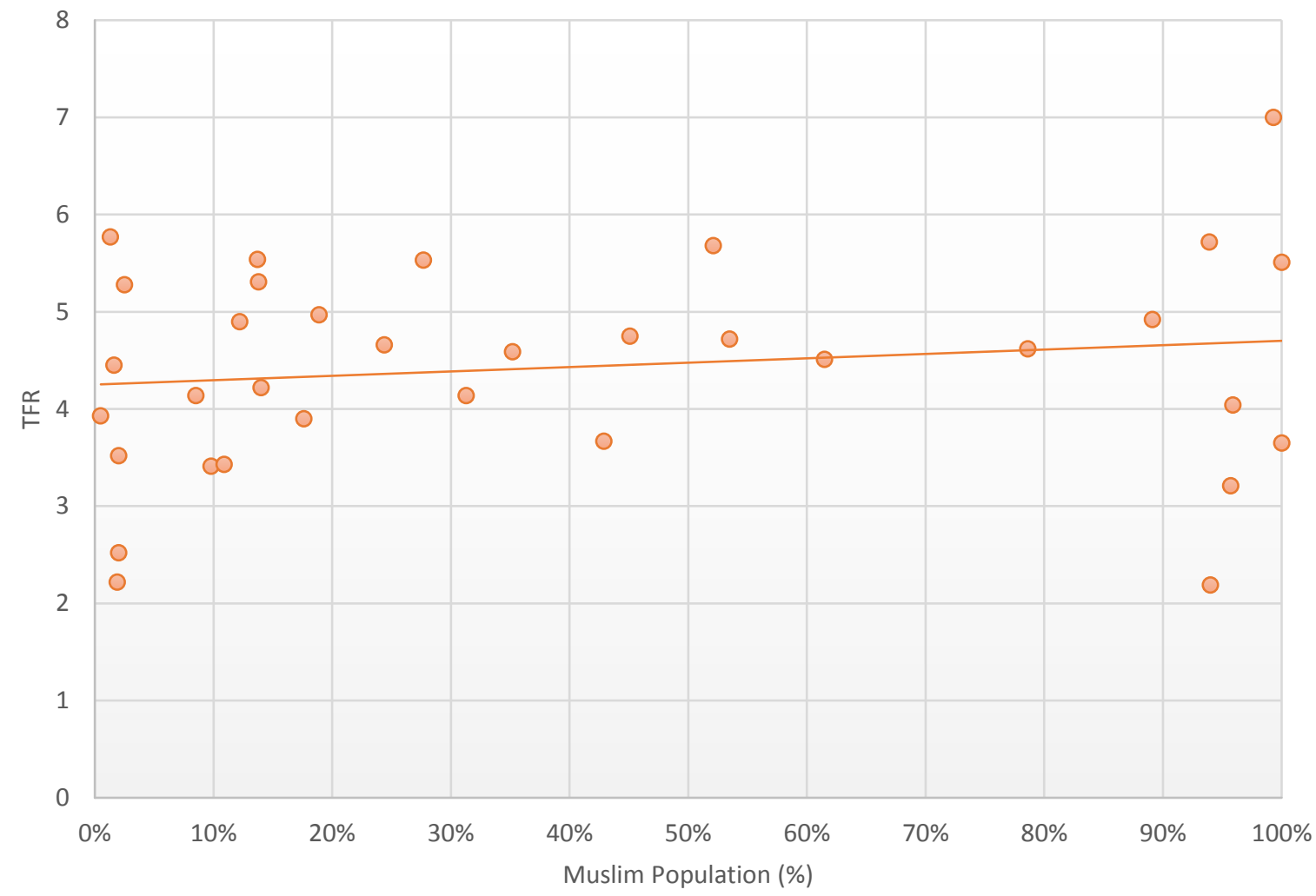

Figure 9. TFR has a weak positive relationship with Muslim populations (\%) across Sub-Saharan Africa.

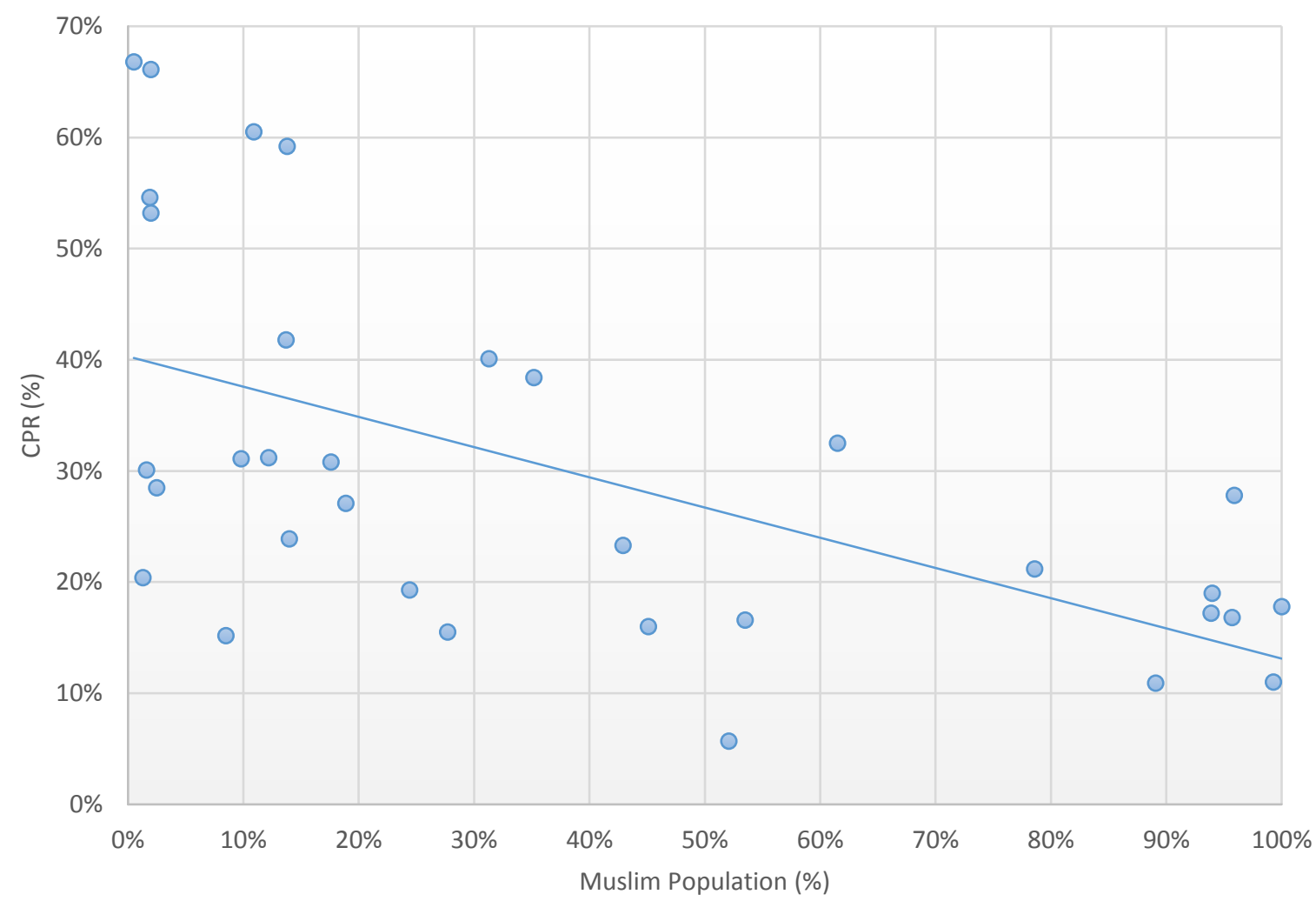

Figure 10. CPR (\%) has a negative relationship with Muslim populations (\%) across Sub-Saharan Africa. 


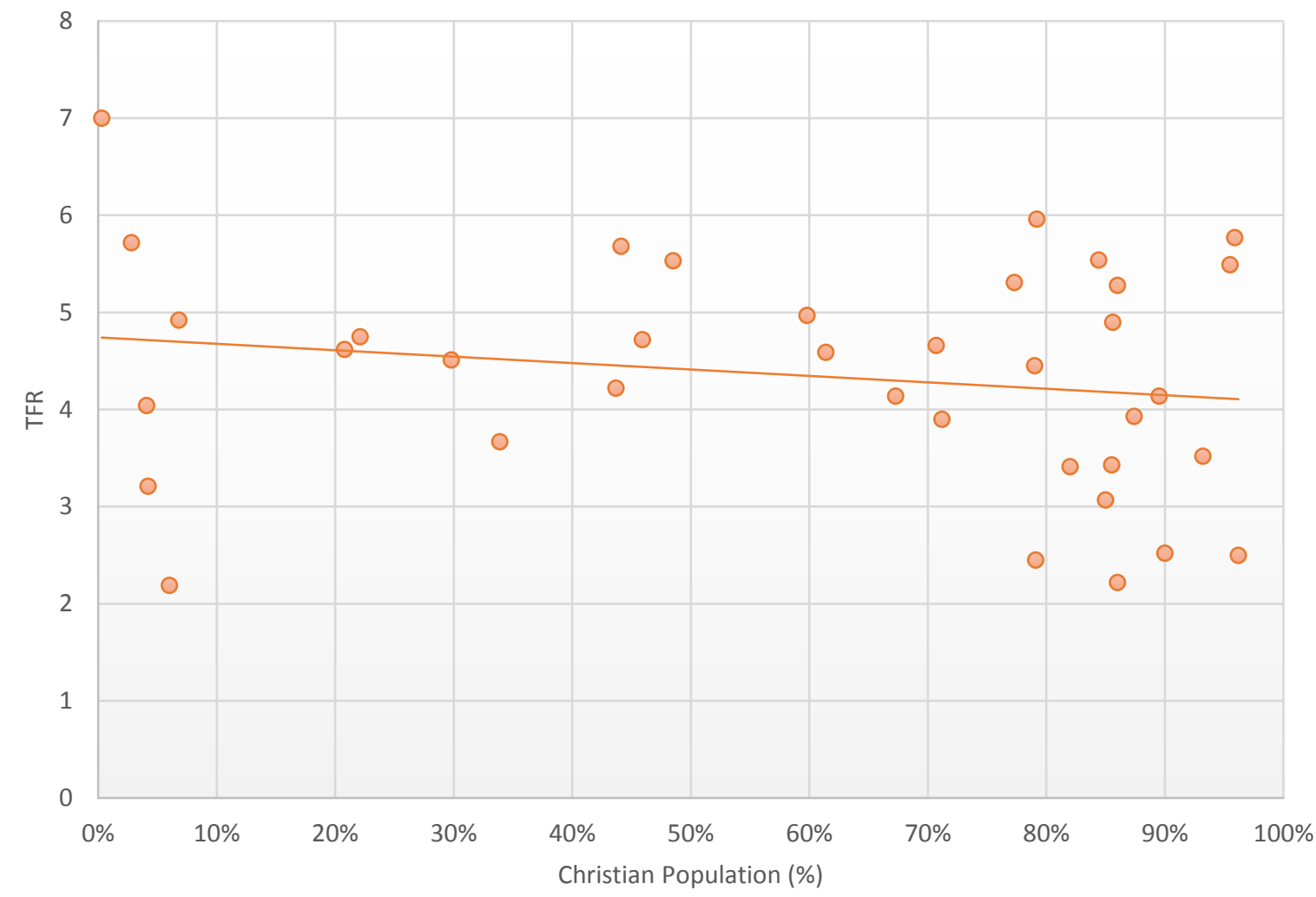

Figure 11. TFR has a weak negative relationship with Christian populations (\%) across Sub-Saharan Africa.

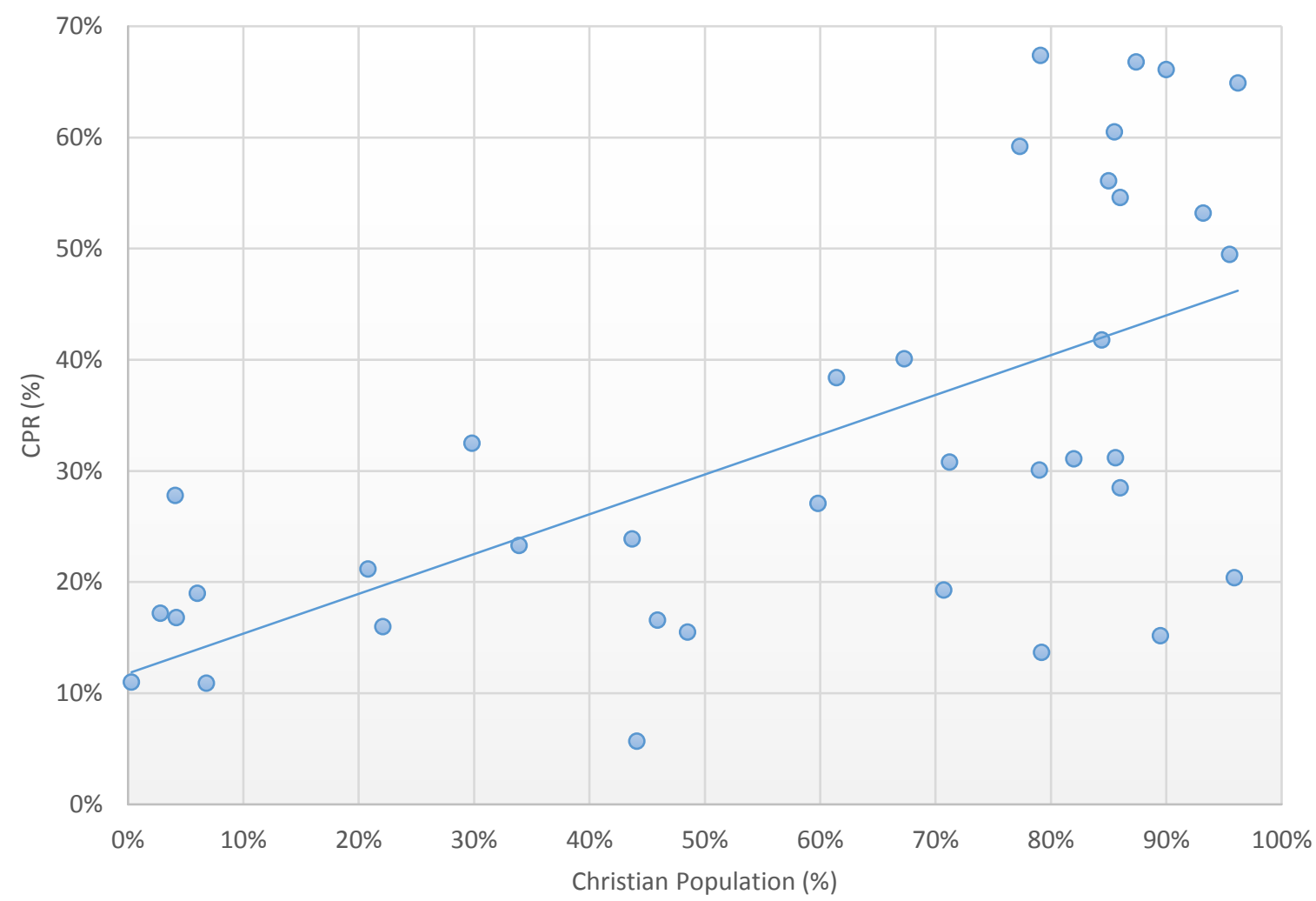

Figure 12. CPR (\%) has a positive relationship with Christian populations (\%) across Sub-Saharan Africa. 


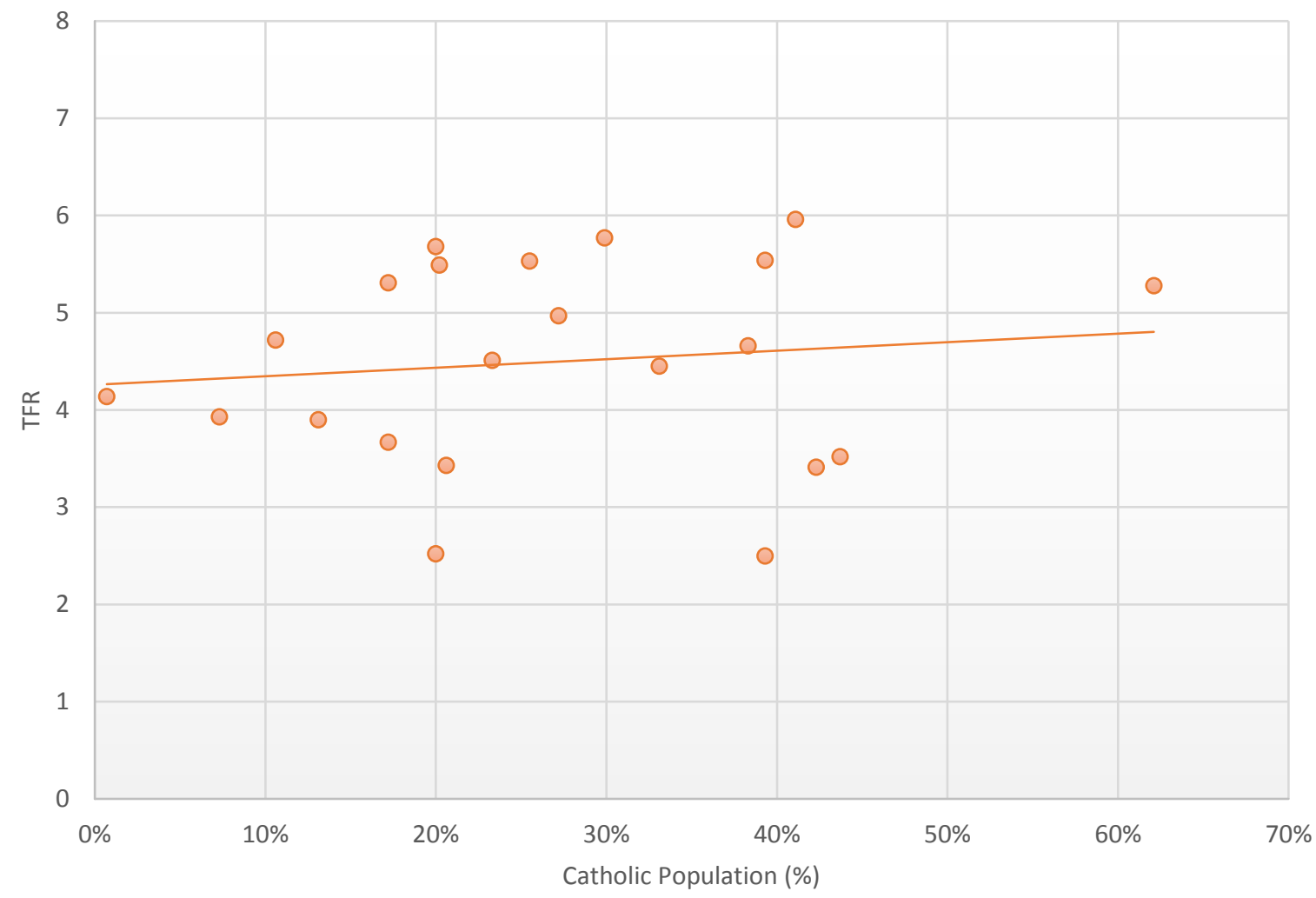

Figure 13. TFR has a positive relationship with Catholic populations (\%) across Sub-Saharan Africa.

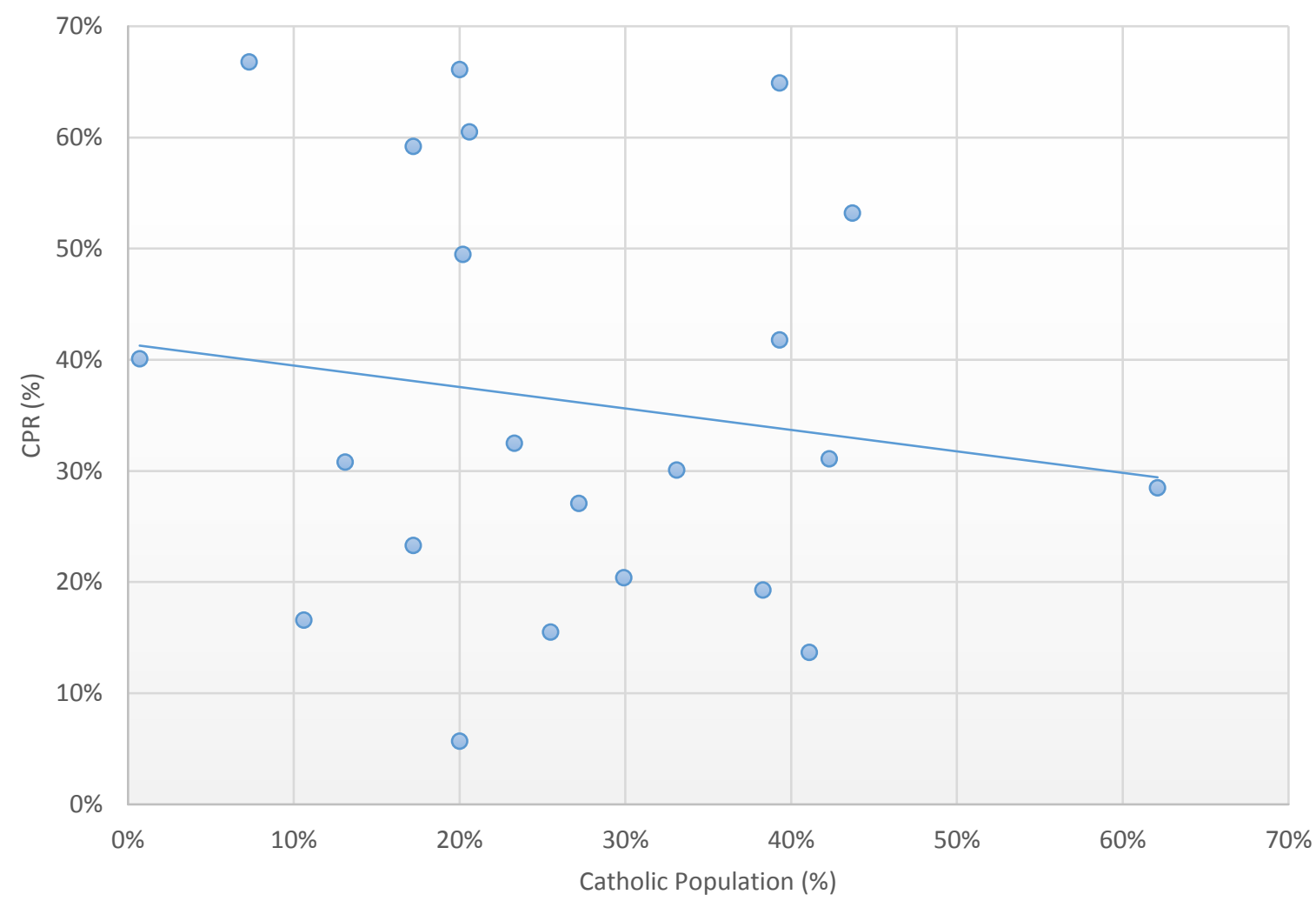

Figure 14. CPR (\%) has a negative relationship with Catholic populations (\%) across Sub-Saharan Africa. 


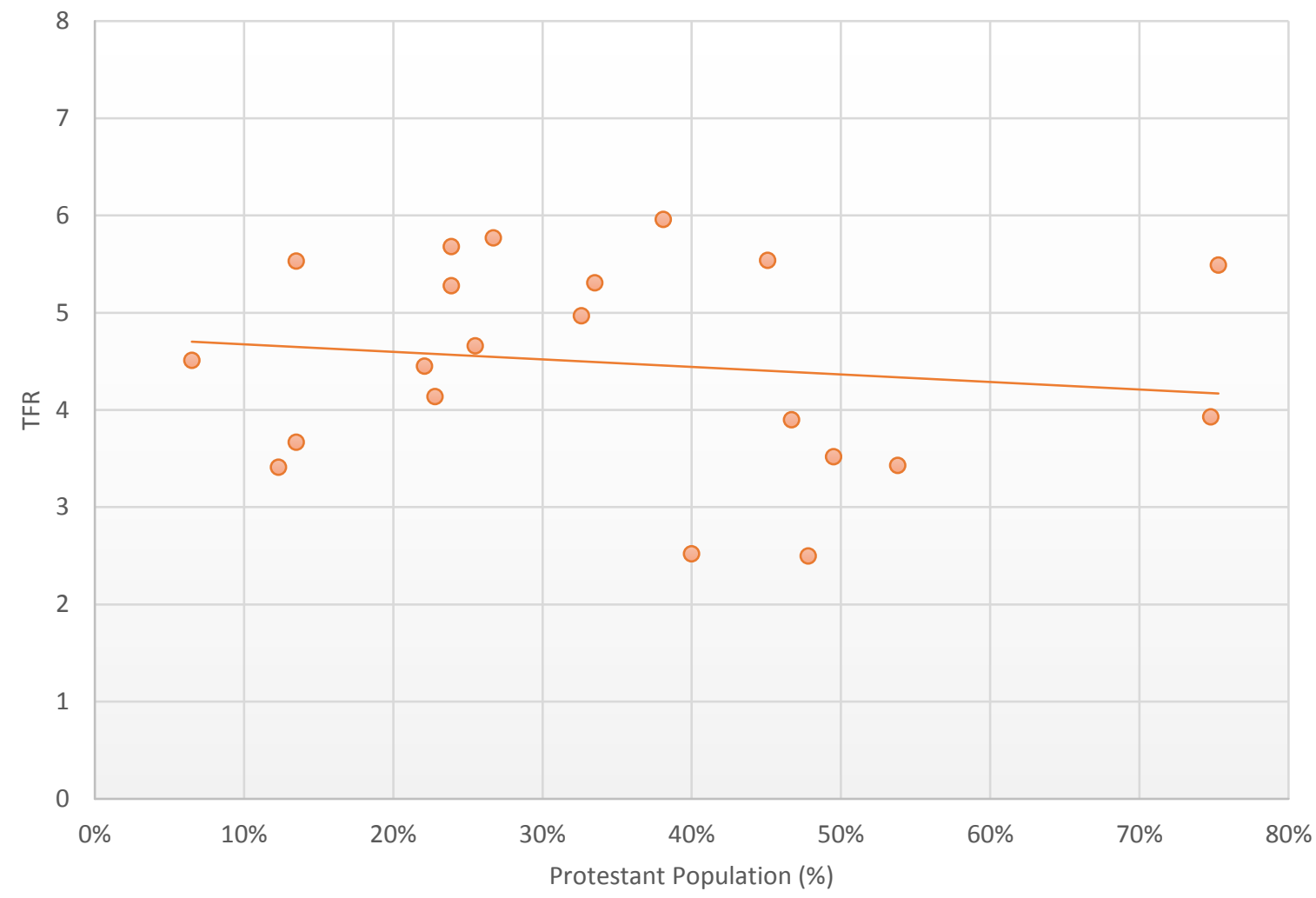

Figure 15. TFR has a negative relationship with Protestant populations (\%) across Sub-Saharan Africa.

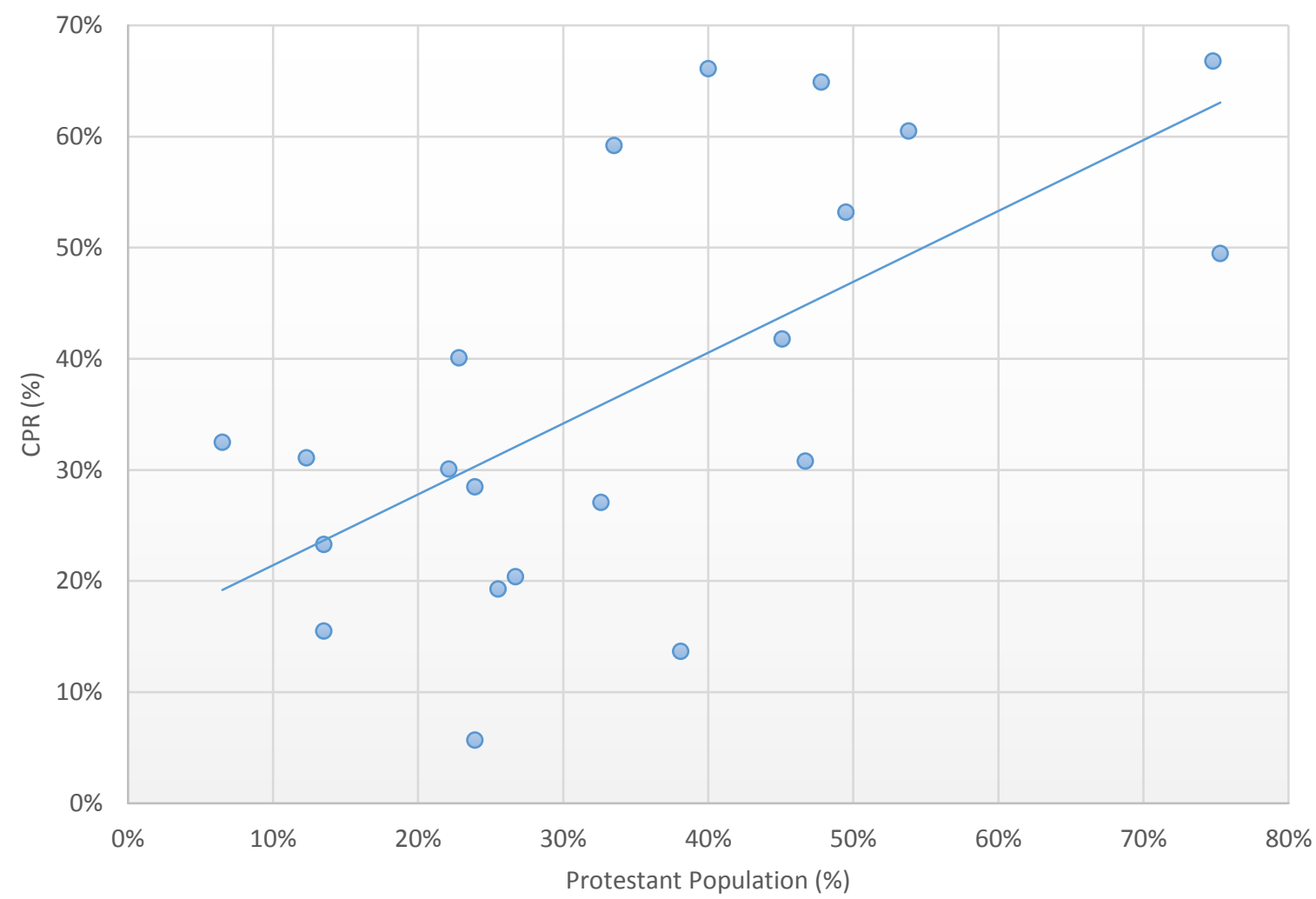

Figure 16. CPR (\%) has a strong positive relationship with Protestant populations (\%) across Sub-Saharan Africa. 


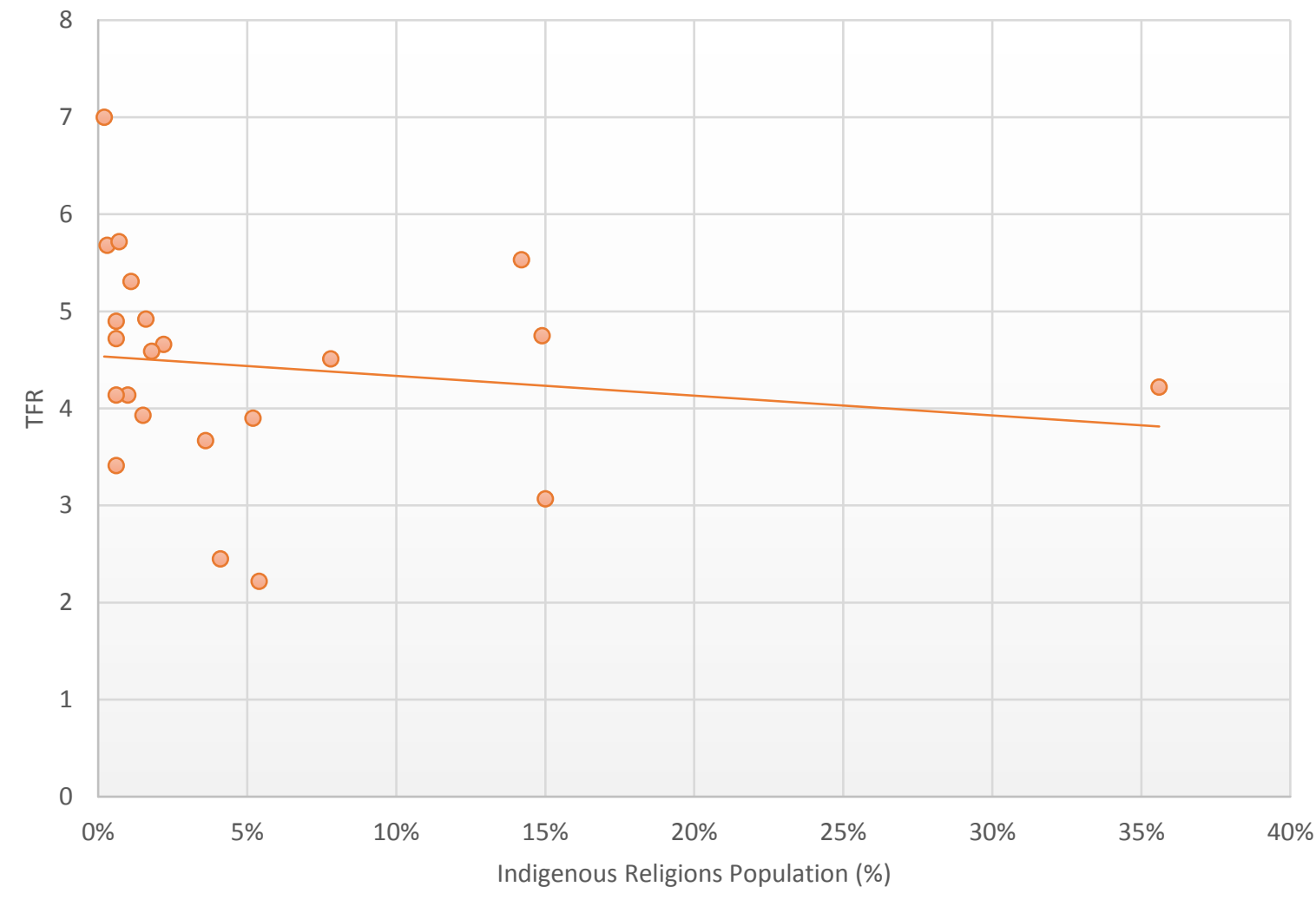

Figure 17. TFR has a negative relationship with Indigenous Religions populations (\%) across Sub-Saharan Africa.

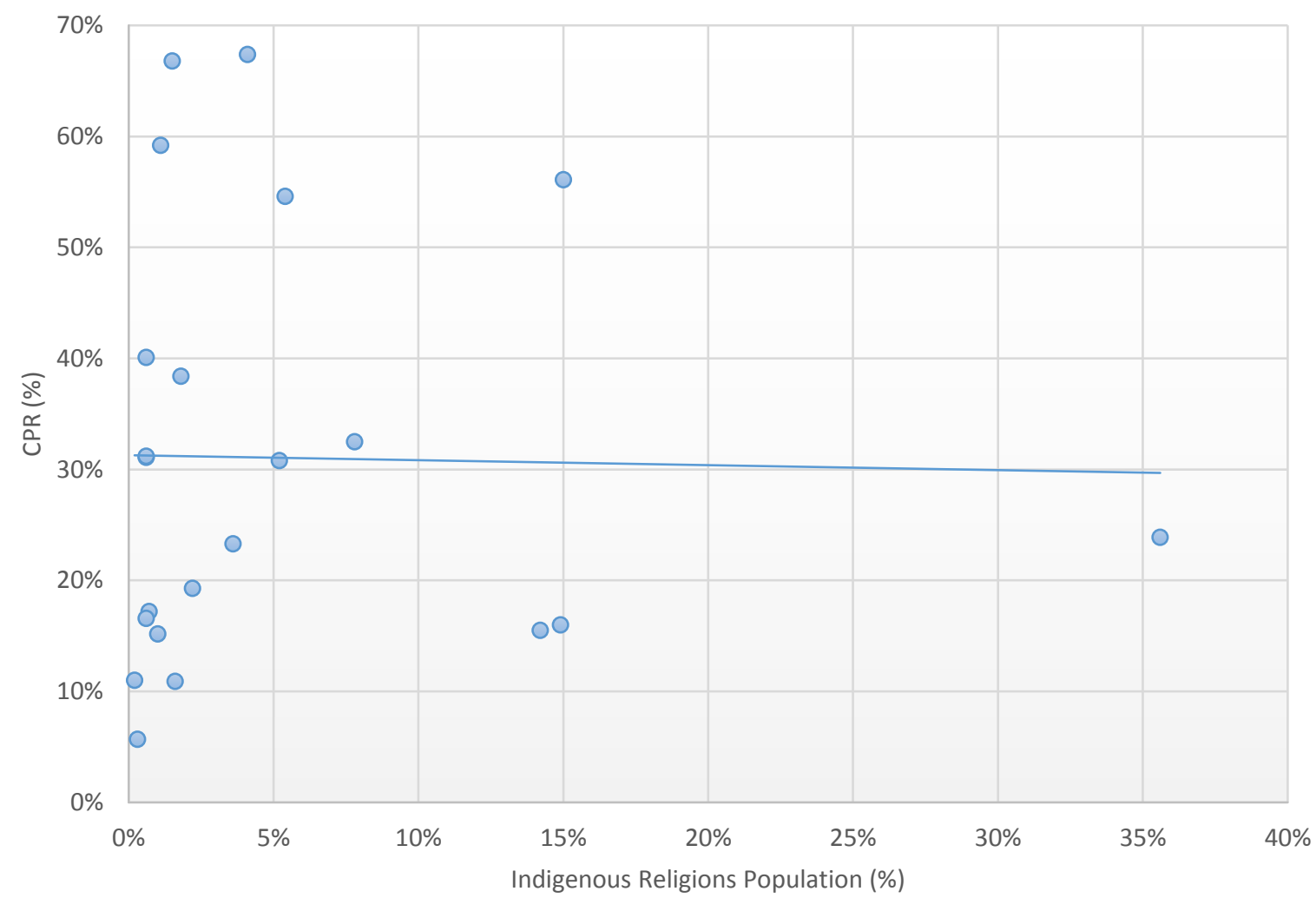

Figure 18. CPR (\%) has a weak negative relationship with Indigenous Religion populations (\%) across Sub-Saharan Africa. 


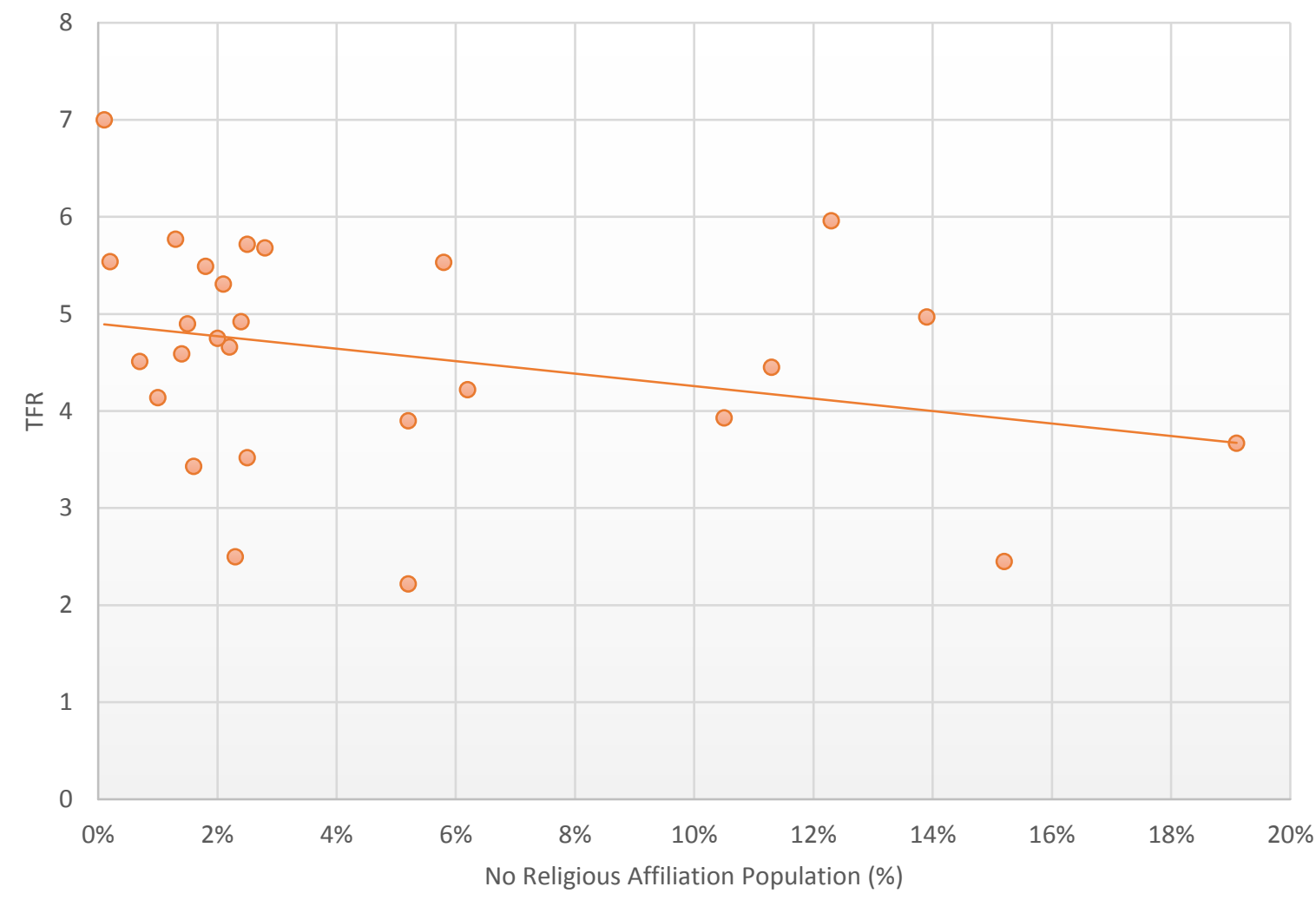

Figure 19. TFR has a negative relationship with no religious affiliation populations (\%) across Sub-Saharan Africa.

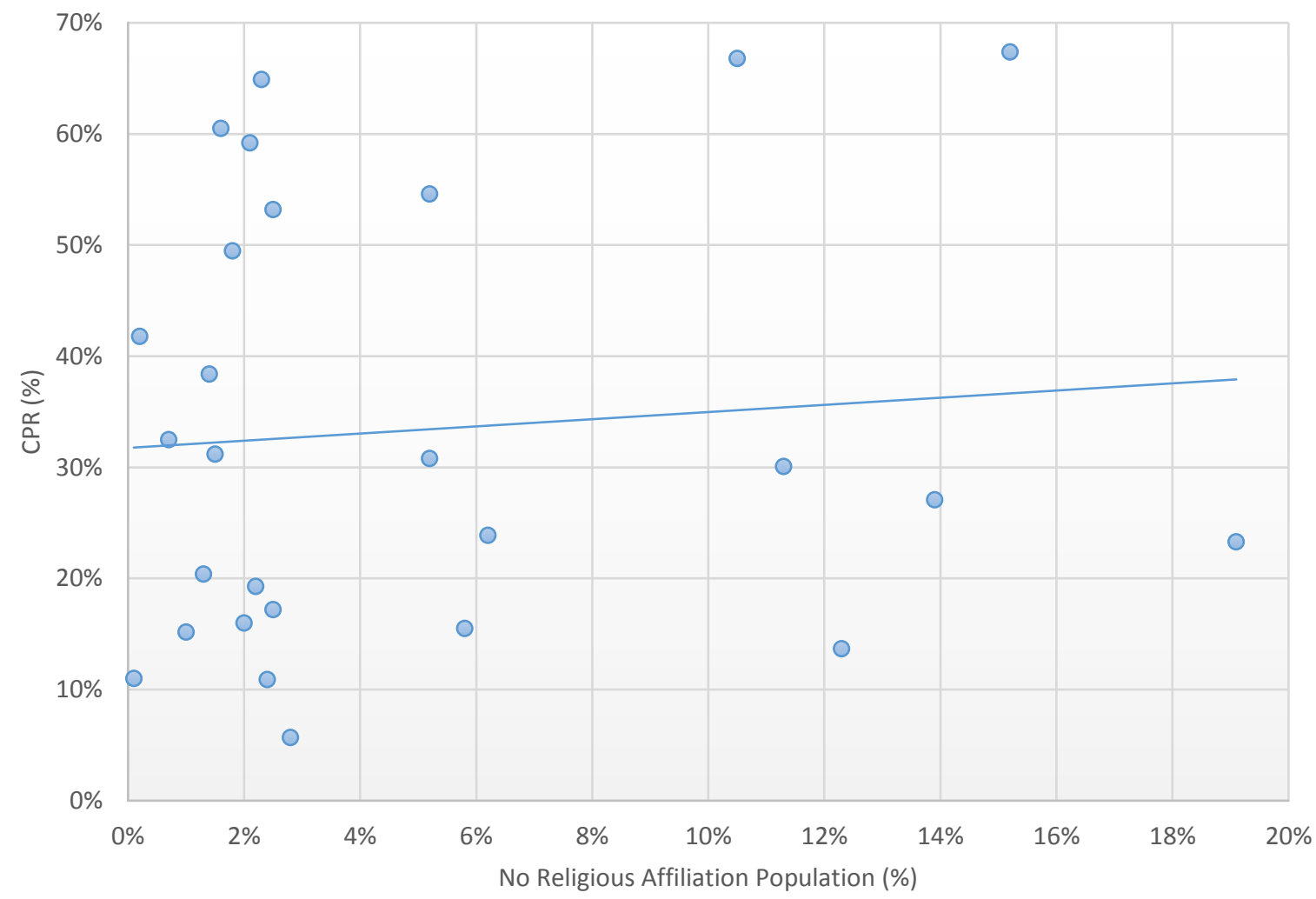

Figure 20. CPR (\%) has a positive relationship with no religious affiliation populations (\%) across Sub-Saharan Africa. 


\subsubsection{Yearly Changes}

Trends between population growth (\% annual change) and religious denominations show increase with the population of Muslims (Figure 21) and Catholics (Figure 23); in contrast, negative relationship exist for other denominations and non-affiliated (Figure 22, Figure 24, Figure 25 and Figure 26).

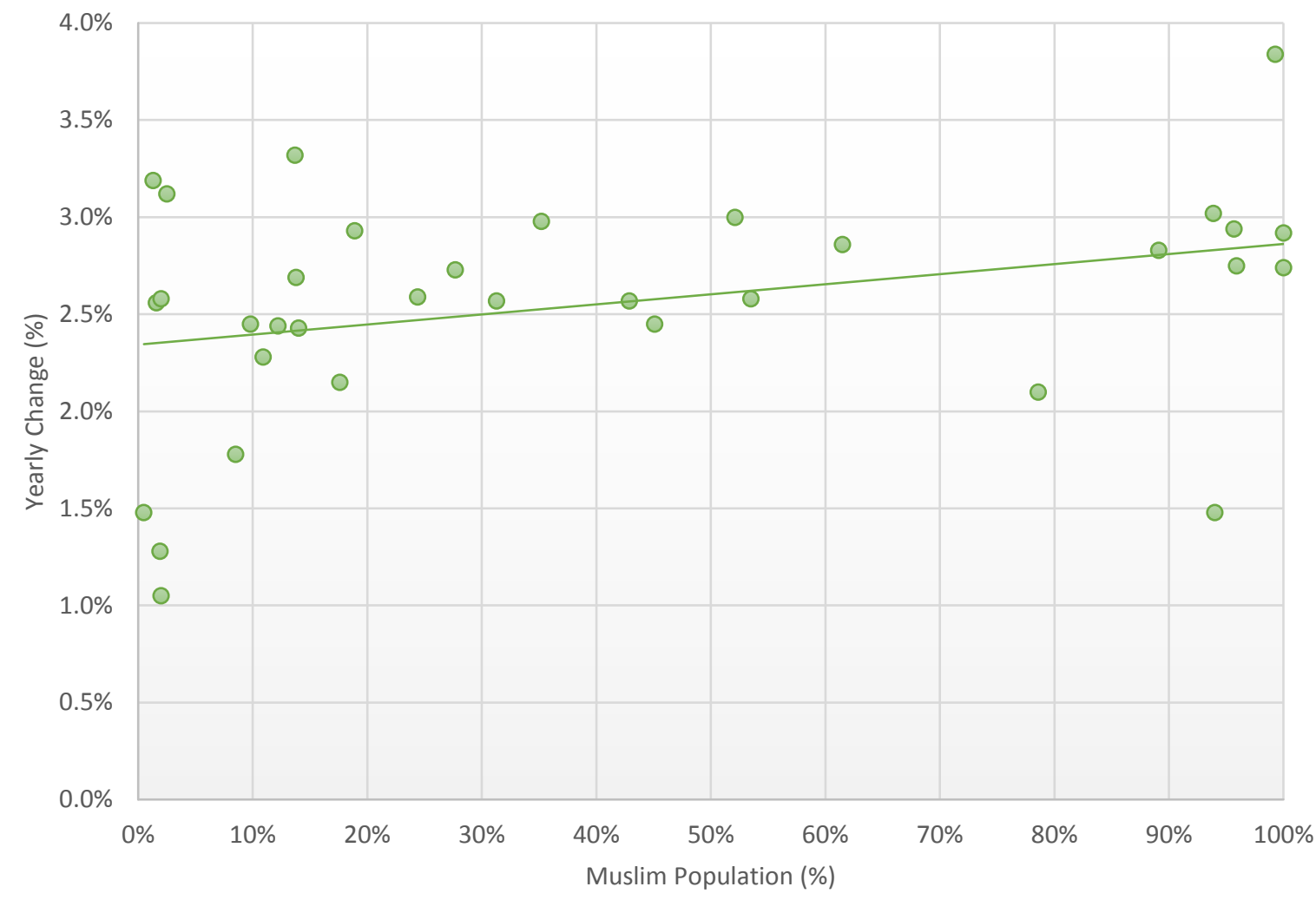

Figure 21. Yearly change (\%) has a positive relationship with Muslim populations (\%) across Sub-Saharan Africa. 


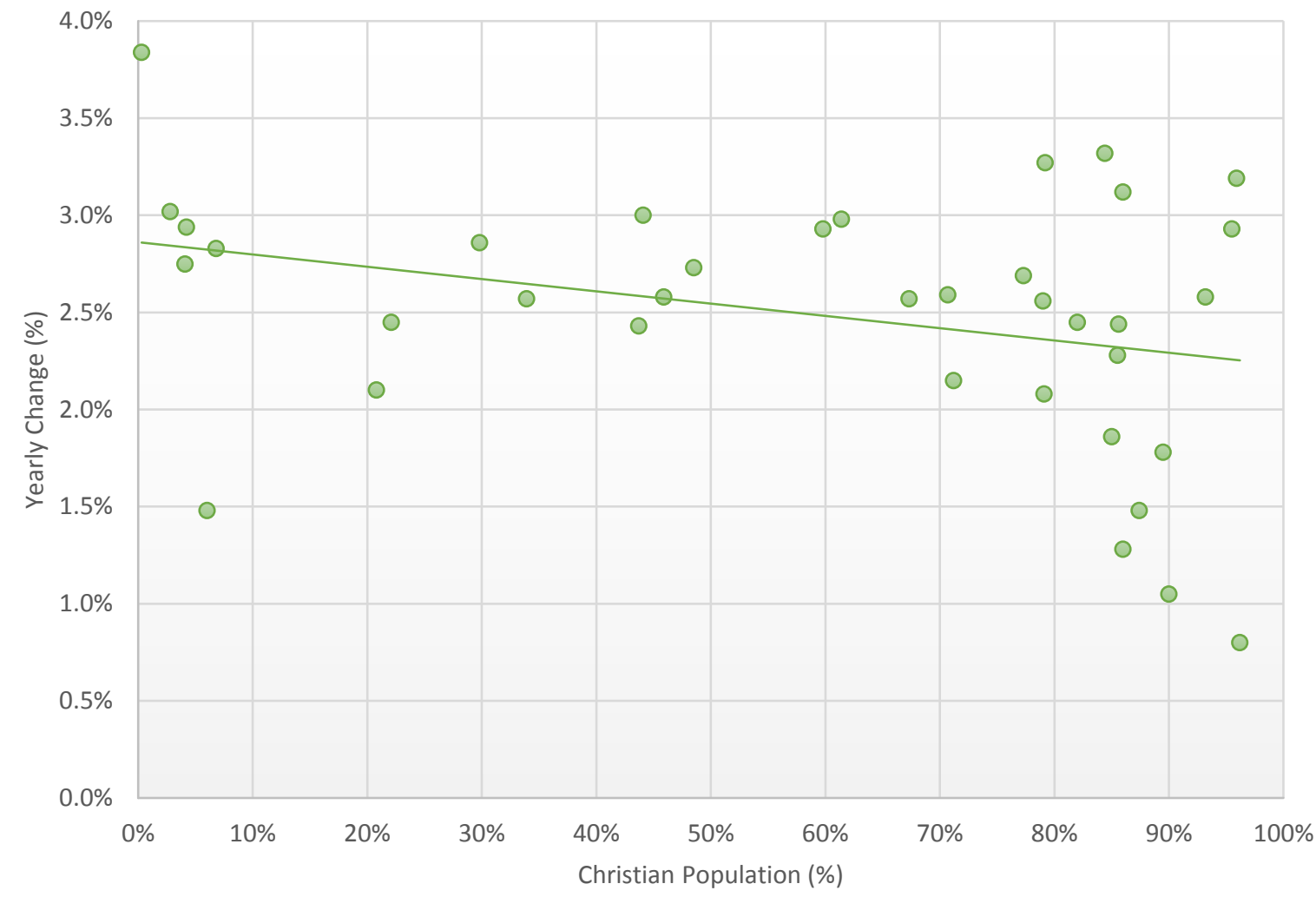

Figure 22. Yearly change (\%) has a negative relationship with Christian populations (\%) across Sub-Saharan Africa.

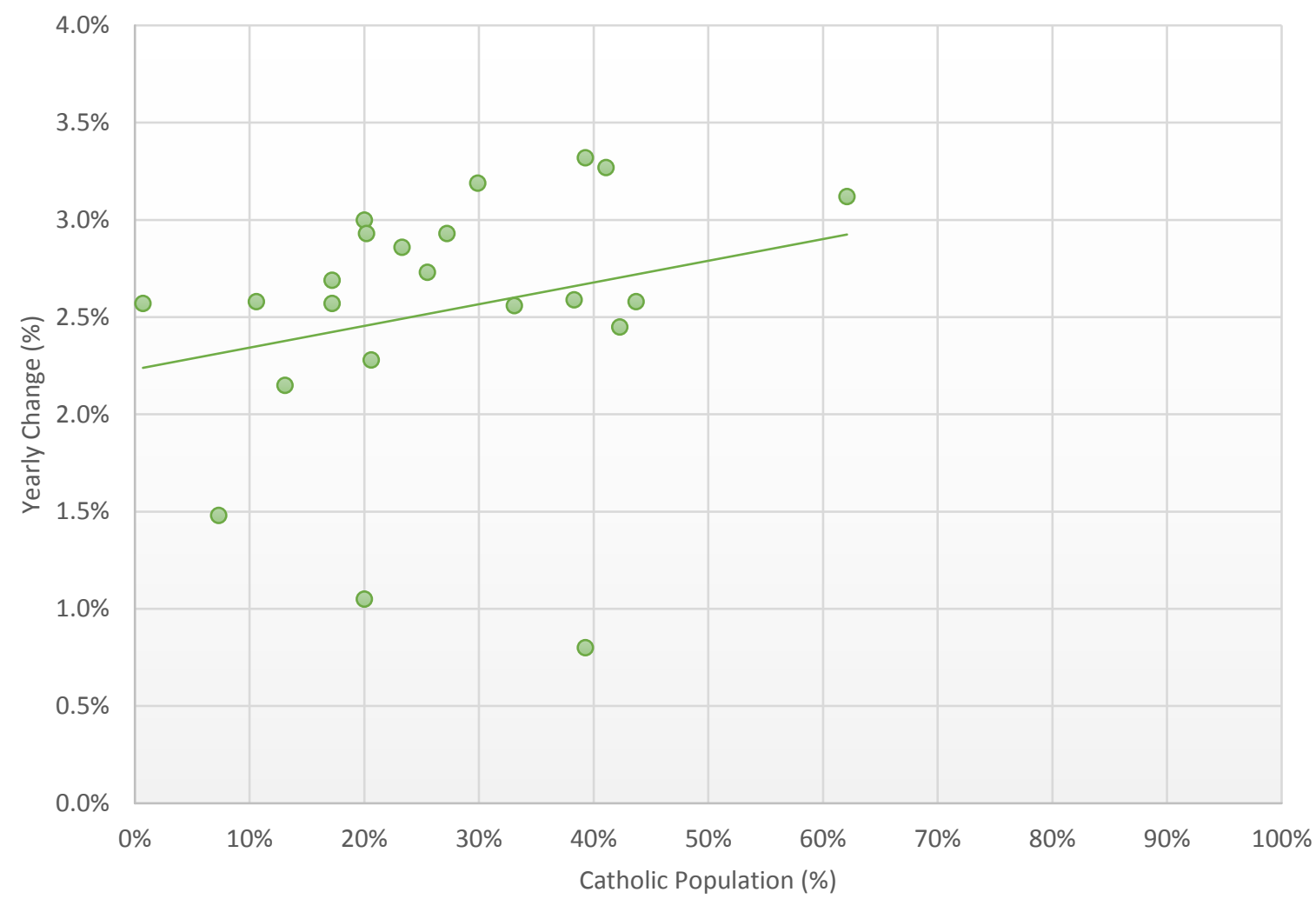

Figure 23. Yearly change (\%) has a positive relationship with Catholic populations (\%) across Sub-Saharan Africa. 


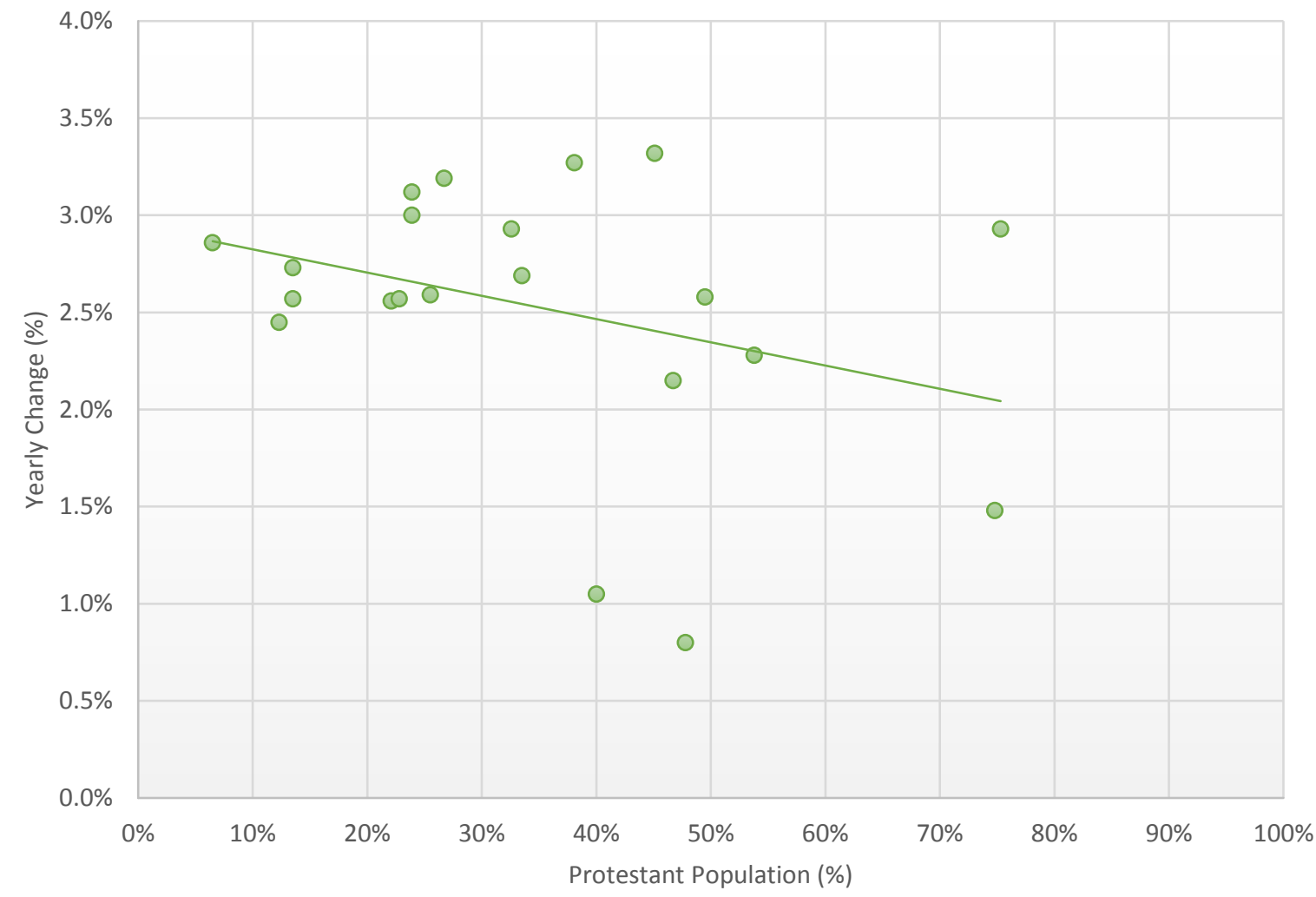

Figure 24. Yearly change (\%) has a negative relationship with Protestant populations (\%) across Sub-Saharan Africa.

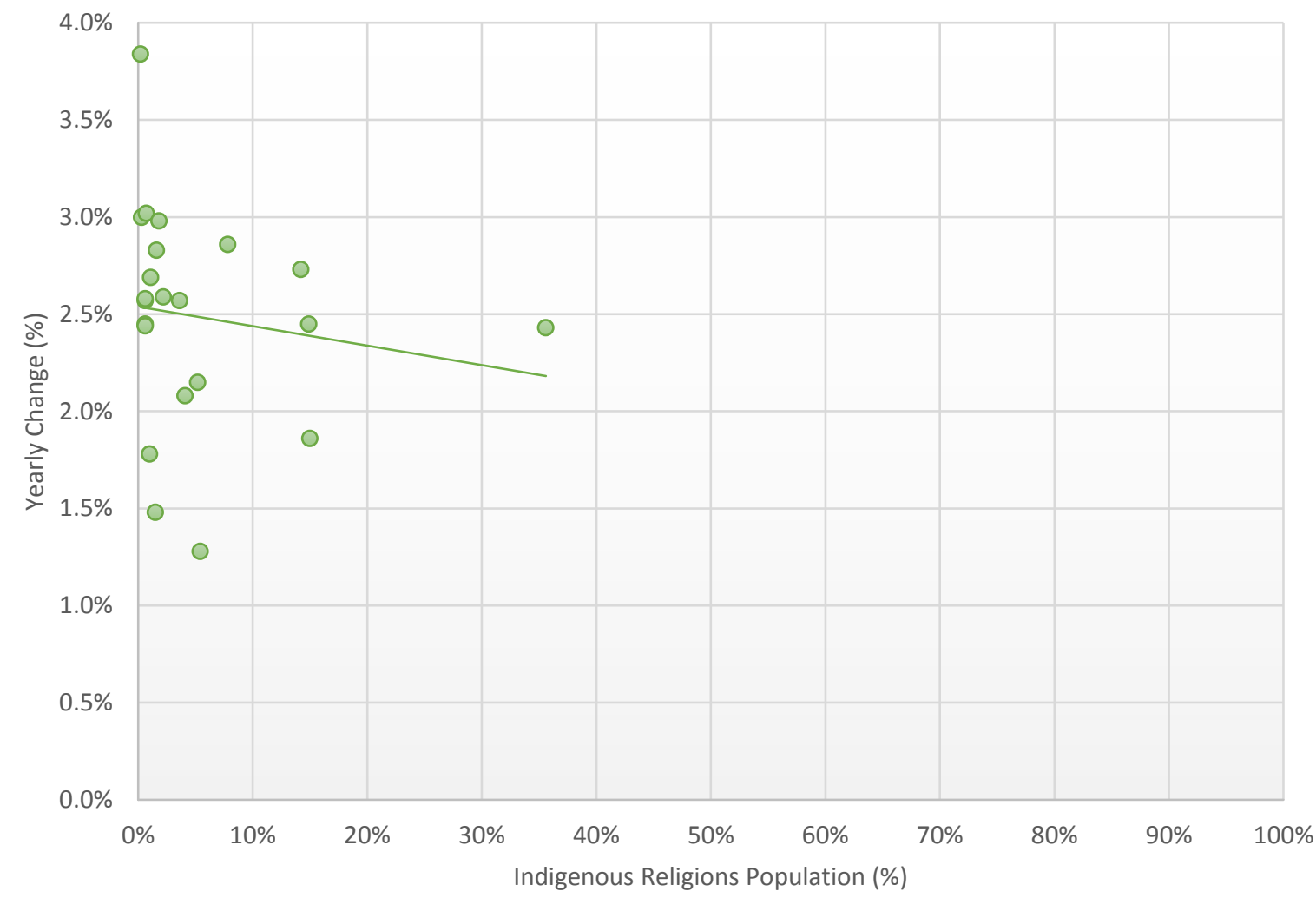

Figure 25. Yearly change (\%) has a negative relationship with Indigenous Religions populations (\%) across SSA. 


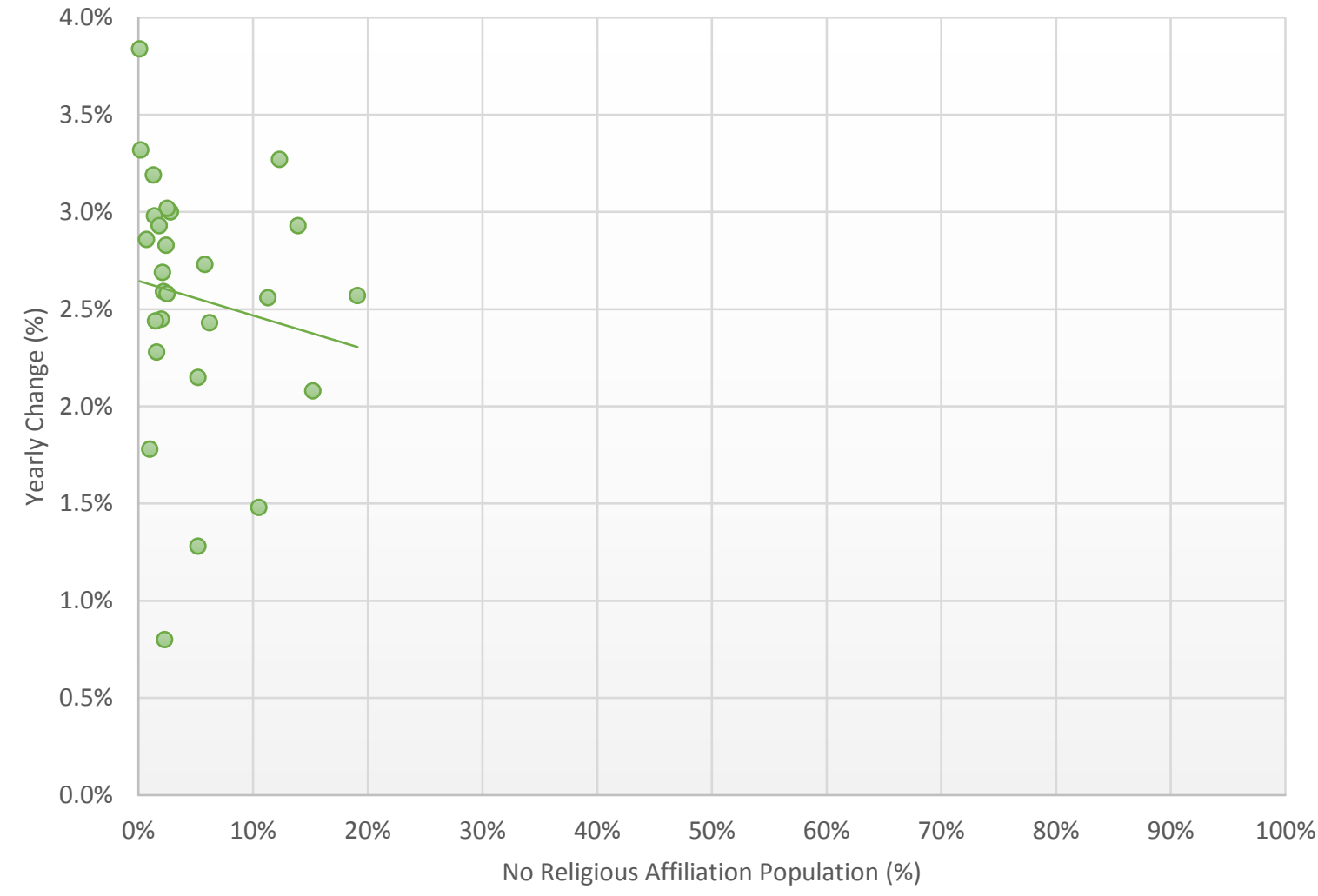

Figure 26. Yearly change (\%) has a negative relationship with no religious affiliation populations (\%) across SSA. 


\section{Methods and Materials}

\subsection{Sub-Saharan Africa}

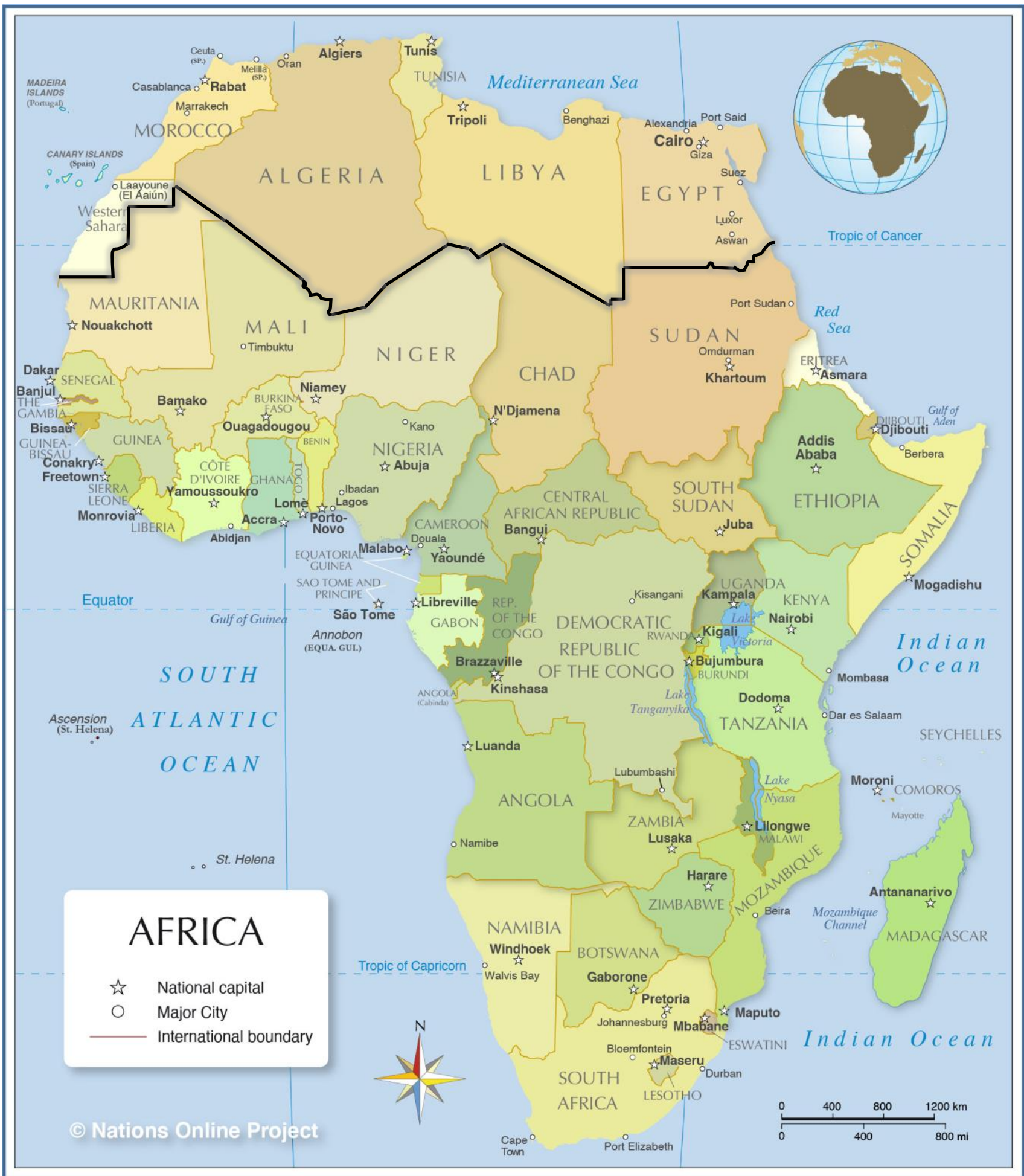

Figure 27. Sub-Saharan Africa is defined by the UN as all African countries that are fully or partially located south of the Sahara Desert. Countries south of the black line are Sub-Saharan nations that were included in this study.

[Source: Nations Online Project, 2019] 
Sub-Saharan Africa (Figure 27) is defined by the UN as all African countries that are fully or partially located south of the Sahara Desert, including six sovereign island nations (Cape Verde, Comoros, Mauritius, Madagascar, Sao Tome \& Principe, and the Seychelles). Of the 54 African countries, the UN classifies 46 as Sub-Saharan. However, this excludes Djibouti, Somalia and Sudan although they are geographically part of Sub-Sahara. Djibouti and Somalia are considered part of the League of Arab States in the Arab World, whereas Sudan is grouped as North Africa according to the UN's geoscheme for Africa. On the other hand, the World Bank identifies 48 countries as part of Sub-Saharan Africa, including Somalia and Sudan. For the purpose of this paper, Sub-Saharan Africa initially included the 48 countries identified by the World Bank, with the addition of Djibouti. However, due to strong religious and cultural differences between the island nations and the continent, and that these nations are isolated with small populations dominated by single religions in addition to strong tourist influences, the five island nations of Cabo Verde, Comoros, Seychelles, Mauritius and Sao Tome \& Principe were excluded from the study. Madagascar was included due to its size and higher religious and cultural similarities with the mainland. Dependencies and other disputed territories were not included in the study (Mayotte [France], Réunion [France], Saint Helena [United Kingdom] and Western Sahara). The final nation count in this study of continental Sub-Saharan Africa is therefore 44. 


\subsection{Systematic Review: Gathering of Literature}

A systematic review of the literature was conducted on papers that focused on religion and religiosity as an influence of fertility and contraceptive use. Using the Web of Science database initially as a primary source for literature, and then performing subsequent searches by Scopus, the following three sets of search terms were generated and applied to search in titles, abstracts and keywords for papers that included topics related to fertility and contraceptive use together with religion and religiosity from countries in Sub-Saharan Africa.

- (country) AND contracept* AND religio*

- (country) AND fertility AND religio*

- (country) AND "family planning" AND religio*

**Whereby (country) is replaced with a country in Sub-Saharan Africa.

"Family planning" was included as part of the search terms as this phrase is often used interchangeably with contraception. Ivory Coast was searched in its French name, Côte d'Ivoire, which is also used internationally. Eswatini was searched for using the name it was formerly known as - Swaziland. It is worth noting that for Scopus it was not necessary to include individual countries in the search terms as countries were subsequently filtered using the refine search filter tool.

All papers from the search results were organised into six separate spreadsheets in an Excel document; each spreadsheet listing the search results for each set of search terms from Web of Science and Scopus, respectively. The spreadsheets were subsequently combined into a single spreadsheet with all duplicates removed, resulting in a total of 600 references, with the oldest paper dating back to 1980 . The information included in the spreadsheet were authors, title, year of publication, country, times cited, language of paper, research classification, as well as each reference's proper citation. A column was also set up to identify which papers were found under each of the search terms "contracept*, "fertility", "family planning", or a combination of these.

Figure 28 shows the percentages of papers that were found through Web of Science, Scopus, and the percentages that overlapped for each decade between 1990 and 2020, as well as the total. On average, only a third (33\%) of papers appeared in the search results of both Web of Science and Scopus. This excludes four papers that pre-date 1990. However, the number of overlapping papers increased over time with $41 \%$ of papers appearing in search results of both Web of Science and Scopus in the last decade.

To test how comprehensive the search results from Web of Science were as regards to importance for the subject had initially yielded, I collaborated with my Thesis supervisor, Frank Götmark, and examined related papers with substantial content he had collected over the last five years $(n=56)$. Of the 56 papers, 19 (34\%) had not appeared in the Web of Science results, motivating the further searches using Scopus. However, none of the remaining 19 papers appeared in the Scopus search results. The 19 papers were included in the review and categorised as the others (see below). 
Using EndNote, I generated a bibliography of papers, with abstracts subsequently extracted. The abstracts were used to find further information including the specific country(ies) or region(s), and type of publication. I categorised publications in nine descriptive types, coded 1-9, as follows:

1. Surveys and polls from quantitative studies (including structured questionnaires and structured interviews).

2. Quantitative analysis with factors (explanatory variables) measured, for example, from agency data, for current situation.

3. Quantitative analysis with factors (explanatory variables) measured, for example from agency data, and longitudinal relationships (history up to present or part of history).

4. Quantitative analysis as above, based on some change, but no pre-change data available.

5. Quantitative analysis as above, based on some change, with before and after data, also referred to as "natural experiment".

6. Qualitative studies, such as focus group discussions and in-depth interviews.

7. Projections for the future for population size, fertility/TFR, birth rates, with model and assumptions for factors.

8. Literature reviews.

9. Other papers, books or chapters.

Furthermore, a new column was created to specify whether religion or religiosity influenced fertility and/or contraceptive use, according to results of analyses and conclusions of author(s) of paper (see also below). Papers where religion or religiosity had an influence, or clear relation to fertility and/or contraceptive use were marked with "Y" ("Yes"), and papers that did not were marked with "N" ("No"). When information was unavailable from the abstracts alone, the full article was sought to obtain the missing information.

Extra searches were carried out in collaboration with Frank Götmark after all papers were gathered. The first involved a search of all reference lists in collected papers from 2020. References of potential interest were collected and extracted for examination $(n=24)$. The other extra search was carried out on Google Scholar and yielded few new relevant papers $(n=3)$. Table 1 summarises the total number of papers found and their corresponding percentages for each literature source. The total number of papers found was 649 (1980-2020).

Table 1. Total number of papers and their corresponding percentages found for each literature source.

\begin{tabular}{rcc}
\hline WoS + Scopus & 600 & $92.9 \%$ \\
Götmark Collection & 19 & $2.9 \%$ \\
Reference List & 24 & $3.7 \%$ \\
Google Scholar & 3 & $0.5 \%$ \\
\hline Total & $\mathbf{6 4 6}$ & $\mathbf{1 0 0 . 0 \%}$ \\
\hline
\end{tabular}




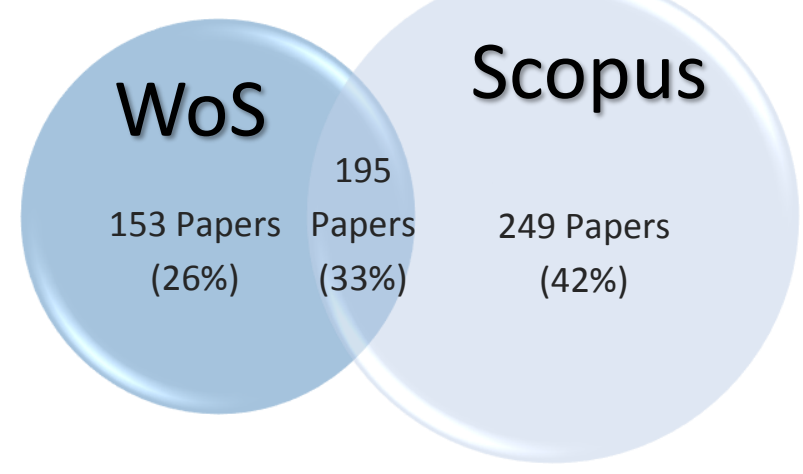

Total: 1990-2020

\section{WoS}

19

39 Papers Papers

(31\%)

\section{Scopus}

68 Papers

(54\%)

\section{WoS}

9

19 Papers Papers

(30\%)

\section{Scopus}

35 Papers

(56\%)

\section{0-1999}

WoS

167

95 Papers Papers

(23\%)

\section{Scopus}

146 Papers

(36\%)

\section{0-2009}

2010-2020

Figure 28. Venn diagrams showing the percentages of papers that were found through Web of Science, Scopus, and the percentages that overlapped for each decade between 1990 and 2020, as well as the total. 


\subsection{Identification of Studies}

Basic information about the papers had to be extracted before I could define a set of inclusion and exclusion criteria. The first step was to group English language papers and those focused on continental Sub-Saharan Africa by decade of publication in separate spreadsheets in a new Excel document:

- $2010-2019+2020$ (only papers from $1^{\text {st }}$ January to $31^{\text {st }}$ August 2020 )

- 2000-2009

- 1990-1999

The literature from each decade was first manually examined by scanning the entire paper to gather further information to help generate the inclusion and exclusion criteria. The additional information extracted to Excel files included focus religion(s), focus contraceptive type(s) (see Table 3), main study concern, study objective(s), methodological and statistical approaches, dependent and independent variables in analyses (where applicable), and conclusions, including two conclusions relating to the outcome of religion and religiosity, in addition to an overall general conclusion. This work served to establish the strength of focus on religion and religiosity in papers. Table 2 outlines the criteria for a ranking of strength of focus on religion and religiosity, where the conclusions of the study were important. This ensured that papers that did not have a considerable focus on religion or religiosity were not included in the study.

Table 2. Criteria to establish the strength of focus on religion and religiosity from conclusions in examined papers.

\begin{tabular}{rll}
\hline Strength & Definition \\
\hline Strong Focus & $\begin{array}{l}\text { Focus of study is religion (regardless of whether the study concluded that religion/religiosity } \\
\text { had no effect on fertility or contraceptive use). }\end{array}$ \\
Moderate-Strong & $\begin{array}{l}\text { Religion is a strong influential factor among other factors. } \\
\text { Religion is an influential factor among other factors with specific religions investigated OR if } \\
\text { Moderate (High) } \\
\text { no link to a specific religion was made but the sample population consists of }>95 \% \text { of a single } \\
\text { religion. }\end{array}$ \\
Meak-Moderate & $\begin{array}{l}\text { Religion is an influential factor among other factors, but no links to specific religions are made. } \\
\text { Religion is broadly discussed but not examined in great depth. } \\
\text { Weak Focus }\end{array}$ & $\begin{array}{l}\text { Religion was only mentioned in passing. No correlation was identified. No specific religions } \\
\text { were examined. }\end{array}$ \\
\hline
\end{tabular}

Table 3 shows the different types of contraceptives and their classifications as defined by the DHS program, which was a primary source of data for the majority of papers in the review. Abortion and menstrual regulation are not classified as contraceptives (Croft, et al., 2018). 
Table 3. Classification of modern and traditional contraceptives as defined by the DHS program.

\begin{tabular}{|c|c|c|c|}
\hline \multirow{9}{*}{$\begin{array}{l}\frac{n}{0} \\
0 \\
\frac{0}{1} \\
\frac{0}{\Sigma} \\
\frac{1}{2} \\
\frac{1}{0} \\
\frac{0}{\Sigma}\end{array}$} & \multirow{2}{*}{$\begin{array}{l}\text { Permanent } \\
\text { Methods }\end{array}$} & Female Sterilisation & Tubal Ligation \\
\hline & & Male Sterilisation & Vasectomy \\
\hline & \multirow{2}{*}{$\begin{array}{l}\text { Long-Acting } \\
\text { Reversible Methods } \\
\text { (LARC) }\end{array}$} & Implants & Norplant \\
\hline & & Intrauterine Device (IUD) & \\
\hline & \multirow{3}{*}{$\begin{array}{c}\text { Short-Acting } \\
\text { Reversible Methods } \\
\text { (SARC) }\end{array}$} & Barrier Methods & $\begin{array}{l}\text { Diaphragm } \\
\text { Female Condom } \\
\text { Male Condom }\end{array}$ \\
\hline & & Injectable Contraceptives & Depo-Provera \\
\hline & & Oral Contraceptives & $\begin{array}{l}\text { Contraceptive Pill } \\
\text { Emergency Contraception }\end{array}$ \\
\hline & \multirow{2}{*}{ Other } & $\begin{array}{l}\text { Lactational Amenorrhea } \\
\text { Method (LAM) }\end{array}$ & \\
\hline & & Periodical Abstinence & Standard Days Method (SDM) \\
\hline \multirow{3}{*}{ 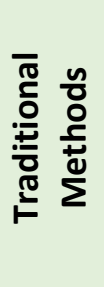 } & & Periodical Abstinence & Calendar/Rhythm Method \\
\hline & & Withdrawal (coitus interruptus) & \\
\hline & & Folk Methods & $\begin{array}{l}\text { Local methods of unproven effectiveness } \\
\text { such as herbs, amulets and concoctions. }\end{array}$ \\
\hline
\end{tabular}

Based on the extracted information and the six categories of papers, the following inclusion and exclusion criteria were generated (Table 4). Papers that met all the inclusion criteria were included in the study; papers that met any of the exclusion criteria were excluded. 
Table 4. List of inclusion and exclusion criteria. Papers that met all the inclusion criteria were included in the study; papers that met any of the exclusion criteria were excluded from the study.

\section{Inclusion Criteria}

- Study concern is related to fertility and/or contraceptive use.

- Strength of religion and/or religiosity in study is ranked as Strong Focus, Moderate-Strong or Moderate (High).

- Studies whereby the outcome variables include fertility and/or contraceptive use.

- Studies where religion and/or religiosity are examined as independent variables for fertility and contraceptive use.

- Accessible papers.

- Studies including one or more of the main religions of continental Sub-Saharan Africa.

- Studies where the focus country or region is within continental Sub-Saharan Africa.

- Published in 1990 or later.

- Published in English.

\section{Exclusion Criteria}

- Study concern is unrelated to fertility and/or contraceptive use.

- Strength of religion and/or religiosity in study is ranked as Moderate (Low), Weak-Moderate or Weak Focus.

- Studies whereby the outcome variables are unrelated to fertility and/or contraceptive use.

- Studies where religion and/or religiosity are not examined as independent variables of fertility and contraceptive use.

- Papers that cannot be found after exhausting all search procedures.

- Studies where religions are not one of the main religions of continental Sub-Saharan Africa.

- Studies where the focus country or region is outside continental Sub-Saharan Africa (e.g. island nations).

- Studies published prior to 1990.

- Non-English language literature. 


\subsection{Data Extraction and Analysis}

Application of the inclusion and exclusion criteria resulted in 152 papers to potentially include from the most recent decade. Because the main interest of this review concerned present conditions in Sub-Saharan Africa, papers from the "decade" 2010-2019 + 2020 were selected and included (152 papers). They were categorised into the following groups and sub-groups, based on characteristics of the sample population and publication type (Table 5). Papers that fell under "Non-General Population" included participants that were community and religious leaders, health care providers, teachers, as well as mixed population, which included a mixture of any of the aforementioned, including samples mixed with the general population.

Table 5. Number of papers represented for each classification.

\begin{tabular}{|c|c|c|c|}
\hline Decade & Study Type & Group & Sub-Group \\
\hline \multirow{16}{*}{$\begin{array}{c}2010-2019+2020 \\
(n=152)\end{array}$} & \multirow{5}{*}{$\begin{array}{l}\text { Quantitative Studies } \\
\qquad(n=117)\end{array}$} & \multirow{4}{*}{$\begin{array}{l}\text { General Population } \\
\qquad(n=115)\end{array}$} & $\begin{array}{l}\text { Adolescents Only } \\
(10-19 \text { years) }(n=4)\end{array}$ \\
\hline & & & $\begin{array}{l}\text { Adolescents and Young Adults } \\
\qquad(13-30 \text { years })(n=10)\end{array}$ \\
\hline & & & $\begin{array}{l}\text { All Reproductive Ages } \\
\text { (12-65 years) }(n=97)\end{array}$ \\
\hline & & & $\begin{array}{l}\text { HIV-Positive } \\
\qquad(n=4)\end{array}$ \\
\hline & & $\begin{array}{l}\text { Non-General Population } \\
\qquad(n=2)\end{array}$ & - \\
\hline & \multirow{5}{*}{$\begin{array}{l}\text { Qualitative Studies } \\
\qquad(n=17)\end{array}$} & \multirow{4}{*}{$\begin{array}{l}\text { General Population } \\
\qquad(n=13)\end{array}$} & $\begin{array}{l}\text { Adolescents Only } \\
(10-19 \text { years })(n=0)\end{array}$ \\
\hline & & & $\begin{array}{l}\text { Adolescents and Young Adults } \\
\qquad(13-30 \text { years })(n=1)\end{array}$ \\
\hline & & & $\begin{array}{l}\text { All Reproductive Ages } \\
\text { (12-65 years) }(n=12)\end{array}$ \\
\hline & & & $\begin{array}{l}\text { HIV-Positive } \\
\qquad(n=0)\end{array}$ \\
\hline & & $\begin{array}{l}\text { Non-General Population } \\
\qquad(n=4)\end{array}$ & - \\
\hline & \multirow{5}{*}{$\begin{array}{l}\text { Mixed Methods } \\
\qquad(n=13)\end{array}$} & \multirow{4}{*}{$\begin{array}{l}\text { General Population } \\
\qquad(n=11)\end{array}$} & $\begin{array}{l}\text { Adolescents Only } \\
\text { (10-19 years) }(n=1)\end{array}$ \\
\hline & & & $\begin{array}{l}\text { Adolescents and Young Adults } \\
\qquad(13-30 \text { years })(n=0)\end{array}$ \\
\hline & & & $\begin{array}{l}\text { All Reproductive Ages } \\
\text { (12-65 years) }(n=9)\end{array}$ \\
\hline & & & $\begin{array}{l}\text { HIV-Positive } \\
\qquad(n=1)\end{array}$ \\
\hline & & $\begin{array}{l}\text { Non-General Population } \\
\qquad(n=2)\end{array}$ & \\
\hline & $\begin{array}{l}\text { Literature Reviews } \\
\qquad(n=5)\end{array}$ & - & - \\
\hline
\end{tabular}


I sorted each sub-group into two further groups, with outcome associated with either fertility or contraception. Due to time constraints, the examination of collected literature focuses on quantitative studies of fertility papers of the largest group "General Population: All Reproductive Ages (12-65 years)", and qualitative studies of fertility and contraceptive use from the last decade. Literature reviews were used for the Discussion.

I classified the quantitative fertility papers according to dependent variables used in the analyses. The results from papers using the same dependent variables were extracted, tabulated and presented in graphs to display the results for different religions in different countries. Where religions from the same country had multiple results (multiple papers), I calculated mean values.

For qualitative papers on contraception and fertility, I categorised and extracted common themes. Themes that represented increasing fertility and lower contraceptive use were separated from themes that represented limiting fertility and higher contraceptive use, respectively. I present frequencies of themes that occurred for increasing and limiting fertility, and lower and higher contraceptive use in which the most commonly occurring themes are identified for each of the two groups. 


\section{Results}

The initial search of the literature yielded 649 potentially relevant papers, with the earliest dating back to 1980. Figure 29 shows the number of papers by decades. The last decade display a remarkable increase in papers published $(n=447)$.

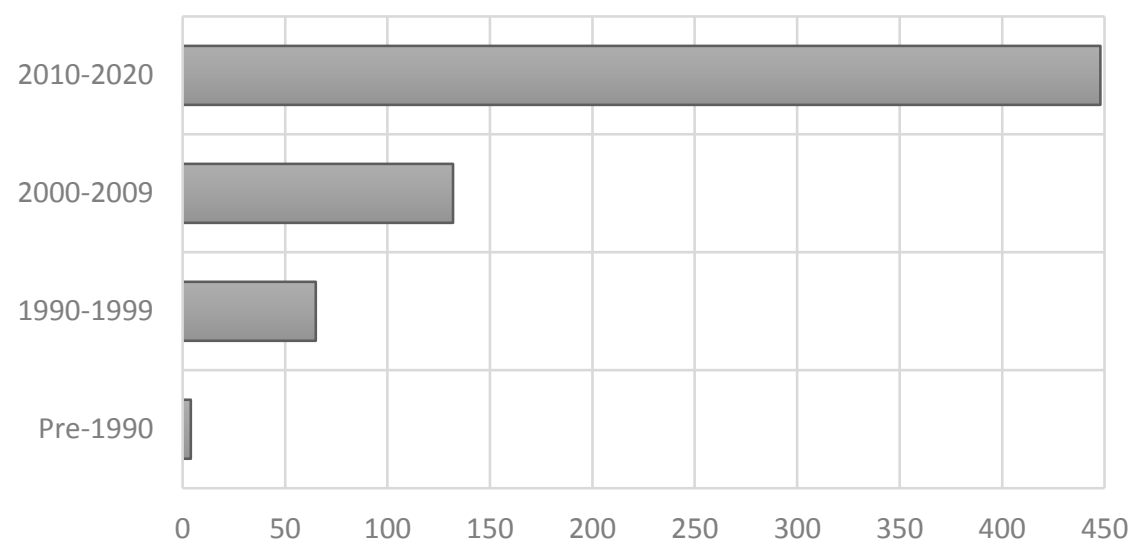

Figure 29. No. of papers found in the initial search by decade. 2020 only includes $1^{\text {st }}$ January to $31^{\text {st }}$ August.

Of the 447 papers published in the last decade, 152 met the inclusion criteria for this review. Figure 30 shows the number of eligible papers from 2010-2020 for each country. The largest number of studies were from Nigeria ( $n=67)$, followed by Ethiopia $(n=29)$, Ghana $(n=20)$ and Kenya $(n=19)$. In contrast, Equatorial Guinea, Guinea-Bissau, Mauritania, Sudan and South Sudan did not yield any papers. Some studies covered multiple countries, therefore the total number of publications from each country $(n=318)$ does not equal the number of papers that met the inclusion criteria from the last decade $(n=152)$. Nigeria's population received much attention recently, as it has the largest population in Africa of 206 million as of 2021 (Worldometer, 2021). This figure is nearly twice that of Africa's second most populous nation, Ethiopia, with a population of 115 million and a land area only slightly larger than that of Nigeria. 


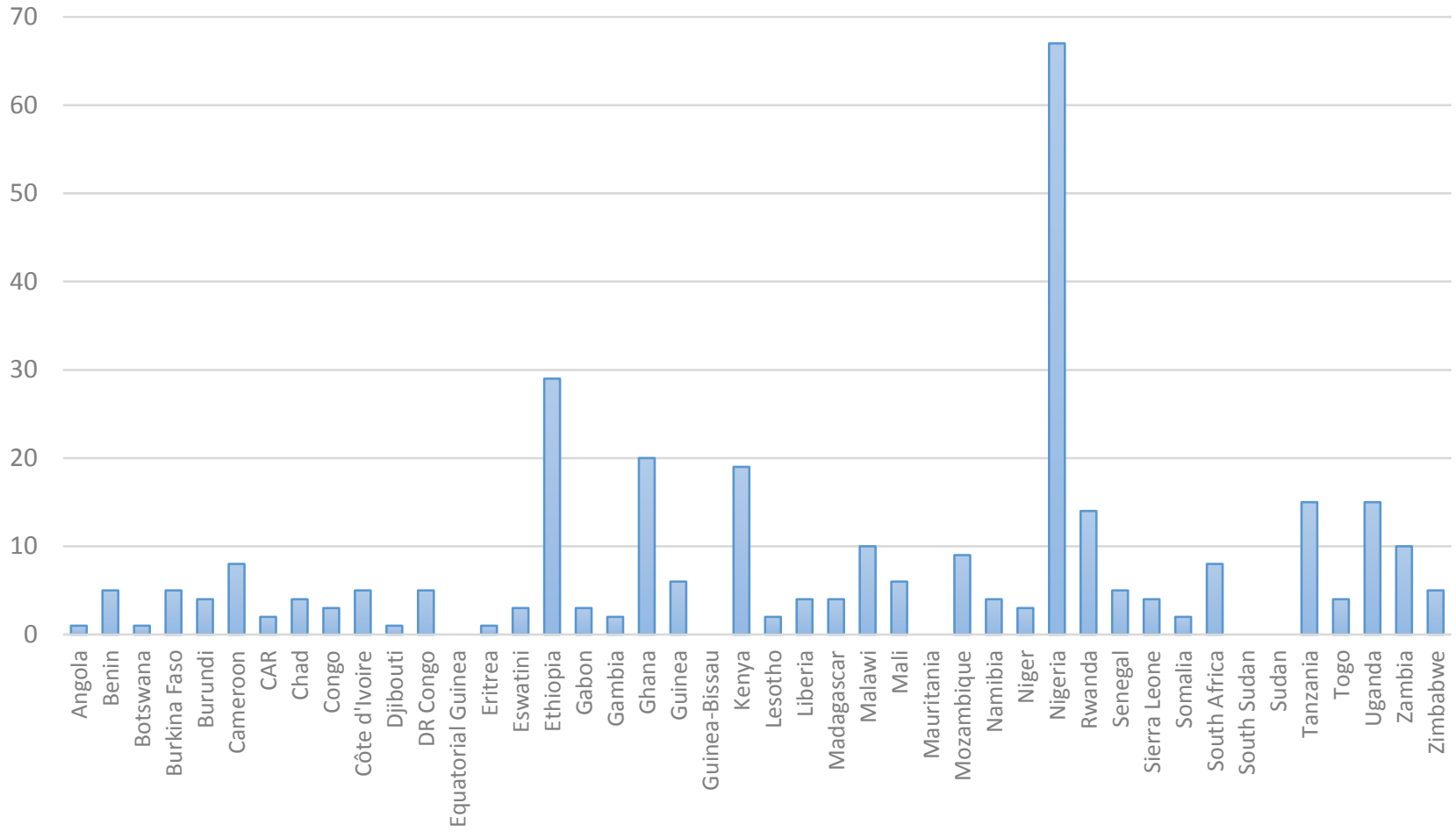

Figure 30. No. of eligible publications per country in Sub-Saharan Africa for the decade 2010-2019 + 2020 .

As mentioned in Section 2.4, due to time constraints, examination of literature in this Thesis focused on fertility papers of the largest group and respective sub-group - "General Population: All Reproductive Ages (12-65 years)" - and qualitative studies of fertility and contraceptive use from the last decade. The literature from these two groups covered 35 countries out of the 44 nations that qualify as continental Sub-Saharan Africa, shown in Figure 31. Quantitative studies on fertility from the general population of all reproductive ages (1265 years) ( $n=19$ ) covered 34 countries with Nigeria having the most papers ( $n=11)$, followed by Ghana $(n=7)$ and Kenya ( $n=6$ ) (Figure 32). Qualitative studies $(n=17)$ covered eight countries with Nigeria yielding the most papers again ( $n=5)$, followed by Tanzania $(n=4)$ (Figure 33 ). The nine countries that were not covered in these two groups are Angola, Botswana, Djibouti, Equatorial Guinea, Eritrea, Guinea-Bissau, Mauritania, Sudan and South Sudan. 


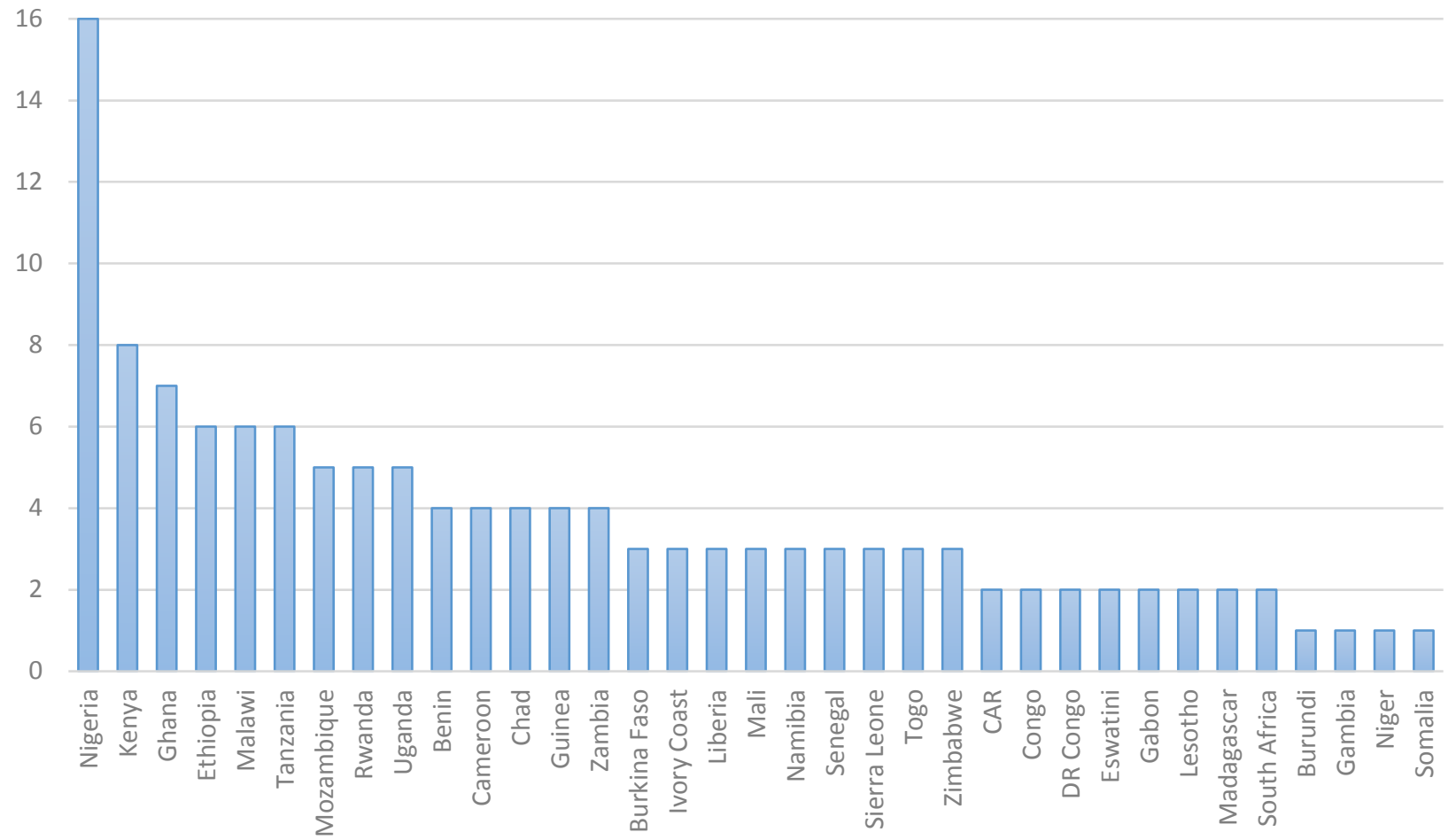

Figure 31. The studies examined cover 35 countries out of the 44 nations that qualify as continental Sub-Saharan Africa.

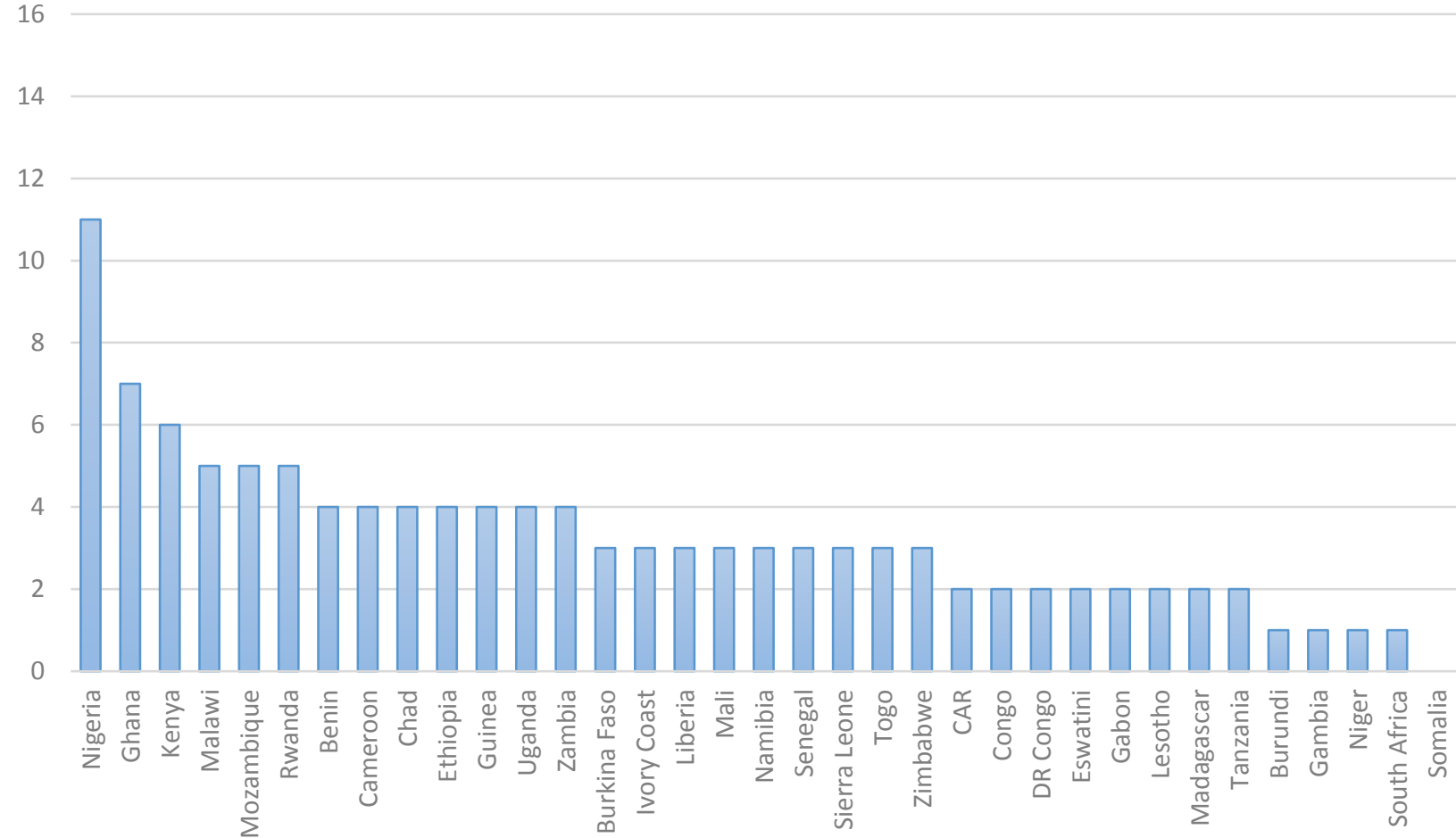

Figure 32. Quantitative studies examined cover 34 countries across continental Sub-Saharan Africa. 


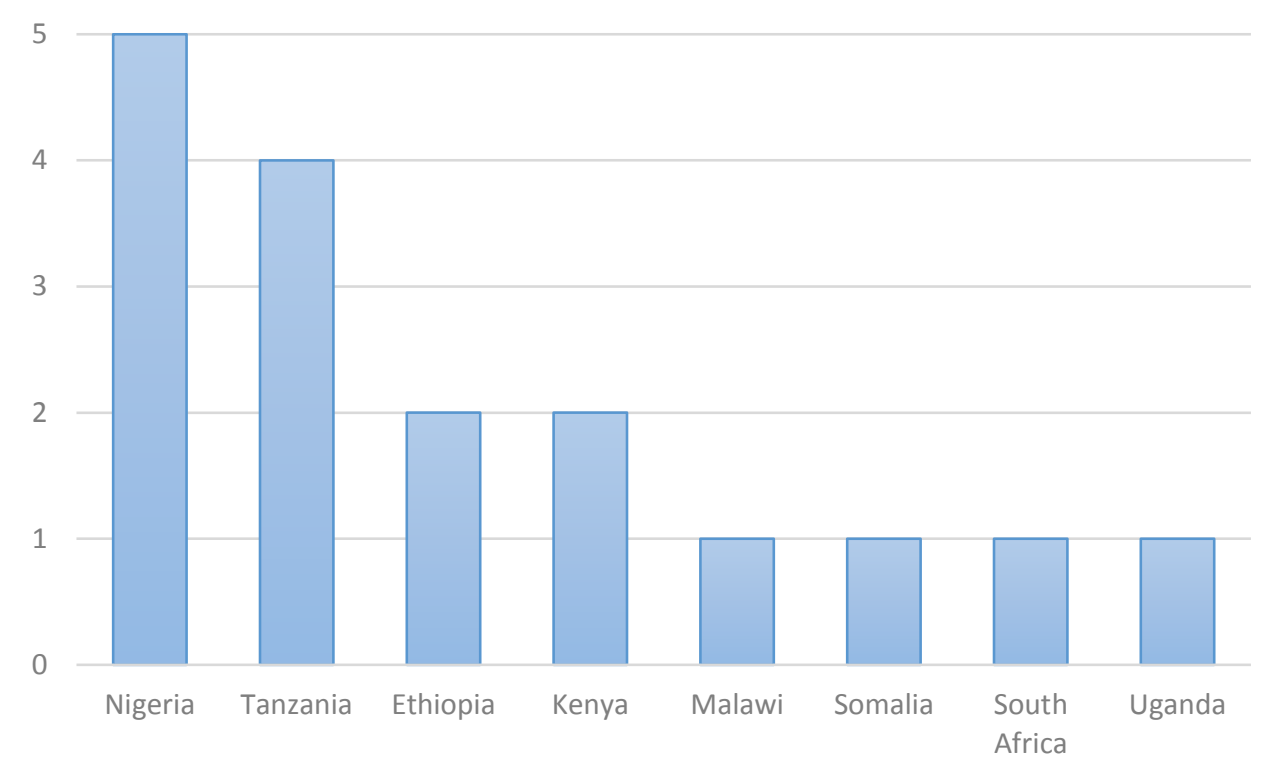

Figure 33. Qualitative studies examined cover eight countries across continental Sub-Saharan Africa.

To summarise, in total 36 studies were included in the review covering 35 countries in Sub-Saharan Africa. Nineteen quantitative studies examined fertility among the general population across all reproductive ages (12-65 years) in 34 countries. Seventeen qualitative studies explored fertility and contraceptive use in eight countries.

\subsection{Quantitative Studies of Fertility}

Of the 98 quantitative studies under "General Population: All Reproductive Ages (12-65 years)" that met the inclusion criteria, 19 studies measured outcomes that related to fertility across 34 countries. Table 6 outlines the number of papers studied for each dependent variable. Children ever born $(n=7)$ was the most frequently studied dependent variable followed by fertility desires and TFR ( $n=5$ for each). One paper (Westoff \& Bietsch, 2015) measured three dependent variables: fertility desires, number of births in last five years and TFR. For characteristics of sample populations and study design, see Appendix C. Religiosity was not explored in these quantitative studies.

Table 6. Number of papers representing each dependent variable relating to fertility for General Population: All Reproductive Ages (12-65 years).

\begin{tabular}{r|c}
\hline \multicolumn{1}{c}{ Dependent Variable } & No. of Papers \\
\hline Achievement of Fertility Desires & 1 \\
\hline Children Ever Born & 7 \\
Fertility Desires & 5 \\
\hline No. of Births in Last 5 Years & 3 \\
\hline Total Fertility Rates (TFR) & 5 \\
\hline
\end{tabular}


Figure 34 to Figure 37 combine the results of all dependent variables to represent the magnitude of fertility differences between religions. Findings of each dependent variable is presented in Sections 3.1.1 - 3.1.5. Participants affiliated with African Indigenous Religions had higher fertility than Christians (all denominations pooled) in all countries that measured fertility for both religious groups, shown in Figure 34 . The magnitude of difference was largest in Liberia, followed by Sierra Leone, Kenya, Zambia and Guinea with fertility differences of $50 \%$ or larger. Zimbabwe, Lesotho, Chad, Mozambique, Benin and Namibia had the smallest magnitude of difference between these two religious groups, with fertility differences of $10 \%$ or below. The average fertility difference between the groups across all countries is $26 \%$. Thus, these results show a marked, consistent difference in fertility between participants affiliated with African Indigenous Religions and Christians.

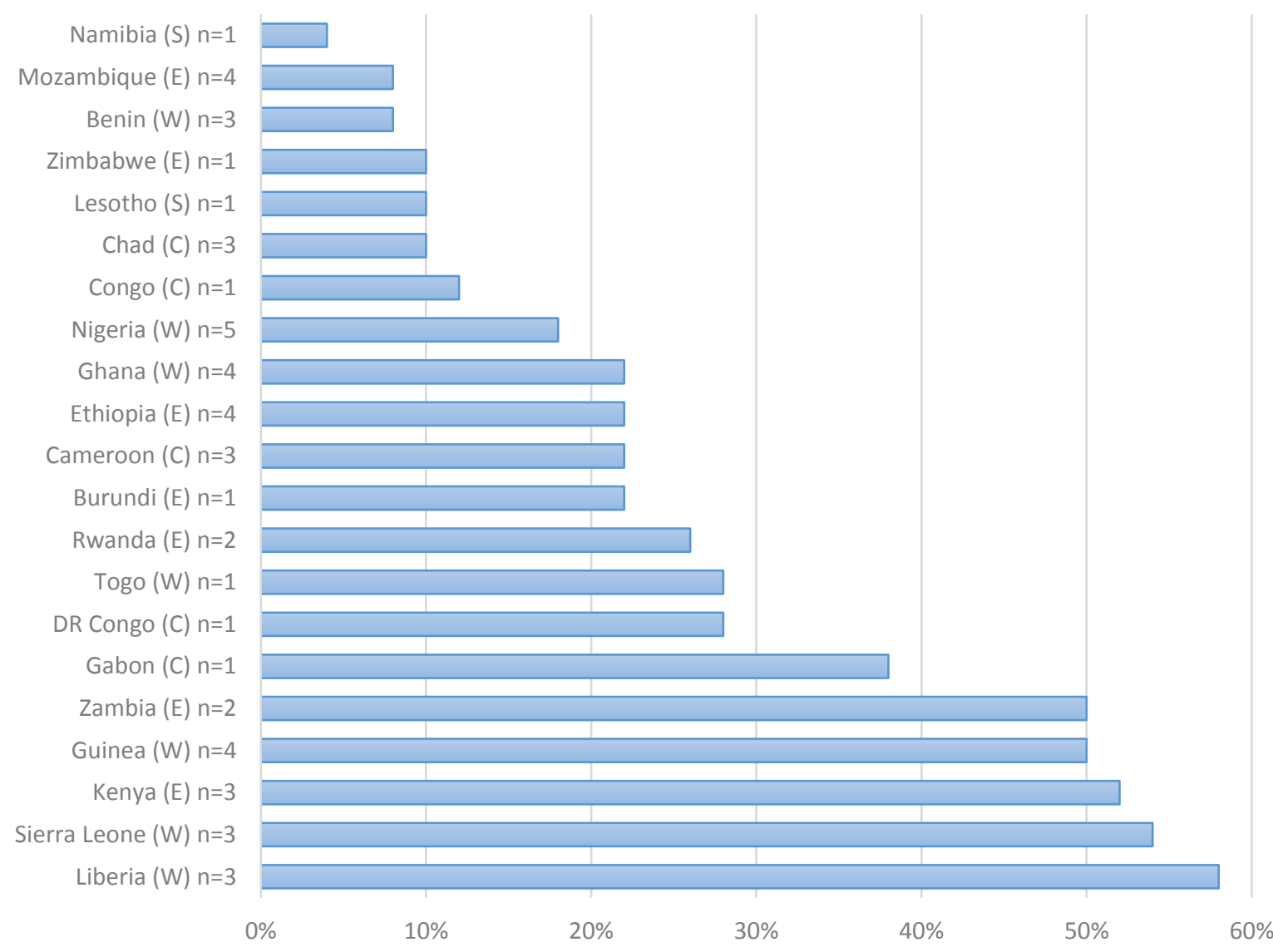

Figure 34. Fertility distribution between Christians and African Indigenous Religions. African Indigenous Religions had higher fertility than Christians across all countries. The size of the bar indicates the magnitude of fertility difference between Christians and African Indigenous Religions. Letter in parentheses refers to region (W = Western; C $=$ Central; $\mathrm{E}$ = Eastern; $\mathrm{S}=$ Southern). [ $n=$ No. of papers.]

Figure 35 shows that Muslims had higher fertility than Christians (all denominations pooled) in countries that measured fertility for the two religions, except Uganda and Zimbabwe which showed the opposite trend. Gabon displayed the largest magnitude of difference of $36 \%$. Rwanda, Tanzania, Ivory Coast, Burkina Faso, the Central African Republic, Chad and Mozambique had the smallest magnitude of difference of less than $10 \%$. Although Uganda and Zimbabwe were the only countries where Christians had higher fertility than Muslims, the magnitude of difference was only $2 \%$ for both nations. The average fertility difference across all countries 
is $16 \%$. Thus, these results indicate a difference in fertility between Muslims and Christians, with the latter again having lowest fertility.

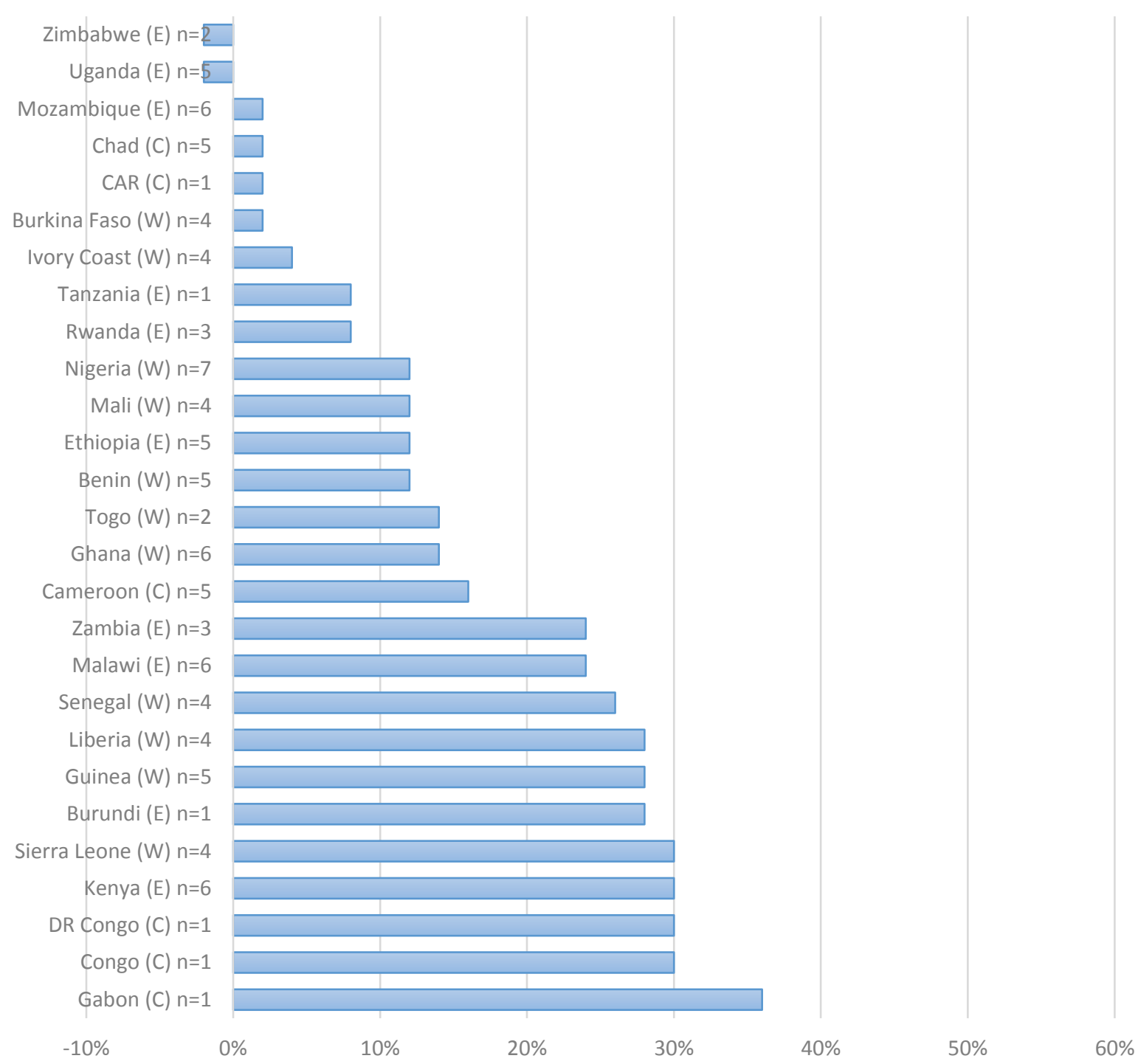

Figure 35. Fertility distribution between Christians and Muslims. Countries where Muslims had higher fertility than Christians is presented on the right; countries where Christians had higher fertility than Muslims is presented on the left. The size of the bar indicates the magnitude of fertility difference between Christians and Muslims. Letter in parentheses refers to region ( $\mathrm{W}=$ Western; $\mathrm{C}=$ Central; $\mathrm{E}=$ Eastern; $\mathrm{S}=$ Southern). [ $n=$ No. of papers.]

Figure 36 shows that Muslims had higher fertility than participants affiliated with African Indigenous Religions in eight countries with the opposite trend in ten countries. Zambia displayed the largest magnitude of fertility difference of $30 \%$ with participants affiliated with African Indigenous Religions having a higher fertility than Muslims. Congo had the highest magnitude of difference of $18 \%$ for the opposite trend. All other countries had a fertility difference of $10 \%$ or less. The fertility difference in Benin was $0 \%$ as both religions had equal levels of fertility. The average fertility difference across all countries is $2 \%$. Thus, these results indicate that, except in Congo and Zambia, difference in fertility between Muslims and participants affiliated with African Indigenous Religions is small and inconsistent. Fertility levels were generally high for both religious groups (see below, Sections 3.1.1 - 3.1.5). 


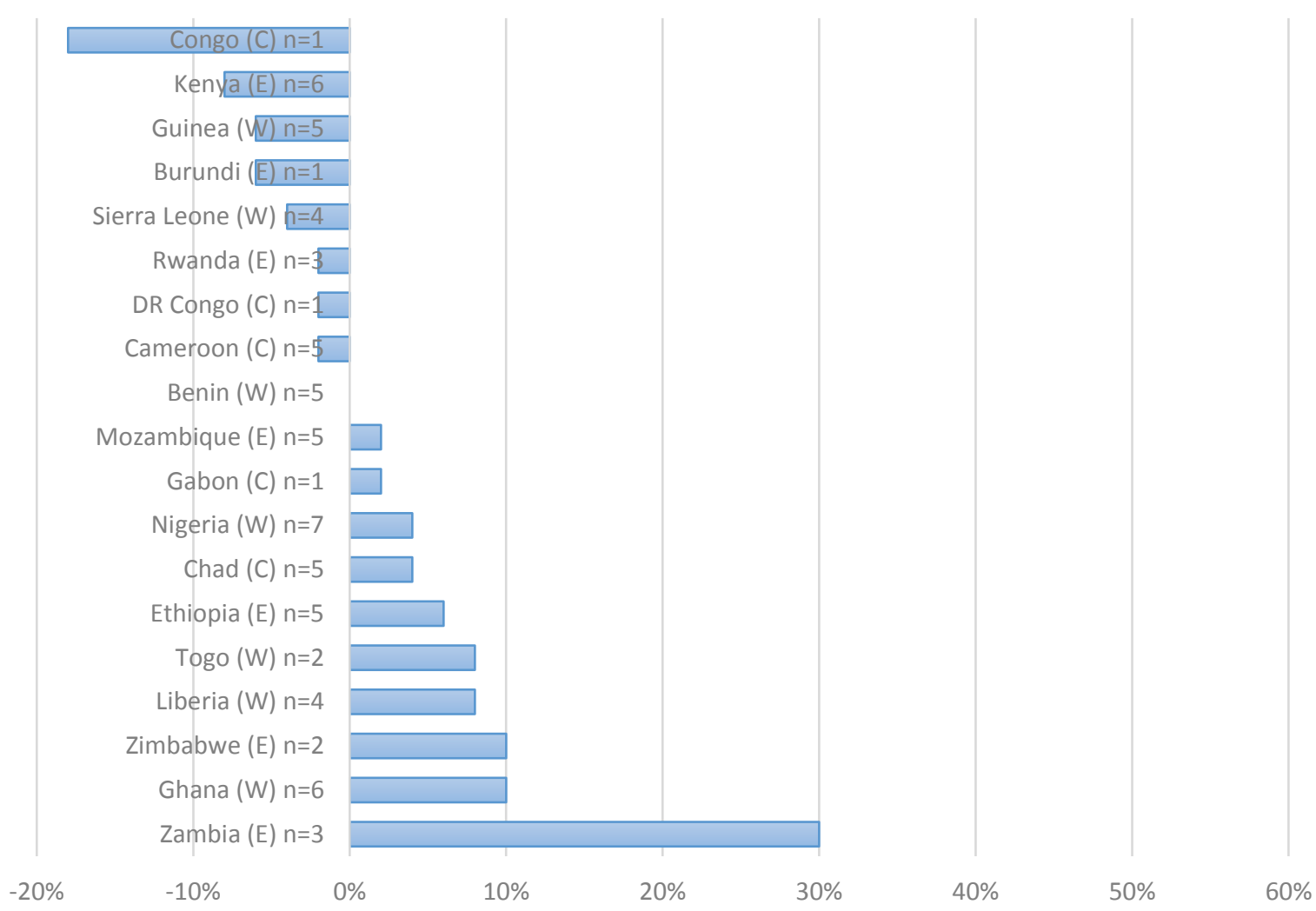

Figure 36. Fertility distribution between Muslims and African Indigenous Religions. Countries where African Indigenous Religions had higher fertility than Muslims is presented on the right; countries where Muslims had higher fertility than African Indigenous Religions is presented on the left. The size of the bar indicates the magnitude of fertility difference between Muslims and African Indigenous Religions. Letter in parentheses refers to region (W = Western; C $=$ Central; $E$ = Eastern; $\mathrm{S}=$ Southern). [ $n=$ No. of papers. $]$

Figure 37 shows that, among Christians, fertility is similar for Catholics and Protestants. Ivory Coast and Lesotho had the largest magnitude of fertility difference of $12 \%$ for both nations with Catholics having higher fertility than Protestants. All other countries had a fertility difference of less than $10 \%$. Burkina Faso, Burundi, Ghana, Namibia and Togo had a difference of $0 \%$ as both denominations had equal levels of fertility. The average fertility difference across all countries is $0 \%$. Thus, these results suggest no, or small difference in fertility between Catholics and Protestants.

To summarise, participants affiliated with African Indigenous Religions had higher fertility than Christians in all countries that measured fertility for both religious groups, showing a marked, consistent difference in fertility between the two groups. Muslims had higher fertility than Christians in countries that measured fertility for both groups, except Uganda and Zimbabwe, also indicating a difference in fertility between the two religions. However, differences in fertility between Muslims and participants affiliated with African Indigenous Religions were small and inconsistent. Fertility is similar for Catholics and Protestants, also suggesting no, or small difference in fertility. 


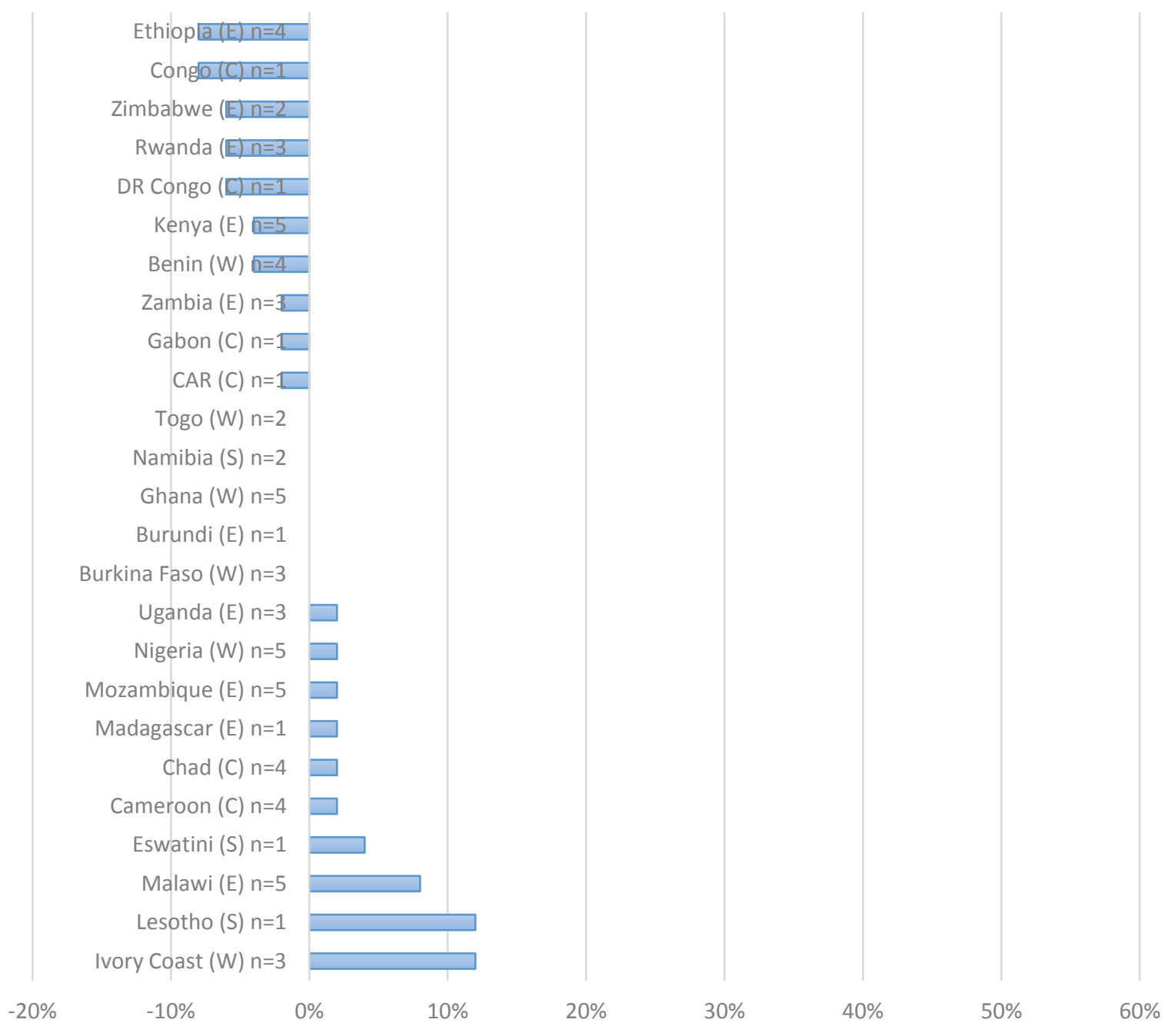

Figure 37. Fertility distribution between Protestants and Catholics. Countries where Catholics had higher fertility than Protestants is presented on the right; countries where Protestants had higher fertility than Catholics is presented on the left. The size of the bar indicates the magnitude of fertility difference between Protestants and Catholics. Letter in parentheses refers to region ( $\mathrm{W}=$ Western; $\mathrm{C}=$ Central; $\mathrm{E}=$ Eastern; $\mathrm{S}=$ Southern). [ $n=$ No. of papers.]

\subsubsection{Achievement of Fertility Desires (in total 1 paper)}

One paper (Babalola, et al., 2017) measured the achievement of fertility desires among 1,921 women in Nigeria. Fertility desires is the mean number of children desired, also known as the mean ideal number of children (Westoff, 2010). The study was conducted between 2010 and 2014 in the cities of Abuja, Benin City, Ibadan, Ilorin, Kaduna and Zaria. Data was collected by utilising non-DHS surveys. The women in the study were in a union, fecund and desired no more children at baseline. $49.4 \%(n=949)$ of the women were Christian while $50.6 \%$ ( $n=972$ ) were Muslim. In this study, no numerical data was available. Nonetheless, Babalola, et al., 2017 concluded that Muslims were less likely to achieve their fertility desires compared with Christians. Fertility desires does not necessarily translate into actual fertility. This study explores why this may be the case and serves as support for studies on Fertility Desires (see Section 3.1.3). Furthermore, this longitudinal study seeks to establish causal relationships rather than just associations, therefore complimenting the crosssectional studies in this review. 


\subsubsection{Children Ever Born (in total 7 papers)}

Children ever born (CEB) is the mean number of children, both surviving and dead, who were born alive to all women in a sample (United Nations, 2021). Seven papers measured the mean number of CEB across five countries, of which five papers used data from the DHS and two used own questionnaires.

Fertility (CEB) for Christians, Muslims, African Indigenous Religions and those with no religious affiliations varied among countries, especially for Christians. Ghana and Nigeria showed similar trends with African Indigenous Religions having the highest CEB (6.2 and 7.2, respectively), followed by Muslims (5.3 and 6.7, respectively) and Christians (4.9 and 5.0, respectively) (Figure 38). Overall, Nigeria had a higher number of CEB across all religions compared with Ghana. In Mozambique, those with no religious affiliation had a slightly higher CEB than Christians (3.7 and 3.6, respectively). In this case, those with no religious affiliation was represented by $11.5 \%$ of the sample population (total sample, 232 individuals), whereas Christians were represented by $88 \%$ (total sample, 2,007 individuals). Mean CEB varied between Christians across the five nations, with Zambia having the highest (7.0) and Eswatini having the lowest (2.6). Christians in Ghana and Nigeria had similar CEB (4.9 and 5.0, respectively) while Muslims had a higher CEB for Nigeria (6.7) than Ghana (5.3).

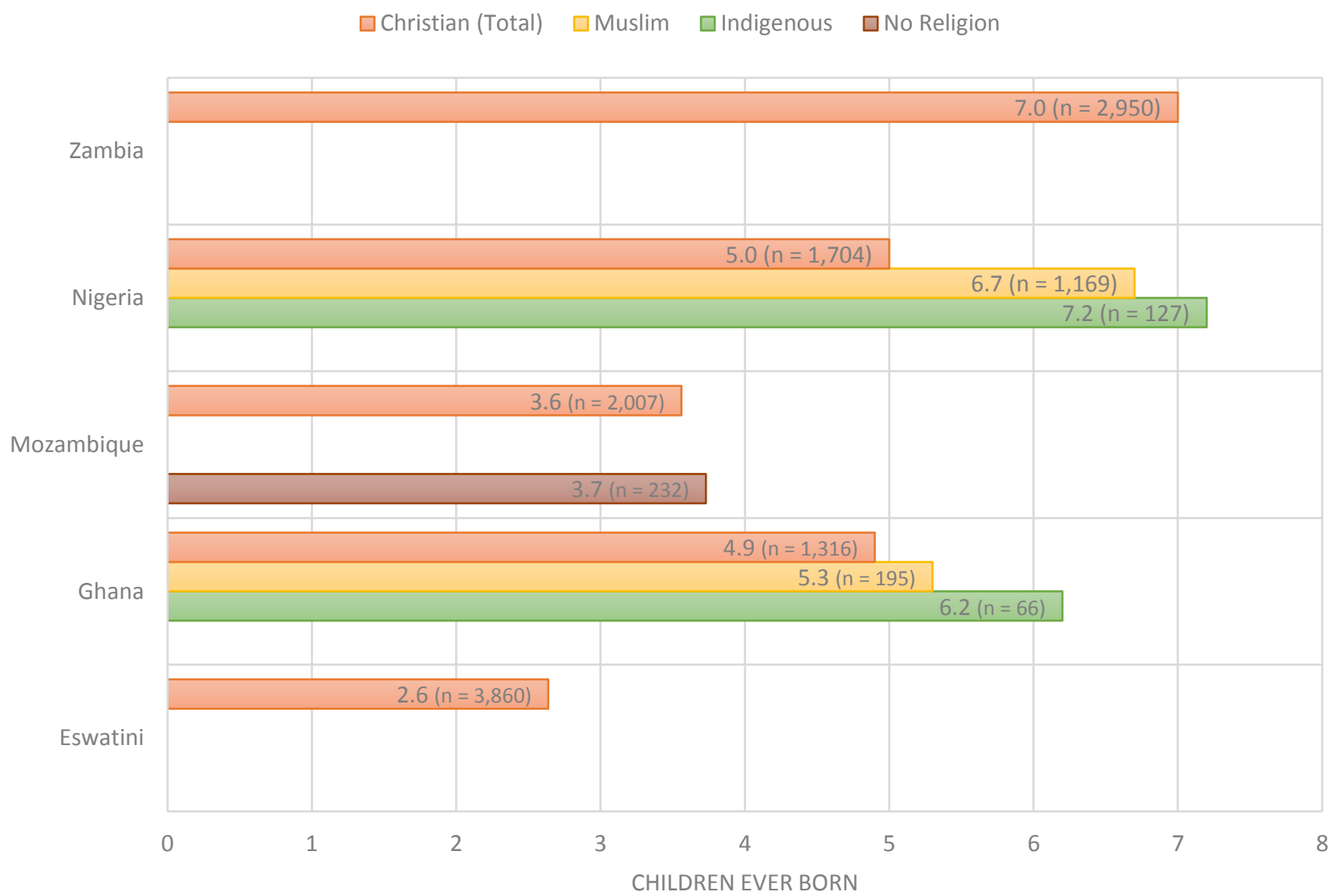

Figure 38. Mean number of children ever born (CEB) for Christians, Muslims, Indigenous religions and no religious affiliation. [ $n$ = Sample size.]

[Data Source: Agadjanian \& Yabiku, 2014; Chemhaka \& Odimegwu, 2020; Ntoimo \& Mutanda, 2017]

[NB: For Eswatini and Mozambique, Christian (Total) was calculated by taking the average of all the Christian religions.] 
In comparisons of only Christian denominations in these countries (Figure 39), country differences (marked) seem to matter more than denomination per se. Overall, Zambia had the highest CEB, followed by Nigeria and Ghana. In all three countries, Catholics had higher CEB than other Christians, but the difference is small. Eswatini and Mozambique had overall lower CEB than the aforementioned countries. In Eswatini and Mozambique, additional Christian denominations were examined, and in both countries, Apostolics had the highest CEB (3.1 and 3.8, respectively) followed by Catholics (2.6 and 3.5, respectively) and Pentecostals (2.5 and 3.4, respectively). In Eswatini, Protestants had the lowest CEB (2.4) of all Christian denominations whereas in Mozambique, Protestants and Zionists had the same CEB as Catholics (3.5). Overall, Mozambique had a higher CEB than Eswatini.

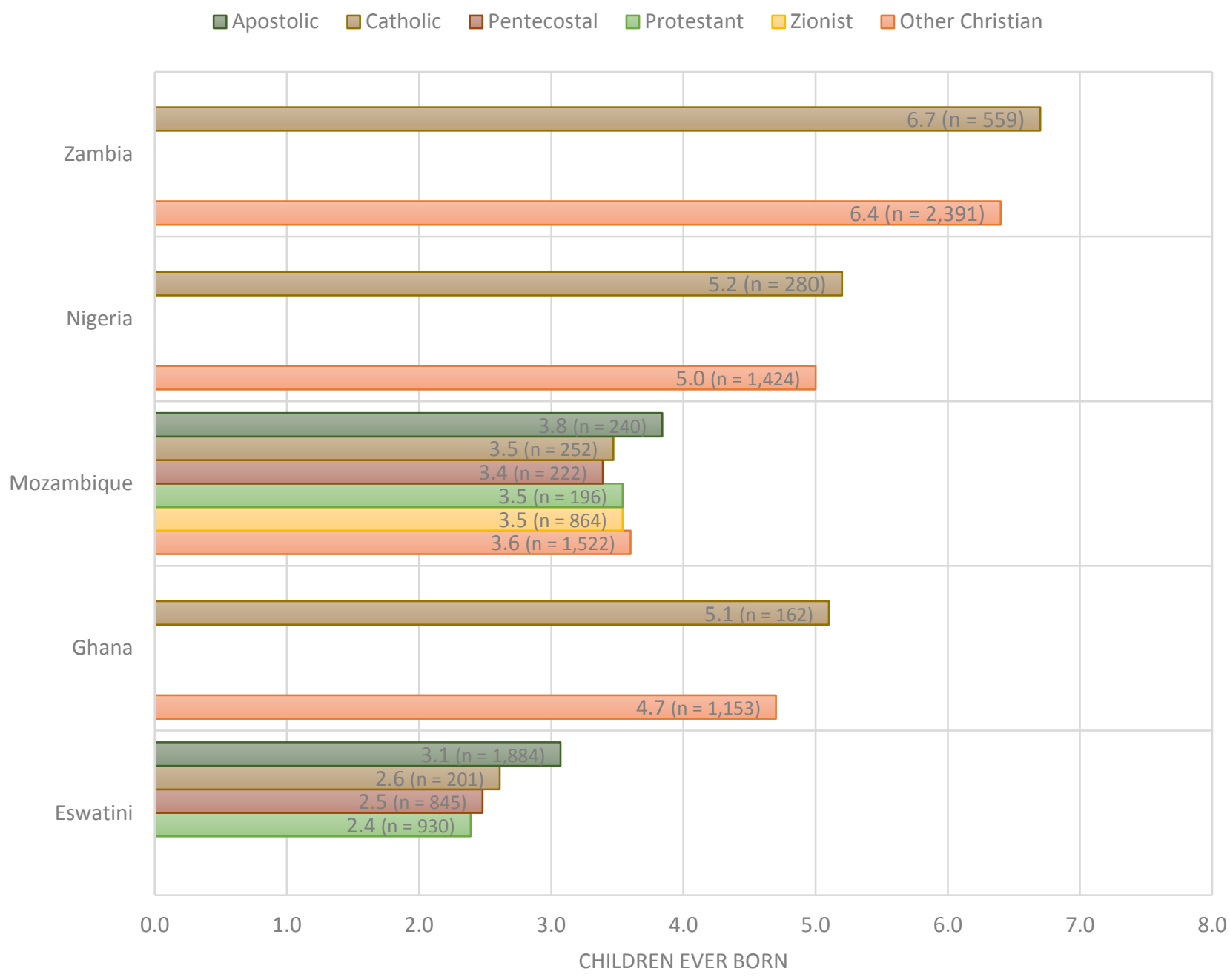

Figure 39. Mean number of children ever born (CEB) for Christian Religions. [ $n=$ Sample size.] [Data Source: Agadjanian \& Yabiku, 2014; Chemhaka \& Odimegwu, 2020; Ntoimo \& Mutanda, 2017] [NB: For Mozambique, Other Christian was calculated by taking the average of all the Christian religions except Catholic. NBB: For Eswatini, "Apostolic/Zion" is represented by "Apostolic", and "Pentecostal/Charismatic" is represented by "Pentecostal".]

Mberu \& Reed (2014) used data from three DHS rounds (2003, 2008 and 2013) to study Nigerian women of two age ranges, $15-49$ years and 40-49 years. In the broader age range of 15-49 (Figure 40), African Indigenous Religions had the highest CEB, see Figure 38. Overtime, the CEB dipped from 5.9 in 2003 to 4.5 in 2008, before 
increasing again to 5.0 in 2013. In 2003, Catholics had the next highest CEB followed by Muslims, however, this trend flipped in 2008 and 2013 with Muslims having a higher CEB than Catholics. Nevertheless, the Muslim trend remained static over the 10 years with the CEB only increasing from 4.1 to 4.2 during that time. The flipped trend between Muslims and Catholics can be defined by the steady decreasing CEB for Catholics from 2003 (4.2) to 2013 (3.7). Protestants had the lowest CEB that steadily decreased from 3.9 in 2003 to 3.6 in 2013. With the exception of Muslims in the sample population, there was an overall decreasing trend of CEB from 4.7 in 2003 to 4.1 in 2013.

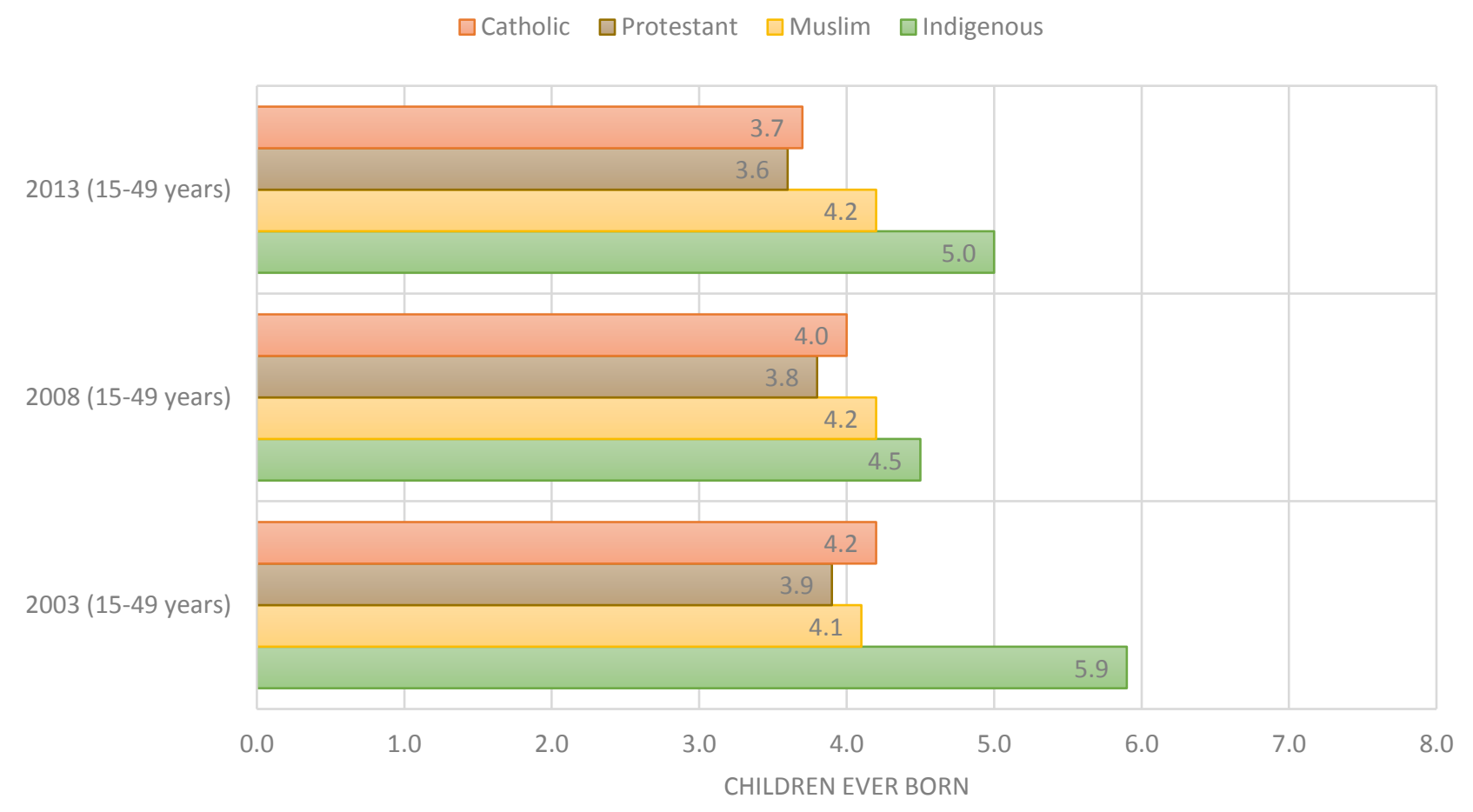

Figure 40. Mean number of children ever born (CEB) in Nigeria between 2003 and 2013 for women aged 15-49 years. [Data Source: Mberu \& Reed, 2014] [NB: Samples sizes were not specified.]

Although the narrower age range of 40-49 (Figure 41) showed a similar trend to that of the broader age range, overall, the CEB was markedly higher across all religions for the older group. CEB for Muslims remained static, increasing only slightly from 7.0 in 2003 to 7.2 in 2013 while the CEB for Catholics steadily decreased from 7.0 in 2003 to 5.8 in 2013. A dip in CEB was also observed for African Indigenous Religions from 7.4 in 2003 to 6.7 in 2008, before increasing to 7.1 in 2013. In the older age group, Mberu \& Reed (2014) replaces the Protestant group with the group Other Christians. Assuming that a substantial portion of other Christians are Protestants, it can be said that Protestants in this age range continue to have the lowest CEB, as observed with the wider sample population, however, with a much steeper decreasing trend from 6.5 in 2003 to 5.3 in 2013. 


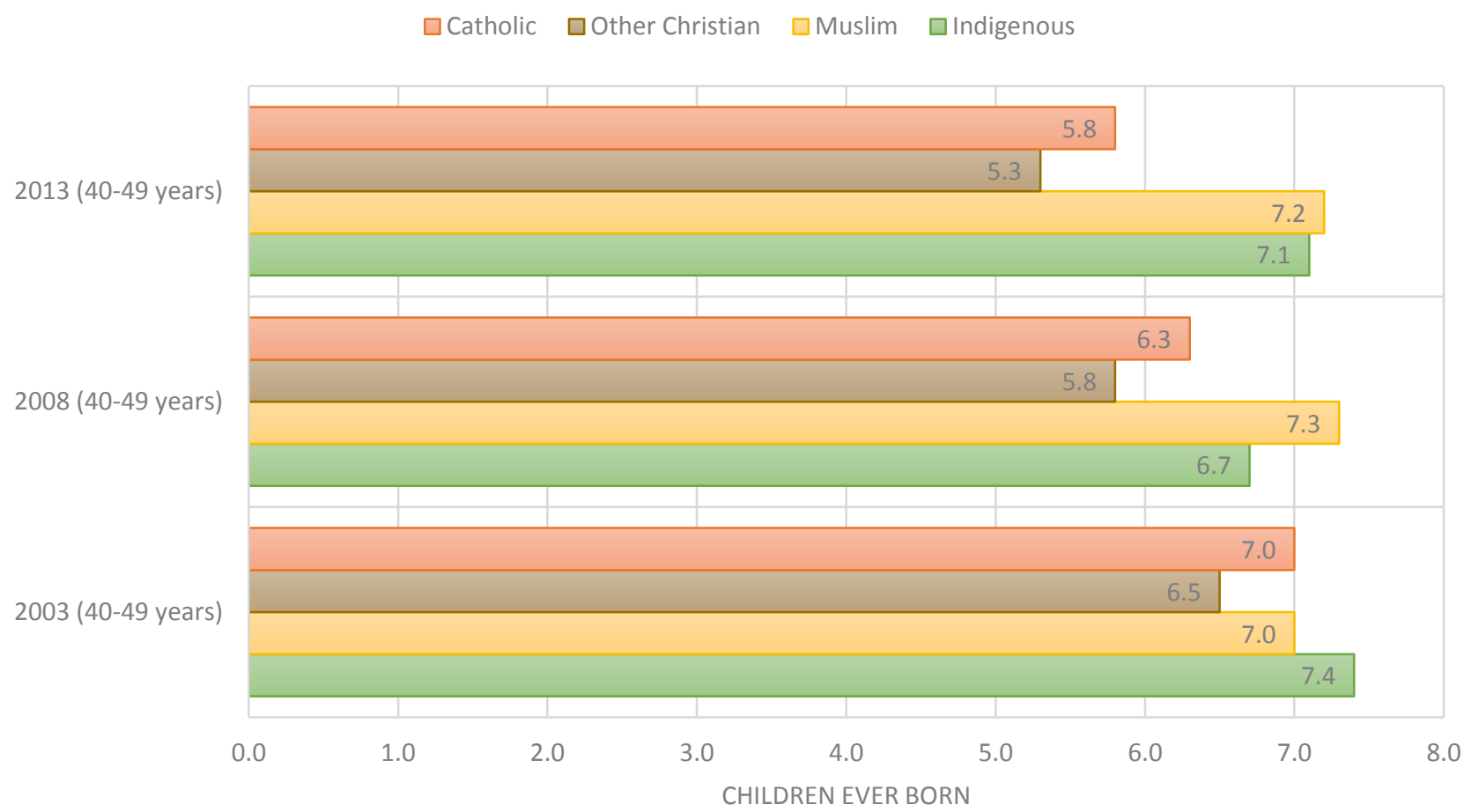

Figure 41. Mean number of children ever born (CEB) in Nigeria between 2003 and 2013 for women aged 40-49 years. [Data Source: Mberu \& Reed, 2014] [NB: Samples sizes were not specified.]

In addition to individually affiliated religions, Ntoimo \& Mutanda (2017) also examined CEB for couples of mixed religions (Figure 42). In Ghana and Nigeria, couples where the wife was Christian and the husband was Muslim, of Indigenous Religion or Other Religion had a slightly higher CEB than couples with the wife Catholic and husband of another Christian faith. However, in Zambia, the opposite was true.

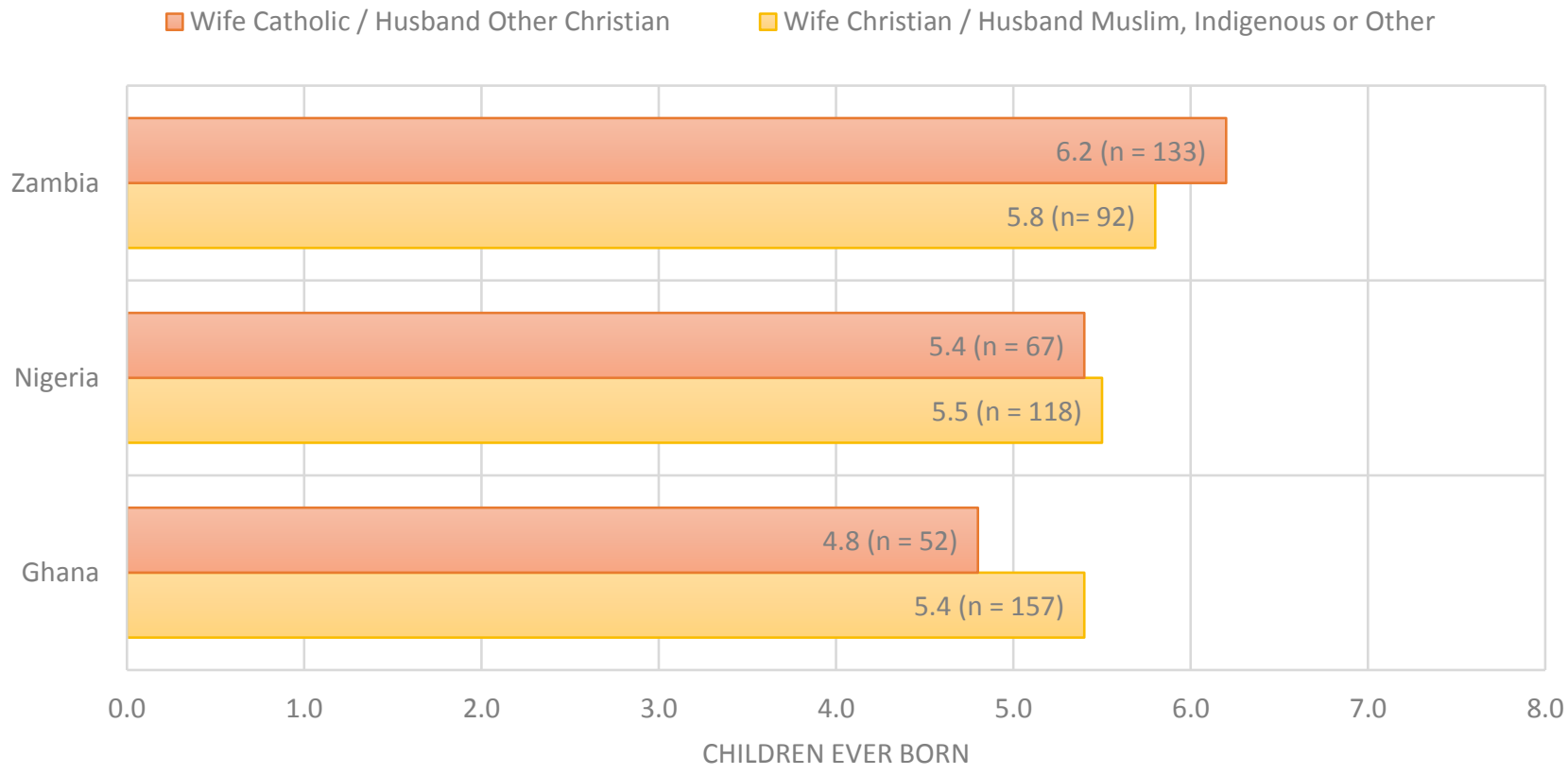

Figure 42. Mean number of children ever born (CEB) for mixed religion couples. [ $n=$ Sample size.]

[Data Source: Ntoimo \& Mutanda, 2017] 
To summarise, participants associated with African Indigenous Religions had the highest CEB (mean CEB, 6.1), followed by Muslims (mean CEB, 5.4) and then Christians (mean CEB, 4.6). Among the Christian denominations, Catholics had the highest CEB except in Eswatini and Mozambique where Apostolicism is practiced and demonstrated the highest CEB.

\subsubsection{Fertility Desires (in total 5 papers)}

Fertility desire is the mean number of children desired, also known as the mean ideal number of children (Westoff, 2010). Using data from the DHS, five papers measured fertility desires with different approaches across 19 countries. Westoff \& Bietsch (2015) used two groups - Muslims and non-Muslims - to study trend in the mean number of children women desired. With the exception of Mali, all countries showed that Muslims had higher fertility desires than non-Muslims, with Nigeria illustrating the largest gap of 2.9 children in fertility desires between Muslims and non-Muslims, followed by Kenya (2.5) and Cameroon (1.8) (Figure 43). Chad had highest fertility desires, quite similar for Muslims (9.7) and non-Muslims (8.6). 


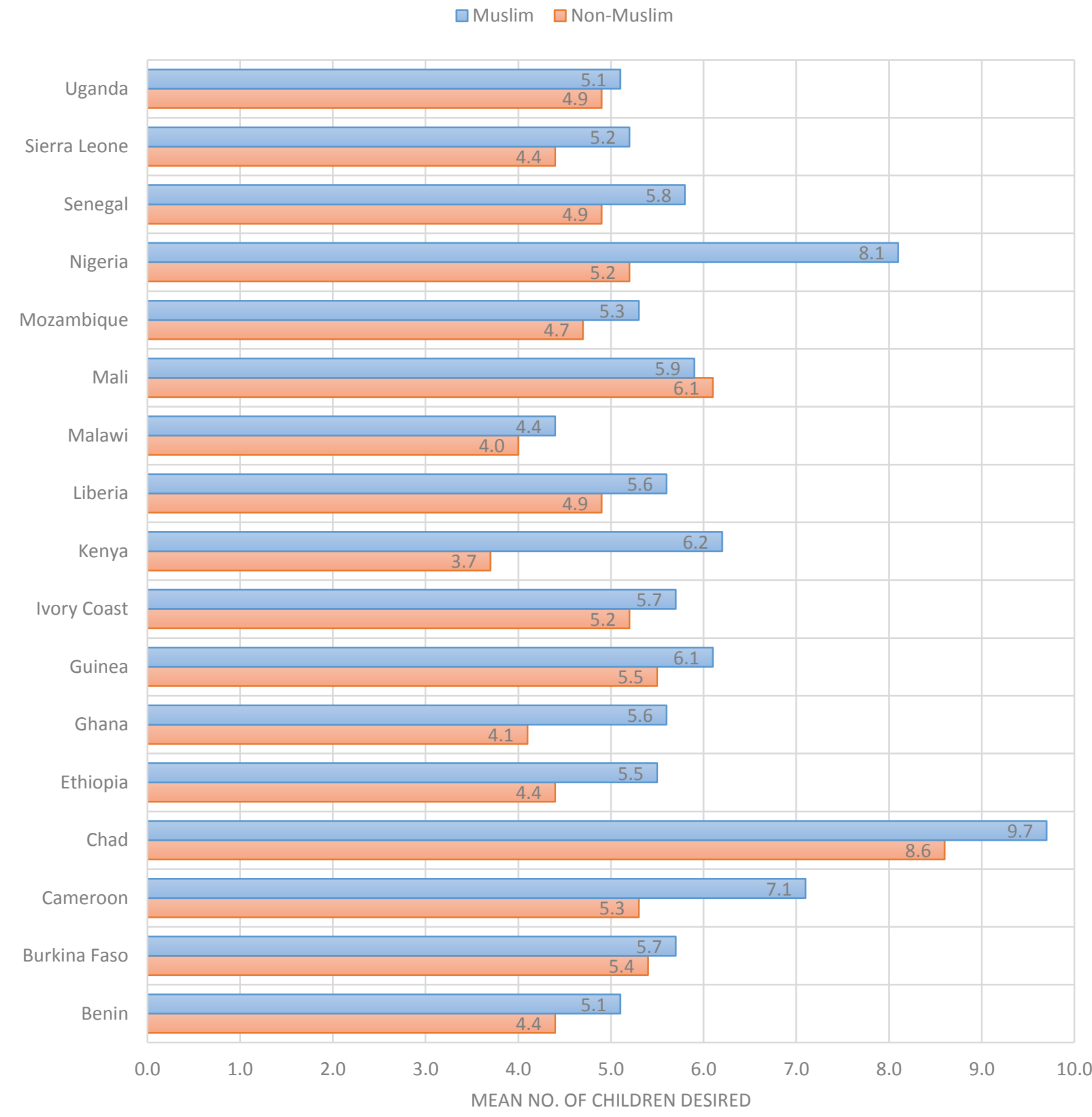

Figure 43. Mean number of children desired for Muslims and non-Muslims. [Data Source: Westoff \& Bietsch, 2015] [NB: Samples sizes were not specified.]

[NBB: For Malawi, average of all non-Muslim religions generated the non-Muslim number for comparative purposes.]

Muhoza, et al. (2014) compared the mean number of children desired between Christians and Muslims across Kenya, Rwanda, Tanzania and Uganda. Muslims had considerably higher fertility desires than Christians in Kenya with Muslims desiring 6.2 children and Christians desiring 3.8 (Figure 44). In Tanzania, Muslims (6.0) also had higher fertility desires than Christians (5.1). However, in Rwanda and Uganda, Christians had slightly higher fertility desires (3.6 and 5.3, respectively) than Muslims (3.4 and 5.1, respectively). Kenya and Rwanda both had relatively low fertility desires for Christians (3.8 and 3.6, respectively), and Rwanda had the lowest fertility desires for both Christians (3.6) and Muslims (3.4). 


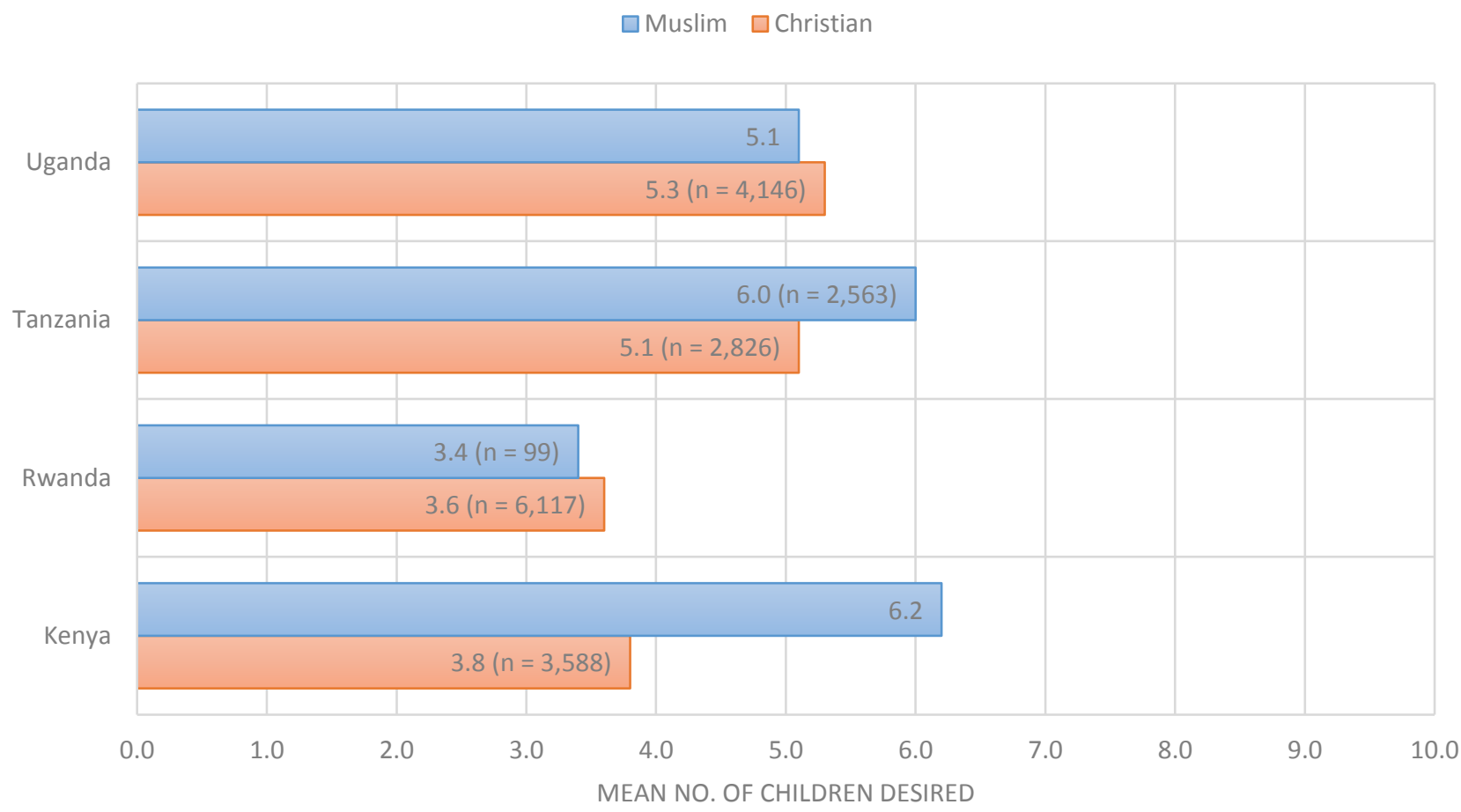

Figure 44. Mean number of children desired. For Christians and Muslims. [ $n=$ Sample size where specified.] [Data Source: Muhoza, et al., 2014; Westoff \& Bietsch, 2015]

Westoff \& Bietsch (2015) also explored, using DHS data, the percentage of women wanting more children for Muslims and non-Muslims. There is a strong trend, with the exception of Guinea, that Muslims had the desire to continue having more children compared to Christians (Figure 45). The gap between Muslims and nonMuslims wanting more children was especially strong in Kenya with $74 \%$ of Muslim women wanting more children while only $42 \%$ of non-Muslims women wanted more children. This was followed by Nigeria with $89 \%$ of Muslim women wanting more children while only $69 \%$ of non-Muslims women wanted more children, corresponding to Westoff \& Bietsch's (2015) earlier findings of mean number of children desired. Overall, Muslim and non-Muslim women in Malawi had the lowest percentage (42\% and 34\%, respectively) of wanting more children. Chad had the highest percentage of non-Muslims wanting more children ( $88 \%)$, followed by Guinea (86\%). Chad also had the highest percentage of Muslims wanting more children (94\%), followed by Nigeria (89\%). 


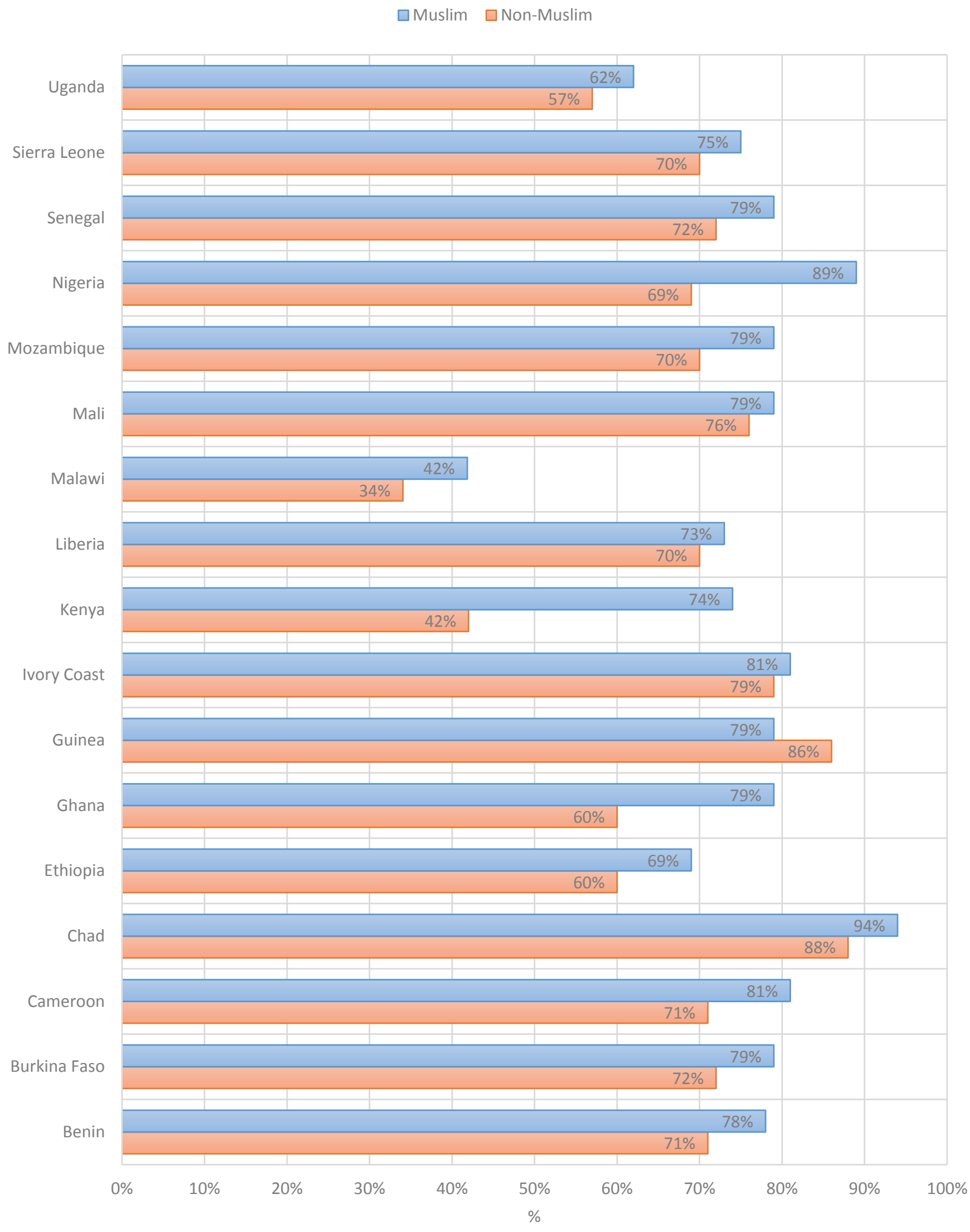

Figure 45. Percentage of women wanting more children for Muslims and non-Muslims.

[Data Source: Westoff \& Bietsch, 2015] [NB: Samples sizes were not specified.]

[NBB: For Malawi, average of all non-Muslim religions generated the non-Muslim number for comparative purposes.] 
Adebowale \& Palamuleni (2015) also explored the percentage of women wanting more children across five religious groups in Malawi. Muslim women had a considerably higher percentage of wanting more children (42\%), followed by Other Religions (21.4\%), Catholics (15.6\%), other Christian religions (15.4\%) and Protestants (12.0\%) (Figure 46). This trend corresponds to the findings of Westoff \& Bietsch (2015) (Figure 43).

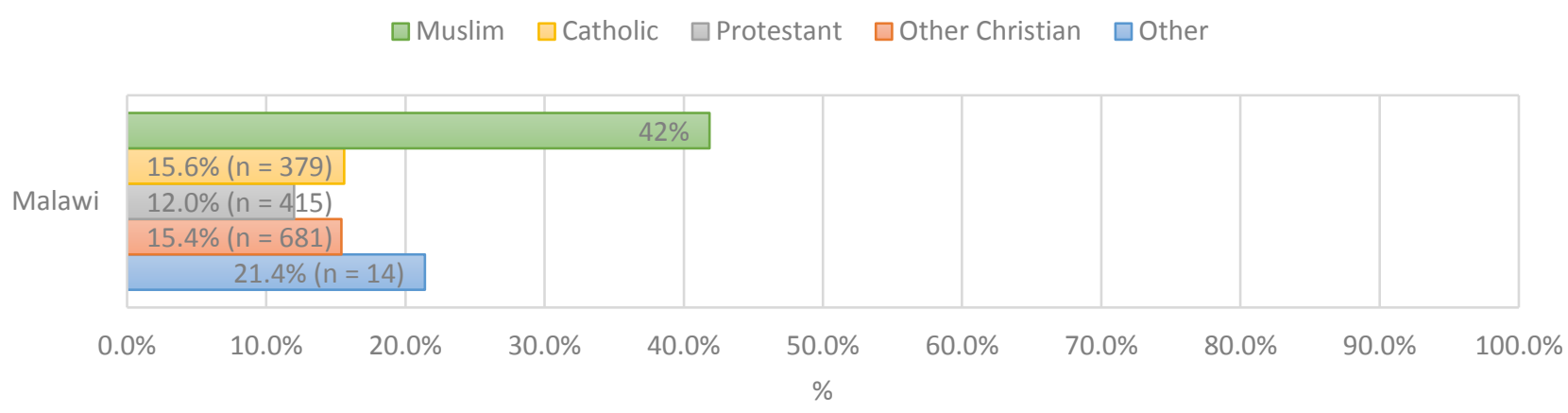

Figure 46. Percentage of women wanting more children for in Malawi. [ $n=$ Sample size where specified.] [Data Source: Adebowale \& Palamuleni, 2015]

Muhoza (2019) categorised fertility desires into three groups in Kenya and Rwanda (Figure 47). In Rwanda, the majority of respondents from all religious groups had the desire to have 0-3 children, with Other Religions having the highest desire (64.5\%), followed by Muslims (57.7\%), Catholics (52.7\%) and Protestants (50.4\%). In Kenya, the majority of respondents from Catholic and Protestant denominations had the desire to have 0-3 children $(47.0 \%$ and $46.8 \%$, respectively). However, respondents of Muslim and Other Religions had the strongest desires to have six or more children (71.1\% and $53.6 \%$, respectively). Although the paper does not specify what religions comprise "Other Religions", it is likely to comprise of those affiliated with African Indigenous Religions, other Christians, and those unaffiliated. 

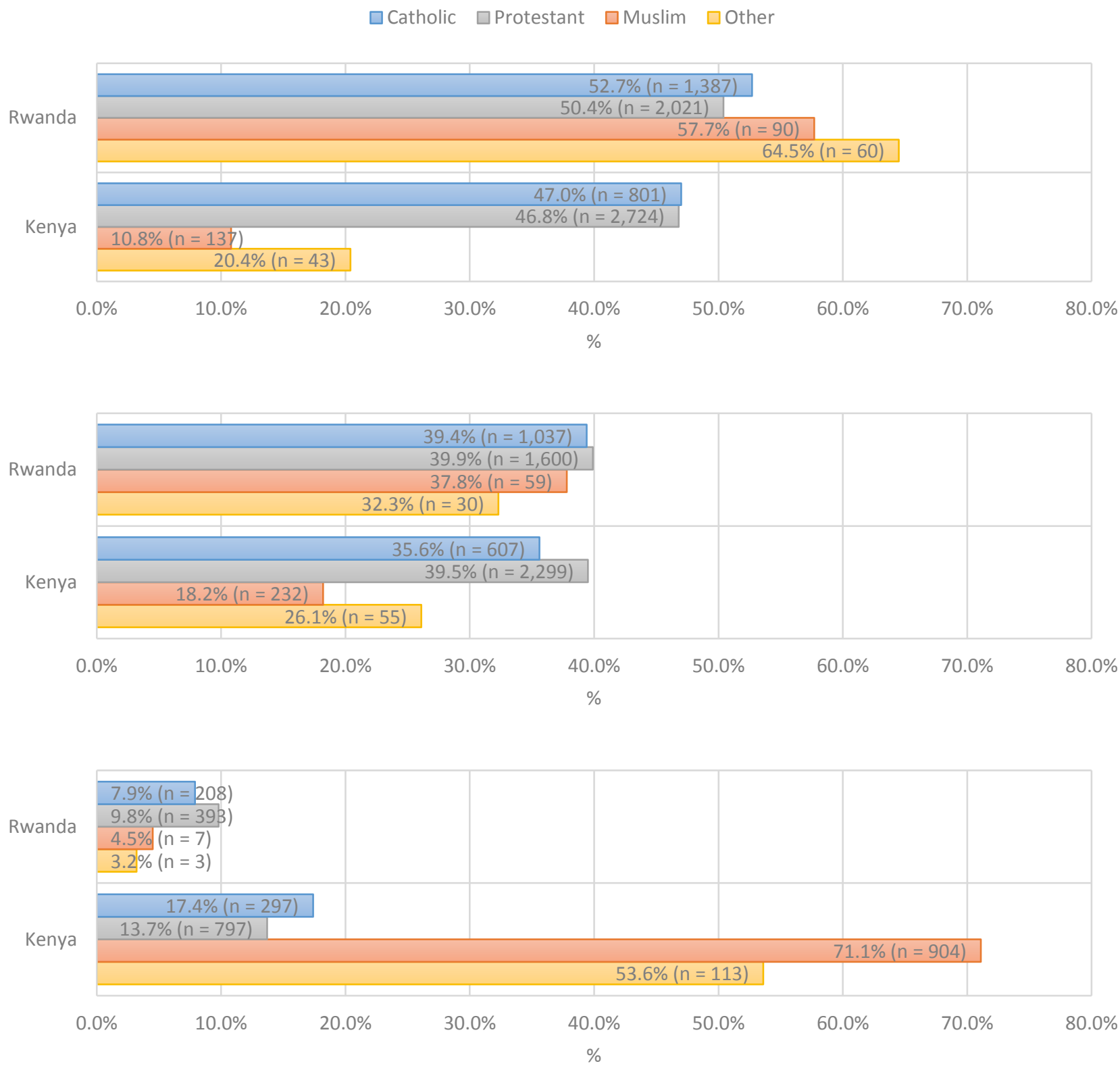

Figure 47. Percentage of women of each religion wanting 0-3 (top), 4-5 (centre) and 6+ (bottom) children in Rwanda and Kenya. [ $n=$ Sample size.] [Data Source: Muhoza, 2019]

Odusina, et al. (2020) examined the equality of fertility desires among couples in Nigeria (Figure 48). In $72.3 \%$ of Christian couples, spouses had equal desires for the ideal number of children. This was clearly higher than that of Muslims (30.8\%) and Indigenous / Other Religions (24.8\%) where spouses differed in opinion. On the other hand, couples of Indigenous / Other Religions had the highest percentage with husband having higher fertility desire (75.2\%), followed closely by Muslims (69.2\%). This was much less for Christians (27.7\%). These results indicate stronger patriarchal influence on fertility in Muslim and Indigenous / Other Religions, compared to Christians. 

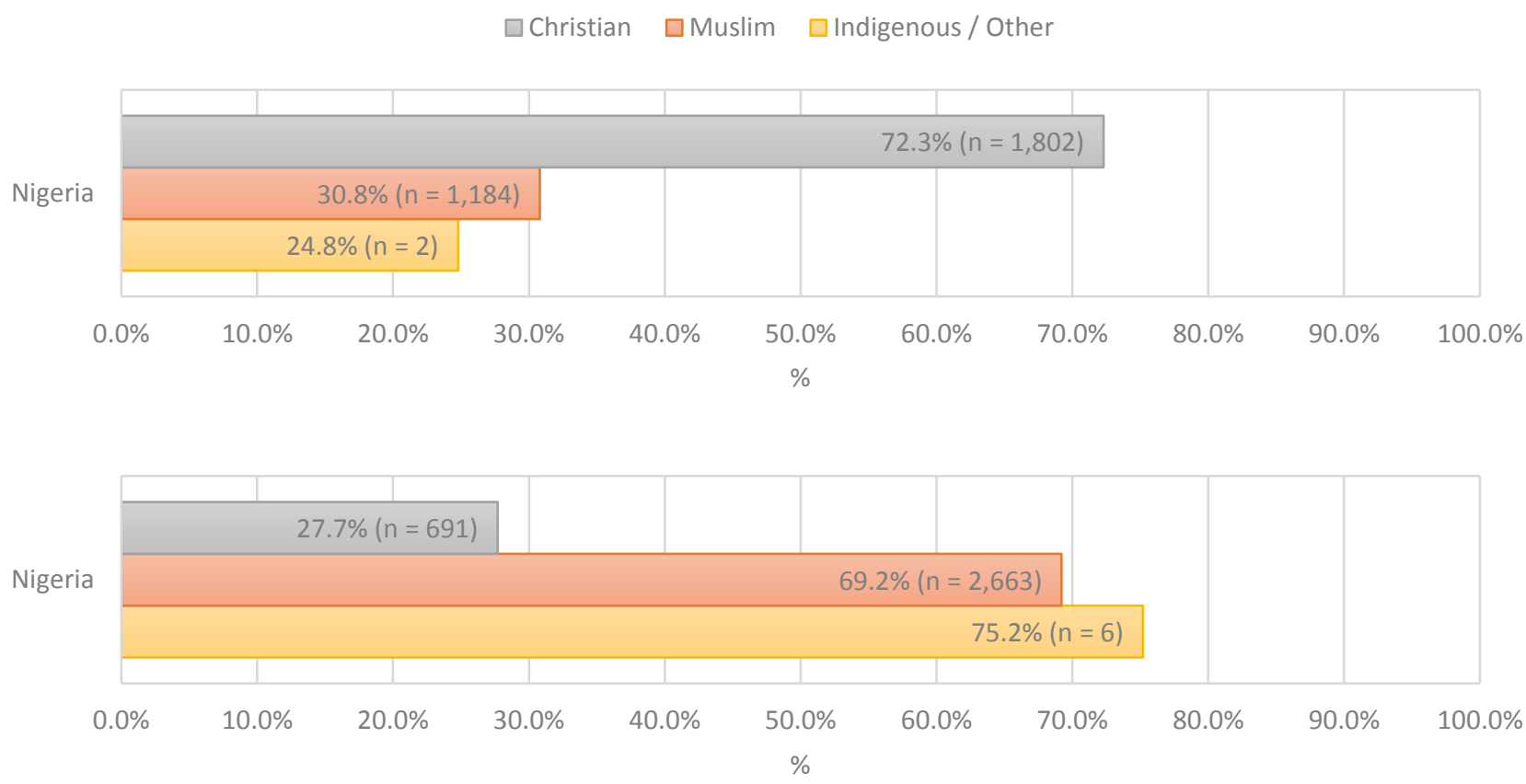

Figure 48. Percentage of couples with equal fertility desires (top) and with husband having higher fertility desires (bottom) in Nigeria. [ $n=$ Sample size.] [Data Source: Odusina, et al., 2020]

To summarise, Muslims generally had higher fertility desires than non-Muslims. However, in one study (Muhoza, et al., 2014), Christians had higher fertility desires than Muslims in Rwanda and Uganda. In Rwanda, the majority of the population desired 0-3 children regardless of religion while in Kenya, Catholics and Protestants desired 0-3 children, whereas Muslims and Other Religions desired six or more children (Muhoza, 2019). In Nigeria, religiously homogamous couples had equal desires for the ideal number of children, whereas religiously heterogamous couples had a higher percentage where the husband desired higher fertility (Odusina, et al., 2020).

\subsubsection{No. of Births in the Last Five Years (in total 3 papers)}

Using data from the DHS, three papers measured fertility trends across 24 countries using the mean number of live births in the last five years. For ease of comparison, I sorted the countries into geographical sub-regions. All countries studied in Western Africa $(n=11)$ showed that Muslims had a higher number of births in the past five years than Christians (Figure 49). In countries where Other Religions and no religious affiliation were also measured, with the exception of Benin, Guinea and Nigeria, populations associated with these groups had a higher number of births in the past five years than both Christian and Muslim groups. Across Christian denominations (Figure 50), Catholics had a higher number of births in the last five years than Protestants in Burkina Faso, Ivory Coast and Nigeria, whereas Benin, Ghana and Togo showed the opposite trend. 


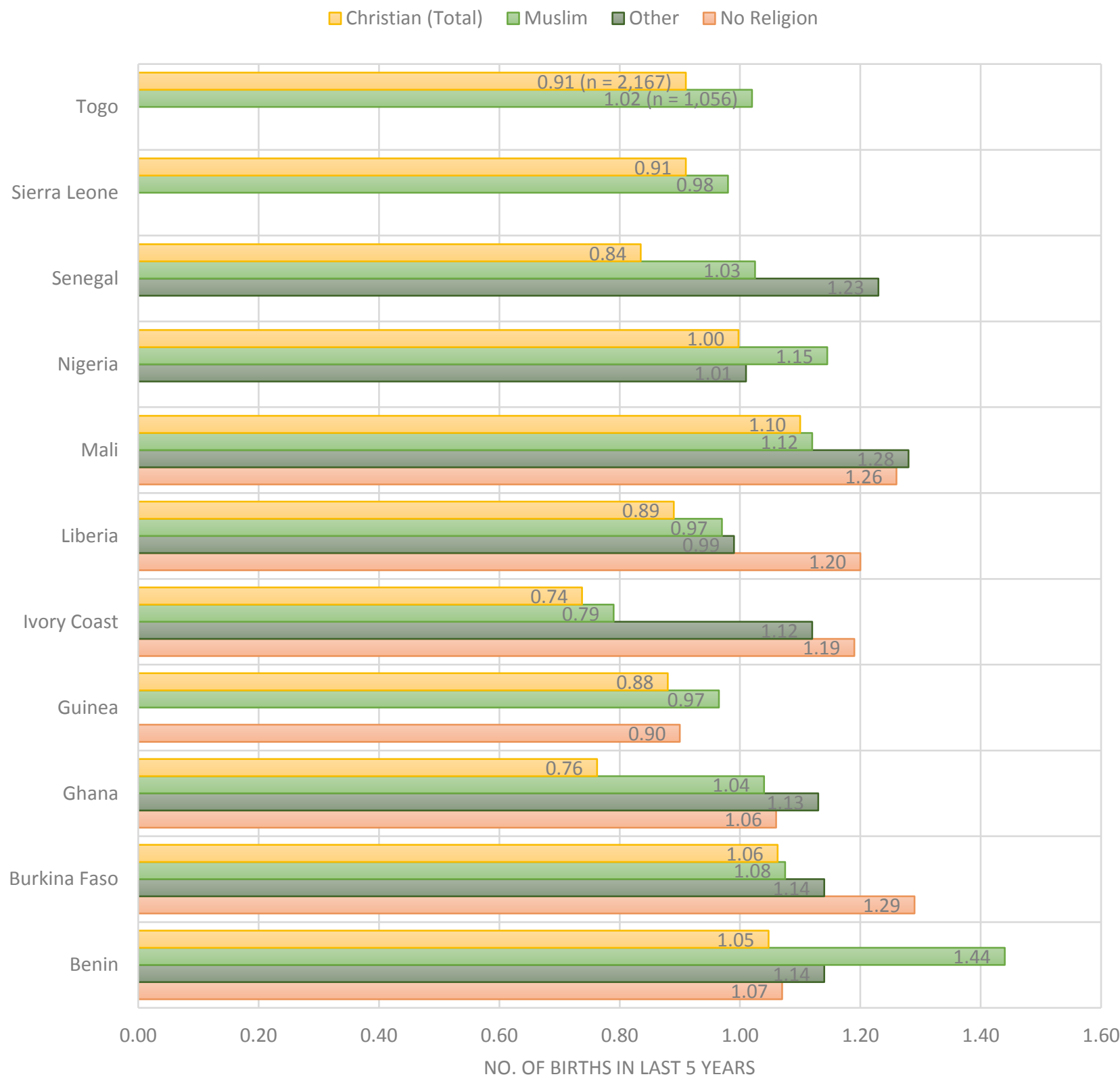

Figure 49. Mean number of births in the last five years for Christians, Muslims, Other Religions and those with no religious affiliation (Western Africa). [ $n=$ Sample size where specified.]

[Data Source: Heaton, 2011; Westoff \& Bietsch, 2015] 


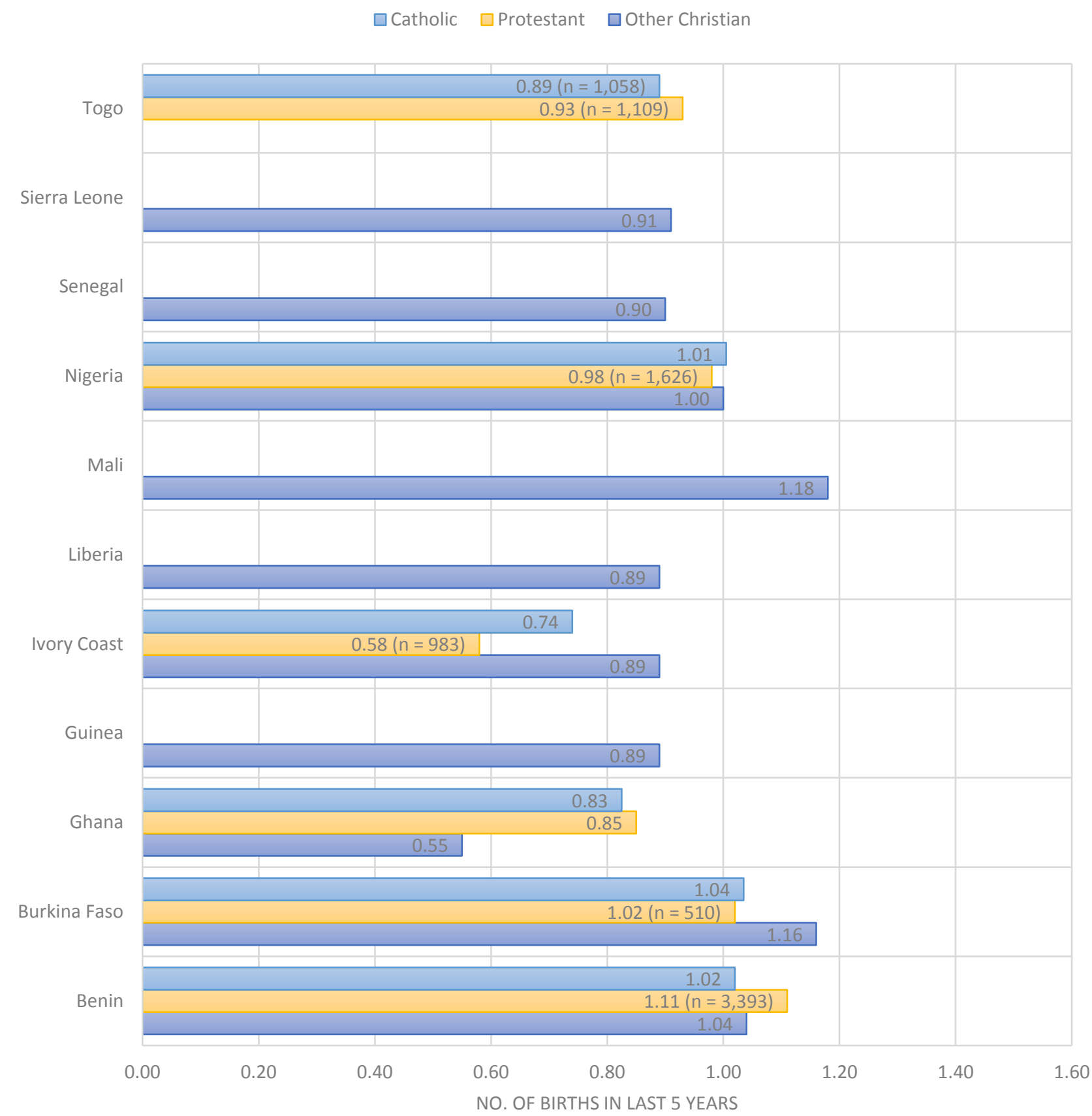

Figure 50. Mean number of births in the last five years for Christian religions (Western Africa). [ $n=$ Sample size where specified.] [Data Source: Heaton, 2011; Westoff \& Bietsch, 2015]

In Cameroon and the Central African Republic in Central Africa, Muslims had higher number of births in the last five years (1.14 and 0.95, respectively) compared with Christians ( 0.95 and 0.92, respectively) (Figure 51). Chad showed the opposite trend with 1.22 births in the last five years for Christians and 1.13 for Muslims. Other Religions and no religious affiliation groups were measured in Cameroon and Chad with the former group showing the highest number of births in the last five years in both countries (1.20 and 1.38, respectively). In Chad, this was followed by the group with no religious affiliation (1.36) whereas in Cameroon, the group with no religious affiliation had a slightly lower number of births in the last five years (1.09) than Muslims (1.14). Across Christian denominations in Cameroon and Chad (Figure 52), Catholics had a slightly 
higher number of births in the last five years (0.95 and 1.22, respectively) than Protestants (0.90 and 1.16). However, for both countries, those affiliated with other Christian religions had the highest number of births in the last five years (1.00 and 1.30, respectively). In the Central African Republic, Protestants had a slightly higher number of births in the last five years (0.93) than Catholics (0.91).

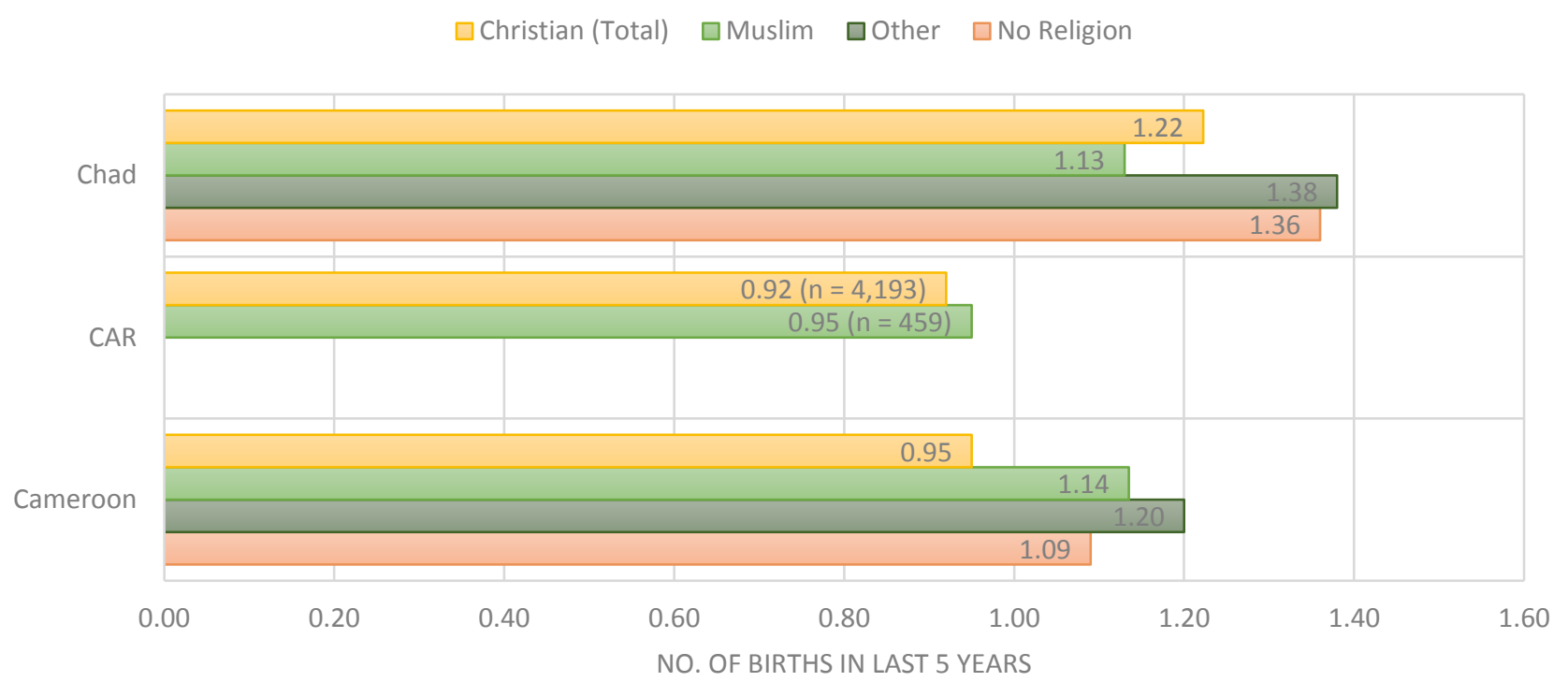

Figure 51. Mean number of births in the last five years for Christians, Muslims, Other Religions and those with no religious affiliation (Central Africa). [ $n=$ Sample size where specified.]

[Data Source: Heaton, 2011; Westoff \& Bietsch, 2015]

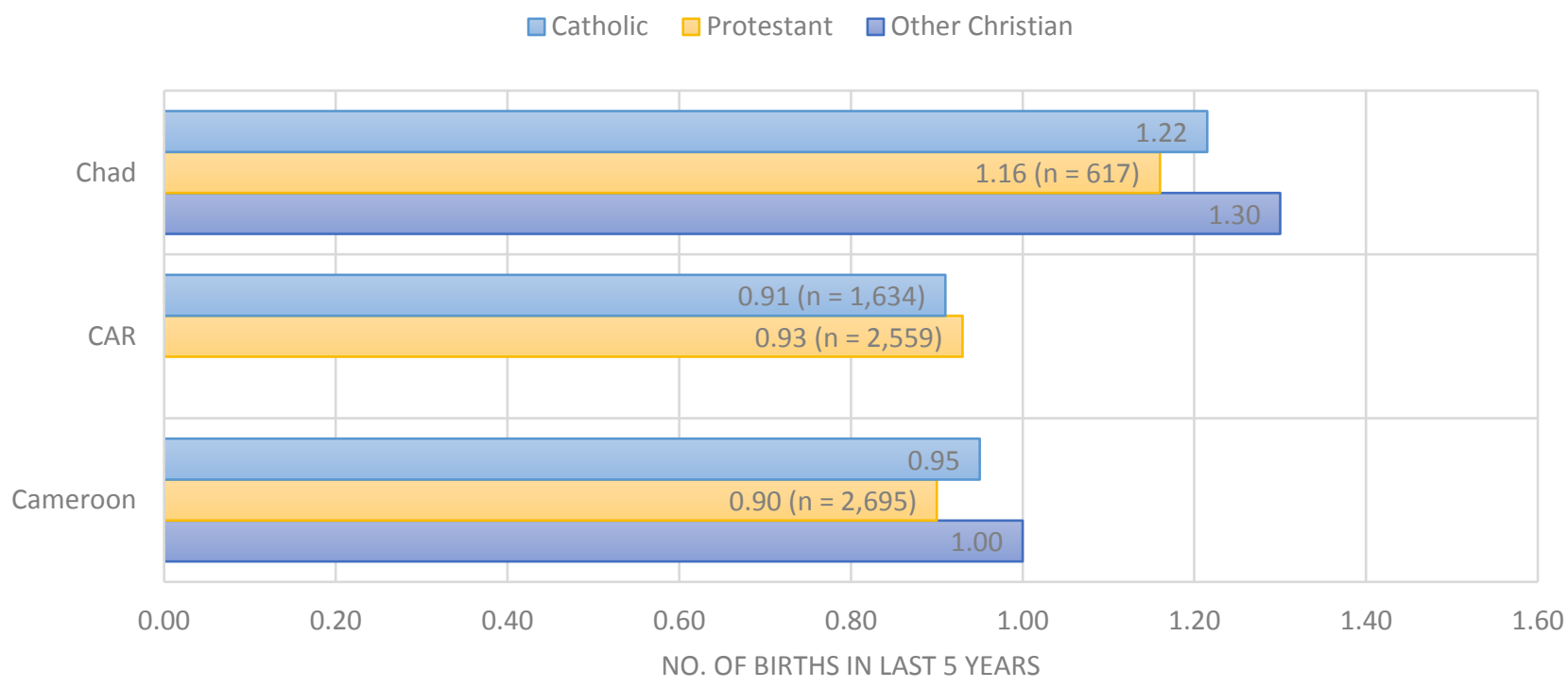

Figure 52. Mean number of births in the last five years for Christian religions (Central Africa).

[ $n=$ Sample size where specified.] [Data Source: Heaton, 2011; Westoff \& Bietsch, 2015]

The nine countries of Eastern Africa that were studied showed more inconsistencies throughout the region. Muslims in Ethiopia, Kenya, Malawi and Rwanda had a higher number of births in the last five years compared with Christians, whereas Mozambique and Uganda showed the contrary (Figure 53). In Mozambique, the 
group of Other Religions had the highest number of children born in the last five years (1.06), whereas in Ethiopia, this was the lowest number (0.9). In Malawi, those with no religious affiliation had the highest number of births in the last five years (1.23), whereas in Mozambique, this was the lowest number (0.75). Across Christian denominations (Figure 54), the number of births in the last five years were also inconsistent throughout the region. Protestants in Kenya, Rwanda, Zambia and Zimbabwe had a higher number of births in the last five years compared with Catholics, whereas Madagascar, Malawi, Mozambique and Uganda showed the contrary. However, those affiliated with other Christian religions had the highest number of births in the last five years in Ethiopia (1.08), Malawi (1.10) and Mozambique (1.08), as was also the case with Cameroon and Chad in Central Africa.

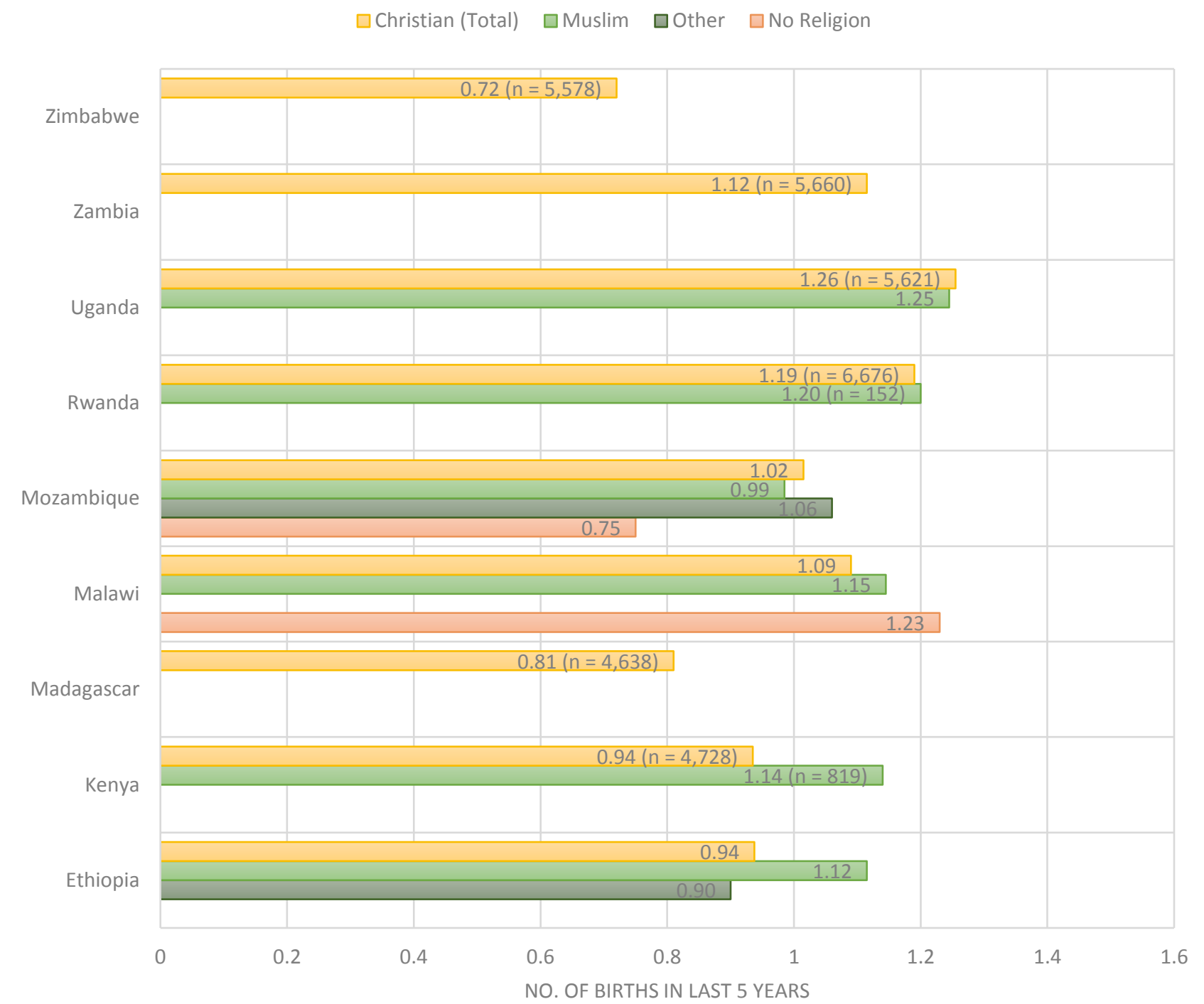

Figure 53. Mean number of births in the last five years for Christians, Muslims, Other Religions and those with no religious affiliation (Eastern Africa). [ $n=$ Sample size where specified.]

[Data Source: Heaton, 2011; Westoff \& Bietsch, 2015] 


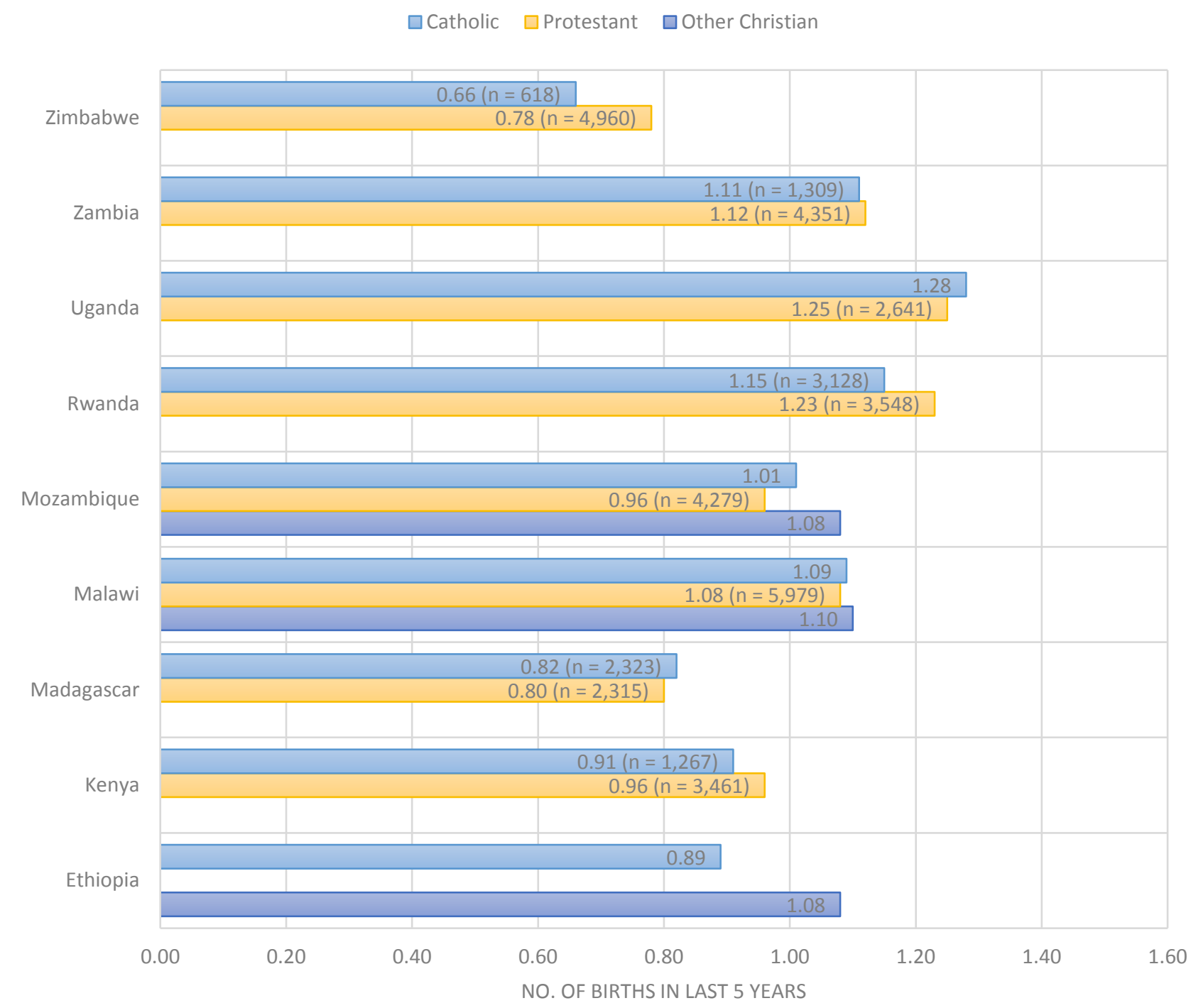

Figure 54. Mean number of births in the last five years for Christian religions (Eastern Africa). [ $n=$ Sample size where specified.] [Data Source: Heaton, 2011; Westoff \& Bietsch, 2015]

The only Southern African country measured for number of births in the last five years was Namibia in which Christianity was the only religion examined with 0.77 births in the last five years (Figure 55). This was low, comparing across all African sub-regions examined. Within Christianity, Catholics had slightly higher number of births in the last five years (0.79) than Protestants (0.74) (Figure 56).

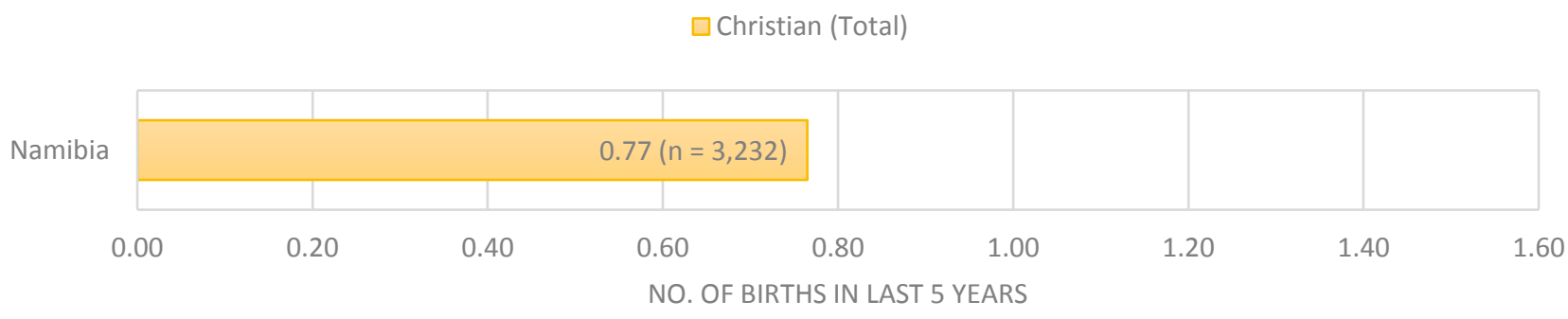

Figure 55. Mean number of births in the last five years for Christians, Muslims, Other Religions and those with no religious affiliation (Southern Africa). [ $n=$ Sample size.] [Data Source: Heaton, 2011; Westoff \& Bietsch, 2015] 


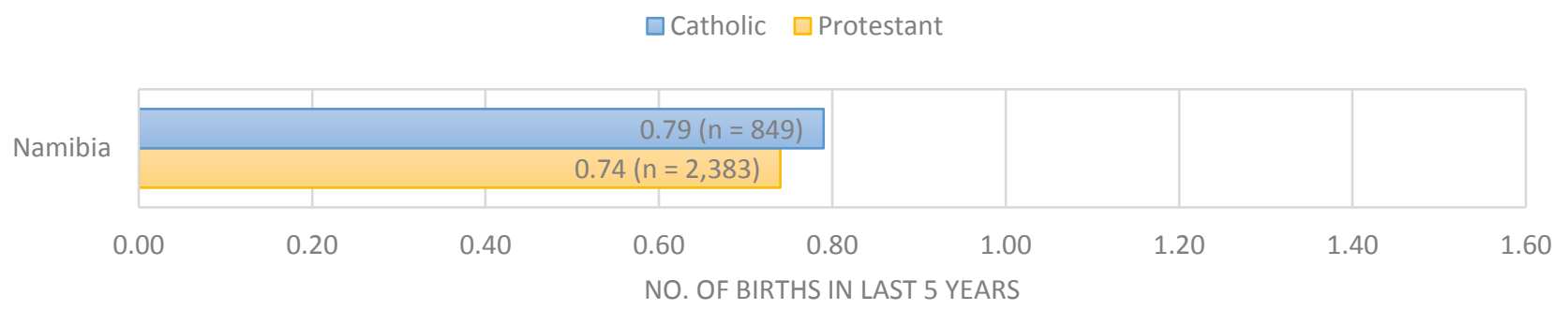

Figure 56. Mean number of births in the last five years for Christian religions (Southern Africa). [ $n=$ Sample size.] [Data Source: Heaton, 2011; Westoff \& Bietsch, 2015]

To summarise, countries in Western and Central Africa showed that Muslims generally had a higher number of births in the past five years than Christians while Eastern Africa showed more inconsistencies. In Namibia, the only Southern African country studied, Christianity had a very low number of births in the last five years (0.77) compared with all African sub-regions examined. Across Christian denominations, there was no consistent trend between Catholics and Protestants.

\subsubsection{Total Fertility Rates (TFR) (in total 5 papers)}

Using data from the DHS, five papers measured TFR across a total of 28 countries. For ease of comparison, I have sorted the countries into their respective geographical sub-regions.

In Western Africa, TFR for Muslims was measured in all 12 countries while TFR for Indigenous / Other Religions was measured in six countries (Figure 57). Across Western Africa, TFR for Muslims and Indigenous / Other Religions was high, and both religions had a higher TFR than Christians. Of the six countries that measured TFR for Muslims and Indigenous / Other Religions, the latter had a higher TFR than Muslims in Benin, Ghana, Liberia and Togo, whereas the opposite trend was observed in Guinea and Sierra Leone. TFR for Christians varied across Western Africa with Burkina Faso having the highest TFR (5.7) and Sierra Leone having the lowest (1.4). Sierra Leone had the largest difference in TFR of 3.7 children between Christians and Muslims, while Burkina Faso and Ivory Coast had the smallest difference of 0.6 children between the two religions.

Across Christian denominations (Figure 58), TFR in Ghana was similar among Catholics (3.8), Pentecostals (3.9), Protestants (3.6) and other Christians (3.8). In Benin, the major Christian religion of the country - Celestial Revival Church - had a much higher TFR (6.1) than the other Christian religions while Pentecostals had the highest TFR in Ghana (3.9) and Togo (5.4). In Togo, TFR for Pentecostals was higher than for the other Christian religions. In Mali, the only Christian religious group that was measured was other Christians with a high TFR value of 7.1. Given the lower TFR value of the total Christian group (3.6), we can assume that the Christian religions that were not measured had a lower TFR value. Catholics had only a slightly higher TFR than Protestants in Ghana and Togo, whereas in Benin, the opposite was observed. 


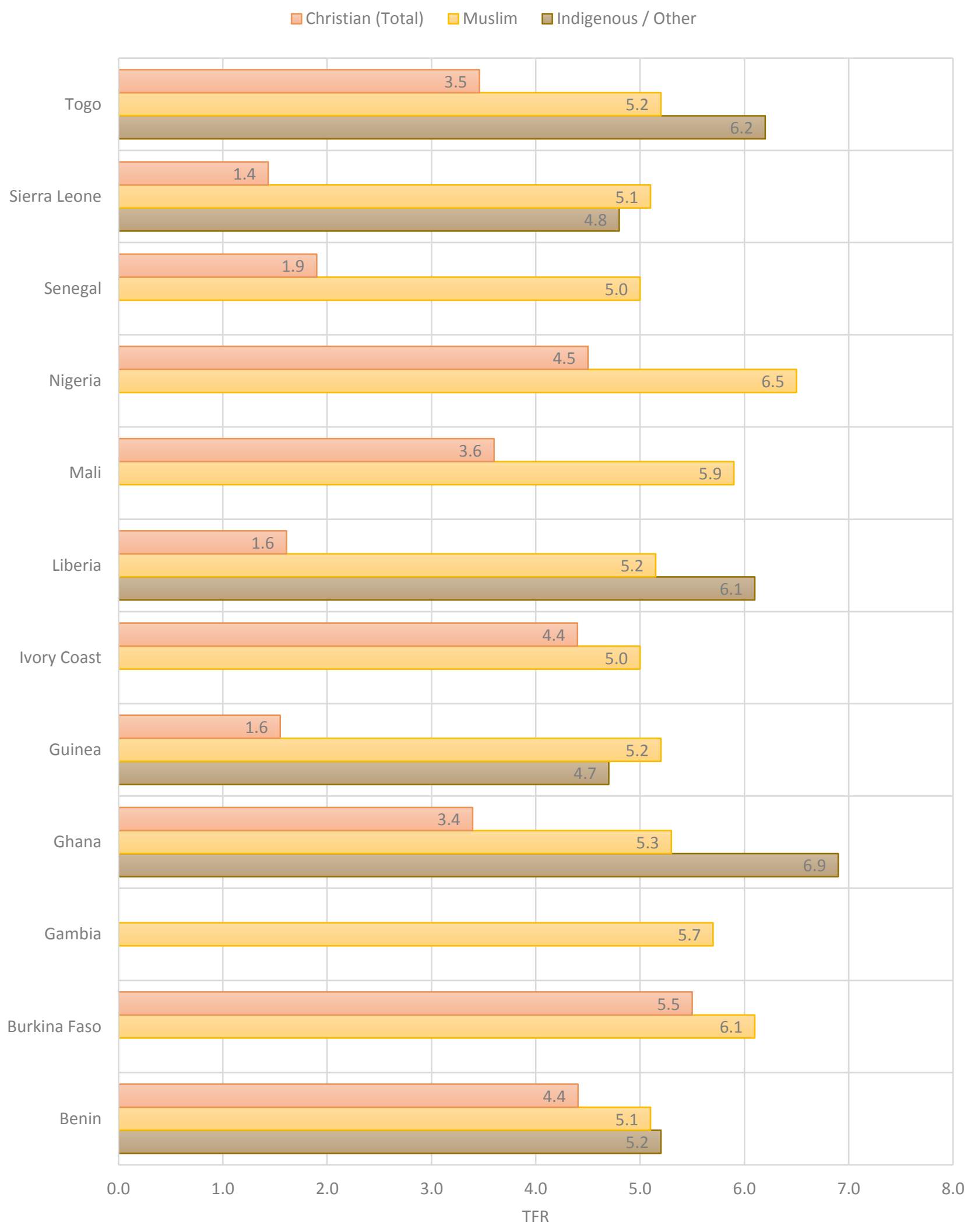

Figure 57. TFR for Christian, Muslim and Indigenous / Other Religions (Western Africa).

[Data Source: Nansubuga, et al., 2011; Westoff \& Bietsch, 2015] [NB: Samples sizes were not specified.] 


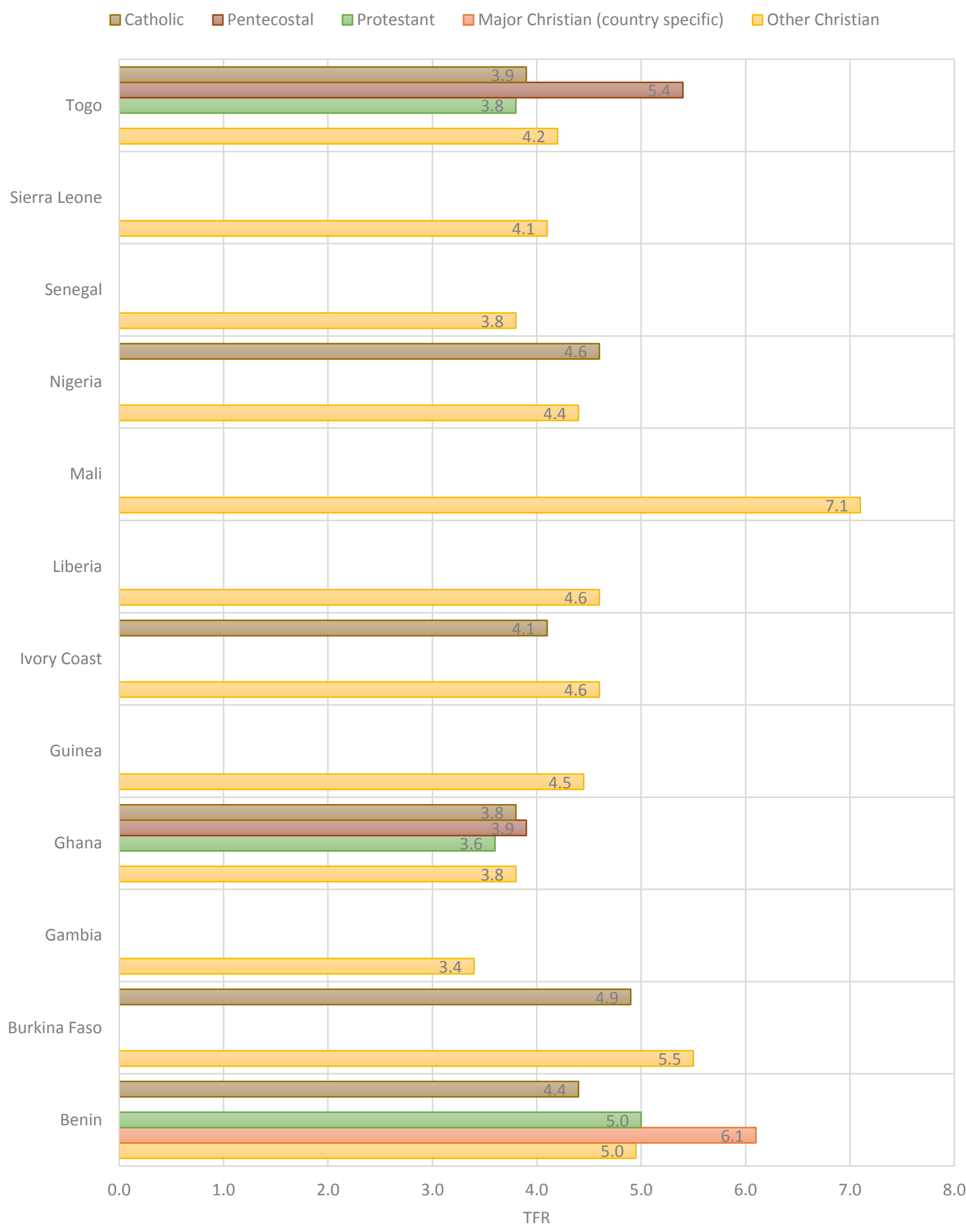

Figure 58. TFR for Christian religions (Western Africa). [Data Source: Nansubuga, et al., 2011; Westoff \& Bietsch, 2015] [NB: Samples sizes were not specified; NBB: Major Christian religion of Benin is Celestial Revival Church.] 
Like in Western Africa, Christians across the Central African nations $(n=5)$ had the lowest TFR with the highest TFR in Chad (5.5) and the lowest in Gabon (2.4) (Figure 59). In Chad and Gabon, TFR for Indigenous / Other Religions (6.7 and 5.4, respectively) was moderately higher than for Muslims (6.1 and 5.1, respectively). In Cameroon and the Democratic Republic of Congo, TFR for Muslims (6.1 and 7.3, respectively) was slightly higher than Indigenous / Other Religions (5.9 and 7.0, respectively) while in Congo, TFR for Muslims (7.9) was considerably higher than Indigenous / Other Religions (5.4). Congo stands out among the other Central African nations, as TFR for Muslims and Indigenous / Other Religions are relatively similar. Across Christian denominations (Figure 60), Protestants had a higher TFR than Catholics in Congo, the Democratic Republic of Congo and Gabon, whereas the opposite was observed in Chad. Chad and the Democratic Republic of Congo had the highest TFR values across all Christian religions whereas Gabon and Cameroon had the lowest. In Chad and Congo, other Christians had the highest TFR (7.1 and 6.2, respectively).

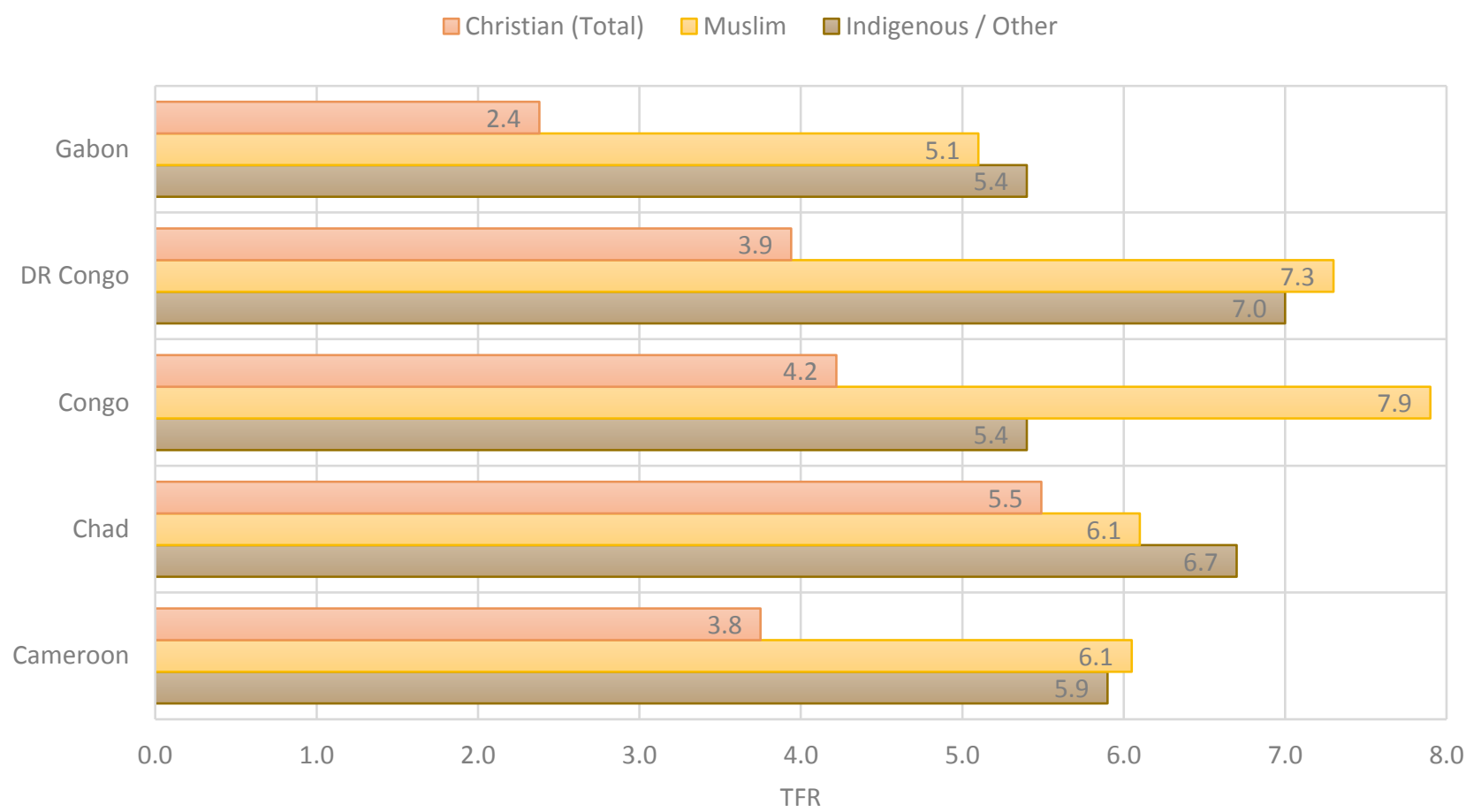

Figure 59. TFR for Christian, Muslim and Indigenous / Other Religions (Central Africa).

[Data Source: Nansubuga, et al., 2011; Westoff \& Bietsch, 2015] [NB: Samples sizes were not specified.] 


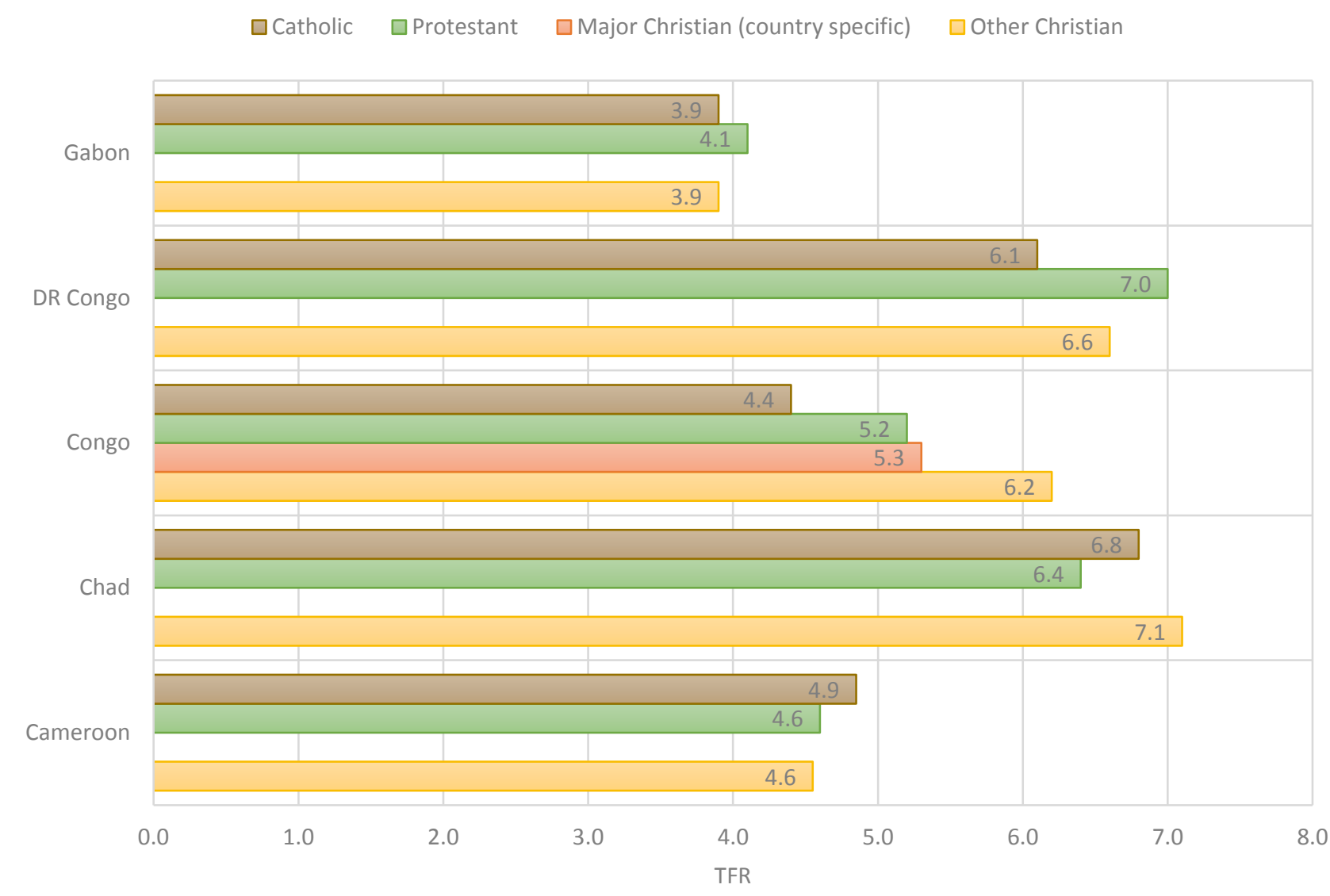

Figure 60. TFR for Christian religions (Central Africa). [Data Source: Nansubuga, et al., 2011; Westoff \& Bietsch, 2015] [NB: Samples sizes were not specified; NBB: Major Christian religion of Congo is unspecified.]

In Eastern African nations ( $n=9)$, Christians had a higher TFR than Muslims in Uganda (6.2 and 5.9, respectively) and marginally so in Zimbabwe (3.8 and 3.7, respectively) (Figure 61). Christians in Kenya, Rwanda and Zambia had the lowest TFR (1.4, 2.5 and 2.0, respectively). In Ethiopia, Mozambique, Zambia and Zimbabwe, Indigenous / Other Religions had a higher TFR than Muslims, whereas the opposite trend was observed in Burundi, Kenya and Rwanda. In Zambia, TFR was substantially higher for Indigenous / Other Religions (6.0) compared with Muslims (3.3). Across Christian denominations (Figure 62), Protestants had a higher TFR than Catholics in Ethiopia, Kenya, Rwanda, Zambia and Zimbabwe, whereas in Malawi and Mozambique, the opposite trend was observed. In Burundi, Catholics and Protestants had equal TFR (6.1). In Mozambique, although Pentecostals had the highest TFR (6.0), TFR values across the Christian denominations were relatively similar except for Protestants who had the lowest TFR (5.3). In Zimbabwe, the major Christian religion (unspecified) had the highest TFR (4.8) followed by Pentecostals (3.6) and Protestants (3.5), while Catholics had the lowest (3.3). In Ethiopia and Malawi, the major Christian religions had the lowest TFR (3.9 and 3.2, respectively). The major Christian religion was Orthodox in Ethiopia but unspecified for Malawi. The highest TFR for Catholics was observed in Uganda (6.3). 


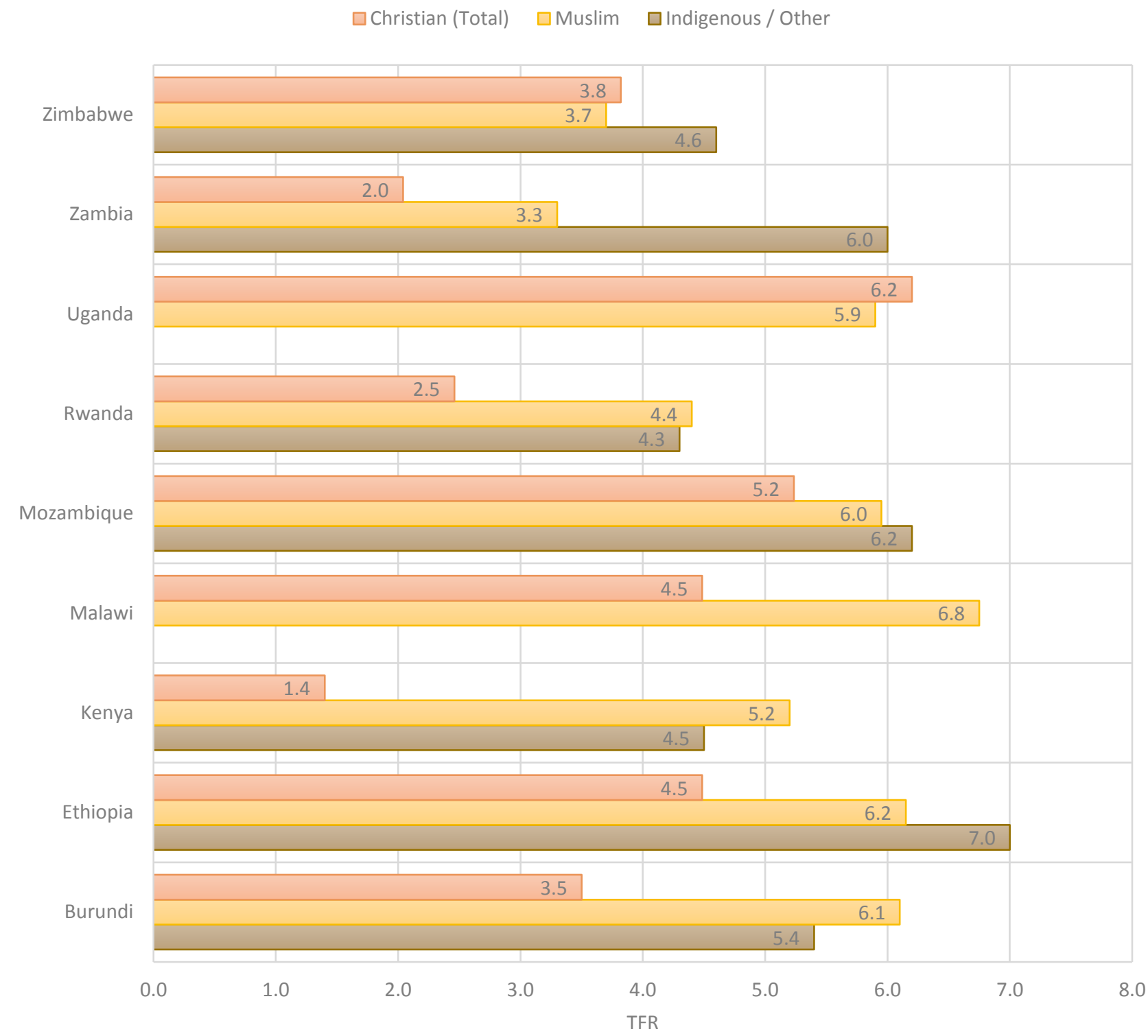

Figure 61. TFR for Christian, Muslim and Indigenous / Other Religions (Eastern Africa).

[Data Source: Nansubuga, et al., 2011; Westoff \& Bietsch, 2015] [NB: Samples sizes were not specified.] 


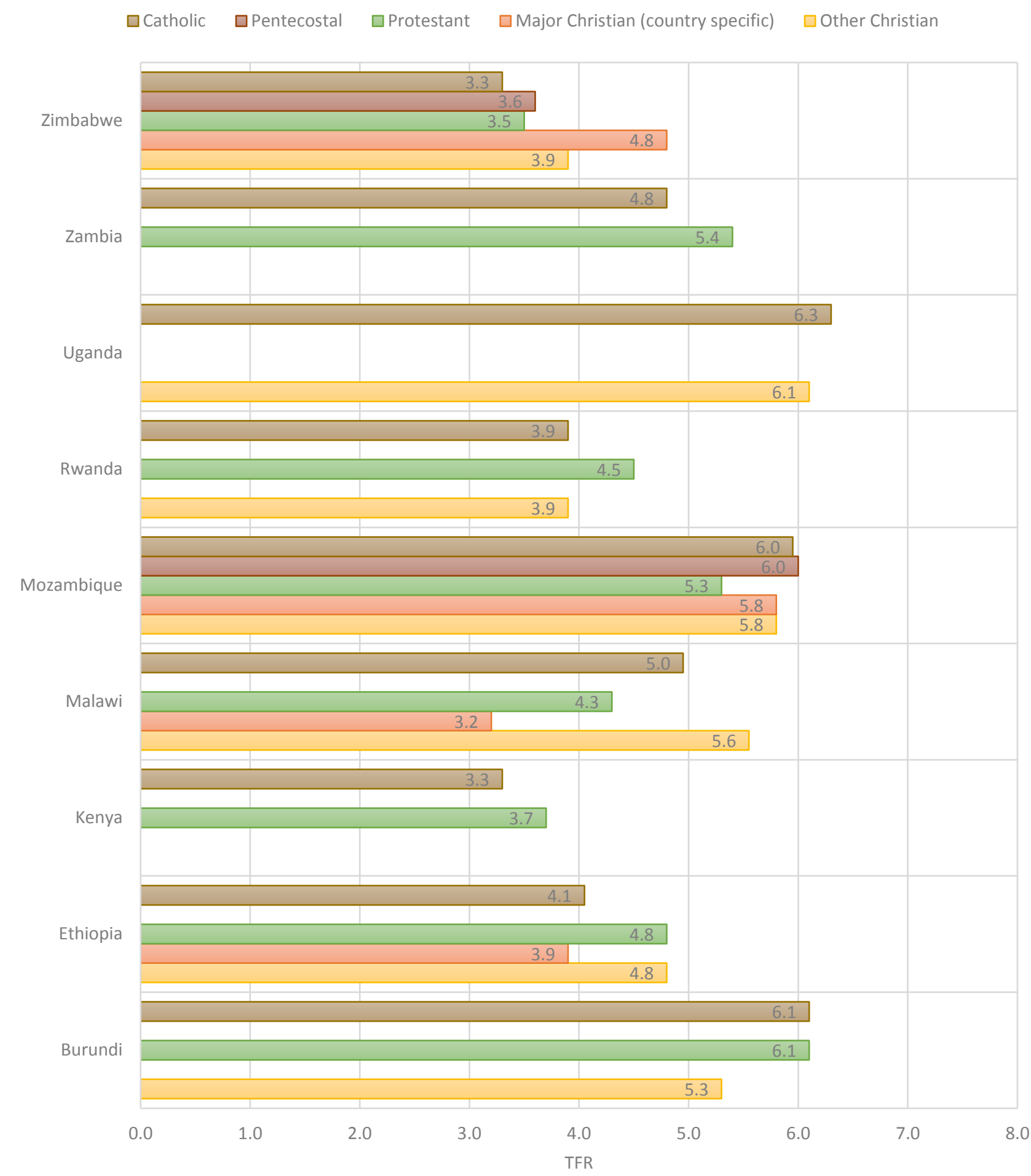

Figure 62. TFR for Christian religions (Eastern Africa). [Data Source: Nansubuga, et al., 2011; Westoff \& Bietsch, 2015] [NB: Samples sizes were not specified; NBB: Major Christian religion of Ethiopia is Orthodox; major Christian religions of Malawi, Mozambique and Zimbabwe are unspecified.]

In the two countries studied in Southern Africa, Lesotho and Namibia, Indigenous / Other Religions had the lowest TFR (3.8 and 3.2, respectively) of all the aforementioned African sub-regions (Figure 63). This was followed closely by Christians (3.1 and 3.0, respectively). Across Christian denominations (Figure 64), Pentecostals had the highest TFR in Lesotho (3.7). Protestants had the highest TFR in Namibia (4.0) but the 
lowest in Lesotho (2.7). The major Christian religion (unspecified) had the lowest TFR in Namibia (3.5). Overall, Lesotho had lower TFR values than Namibia across all Christian denominations.

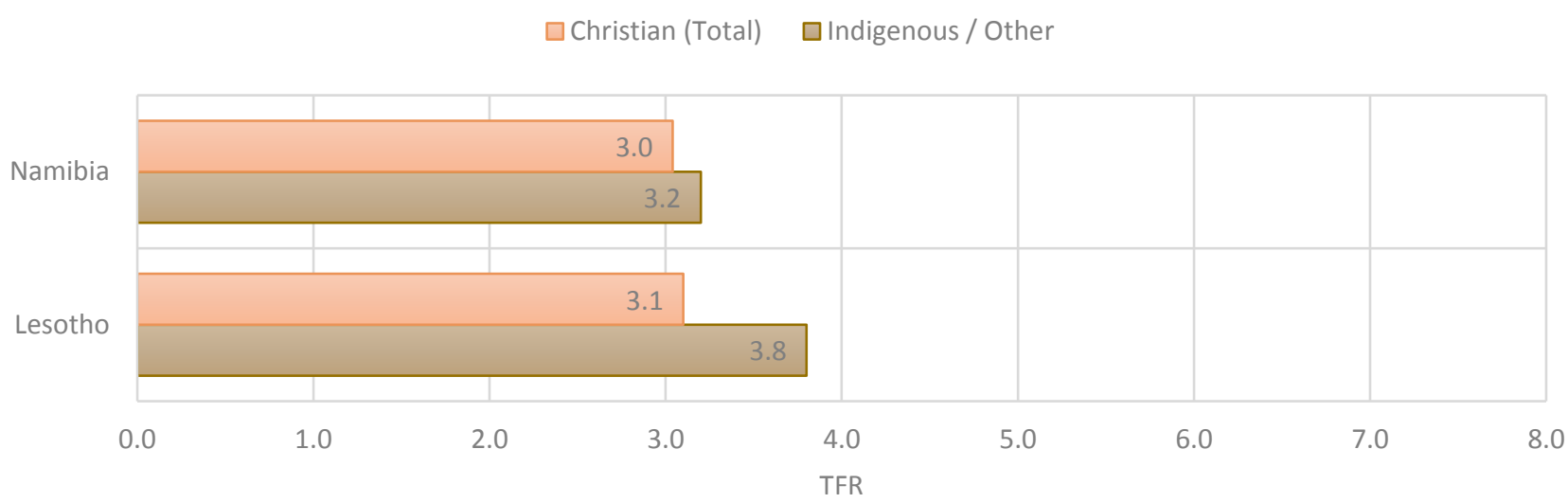

Figure 63. TFR for Christian, Muslim and Indigenous / Other Religions (Southern Africa).

[Data Source: Nansubuga, et al., 2011; Westoff \& Bietsch, 2015] [NB: Samples sizes were not specified.]

$\square$ Catholic $\square$ Pentecostal $\square$ Protestant $\square$ Major Christian (country specific) $\square$ Other Christian

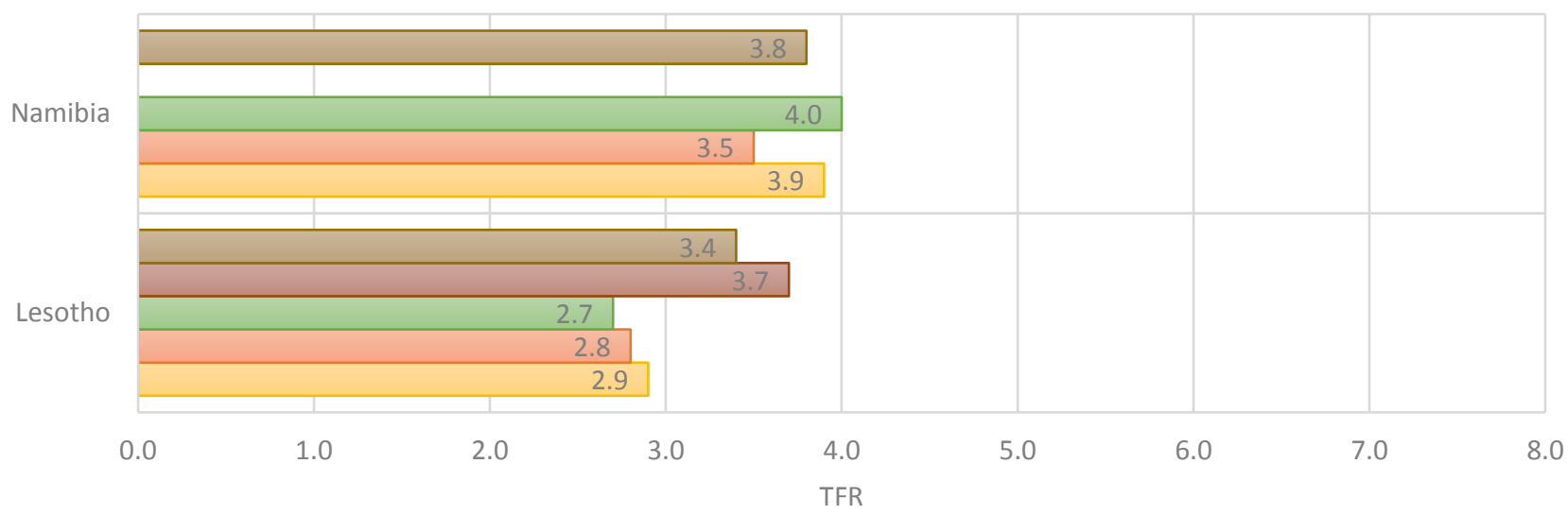

Figure 64. TFR for Christian religions (Southern Africa). [Data Source: Nansubuga, et al., 2011; Westoff \& Bietsch, 2015] [NB: Samples sizes were not specified; NBB: Major Christian religions of Lesotho and Namibia are unspecified.]

Stonawski, et al. (2016) explored TFR for Christians and Muslims in Nigerian states governed by Sharia and non-Sharia Islamic Law using three round of DHS data: 1990, 2008 and 2013 (Figure 65). In 1990, Muslims in Sharia and non-Sharia States had equal TFR (6.4). However, in 2008, the TFR for Muslims in Sharia States increased to 7.8 children and slightly decreased in 2013 to 7.2 children. On the other hand, TFR for Muslims in non-Sharia States decreased in 2008 to 5.4 children (5.5 in 2013). TFR for Christians in non-Sharia States steadily decreased from 6.0 in 1990 to 4.5 in 2013. Because of the small number of observations for Christians in Sharia States in 1990, it was not possible to calculate TFR. However, TFR for Christians in Sharia States in 2008 decreased from 5.5 to 4.2 in 2013 making Christians in Sharia States flip from having a higher TFR than non-Sharia Christians and Muslims to having a lower TFR than both non-Sharia religions, and having the lowest TFR overall. 


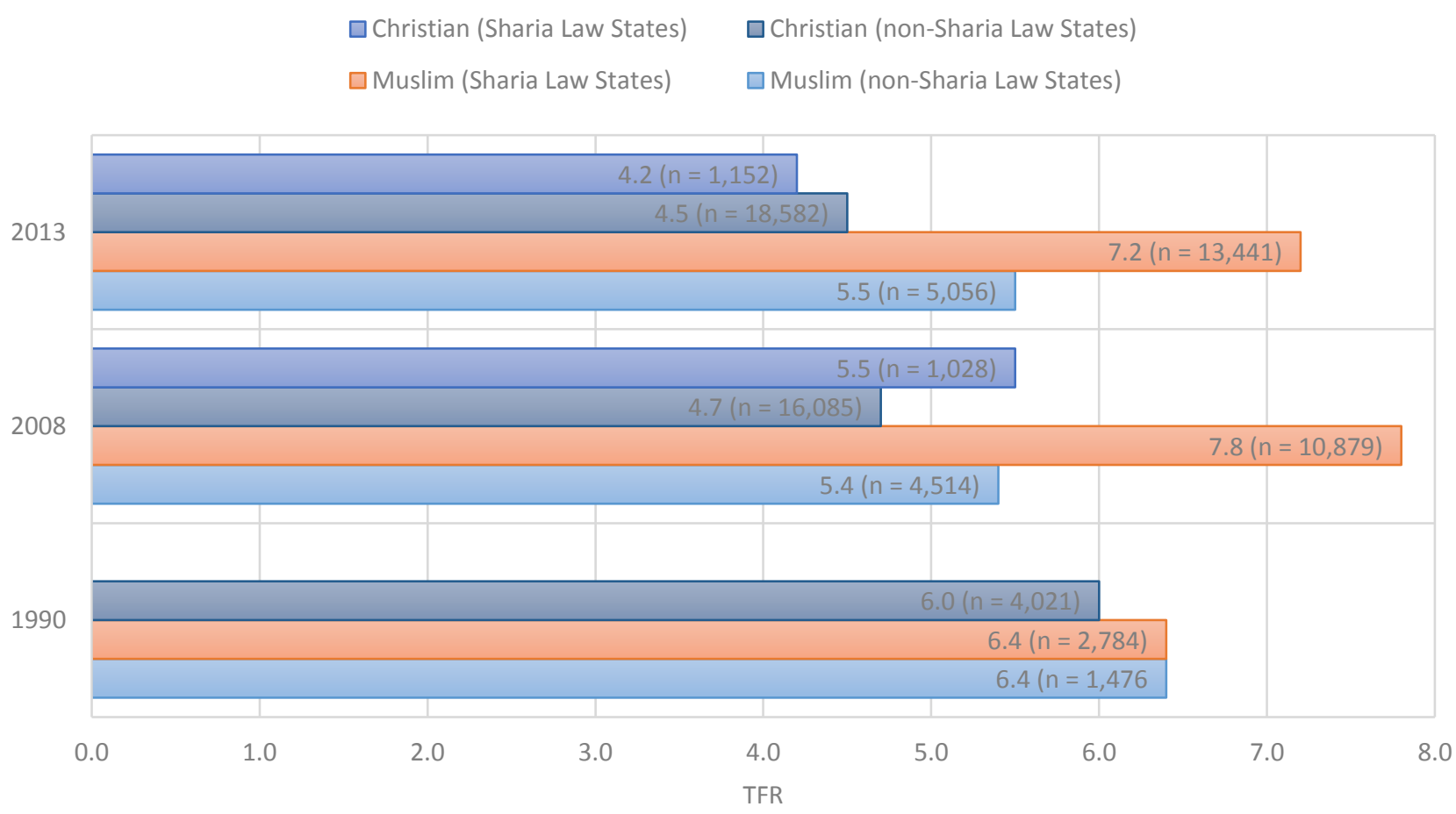

Figure 65. TFR for Christians and Muslims in Sharia and Non-Sharia Law States in Nigeria between 1990 and 2013. [ $n=$ Sample size.] [Data Source: Stonawski, et al., 2016] [NB: Because of the small number of observations, it was not possible to calculate TFR for Christians in Sharia States in 1990.]

Similarly, McGovern, et al. (2019) explored TFR for Customary and Religious Law (CRL) States in Nigeria in 2013 (Figure 66). Religious Law refers to Sharia Law while Customary Law is Indigenous to Nigeria and refers to each of the various ethnic groups in the country having its own Customary Law. Within Sharia Law States, there are pockets of non-Muslim people to which the Customary Law applies (Oba, 2011). In the study, CRL States were composed of 12 states while non-CRL States were composed of 25 states. The findings show that TFR was higher in CRL States (6.7) than non-CRL States (4.7), agreeing with the findings of Stonawski, et al. (2016) where TFR in Sharia Law States (5.7) was higher than TFR in non-Sharia Law States (5.0) in 2013.

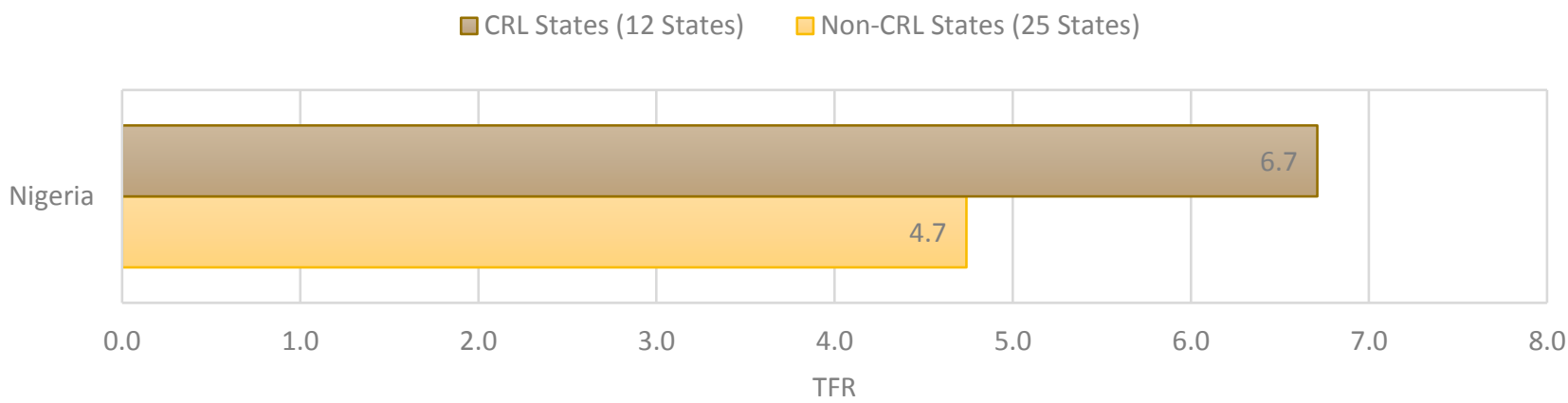

Figure 66. TFR for CRL and Non-CRL States in Nigeria. [McGovern, et al., 2019] [NB: Samples sizes were not specified.]

To summarise, Muslims and African Indigenous Religions generally had higher TFR than Christians. However, in Uganda and Zimbabwe, Christians had higher TFR than Muslims. Across Christian denominations, there was no consistent trend between Catholics and Protestants. 


\subsection{Qualitative Studies}

Of the seventeen qualitative studies that met the inclusion criteria, most covered both fertility and contraceptive use. One study (Davidson, et al., 2017) included refugees in Ethiopia from Eritrea and Somalia. Four studies conducted focus group discussions, four studies conducted in-depth interviews and nine studies combined the two approaches. All participants were affiliated with either Christianity or Islam. No participants were affiliated with African Indigenous Religions. For characteristics of sample populations and study design, see Appendix D. Religiosity was explored in one study (Akinyemi, et al., 2020), while interpretations of the respondents' quotes from the rest of the studies offered some idea of their level of religiosity.

\subsubsection{Fertility}

Fifteen qualitative studies reported influences on fertility levels across Ethiopia $(n=2)$, Kenya $(n=2)$, Nigeria $(n=4)$, Malawi ( $n=1)$, Somalia ( $n=1)$, Tanzania $(n=4)$ and Uganda $(n=1)$. The theme of religion was mentioned by respondents 13 times, 11 of which related to high fertility while only two mentions in Nigeria and Tanzania related to the limitation of fertility (Figure 67). Religion was not mentioned as an influence on fertility in Malawi. For themes, summaries of findings and representative quotes from the studies, see Appendices E1E7 for increasing fertility and Appendices F1-F5 for limiting fertility.

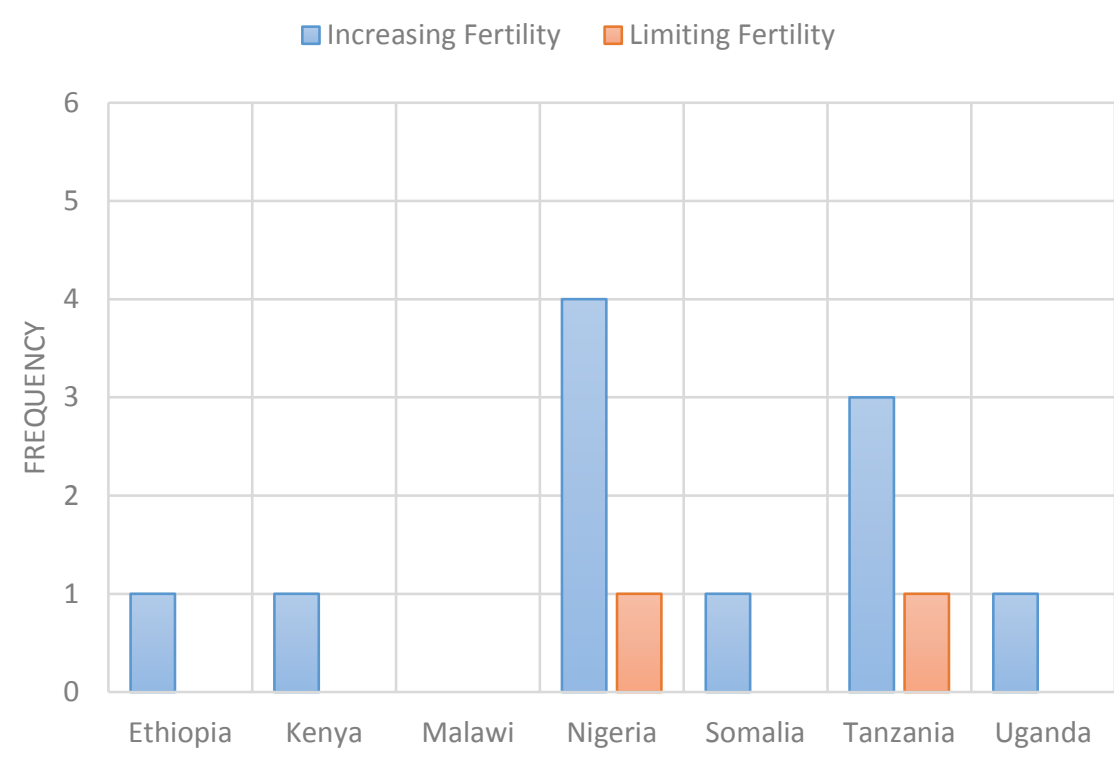

Figure 67. Frequency the theme of religion was mentioned as a factor for fertility.

Other common themes that were frequently mentioned as factors relating to increasing fertility were polygyny and social status (Figure 68). Polygyny was mentioned in Kenya, Malawi and Nigeria. Respondents cited that polygyny fuelled competition between co-wives and that the more children each co-wife had, the more financial support they would inherit. Having more children would also prevent husbands from taking on additional wives. Some women also perceived that by having more children, they would come across as more attractive to their husbands. Social status was cited in Kenya, Malawi, Nigeria and Tanzania. Respondents 
reported that for men, the more children a man had, the more respected he was in the community as men with many children were viewed as powerful, proud and rich.

Common themes frequently mentioned as factors relating to limiting fertility were financial constraints and quality of life (Figure 68). Financial constraints were mentioned in Ethiopia, Kenya, Malawi, Nigeria and Tanzania. Quality of life was mentioned in Ethiopia and Tanzania. Respondents commented that a large number of children resulted in poor living standards, and that having too many children meant that families could not pay school fees, consequently leaving children uneducated and not improving living conditions in the future. Large family sizes can cause stresses on men as breadwinners of the family while having fewer children improves living and hygiene standards and allows each child to receive more attention.

To summarise, themes relating to high fertility $(n=71)$, including religion, were cited more times than themes relating to limiting fertility ( $n=27)$. In addition, polygyny and social status were frequently cited as relating to increasing fertility while financial constraints and quality of life were cited as relating to limiting fertility.

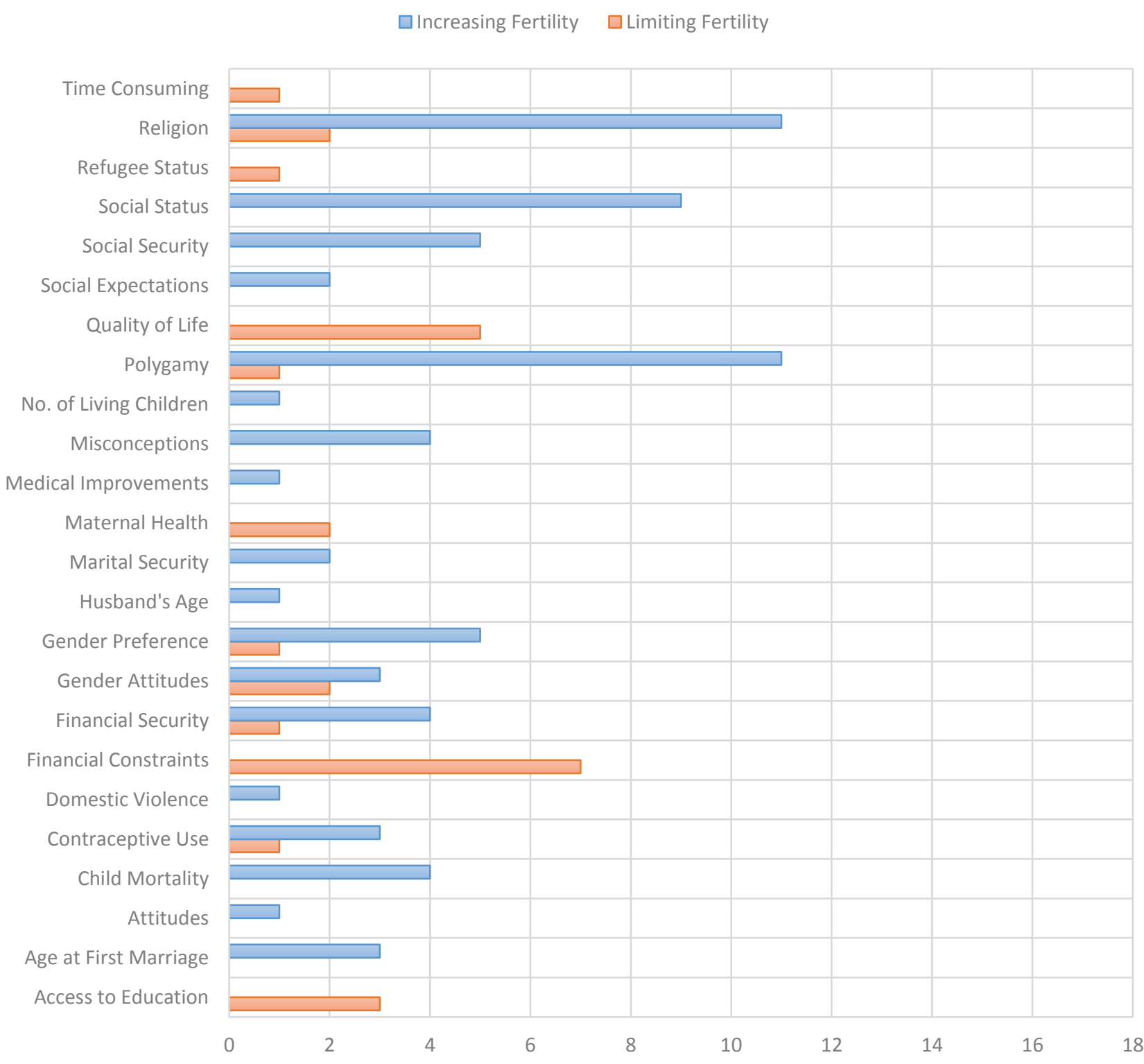

Figure 68. Total frequency of themes across all countries for fertility. 


\subsubsection{Contraceptive Use}

Sixteen qualitative studies reported influences on contraceptive use across Ethiopia ( $n=2)$, Kenya ( $n=1)$, Nigeria $(n=5)$, Malawi $(n=1)$, Somalia $(n=1)$, South Africa $(n=1)$, Tanzania $(n=4)$ and Uganda $(n=1)$. Religion was mentioned by respondents 33 times, 18 of which related to lower acceptance of contraceptive use while 15 mentions related to higher acceptance of contraceptive use (Figure 69). Religion was associated with lower acceptance of contraceptives in Nigeria, Tanzania and South Africa, and higher acceptance in Kenya and Somalia. For themes, summaries of findings and representative quotes from the studies, see Appendices G1G8 for lower acceptance of contraceptive use and Appendices H1-H8 for higher acceptance.

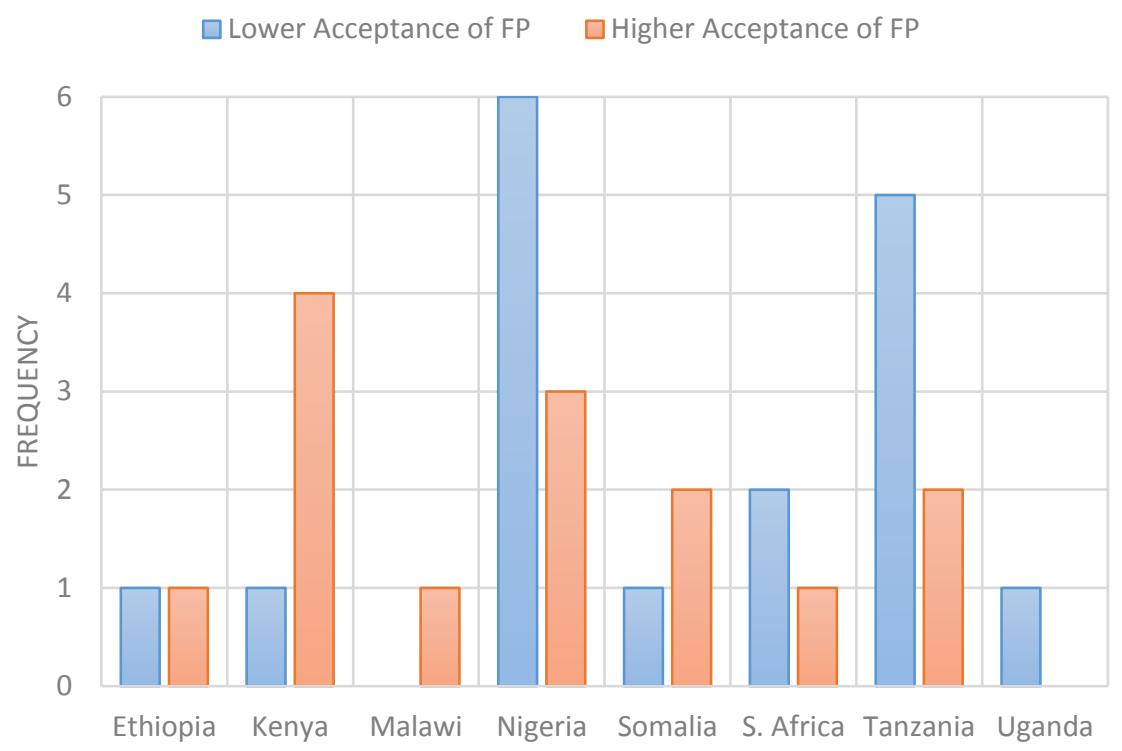

Figure 69. Frequency the theme of religion was mentioned as a factor for acceptance of family planning (FP).

Other common themes that were frequently mentioned as factors relating to lower acceptance of contraceptive use were gender attitudes, misconceptions and general attitudes (Figure 70). Gender attitudes was mentioned in Ethiopia, Kenya, Malawi, Nigeria, South Africa and Tanzania. Many participants agreed that child upbringing was more the woman's duty and therefore, contraceptive uptake was viewed as the woman's responsibility. However, husbands were often the head of the household and therefore the main decisionmaker and if husbands did not support the use of contraceptives, women would resort to covert use. Misconceptions were mentioned in Ethiopia, Kenya, Malawi, Nigeria, Somalia and Tanzania. A number of respondents believed that contraceptives would reduce sexual desire and performance, and cause body deformations, infertility and cancer. These misconceptions were either experienced first-hand or heard from others in the community. General attitudes were mentioned in Ethiopia, Malawi, Nigeria, South Africa and Tanzania. Family planning was often seen as taboo. Women who used contraception were viewed as promiscuous and men who let their wives use contraception were considered weak and powerless to their wives. Some respondents reported that some healthcare provider would not provide contraceptives to unmarried women or to married women who had less than three children.

Common themes frequently mentioned as factors relating to higher acceptance of contraceptive use were birth spacing, knowledge offamily planning and financial constraints (Figure 70). Birth spacing was mentioned 
in Ethiopia, Kenya, Nigeria and Somalia. Many respondents reported that the use of certain types of family planning was acceptable for spacing births at about two-year intervals to allow mothers time to physically and psychologically recover from the pregnancy. Knowledge of family planning was mentioned in Ethiopia, Malawi, Nigeria and Tanzania. Many participants had a good level of knowledge of different types of modern contraceptives and their advantages (though knowledge did not necessarily translate into behaviour). Financial constraints were mentioned in Kenya, Malawi, Nigeria and Tanzania. As stated with limiting fertility, participants showed interest in family planning due to economic constraints and stresses caused by large family sizes. Having many children and not being able to care for them leave families stuck in poverty.

To summarise, themes relating to lower acceptance of contraceptive use $(n=117)$, including religion, were cited more times than themes relating to higher acceptance of contraceptive use $(n=83)$, however, this discrepancy is not as large as that observed between increasing and limiting fertility. In addition, gender attitudes, misconceptions and general attitudes were themes frequently associated with lower contraceptive use while birth spacing, knowledge and financial constraints were associated with higher uptake.

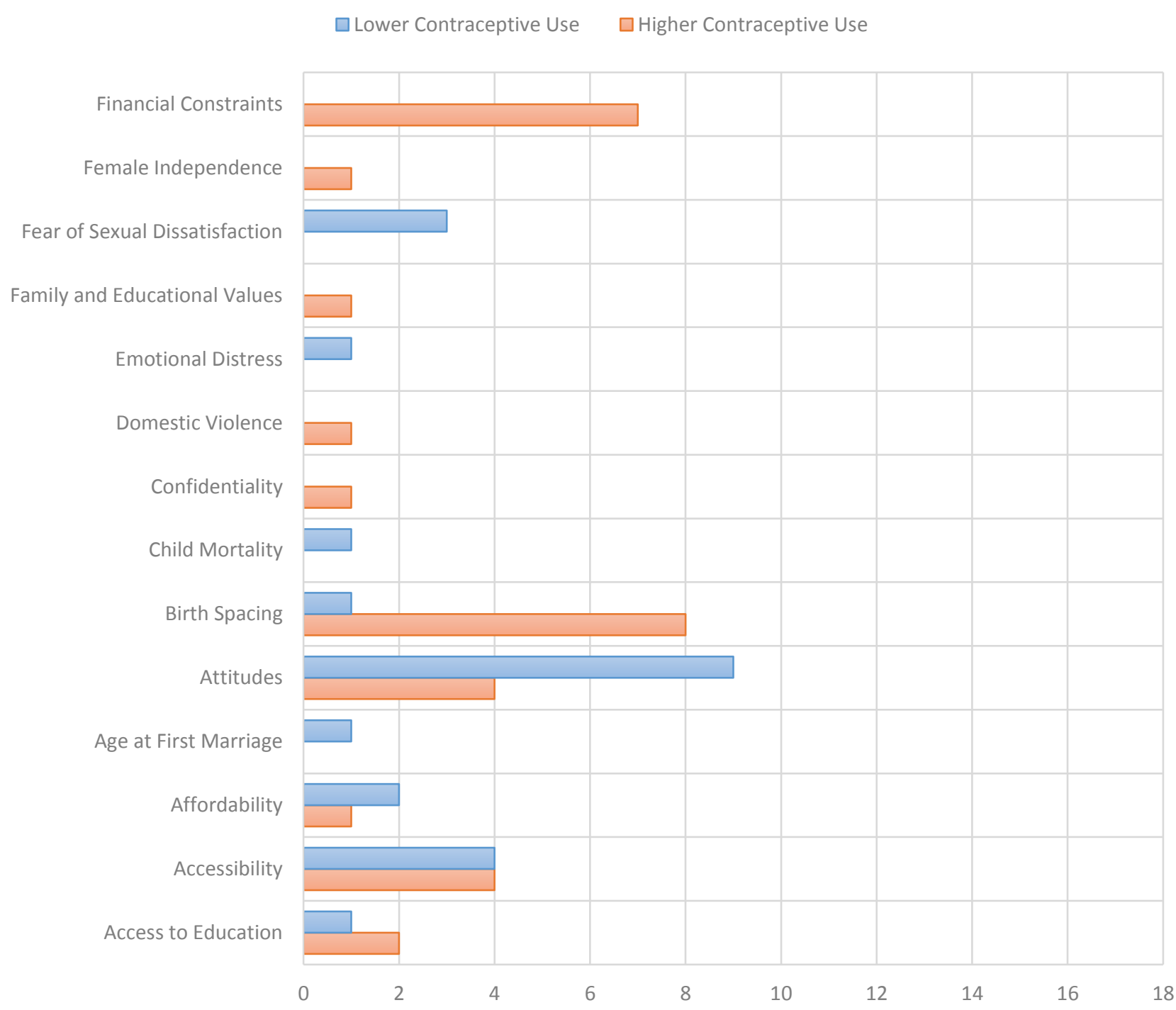

Figure 70. Total frequency of themes across all countries for acceptance of family planning (FP). 
Spousal Communication

Source of Information

Social Status

Social Security

Social Expectations

Side Effects

Self-Control

Religion

Refugee Status

Quality of Life

Quality of FP \& Services

Promotion of FP

Pregnancy and Disease Prevention

Polygamy

Modern Development

Misconceptions

Maternal Health

Marital Security

Male Involvement

Knowledge of FP

Intimacy

Gender Preference

Gender Attitudes

Financial Security
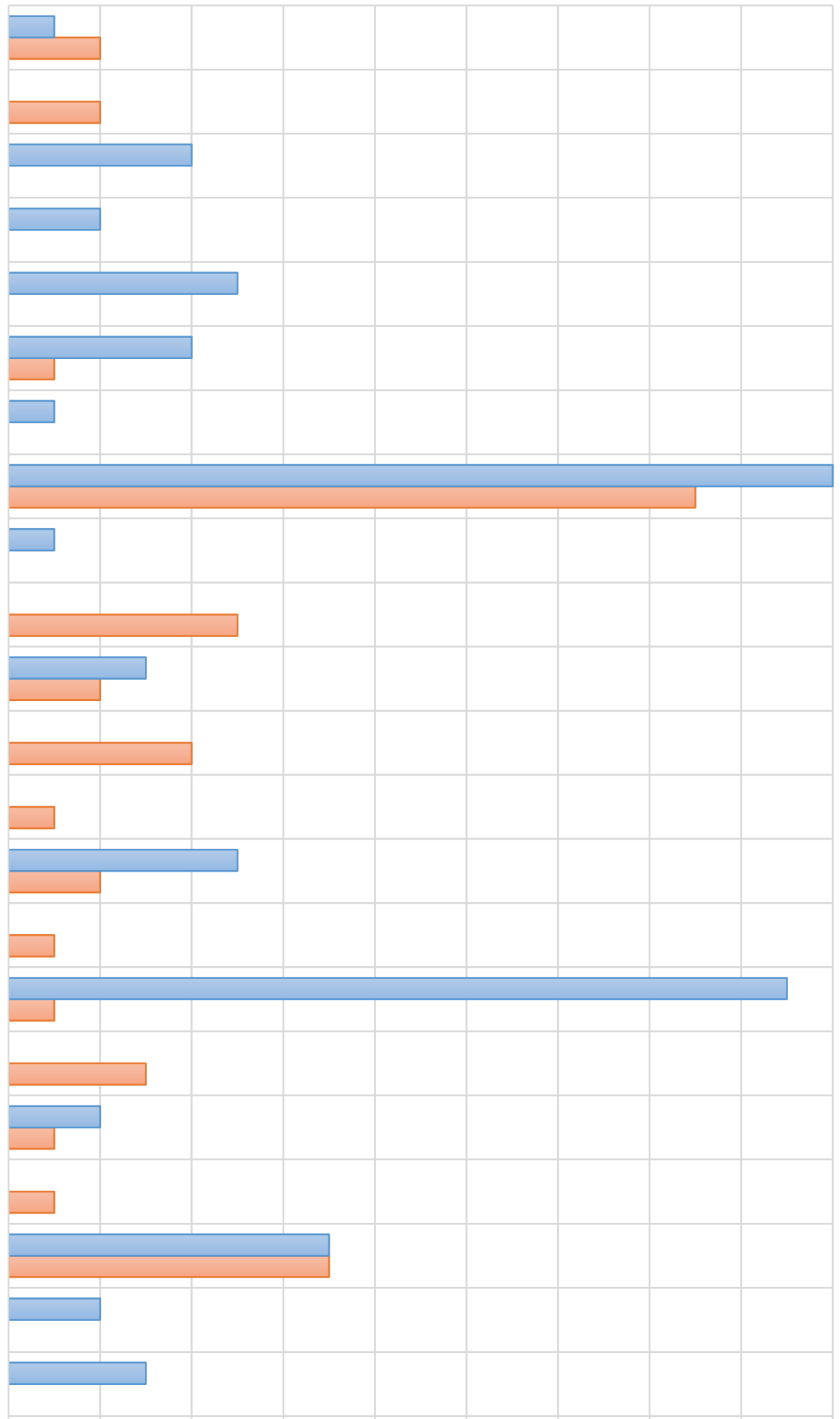

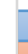

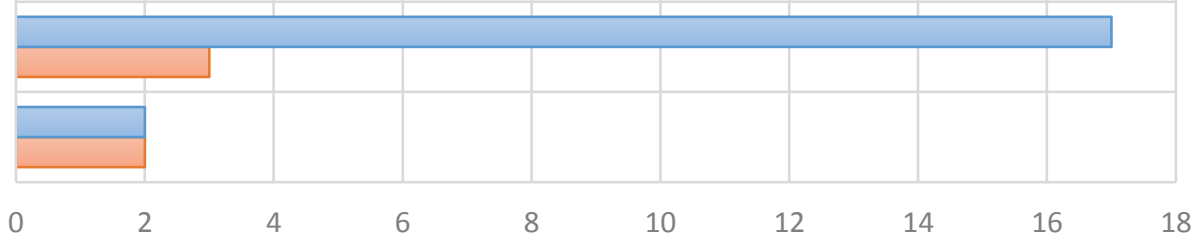

Figure 70. (cont'd) Total frequency of themes across all countries for acceptance of family planning (FP). 


\section{Discussion}

The aim of this review was to explore and seek to clarify the role of religion and religiosity on fertility and contraceptive use in Sub-Saharan African countries. I have shown general trends in how religious affiliation influences fertility levels and contraceptive use. These trends are not always consistent within and across countries, suggesting additional influences of other factors, as discussed below.

A clear trend is that participants affiliated with African Indigenous Religions had higher fertility than Christians in all 21 countries that measured fertility for both religious groups. This difference is strong and consistent. Similarly, Muslims had higher fertility than Christians in 26 countries that measured fertility for both religious groups. Uganda and Zimbabwe showed the opposite trend, but the magnitude of difference was only $2 \%$ in both cases. These results indicate a strong difference in fertility between Muslims and Christians. However, fertility differences between Muslims and participants affiliated with African Indigenous Religions were minor and inconsistent. Across Christian denominations, Catholics generally had higher fertility than Protestants although the difference is small and inconsistent within and across countries. Followers of the Apostolic Church exhibited the highest fertility among Christian groups. Religious leaders across all religions were found to be highly influential and many participants were inclined to follow the recommendations of religious leaders regarding fertility and contraceptive use. The findings clearly suggest that religion influences fertility and contraceptive use, though deviations exist in some countries. Overall, these findings agreed with my expectations from the research questions.

To reference the initial research questions, across Sub-Saharan Africa, fertility increases with degree of religiosity, and decreases with contraceptive use. Focus group discussions and in-depth interviews suggest that these relationships are stronger in Islam compared with Christianity, although highly religious Christian respondents were also noted. This was in line with my expectations. However, there were no indications for degree of religiosity for African Indigenous Religions, thus this could not be determined.

Education, economy, gender equality and access to family planning have a negative association with religiosity, but the strength of this association varies depending on religion, residence and region, with Muslims (particularly those residing in rural areas) generally reported as the most disadvantaged in terms of levels of education and wealth across Sub-Saharan Africa. Fertility is lower in predominantly Christian Southern Africa where levels of education are high for both men and women. Religion and religiosity have an important role to play in relation to fertility and contraceptive use, but they also depend on other factors, their interactions and their relative influences. They have variable relationships to education, economy, gender equality, residence (rural/urban) and access to family planning due to the different levels of these factors among and within countries in Sub-Saharan Africa. These findings, too, met my expectations.

Several limitations were encountered. First, of the 44 countries classified as continental Sub-Saharan Africa, the search of databases revealed no relevant studies from nine countries. Second, there was a bias in number of studies from different countries. Countries with more studies provided more representative data than countries that had fewer studies. Third, there were a lack of studies on religiosity, mainly because it is not measured in DHS surveys, a primary source of data for many papers. Fourth, there is a lack of longitudinal data due to the relatively recent attention on the influence of religion on fertility and contraceptive use in SubSaharan Africa. DHS analysis utilised cross-sectional data; hence, only associations and no firm causal 
relationships can be established. Fifth, the grouping of religions is far too simple to capture distinctions within Christianity and Islam. For example, as described by Heaton (2011), the mix of Protestant groups varies considerable across countries and to lump them all together may overlook certain characteristics that could explain fertility differences. In a study by Chamie (1981) on Arab-Christian and Muslim differentials on fertility in Lebanon, Chamie discovered significant differences in fertility behaviour between the Shias and Sunnis of Islam. Moreover, the role of religion was studied on a continent where essentially all are religious and therefore a control group that is shielded from the influences of religion cannot be compared. Nevertheless, the results of the review are valuable as Sub-Saharan Africa is comprised of several contrasting religions in which it is possible to identify patterns. Finally, many study samples focused on married women and thus the results may be incomparable to the rest of the population, such as adolescents and particularly married men, who tend to be household decision-makers in many African societies. Women's choices in fertility and contraceptive uptake may ultimately be decided by their male counterparts. Furthermore, fertility and contraceptive behaviours associated with unmarried women may differ strongly due to the stigmatisation of premarital sex across religious groups.

The following sub-sections explore and interpret the results of each of the indicators of fertility as well as the qualitative findings. The fertility indicator of "Achievement of Fertility Desires" is incorporated into Section 4.1 due to the absence of numerical data.

\subsection{Fertility Desires}

Of the seventeen countries that measured fertility desires, Muslims had a higher fertility desire than nonMuslims in all countries except Mali. This difference is especially strong between Christians and Muslims in Nigeria (see below). Chad also stood out with both religious groups desiring high fertility. TFR in Chad is 5.7 and CPR is extremely low at 5.7\% (United Nations, 2020), the second lowest in Sub-Saharan Africa after South Sudan (4\%). Chad has one of the lowest GDP per capita in the world (US\$710) and only $24 \%$ of the population live in urban areas (United Nations, 2020). Level of education is below average with a large gap between men and women (Garenne, 2012). In a study by Götmark \& Andersson (2020), fertility correlates negatively with education and GDP per capita. Chad's extremely low education and GDP per capita are factors that likely contribute to its very high fertility. Although Muslims had higher fertility desires than Christians in Chad (9.7 versus 8.6 children), both religions are experiencing similar impacts from low education and extreme poverty, thus fertility desires are high for both religions. In Chad, influences of religion on fertility desires are not as strong as socioeconomic factors. Nevertheless, across Sub-Saharan Africa, it is clear that Muslims have higher fertility desires than Christians.

Muslim fertility desires in Mali were lower than the non-Muslim group due to the higher fertility for Animists and women in other Indigenous religions. Furthermore, the three predominantly Muslim regions in the north of Mali were excluded from the 2012/13 DHS due to security (Westoff, et al., 2014; Westoff \& Bietsch, 2015).

Similarly, with the exception of Guinea, more Muslims desired to continue having more children than Christians in sixteen countries (Westoff \& Bietsch, 2015; Adebowale \& Palamuleni, 2015). This is in agreement with the outcome of previous studies conducted across Sub-Saharan African where Muslims have higher fertility desires than their Christian counterparts (Adedokun, 1979; Faramade, 2006). Guinea's population is 
comprised of $89.1 \%$ Muslims and 6.8\% Christians (United Nations, 2020), and is characterised by low levels of education (Garenne, 2012) and a low GDP per capita (US\$963). TFR is 4.9 and CPR is low at 10.9\% (United Nations, 2020). TFR for Muslims in 1999 was 4.4 which increased to 5.5 in 2012 while Christian TFR was 5.5 in 1999 and decreased to 5.2 in 2012. Muslims had higher rates of child mortality and lower levels of education than Christians (Westoff \& Bietsch, 2015). Yet in Guinea, more Christians desired to continue having children than Muslims. This contradicts with what is expected in a country with such characterisation. One possible explanation for Muslims having lower fertility desires could be related to more Muslims living in urban areas (39\%) than non-Muslims (20\%) (Westoff \& Bietsch, 2015) and likely have better access to family planning resources. Previous studies in Sub-Saharan Africa have shown that in urban settings, TFR is lower and CPR is higher than in rural settings (Canning, et al. 2015). Although Muslims in Guinea had lower fertility desires than Christians, TFR remains higher than Christians, and continues to increase. This could be attributed to the practice of polygyny in Islam where women often over-achieve their fertility desires as a result of ongoing competition between co-wives for a larger share of the husband's wealth and attention. Western Africa is strongly characterised by polygyny (Fenske, 2013). This was also reported in a study in Nigeria (Babalola's, et al., 2017) (see below) and further supported by qualitative studies explored in this review (Abdi, et al., 2020; Izugbara \& Ezeh, 2010; Jensen, 2017; Kabagenyi, et al., 2016; Kok, et al., 2020; Sinai, et al., 2019). Thus, fertility desire does not necessarily translate to actual fertility.

Adebowale \& Palamuleni (2015) identified additional variables associated with high fertility desires in Malawi. Gender preference and sex composition of current children was associated with wanting to have more children. In Malawi, the majority of women studied had a preference for female children that could be attributed to many ethnic groups being matrilineal. In these settings, men live in their wives' villages when they get married and children trace their lineage to their mother's side. This is contrary to most patriarchal African settings where families prefer male children (Adeleye \& Okonkwo, 2010; Chai \& Nam-Hoon, 1995; Obikeze, 1988). Adebowale \& Palamuleni (2015) also attributed women's empowerment to low fertility as more empowered women have more decision-making authority including decisions on contraceptive use, therefore reducing fertility. However, fertility is higher among Muslims than non-Muslims which may relate to traditional patriarchal gender roles of Islam where men hold the authority and are the main decision-makers of the household (Abdi, et al., 2021). It was also observed that women in the lower wealth quintile who wanted more children after having five children were three times as those in the richest quintile. Pew Research Centre (2016) reported that Muslims in Malawi had relatively low access to schools and that rates of poverty were relatively high. This likely explains why fertility among Muslims are higher than non-Muslims.

However, in the study by Muhoza, et al. (2014), Christians had higher fertility desires than Muslims in Rwanda and Uganda. Similar findings in Uganda were also reported for number of births in the last five years and TFR (see Sections 4.3 and 4.4, respectively). This is contrary to what is expected from the main findings. Wealth influences children desired in Rwanda and Uganda (Muhoza, et al., 2014) in that the poor are more aware of the financial difficulties of having too many children than the middle and richer classes, and the poor tend to more often be Muslims (Heaton, 2011; Pew Research Centre, 2011). This is contrary to the findings from Adebowale \& Palamuleni's (2015) study in Malawi. The difference in fertility desires between Christians and Muslims is however only 0.2 in both countries, suggesting that religious affiliation does not play a strong role in this awareness.

In the study by Muhoza (2019), the majority of Catholics, Protestants, Muslims and Other Religions in Rwanda desired 0-3 children. This is in agreement with Muhoza, et al. (2014) which concluded that in densely 
populated Rwanda, particularly the poor, are more aware of the financial difficulties of large families and therefore prefer fewer children. Although more Muslims preferred to have 0-3 children than Christians, the difference was small. In Kenya, on the other hand, the majority of Catholics and Protestants desired 0-3 children, whereas Muslims and Other Religions desired six or more children (Muhoza, 2019). Community size and type of residential environment are possible influences of these religious differences in fertility. For example, in Rwanda, the majority of Muslims reside in cities in small groups among larger Christian communities, which may influence their attitudes. On the other hand, Muslims in Kenya represent an important part of both urban and rural communities, particularly in the Eastern and Northeastern regions where fertility is almost at uncontrolled levels (Muhoza, et al., 2014). Furthermore, higher fertility in Kenya is associated with polygynous unions where in Islam men are allowed to have up to four wives (Pew Research Centre, 2013). In Kenya, women born into large families prefer large families, and vice versa (Muhoza, 2019). However, a main difference between Rwanda and Kenya relates to socioeconomic factors. In Kenya, women with no education or residing in poor households are more likely to desire high fertility. This can be attributed to the familial system, which is common across Africa, where there is less incentive to limit family size as children are often raised by other people than their parents, such as grandparents, uncles and aunts, who cover various costs (Caldwell \& Caldwell, 1990; Korotayev, et al., 2016). Due to the strong cultural prevalence associated with fertility observed in Kenya and across many parts of Africa, Caldwell \& Caldwell (1990) predicted that traditional explanations of fertility, such as wealth, education, health and urbanisation, are not adequate to assess fertility trends in Africa. Cultural influences such as social and familial traditions need to be taken into account. Furthermore, Muslim populations in Kenya and Tanzania are poorer and more uneducated than their Christian counterparts (Muhoza, et al., 2014). In Rwanda, on the other hand, socioeconomic variables displayed little variation in fertility preferences with the whole country having a homogenous preference for low fertility. Lack of jobs and land scarcity in Rwanda invalidates potential economic benefits for families from having more children. Smaller household plots mean that having many children poses a burden to the parents (Muhoza, et al., 2014; Musahara \& Huggins, 2004). In all countries, older women, those already with high fertility and those who have lost some of their offspring were associated with high fertility. Women who have lost a child are more likely to have more children to replace the lost one and ensure the survival of others. This is in agreement with previous studies elsewhere (Angeles, 2010) and is further supported by qualitative studies explored in this review (Abdi, et al., 2020; Davidson, et al., 2017; Izugbara \& Ezeh, 2010; Sinai, et al., 2019). Lack of access to contraceptives has also resulted in many women having more children than they desired. Muhoza's (2019) findings imply that although religion plays a role in fertility desires, it is the interaction with socioeconomic and cultural variables that paints a fuller picture.

In Nigeria, a high percentage of Christians within the couples had equal desires for the ideal number of children while heterogamous couples of Muslim and Indigenous / Other Religions had the highest percentage of which the husband had higher fertility desires (Odusina, et al., 2020). Islamic Law permits polygyny, therefore fertility desires of husbands in polygynous marriages were higher than that of husbands in monogamous marriages, which is supported by other studies in Nigeria (Lawson \& Gibson, 2018; Patel, 2017). The high fertility desires of husbands than that of wives show the pronatalist tendency of Muslim men in Nigeria which may relate to gender roles where men with many children are viewed in the community as powerful, proud and rich (Oyediran, 2006) This was also supported by qualitative studies in this review (Msoka, et al., 2019; Pallangyo, et al., 2020). Traditional gender roles also position men as the decision-makers of the household, which includes deciding on how many children to have as well as decisions on contraceptive use, while women are expected to obey their husband's decisions and not assert their views on family matters (Bankole \& Singh, 
1998; Ezeh, 1997; Oyediran, 2006). Higher fertility desires of husbands meant that they were less likely to use contraceptives.

Babalola's, et al. (2017) longitudinal study on the achievement of fertility desires corresponds with this finding where Muslim women in Nigeria were less likely to achieve their fertility desires than Christians. Although Muslim women tend to have lower fertility desires than their husbands, most tended to over-achieve their fertility goals as a result of ongoing competition between co-wives for a larger share of the husband's wealth and attention. This trend is reported in previous studies from Nigeria (Turnwait \& Alfred, 2018; Odusina, et al., 2020) and further supported by qualitative studies explored in this review (Abdi, et al., 2020; Izugbara \& Ezeh, 2010; Jensen, 2017; Kabagenyi, et al., 2016; Kok, et al., 2020; Sinai, et al., 2019). The Northern part of Nigeria was also noted to have higher fertility desires (Odusina, et al., 2020) and is likely attributed to the strong presence of Islam, leading to early marriage, polygyny and high fertility. Babalola, et al. (2017) identified age and parity as significant factors associated with the achievement of fertility desires. In other words, the older the woman's age and the higher the number of children she already has, the stronger the motivators for not having any more children, agreeing with the study of Muhoza (2019) on Kenya and Rwanda. This is supported in other studies from Nigeria (Adebowale, et al., 2013; Adhikari, et al., 2009; Adiri, et al., 2010; De Silva, 1992; Oyediran, 2006). Spousal communication about fertility desires and contraceptive use was also a strong predictor of achievement of fertility desires as well as the acceptance of contraceptives. Given that traditional gender roles where husbands are the main decision-makers are still very prominent among Muslims in Nigeria, heterogenous couples that are Indigenous / Other Religions and Muslim are less likely to engage in spousal communication than Christians. This is consistent with results from previous studies (Abdi, et al., 2021).

\subsection{Children Ever Born}

Participants associated with African Indigenous Religions had the highest CEB, followed by Muslims and then Christians. Previous studies across Sub-Saharan Africa show the same trend. In Ghana, Christians tend to start families later, are less likely to be in formal marriages and polygynous unions, are more likely to get divorced or separated, and are more likely to use contraception than Muslims and those affiliated with African Indigenous Religions (Blackstone, et al., 2017; Heaton \& Darkwah, 2011; Machiyama \& Cleland, 2013). These are contributing factors to Christians having lower fertility than Muslims and African Indigenous Religions, and remain significant even after controlling for variables such as education, residence (rural/urban) and region. However, both Christians and Muslims in Ghana were generally more accepting of contraceptives compared with other countries in Sub-Saharan Africa (Avogo \& Agadjanian, 2008; Doctor, et al., 2009).

In Nigeria, Muslims and those affiliated with African Indigenous Religions had higher fertility than their Christian counterparts (Faramade, 2006). However, this trend was not consistent across the country. Adedokun (1979) found that African Indigenous Religions had the highest fertility in Western Nigeria, followed by Christians and Muslims, but in certain rural and urban areas, Muslims had the highest fertility, followed by Christians and lastly African Indigenous Religions. In the case of Nigeria, Muslims also had higher CEB than Christians and that CEB was higher in the Northeast where it is predominantly Muslim compared with a lower CEB in the Southwest (Ibeji, et al., 2020). Additional variables that influenced CEB were residence (rural women 
had higher fertility than urban women) and mother's educational level (the higher the mother's level of education, the lower the CEB).

Between the Christian denominations across Sub-Saharan Africa, Catholics consistently had the highest CEB, except in Eswatini and Mozambique. This consistent trend contrasts with the overall inconsistent differential across all dependent variables (see Figure 37). This suggests that Catholicism may in fact be associated with higher CEB than Protestants, though the difference is small. In a study on heterogamous and homogamous couples in Ghana and Nigeria, Ntoimo \& Mutanda's (2017) found that couples that were both Catholic had higher CEB than couples that were both other Christian. Yet, Heaton (2011) maintains that across Sub-Saharan Africa, Catholics' fertility does not show consistent patterns. In Eswatini and Mozambique, Apostolicism demonstrated the highest CEB across Christian denominations (Chemhaka \& Odimegwu, 2020; Agadjanian \& Yabiku, 2014). Apostolics in Eswatini and Mozambique comprise of $40 \%$ and $15 \%$ of the population, respectively (United Nations, 2020). In Agadjanian \& Yabiku's (2014) study, the share of reproductive life spent in the Apostolic Church was associated with significantly higher completed fertility regardless of other factors and that Apostolics had a significantly higher net risk of birth in any given year. Apostolicism in Africa was founded on early native resistance to foreign divinities and therefore characterised by a mixture of Christian and African Indigenous religious elements (Dodzo, et al., 2016). The Apostolic Church strongly promotes high fertility and early marriage, and contraception is believed to be against God's Commandment. Gender inequality is prominent in Apostolicism and polygyny is justified. Male domination of females and disempowerment of women and girls is celebrated. This takes away women's decision-making rights, particularly in relation to contraceptive use. One Apostolic sect leader explained that men carry the seed that God gave to them in abundance and therefore it is their duty to sow it. He further goes on to explain that the fact that men never stop reproducing while women go into menopause is a justification for polygyny (Dodzo, et al., 2016). This high regard for high fertility and non-use of contraceptives in addition to the acceptable practice of polygyny and the low status of women explains the high fertility among Apostolics compared with other Christian denominations in Eswatini and Mozambique.

In the longitudinal study by Mberu \& Reed (2014) in Nigeria among women aged 15-49, Muslims had the highest CEB in 2003. However, in 2013, CEB for Muslims had decreased slightly but increased for African Indigenous Religions, consequently becoming the denomination with the highest CEB. Nigeria's fertility transition is at different levels across sub-groups throughout the country with fertility decline appearing to have stalled across some of these sub-groups, in particular, the Hausa, Fulani and Kanuri ethnic groups, those residing in the Northwest and Northeast regions, Muslims and African Indigenous Religions, those in the lowest wealth quintile and those with no formal education (Mberu \& Reed, 2014). Although the fertility difference flipped between Muslims and African Indigenous Religions, the difference is small and both religious groups continued to exhibit a CEB of more than seven over the 10 years, indicating a stalling fertility transition among the two religious groups. The study also found negative attitudes towards family planning and perceived husband opposition to contraceptive use as contributors to high fertility in areas where a fertility stall was observed. This may have been related to the neglect of family planning programs by governments and global institutions in the last two decades (Mberu \& Reed, 2014; Bongaarts, 2016). Christians had the lowest CEB with Catholics having a higher CEB than other Christians, which is in agreement with the other studies that measured the outcome of CEB in this review (Chemhaka \& Odimegwu, 2020; Agadjanian \& Yabiku, 2014). This is also supported by other studies in Nigeria. In Arowolo's (1973) study, Catholics exhibited higher fertility levels than Protestants in the town of Share. In Western Nigeria, Catholics had higher fertility than Protestants (Adedokun, 1979). However, in Ibadan, Catholics and Protestants exhibited equal fertility 
levels (Arowolo, 1973), and thus fertility patterns between Catholics and Protestants vary throughout Nigeria. Upon closer examination of the older age group (40-49 years) in Mberu \& Reed's (2014) study, the fertility trend across all religious groups was the same as the broader age group, but CEB was higher, pointing perhaps to historical disadvantage in labour force participation in older women.

Couples where the wife was Christian and the husband was non-Christian had a higher CEB than couples where the wife was Catholic and the husband was other Christian in Ghana and Nigeria (Ntoimo \& Mutanda, 2017). In Zambia, the opposite trend was observed. Zambia has a high level of inter-faith and inter-ethnic marriages which may indicate a higher tolerance of marital heterogamy in Zambia than in Ghana and Nigeria (Ntoimo \& Mutanda, 2017). In support of this view, Kalmijn (1991; 1998) stated that homogamy and endogamy are indications of more open, tolerant and equal society. Possibly, religiously heterogamous marriages imply weaker religious adherence on both parts of the couple, resulting in lower fertility. In Ghana and Nigeria, couples who were both affiliated with African Indigenous Religions had more children than couples who were both Muslims (Ntoimo \& Mutanda, 2017), supporting the overall trend across studies in this review that those affiliated with African Indigenous Religions had higher CEB than Muslims (Chemhaka \& Odimegwu, 2020; Agadjanian \& Yabiku, 2014). In Ghana and Nigeria, lower fertility was also observed where at least one partner was educated to secondary level or above. In Ghana, Nigeria and Zambia, occupational homogamy, particularly in white collar professions, predicted lower fertility. However, in Zambia and Ghana, couples in agricultural occupations who were homogamous had highest CEB. Previous studies across Sub-Saharan Africa documented the use of children for labour in agriculture as one of the determinants of high fertility (Caldwell \& Caldwell, 1987). CEB was also lower when couples were of the same age or when wives were older or younger by 1 to 4 years, suggesting that smaller age gaps between couples is related to more equal gender roles and more empowered women, particularly for decision-making concerning fertility and contraceptive use. Studies across Sub-Saharan Africa indicate the more dominant role of male fertility preference when determining family size when the wife is considerably younger and less educated (Dodoo \& Seal, 1994; Oyediran \& Isiugo-Abanihe, 2002).

Studies that examined CEB showed a clear and consistent trend that African Indigenous Religions had the highest CEB, followed closely by Muslims while Christians had the lowest CEB. Across the Christian denominations, Catholics consistently had higher CEB than Protestants, except in Eswatini and Mozambique where Apostolicism is practiced and has a much higher CEB.

\subsection{No. of Births in the Last Five Years}

All countries studied in Western, Central and Eastern Africa showed that Muslims had a higher number of births in the past five years than Christians, with the exception of Chad, Mozambique and Uganda. The magnitude of the difference in the number of births varied considerably. Heaton (2011) found that the Christian and Muslim difference increased with higher levels of development and higher levels of educational attainment. This suggests that changes in attitudes and behaviour as a result of socioeconomic development has a stronger influence on Christian groups than Muslims. A possible explanation for this is the more conservative familial roles of women in Islam that shields Muslims from social changes associated with development. However, as Heaton (2011) states, a complete test of this hypothesis would require longitudinal data to take into account changes in development and religious group differences as well as the inclusion of 
more developed countries. Also, Muslims and Christians can differ in level of education, type of residence, marriage timing, contraceptive use and divorce (Heaton, 2011). This requires more study.

The case of Chad shows a stark contrast to the findings of fertility desires (see Section 4.1) where Muslims had higher fertility desires than Christians. Christians having a higher number of births than Muslims in the last five years, despite the opposite for fertility desires, was reported in two studies (Westoff \& Bietsch, 2015; Heaton, 2011). This contrast in results could be attributed to desired fertility not necessarily translating to actual fertility. A possible explanation could be the report of a sub-fertility belt stretching across Central Africa in which Muslims consistently had higher levels of sterility than Christians. A reason for this was the spread of untreated sexually transmitted diseases relating to cultural practices among Muslims (Larsen, 1989). Given the extreme poverty in Chad, and that Muslims are more likely to have lower levels of education and wealth than Christians (Heaton, 2011; Pew Research Centre, 2011), this explanation is plausible.

In Mozambique, higher number of births in the last five years among Christians than Muslims is likely attributed to the practice of Apostolicism in which high fertility is strongly promoted, contraception is forbidden and polygyny is justified (see Section 4.2).

In Uganda, Christians had a higher number of births in the last five years than Muslims. This corresponds to the findings of Sections 4.1 and 4.4 in which Christians in Uganda also had higher fertility desires and TFR than Muslims, respectively. Muhoza, et al. (2014) found that the poor in Uganda are more aware of the financial difficulties of having too many children than the middle and richer classes, and the poor tend to more often be Muslims (Heaton, 2011; Pew Research Centre, 2011). Furthermore, while Christians comprise $84.4 \%$ of the population and Muslims $13.7 \%$ (United Nations, 2020), only $18 \%$ of non-Muslims live in urban areas compared with 32\% of Muslims (Westoff \& Bietsch, 2015). Those living in urbans areas likely have better access to family planning resources. Previous studies in Sub-Saharan Africa have shown that in urban settings, TFR is lower and CPR is higher than in rural settings (Canning, et al. 2015). Catholics, which comprise $39.3 \%$ of the population, were also found to have a high unmet need for family planning (Kaida, et al., 2005; Wablembo, et al., 2011). This probably explains the higher number of births in the last five years among Christians in Uganda compared with Muslims. However, Anglicans, which comprise 45.1\%, were more open towards contraceptive use (Kaida, et al., 2005). This contrast between Catholics and Anglicans likely erases fertility differences from the overall Christian average, therefore reducing the accuracy of the result. It seems, however, that fertility differences in religions exist, but are also affected by strong socioeconomic factors.

The sole Southern African country studied was Namibia in which Christianity was the only religion examined with a very low number of births in the last five years (0.77), thus also low across the African sub-regions studied. In Garenne's (2012) study on education and fertility in Sub-Saharan Africa, countries with the highest level of education were located in predominantly Christian Southern Africa. South Africa had the highest percentage of women who had completed primary education (86\%), followed by Zimbabwe (78\%), Eswatini (75\%), Lesotho (74\%) and Namibia (71\%). In addition, the ratio of the difference between males and females to the average of males and females that were educated was smallest in the same Southern African countries (i.e. the difference between educated males and females is small). Interestingly, South Africa, Namibia and Eswatini had a higher mean level of education for women than for men. This higher level of education in Southern Africa likely explains the low fertility observed in Namibia and agrees with Heaton's (2011) findings that changes in attitudes and behaviour as a result of socioeconomic changes has a stronger influence on Christian groups. 
In countries where no religious affiliation was measured, with the exception of Benin, Cameroon, Guinea and Mozambique, populations associated with this group had a higher number of births in the past five years than both Christian and Muslim groups. This is the opposite patterns of what is expected from the more developed regions of the world (Götmark \& Andersson, 2020). A possibly or likely explanation is that women who were identified as having no religion were less educated than the women with religious affiliation. The calculations were also based on a small number of women (Westoff \& Bietsch, 2015).

Across Christian denominations, all Sub-Saharan African sub-regions showed small and inconsistent fertility differences between Catholics and Protestants. This corresponds to similar trend in fertility differences observed between Catholics and Protestants when all dependent variables are combined (see Figure 37), and is in agreement with the findings of Heaton (2011). Thus, it is likely that socioeconomic influences on Christian fertility impacts all Christian denominations similarly.

Despite the limitations, findings from these papers do confirm considerable differences in fertility between Christians and Muslims, and variability cross-nationally. Religion and the interaction between religion and socioeconomic variables are important when assessing influences on fertility.

\subsection{Total Fertility Rates (TFR)}

Across Western and Central Africa, TFR for Muslims and Indigenous / Other Religions was high, with both religious groups having higher TFR than Christians. This agrees with previous studies across Sub-Saharan Africa that showed that African Indigenous Religions and Islam had consistently higher fertility than their Christian counterparts (Faramade, 2006). However, in Eastern Africa, Christians had a higher TFR than Muslims in Uganda and Zimbabwe although the difference is small (6.2 versus 5.9 for Uganda; and 3.8 versus 3.7 for Zimbabwe). Although Zimbabwe is classified by the UN as Eastern Africa, geographically it is located in the southern-most part of the sub-region, bordering Southern Africa. This region is predominantly Christian (United Nations, 2020) and characterised by high levels of education (Garenne, 2012) (see Section 4.3). In Zimbabwe, $87.4 \%$ of the population are Christians with $74.8 \%$ identifying as Protestants. Muslims comprise of only $0.5 \%$ and non-affiliated make up $10.5 \%$ (United Nations, 2020). The average years of schooling in Zimbabwe is 9.0 years, the second highest in Sub-Saharan Africa after South Africa ( 9.8 years). These are similar to values found in European countries where average age of schooling ranges between 9.0 and 9.9 years (Garenne, 2012). Zimbabwe also had the second highest percentage of women who had completed primary education (78\%), after South Africa (86\%). The higher level of education in predominantly Christian Zimbabwe (where little religious variation exists) likely explains the relatively low fertility. This agrees with the study by Götmark \& Andersson (2020) in which fertility correlates negatively with education. Uganda is also a primarily Christian country with $84.4 \%$ of its population identifying as Christian and $13.7 \%$ being Muslim (United Nations, 2020). However, average years of schooling is 5.4 years with $33 \%$ of women having had completed primary education (Garenne, 2012) which explains why overall TFR is higher than Zimbabwe. The case of Uganda was explored in Sections 4.1 and 4.3 in which Muhoza, et al. (2014) found that the poor in Uganda are more aware of the financial difficulties of having too many children than the middle and richer classes, and the poor tend to more often be Muslims (Heaton, 2011; Pew Research Centre, 2011). Furthermore, a higher proportion of Muslims live in urban areas (32\%) compared with non-Muslims (18\%) 
(Westoff \& Bietsch, 2015). Those living in urbans areas likely have better access to family planning resources. Previous studies in Sub-Saharan Africa have shown that in urban settings, TFR is lower and CPR is higher than in rural settings (Canning, et al. 2015). This likely explains the higher TFR among Christians in Uganda compared with Muslims. However, the difference in TFR between Christians and Muslims in Uganda and Zimbabwe is small suggesting that religious affiliation may not play a strong role in this awareness.

In the two Southern African countries, Lesotho and Namibia, although Indigenous / Other Religions had a higher TFR than Christians, like in Western and Central Africa, Indigenous / Other Religions had the lowest TFR of all the aforementioned African sub-regions. This corresponds with the findings in Section 4.3 on number of births in the last five years, where the lowest number was also observed in Southern Africa. The higher level of education (and/or lower degree of religiosity) in Southern Africa likely explains the low fertility observed in Lesotho and Namibia. While fertility for Indigenous / Other Religions was also comparatively low, it still agrees with Heaton's (2011) findings that changes in attitudes and behaviour as a result of socioeconomic changes has a stronger influence on Christian groups, though the differences between groups were quite small.

Across the Sub-Saharan African sub-regions, relationships between TFR and Christian denominations showed no consistent difference, in line with findings for the number of births in the last five years (see Section 4.3). Thus, it is likely that socioeconomic influences on TFR impacts Christian denominations similarly.

Muslims in Sharia and non-Sharia States had equal TFR (6.4) in 1990. However, in 2013, TFR for Muslims in Sharia States had increased while TFR for Muslims in non-Sharia States decreased. In 2008, TFR for Christians in non-Sharia States was lower than Christians in Sharia states, however, this trend flipped in 2013 with Christians in Sharia States having the lowest TFR overall (Stonawski, et al., 2016). The authors predict that Nigeria will become a majority Muslims country in a couple of decades unless the differential between Muslim and Christian fertility quickly narrows. However, this is unlikely given high fertility ideals, low prevalence of family planning, low educational improvements and high population growth in Sharia States. Sharia Law may or will sustain high fertility in opposition to Western influence and to preserve the local culture. High fertility is engrained in part of the local customs with more than $50 \%$ of women in Sharia States wanting 10 children or more, or "any number of children God gives them", while only $7 \%$ feel that four children or fewer is ideal. Other factors that are associated with high fertility in Sharia States include marriage customs, polygyny and liberal divorce regulations leading to high divorce rates. According to the 2008 Afrobarometer, religion is a significant part of Nigerian society with $95 \%$ of Muslims and $88 \%$ of Christians saying that religion is a very important part of their lives. Religion is also frequently cited as the reason for violence with rivalry between the Muslim North and Christian South intensifying (Stonawski, et al., 2016).

In a 2013 Nigerian study (McGovern, et al., 2019), TFR was higher in Customary and Religious Law (CRL) States than non-CRL States. McGovern, et al. (2019) state that Christian and Muslim doctrines can vary within the States which supports Stonawski's, et al. (2016) findings that Christians in Sharia States had the lowest TFR overall while Muslims in Sharia States had the highest. Poverty is also more widespread in the Northern States that are predominantly Muslim compared to the Christian Southern States. However, McGovern, et al. (2019) conclude that economic differences were insufficient to explain the fertility differences between CRL and non$\mathrm{CRL}$ States and that the differential is robust even after taking economic conditions into account. Sharia Law allows children to marry early, but Nigeria and other countries across Sub-Saharan African have been directed by the Convention on the Rights of the Child (CRC) to review the compatibility of customary laws with the values of the CRC, especially regarding child marriage (CRC, 1995). Despite many countries across Sub-Saharan 
Africa signing on to the CRC, which sets the minimum age of marriage to 18 years, many countries or states under Sharia Law continue to practice child marriage, which is a contributing factor to high fertility, especially among adolescents. The lack of enforcement can be attributed to contradictory law, inconsistent legal frameworks and unenforceable international treaties in Nigerian courts, where e.g. the CRC and Convention of the Elimination of Discrimination Against Women (CEDAW) are seen to violate religious and customary practices (CEDAW, 2008; Global Commission on HIV and the Law, 2012; Maswikwa, 2015). In Northern Nigeria, male interpretations of religious traditions have been used to legitimise the inferior status of women by emphasising female submission and their role to obey and seek consent from their husbands and give birth to many children (Bawa, 2017; Centre for Reproductive Rights, 2013; Pereira, 2010). This increases women's socioeconomic dependence on their husbands, limits decision-making autonomy, and upholds patriarchal norms (Al-Mujtaba, 2016; Ejembi, 2015; Ndulo, 2011). These harmful practices have adverse effects on the rights of women and children, and contribute to population growth.

These quantitative results for TFR show high variation between religions, countries, regions and socioeconomy. Affiliation with African Indigenous Religions, Islam and Christianity influences fertility. The influence on TFR is similar among Christian denominations, which do not differ strongly, with the exception to Apostolicism, associated with higher fertility. Socioeconomic factors, including education, wealth and access to family planning, and their interactions with religion, are important.

\subsection{Qualitative Studies}

These studies give supportive insights to the quantitative findings by examining actual quotes of respondents' views and opinions of fertility and contraceptive use from focus group discussions and in-depth interviews. Some views presented were not identified in the quantitative findings. The results offer a better understanding of the level of religiosity of the respondents, a limiting factor in the quantitative studies, particularly in those that utilised DHS surveys. Seventeen studies were examined across eight countries, thus countries included are fewer compared to quantitative studies.

\subsubsection{Religion}

Across all studies in the review, many Christian and Muslim respondents stated that contraceptive use contradicted their religious beliefs, and that their religion encourages them to have as many children as possible (e.g. to use up all the eggs that God gave them). This was also reported in other studies in Sub-Saharan Africa (Akpor, et al., 2016; Dubiwak \& Seme, 2014; Kabagenyi, et al., 2014; Plummer, et al., 2006). However, the adherence to this belief depended on the situation. This view was particularly strong in predominantly Muslim Northern Nigeria and Somalia, whereas in Kenya, most religious leaders and scholars from Lamu and Wajir Counties agree that family planning is supported by Islam within the context of marriage and that nowhere in the Quran or Sunnah prohibits its use (Abdi, et al., 2020). In fact, the Sunnah specifically mentions the acceptance of the withdrawal method (Deuraseh, 2003). This belief was stronger in Lamu compared with Wajir which Abdi, et al. (2020) attributes to different interpretations of Islamic teachings. It is possible that age, education and degree of religiosity are contributing factors, however, but this was not explored. 
In Northwestern Nigeria, despite a high level of awareness and knowledge of family planning, most respondents believed that the concept of contraceptives contradicted Islamic beliefs and that this was the root of their negative perceptions of family planning. In this region, family planning is strictly forbidden in Islam (Adefalu, et al., 2019). This notion is supported by other studies in predominantly Muslim settings in Northern Nigeria (Ejembi, et al., 2004), Northern Ghana (Agyei-Mensah \& Owoo, 2015) and e.g. in Bangladesh outside Africa (Mohsena \& Kamal, 2016) where respondents reported religious beliefs as a hindrance to contraceptive uptake. Religiosity is reportedly stronger in these regions, reducing contraceptive uptake (Akinyemi, et al., 2020). Both Christian and Muslim participants believed that children are a gift from God and should not be declined. Therefore, many women do not feel empowered to make contraceptive decisions (Sinai, et al., 2019). Despite some respondents believing that the number of children they will have is up to God, other respondents in Nigeria believed that both God and the people had the power to control fertility (Izugbara and Ezeh, 2010).

Despite the general perception that family planning contradicts Islamic beliefs, Muslim respondents in Kenya, Somalia and Nigeria agreed that use of family planning is acceptable for birth spacing, but only when used in compliance with Islamic religious beliefs. Breastfeeding is the most accepted form of birth spacing and is mentioned 14 times in the Quran (Egeh, et al., 2019). Most respondents from Wajir County, Kenya, also referred to the Quranic recommendation that mothers breastfeed their children for two years to restore their physical and psychological health before continuing with another pregnancy, up until menopause (Abdi, et al., 2020; Afifi, 2008; World Health Organisation, 1998). However, there is still a $5 \%$ risk of a woman becoming pregnant within the first six months, and the risk increases after six months (Ekpenyong, et al., 2013). The withdrawal method was also mentioned as another acceptable form of family planning (Abdi, et al., 2020; Ujuju, et al., 2011), however, condoms are prohibited as religious leaders stated that it would likely promote sexual activity outside of marriage (Egeh, et al., 2019; Ujuju, et al., 2011). Permanent and non-reversible contraceptive methods are not permissible (Atighetchi, 1994; Dubiwak \& Seme, 2014; Omra, 1992; Shaikh, et al., 2013). Although oral contraceptives are prohibited in Islam, religious leaders in Somalia agreed that is permissible for birth spacing unless health problems for women exist (Egeh, et al., 2019). This is supported by similar studies on Somali family planning practices (Davidson, et al., 2017; Kiura, 2014).

In Kenya, contraceptives are also permissible if the mother's health is at risk from another pregnancy, according to Islam (Abdi, et al., 2020). However, in Nigeria, the contrary view is held, and that family planning is strictly forbidden in Islam, even if the mother has medical issues (Adefalu, et al., 2019). This could be attributed to Nigeria having a higher Muslim population (53.5\%) than Kenya (10.9\%) (United Nations, 2020), and higher religiosity ( $90 \%$ versus $74 \%$, respectively, who had attended religious services in the past week) (Stark, 2015).

Despite the belief that Islam does not support the use of contraception, especially for limiting births, many respondents in Kenya justify their use of contraception as a result of economic constraints (smaller family size gives access to better quality of life), particularly in Lamu (Abdi, et al., 2020). In the study by Davidson, et al. (2017) on Eritrean and Somali refugees in Ethiopia, Somalis cited Islamic religion as a deterrent for use of contraceptives, and inducing its followers to have many children. Many Somali respondents desired large family sizes of up to 15 to 20 children, despite their refugee status. Somalis felt that religious beliefs outweighed economic concerns as they believed Allah would provide them with protection. This sentiment was echoed by Somali refugees living in Djibouti (UNHCR, 2011) and Finland (Degni, et al., 2006). Eritreans, who practice Christianity, preferred to limit their family size to 3 to 5 children due to economic constraints 
and refugee status, and were not influenced by their religious beliefs. In Tanzania, some Christian respondents believed that using family planning was a moral responsibility (Aristide, et al., 2020) and that limiting the number of children was in line with religious texts (caring for children and living within one's means). Using contraceptives was consistent with these moral standards. Other respondents supported the view that family planning is against their religion; however, they were also in support of the use of family planning given hardships in life, including economical and the spread of diseases (Sundararajan, et al., 2019).

The survival of Islam was also mentioned as a motivator for high fertility by Muslim women in Northern Nigeria (Izugbara and Ezeh, 2010). Respondents cited that high fertility guarantees the survival of religion and helps the religion flourish. However, like the above paragraph, the women interviewed did not support unregulated childbearing as they were aware of the consequences of poverty, lower quality of life, ill-health and reduced opportunities for their children. The awareness of the dangers of unlimited childbearing is widespread among women in Northern Nigeria (Duze \& Mohamed, 2006).

In Malawi, although Catholics and other Christians do not support the use of modern contraceptives because of the Christian importance of multiplying and filling the Earth and avoiding the sin of "killing the child", the majority of participants said that religion did not influence their need and decision-making for contraceptives. Churches also seemed to tolerate the use of modern contraceptives silently (Kok, et al., 2020). However, TFR in Malawi is still high (5.3) and could possibly be attributed to gender preference and sex composition of children (Adebowale \& Palamuleni, 2015) (see Section 4.1).

In South Africa, where $95 \%$ of participants said religions plays an important role in their everyday life, the Catholic Church prohibits contraceptive use as well as premarital sex. However, unlike in Malawi, participants felt conflicted and uncertain about how their religious beliefs might impact sex and condom use. Some participants also felt that they did not need condom protection as God would protect them. The sexual act itself is stigmatised by the Church, and discussing condom use or carrying a condom around implies that the sexual act was planned. Several female participants felt embarrassed when buying condoms. On the other hand, some participants reported that they were able to disassociate their religious beliefs from sex and condom use (Protogerou, et al., 2014). However, South Africa has a much lower TFR (2.2) compared with other countries in Sub-Saharan Africa. South Africa is characterised by high levels of education (Garenne, 2012) and relatively high GDP per capita (US\$6,001) (United Nations, 2020). Fertility correlates negatively with education and GDP per capita (Götmark \& Andersson, 2020), thus South Africa's high education and GDP per capita are factors that likely contribute to its relatively low fertility.

In Tanzania, the view that limiting the number of children goes against God's plan was particularly strong in rural areas for Christians and Muslims (Aristide, et al., 2020; Keele, et al., 2005; Msoka, et al., 2019; Pallangyo, et al., 2020; Sundararajan, et al., 2019). Tanzania is a deeply religious country with $93 \%$ of its population rating religion as very important to them (Pew Research Centre, 2010). Women who regularly attend religious services were reported to be less likely to receive family planning information from health care facilities (Dynes, et al., 2018). Some Christian respondents were unsure whether their faith allowed them to control the number of children they give birth to due to vague statements and interpretations regarding fertility in the Bible, and lack of talk on the subject from religious leaders (Aristide, et al., 2020). Although some participants did not feel it was appropriate that family planning was discussed in a religious setting, others were open to it (Sundararajan, et al., 2019). Previous interventions in the context of religious beliefs showed that when religious leaders were educated about family planning, which they then conveyed to their 
congregation, Church attenders became eager to learn more about family planning (Downs, et al., 2013; Downs, et al., 2017; Yeatman, \& Trinitapoli, 2008). Outreach to Church leaders in Aristide's, et al. (2020) study overcame barriers to the uptake of family planning including opposition by male partners / husbands and uncertainty of compatibility with religious faith. In a study in Mwanza in Tanzania (Nsanya, et al., 2019), postintervention showed increased self-efficacy among male and female Church leaders as well as in the population, including increased use of oral contraceptives among unmarried sexually active women. This demonstrates the strong influence religious leaders have on the community and the potential impact this has on fertility and contraceptive behaviour. However, interventions with Muslims leaders must be structured differently to that of Christian Church leaders, due to stronger Islamic teachings on sex and family size (Aristide, et al., 2020).

In Ethiopia, Orthodox Christians form the largest religious group (43.5\%) (Population Census Commission, 2008) and is highly religious with $78 \%$ attending Church on a weekly basis, while only $6 \%$ of Orthodox Christians in Russia say they do this (Pew Research Centre, 2017). Muslims and Protestants make up $33.9 \%$ and $18.6 \%$ of the population, respectively (Population Census Commission, 2008). Although the Orthodox Church was once against the use of contraceptives, it has since downplayed this rhetoric (UN Population Fund, 2012). While a third of the respondents in the study by Mjaaland, et al. (2020) specified not wanting to use family planning because they believed the Orthodox Church did not allow it, there was a 57\% higher contraceptive use reported among Orthodox Christians than among Muslims and Protestants (UN Population Fund, 2012). Another third of the respondents interpreted the Orthodox Church's silence on the issue to mean they were allowed to use family planning. The final third believed the Church was still against contraceptive use, but they still decided to use it anyway as they felt it was necessary (Gebrelibanos, 1999). The interviews and exploratory household surveys in the study by Mjaaland, et al. (2020) show that women's interpretations on the Orthodox Church's stand on contraceptive use differs across age groups, educational levels and residential settings (i.e. rural and semiurban). Although women were much more religious than men in this study, many women ignored religious disapproval of contraceptive use (mostly Orthodox women). Participants from both rural and suburban areas stated that if they could not afford children, then they should not have any. This indicates a high level of female empowerment of Orthodox women in Ethiopia. Limiting fertility and using contraceptives helps with escaping poverty and hunger, improve living conditions and health, and be able to provide all their children (rather than just their cleverest boys) with an education. In a study in Addis Ababa where TFR is low (1.9), women with low or no levels of education and who had access to less than a dollar per day had longer birth intervals than women who were better-off (Gurmu \& Mace, 2008). However, it is possible that when children become more educated and the economic situation improves, fertility would increase again. This causality is applicable when economic considerations are central to their reasoning (Mjaaland, et al., 2020).

The qualitative studies strongly suggest that religion/religiosity can increase fertility, but also demonstrate mixed views on the influence of religion on fertility and contraceptive use. While some respondents strongly believed family planning and limiting fertility was forbidden in their religion, some felt religion did not influence their decision, while others felt conflicted on the issue. Stronger religiosity is associated with less contraceptive uptake, or hesitation. Previous studies across Sub-Saharan Africa showed similar religious barriers (Frajzyngier, et al., 2006; Mungure \& Owaga, 2014; Shattuck, et al., 2016). A religion's stance on fertility and family planning plays an influential role. Among Muslims, family planning is acceptable for spacing births, but not for limiting family size. Economic constraints also influenced contraceptive uptake, regardless of religion. Ultimately, religious leaders can strongly influence a community and spread messages on family 
planning that could potentially impact fertility and contraceptive behaviour. The following sub-sections summarise other frequently cited influences on fertility and contraceptive use.

\subsubsection{Polygyny}

Polygyny was mentioned as an influence for both increasing and limiting fertility in Malawi, Nigeria and Uganda. Polygyny is common in Islam where men are allowed to have up to four wives (Pew Research Centre, 2013), but it also occurs in Christianity (Cahu, et al., 2011; 2014). Across Sub-Saharan Africa, women who have competing co-wives have many children to get more attention and higher share of wealth from husbands (Audu, et al., 2008; Foley, 2001; Sinai, et al., 2019; Wilson, 1997). Furthermore, women give birth to more children to prevent husbands from taking on more wives. More children mean higher financial responsibility for the husband (Audu, et al., 2008; Izugbara \& Ezeh, 2010). Yet, many co-wives are less inclined to use contraception. This practice was also reported in Senegal (Foley, 2001; 2007) where high fertility was a microtactic of economic survival for women where few opportunities exist for female autonomy. Studies across Africa have shown that although this type of patriarchy is engrained in society, it is also preserved by the women of society when they apply these strategies for economic survival, creating a never-ending cycle without intervention (Florence, 2013; Femininity, 2006).

In addition, women in Nigeria perceived men to view women more beautifully and love them more if they had more children, particularly if competition between co-wives is involved. This view was stronger among women in the 30-49 age group than 20-29 (Sinai, et al., 2019) where older women are likely trying to prevent their husbands from taking on younger wives. In contrast, some women in Malawi stated that having fewer children helped them remain attractive to their husbands thereby avoiding them taking on a younger second wife (Kok, et al., 2020). In Nigeria, others felt that if they spaced their children, the effect of repeated deliveries would have less of an effect on their bodies and they would look more attractive, healthier and youthful to their husbands, especially if there was competition between co-wives (Akinyemi, et al., 2020; Sinai, et al., 2019). Therefore, these women were more inclined to use contraceptives. This sentiment resonated more with women in their forties than in their twenties (Sinai, et al., 2019).

In a study by Cahu, et al. $(2011 ; 2014)$, at the community level, polygyny was found to increase fertility, even among women in a monogamous union. This suggests that the impact of high fertility as a result of polygyny is influential. Although the studies in this review do not explicitly show any indication that this is the case, this finding is important to consider in population policies. The effect is likely to be stronger when there is variation in marital type (e.g. polygamous) and possibly even religious groups in a community, though a religion that practices polygyny must comprise a substantial proportion of the population.

In Nigeria, most women desired five children or fewer; however, most women had far more than their desired number, exceeding six children. Those who had not yet achieved their fertility desires predicted that they would likely overshoot their desired mark. This was the results of competition between co-wives (Izugbara \& Ezeh, 2010). According to the Islamic inheritance system, in polygynous marriages, women with more children get a higher share of the husband's daily earnings as well as inheritance at death. Even when there is not much to be inherited, husbands do not ask their wives to stop giving birth and competing. This is likely to be attributed to their elevated social status and power from having many children (Izugbara \& Ezeh, 2010). 
Finally, a strategy to deal with the threat of divorce is to have many children, especially when Muslim men have reached their allowed limit of four wives. In Northern Nigeria, divorced women do not leave with their children, but rather, the children are left with the husbands. Therefore, having many children will put husbands off from divorce (Izugbara \& Ezeh, 2010).

\subsubsection{Gender Attitudes}

Male and female respondents frequently cited that men were the sole decision-makers of the household and women did not have much say in their choice for contraceptive use, despite family planning and child upbringing being seen as women's issues and responsibilities. This was reported in Malawi, Nigeria, Tanzania, Uganda and among Somali refugees in Ethiopia (Aristide, et al., 2020; Davidson, et al., 2017; Kabagenyi, et al., 2016; Kok, et al., 2020; Pallangyo, et al., 2020; Sinai, et al., 2019; Sundararajan, et al., 2019) and in other studies across Sub-Saharan Africa (Dral, et al., 2018; Farmer, et al., 2015; Harrington, et al., 2016; Hubert, et al., 2016; Kabagenyi, et al., 2014; Kululanga, et al., 2012; Mosha, et al., 2013; Nyamhanga, et al., 2014). Male resistance to contraceptive use was related to the idea that men with more children gain more respect in the community (see Section 4.5.4) as well as misconceptions about family planning (see Section 4.5.7). Other reported reasons for resistance were the desire for men to exert power and control over the sexual and reproductive lives of their wives, and to prevent wives from engaging in extramarital sexual activities (Kaneka \& Mturi, 2017). In Uganda, women who use modern contraception are mocked for having few children and referred to as prostitutes or adulterers (Kabagenyi, et al., 2016).

Consequently, some women resort to covert contraceptive use, making adhering to products' correct usage difficult, resulting in risk of pregnancy (Izugbara \& Ezeh, 2010; Sinai, et al., 2019; Ujuju, et al., 2011; Kok, et al., 2020), and is reported by previous studies in Sub-Saharan Africa (Gasca \& Becker, 2018). Other women would visit the health clinic at night to get the injection for Depo-Provera (Kok, et al., 2020).

Women were also perceived to be obligated to grant a man as many children as he desires, which is seen as a sign of respect and love for the husband (Aristide, et al., 2020; Kabagenyi, et al., 2016). If a woman does meet the marital expectations, she can be chased away from her marital home. Bridal price is also given with an expectation that women would bear as many children as possible (Kabagenyi, et al., 2016).

In South Africa, all male participants reported that the decision to use condoms were up to men. Half of the female participants were unsure who decides to use a condom, and the other half stated that either the man decides or that it was a shared decision, but none said it was entirely the woman's decision (Protogerou, et al., 2014). It was often difficult for women to persuade men to use a condom, if they mentioned it at all. On the contrary, male respondents claimed that condom use had become a habit. This attitude may have been influenced by their high educational levels and urban residence where attitudes and access to condoms are optimal (Hargreaves, et al., 2008). These conflicting accounts between men and women suggest that South Africa is likely in a state of transition where the status of women is elevating, yet some social confusion still exist. Furthermore, some female respondents felt that they were mismatched with their partners in terms of age, educational level, cultural background, life goals and residence (rural/urban and/or different province). Thus, gender imbalances may possibly also be influenced by additional imbalances (Chimbindi, et al., 2010). Participants also cited that men feared strong, empowered women and would therefore feel intimidated by a woman who carried a condom around (Protogerou, et al., 2014). 
Finally, domestic violence was cited as a reason for increased contraceptive uptake in South Africa, but nonuse in Uganda. In South Africa, four female participants reported experiencing intimate partner violence, with one being physical violence, leading to increased condom use and precaution due to lack of trust (Protogerou, et al., 2014). In Uganda, some women feared domestic violence as a result of not producing enough children or using contraceptives without the husband's approval (Heise \& Garcia-Moreno, 2002; Kabagenyi, et al., 2016; Kwagala, et al., 2013). In such patriarchal societies, women's obedience to husbands is highly regarded resulting in poor spousal communication, particularly in relation to family planning (Bawah, 2002; Kulczycki, 2008).

Several studies suggest that increasing male knowledge of family planning could increase spousal communication, therefore increasing the odds of couples using contraceptives through joint decision-making (Flemming, et al., 2018; Hartmann, et al., 2012; Lutalo, et al., 2018; Mosha, et al., 2013; Olakunde, et al., 2019; Sharan \& Valente, 2002). Changing attitudes towards gender equality can increase contraceptive uptake, thus reducing fertility in the long-term.

\subsubsection{Social Status}

Social status was mentioned as a motivator for high fertility in Nigeria and Tanzania, and is reported by other studies across Sub-Saharan Africa. Culturally, and in a highly patriarchal setting, having many children brings men high esteem among their peers. Men with many children were regarded as powerful, proud and respected in the community (Alemayehu, et al., 2012; Shattuck, et al., 2016). Those who practice contraception and have few children are seen as weak and submissive to women (Pallangyo, et al., 2020; Sinai, et al., 2019). Furthermore, large families symbolise fame, respect and wealth, and serve to expand men and women's social networks and potentially elevate families up the social hierarchy. In addition, some of the many children could potentially marry into wealthy and powerful households, bringing parents wealth and social standing (Izugbara \& Ezeh, 2010). Children are seen as assets for future wealth, labour and social support (Adongo, et al., 2014; Msoka, et al., 2019). Therefore, social status is one component in high fertility and low contraceptive use.

\subsubsection{General Attitudes and Social Stigma}

Stigma associated with the uptake of contraception and premarital sex was reported in Malawi, Nigeria and Tanzania. This stigmatisation leaves women unwilling to obtain contraception, resulting in undesired high fertility. In Northwest Nigeria (Adefalu, et al., 2019), with the exception of one area (Sokoto South), unmarried women were less comfortable obtaining family planning due to the social stigma attached. Women who use contraception are viewed as promiscuous (Ankomah, et al., 2013; Sinai, et al., 2019; Ujuju, et al., 2011) and men who let their wives use contraception are considered weak (Ankomah, et al., 2013; Sinai, et al., 2019). Kok, et al. (2020) found the same attitudes present among young people, particularly young women, in Malawi. Tanzanian men expressed fear that contraceptive use would promote promiscuity among their female partners (Mwageni, et al., 1998; Sundararajan, et al., 2019). This association between contraceptives and promiscuity is reported in studies done by Adongo, et al. (2014) and Ochako, et al. (2015) who reported similar 
findings in other African settings. Sokoto South was the only area in the study in Nigeria where respondents felt that there was no social stigma attached to unmarried women obtaining family planning (Adefalu, et al., 2019). This could be attributed to knowledge of family planning among the population there.

Despite the overall view that women who use contraceptives are promiscuous, many women in Nigeria considered such women to be smart and courageous, suggesting that women's ideations are gradually changing and society is evolving (Sinai, et al., 2019).

\subsubsection{Financial Constraints and Security}

Economical motives were mentioned in Malawi, Tanzania and Nigeria as reasons for both increasing and limiting fertility. In Nigeria and Tanzania, respondents reported financial security as a reason for high fertility and lower contraceptive uptake. Having many children provides financial security and labour for the future (Msoka, et al., 2019; Rhine, 2009; Sinai, et al., 2019), in addition to security and care for parents in their old age (Adongo, et al., 2014; Izugbara \& Ezeh, 2010).

However, financial constraints were reported considerably more often in all three countries as reasons for limiting fertility and using contraceptives. Despite the influences of wanting to have many children, most women did not support unregulated childbearing and understood the consequences of high fertility (Duze \& Mohamed, 2006). Respondents stated that having many children is costly and keeps women stuck in poverty (Kok, et al., 2020). High fertility also causes stress on men as breadwinners of the family (Sundararajan, et al., 2019). Having fewer children would be easier financially (Msoka, et al., 2019), improve hygiene standards, quality of life and opportunities available for the children (Akinyemi, et al., 2020; Izugbara \& Ezeh, 2010; Pallangyo, et al., 2020). Perceptions across Africa are gradually changing and people are beginning to realise that it is difficult to support many children and are therefore open to contraceptive use (Sinai, et al., 2019). This perception is echoed in other African countries (Ajayi, et al., 2018; Bunce, et al., 2007; Lanham, et al., 2014) and across Christians and Muslims (Sundararajan, et al., 2019). In spite of this motive and knowledge of modern contraceptives, use of modern methods is still reportedly low across Sub-Saharan Africa, where the preference for traditional and unconventional methods is still high (Ajayi, et al., 2018; Asare, et al., 2017).

\subsubsection{Misconceptions}

Misconceptions of contraceptives were reported in Malawi, Nigeria, Tanzania, Somalia and Uganda. Misconceptions included perceived side effects of modern contraceptive methods such as prolonged bleeding, birth deformities, infertility, miscarriage, cancer and bodily pains (Kabagenyi, et al., 2016; Sinai, et al., 2019; Sundararajan, et al., 2019; Ujuju, et al., 2011). Hormonal methods were thought to cause dizziness, lack of sexual libido, and impromptu bleeding (Kabagenyi, et al., 2016). These perceived side effects were also reported in other studies across Sub-Saharan Africa (Audu, et al., 2008; Mosha, et al., 2013; Nalwadda, et al., 2010; Olakunde, et al., 2019; Otoide, et al., 2001; Thummalachetty, et al., 2017). In Nigeria and Tanzania, the source of this information was often from family and friends rather than from health facilities (Aristide, et al., 2020; Sinai, et al., 2019), and enforced by some political and religious campaigns against modern methods (Izugbara \& Ezeh, 2010). 
In Nigeria and Uganda, folkloric methods believed to regulate fertility were preferred over modern methods due to fear of perceived side effects (Kabagenyi, et al., 2016; Prata, 2009; Sadat-Hashemi, et al., 2007). Folkloric methods include tying an umbilical cord or traditional herbs around the waist or inserting them into the woman's vagina, mixing of herbs with a woman's menstrual blood, and drinking concoctions (Izugbara \& Ezeh, 2010; Kabagenyi, et al., 2016; Sinai, et al., 2019). Information about these methods was circulated by religious and traditional leaders, as well as by men and women in the community (Sinai, et al., 2019).

Other misconceptions included perceived reduced sexual satisfaction and performance from condoms (Chipeta, et al., 2010; Kriel, et al., 2019; Msoka, et al., 2019; Ujuju, et al., 2011), the belief that women are born with a limited number of eggs and that they must give birth to all the eggs or the remaining eggs will make them ill (Sinai, et al., 2019; Sundararajan, et al., 2019), and that only pre-ejaculate liquids could make them pregnant (Sinai, et al., 2019).

In Malawi, health care providers mainly targeted women with existing knowledge and assisted them with covert use of contraceptives (Kok, et al., 2020), in particular Depo Provera which is the most preferred method for secret use (Bisika, 2008), likely contributing to persisting misconceptions. Health care providers need to be trained in communicating to all clients about the benefits of family planning, providing accurate information, involving male partners and contraceptive provision to unmarried youth (Kok, et al., 2020).

These misconceptions among the populations create a negative perception of modern methods and form the belief that modern methods are harmful causing users to resort to folkloric methods which do not work. Misconceptions about traditional and natural methods renders these methods in effective (e.g. the belief that only pre-ejaculate liquids causes pregnancy makes the withdrawal method ineffective). Thus, persistent misconceptions result in unplanned pregnancies, and ultimately high fertility. It is important that communities are educated with accurate information on family planning and that modern methods are easily accessible.

\subsubsection{Summary of Qualitative Studies}

To summarise, quotes from focus group discussions and in-depth interviews reveal views and opinions of the respondents that were not identified in the quantitative studies. Views on religion were mentioned the most in relation to fertility and contraceptive use. The qualitative studies strongly suggest that religion/religiosity can increase fertility, but also demonstrate mixed views on the influence of religion on fertility and contraceptive use. While some respondents strongly believed family planning and limiting fertility was forbidden in their religion, some felt religion did not influence their decision, while others felt conflicted on the issue. Stronger religiosity is associated with less contraceptive uptake, or hesitation. A religion's stance on fertility and family planning plays an influential role. Among Muslims, family planning is acceptable for spacing births, but not for limiting family size. Economic constraints also influenced contraceptive uptake, regardless of religion. Polygyny, commonly practiced in Islam and also occurs in Christianity, was associated with lower contraceptive use and high fertility in which co-wives bore more children to compete for a higher share of their husband's attention and financial wealth, and to prevent husbands from divorcing them or taking on additional wives. Contrastingly, however, some women mentioned that limiting fertility was their strategy of staying attractive to prevent husbands from straying. Ultimately, religious leaders can strongly influence a 
community and spread messages on family planning that could potentially impact fertility and contraceptive behaviour.

Additionally, gender attitudes were identified as a barrier to contraceptive uptake with respondents frequently citing that men were the sole decision-makers of the household and women did not have much say in their choice for contraceptive use, despite family planning and child upbringing being seen as women's issues and responsibilities. In many cases, men prohibited contraceptive use as men with many children were respected in the community and viewed as powerful, proud and rich. Furthermore, modern contraceptives were stigmatised in the community and women who used contraceptives were viewed as promiscuous.

Finally, misconceptions of modern contraceptives were associated with lower contraceptive uptake. Many believed that modern methods cause prolonged bleeding, birth deformities, infertility, miscarriage, cancer and bodily pains, and would therefore resort to folkloric methods, which do not work, resulting in unplanned pregnancies and high fertility. Misconceptions were often circulated by religious and traditional leaders, as well as by men and women in the community. It is important that communities are educated with accurate information on family planning and that modern methods are easily accessible. Religious leaders and health care providers can spread messages about the benefits of family planning and provide accurate information, removing any stigma attached. Increasing male knowledge of family planning and changing attitudes towards gender equality can increase contraceptive uptake, thus reducing fertility in the long-term. 


\section{Conclusion and Implications}

This review explored and sought to clarify the role of religion and religiosity on fertility and contraceptive use in continental Sub-Saharan African countries. The review of quantitative and qualitative publications shows that followers of African Indigenous Religions and Islam have higher fertility rates than followers of Christianity. Across Christian denominations, Catholics generally had higher fertility than Protestants although the difference is small and inconsistent within and across countries. This may be attributed to the broad groupings of religions in DHS surveys and other study methods, thus eliminating specific characteristics that may explain fertility differences across religious denominations. Followers of the Apostolic Church exhibited the highest fertility among Christian groups. The findings clearly suggest that religion influences fertility and contraceptive use, though deviations exist in some countries. Although one qualitative study explored religiosity, interpretations of the respondents' quotes from focus group discussions and in-depth interviews offered some idea of their level of religiosity. Existing results suggest that across Sub-Saharan Africa, fertility increases with degree of religiosity, and decreases with contraceptive use (Akinyemi, et al., 2020; Götmark \& Andersson, 2020). Focus group discussions and in-depth interviews suggest that these relationships are stronger in Islam compared with Christianity, although highly religious Christian respondents were also noted. However, there were no indications for degree of religiosity for African Indigenous Religions, thus this could not be determined. A religion's stance on fertility and family planning as well as interpretations of religious teachings play a powerful role. Religious leaders across all religions were found to be highly influential and many participants were inclined to follow the recommendations of religious leaders regarding fertility and contraceptive use.

In addition, other important socioeconomic and cultural factors influence fertility and contraceptive use. Education, economy, gender equality and access to family planning have a negative association with religiosity, but the strength of this association varies depending on religion, residence and region, with Muslims (particularly those residing in rural areas) generally reported as the most disadvantaged in terms of levels of education and wealth across Sub-Saharan Africa (Heaton, 2011). Furthermore, fertility was generally low across predominantly Christian Southern Africa in which its nations have the highest levels of education across the continent for both men and women (Garenne, 2012). Religion and religiosity have an important role to play in relation to fertility and contraceptive use, but they also depend on other factors, their interactions and their relative influences. They have variable relationships to education, economy, gender equality, residence (rural/urban) and access to family planning due to the different levels of these factors among and within countries in Sub-Saharan Africa. Overall, these findings agreed with my expectations from the research questions.

These results have significant implications for long-term changes in the future relative size and composition of religious groups in Sub-Saharan Africa, as has been emphasised by Pew Research Centre (2010) and Heaton (2011). Higher fertility growth is anticipated among rural, poor and less educated Muslims relative to other religious groups. This difference will add to the challenge of improving educational opportunities and family planning for Muslim populations (Garenne, 2012; Heaton, 2011). Religions with higher fertility increase their share of the population, thus, unless attitudes towards and preferences for higher fertility are changed, population size will continue to drastically increase, exacerbating the devastating impact that overpopulation has on the planet, for both the environment and on humans. 
Presently, occasionally priests and some denominations across Sub-Saharan Africa raise their voices and emphasise the need for family planning services and access to contraception (Shaikh, et al., 2013; Shea, et al., 1971). But the implication of the findings from the review is that reaching out to and educating religious leaders about family planning and its benefits should be part of a comprehensive strategy to increase contraceptive uptake and reduce fertility. With this knowledge, religious leaders will spread accurate messages about family planning to their followers, promoting higher contraceptive use. Hopefully, this improves the situation for many women, and help reduce the currently high fertility in Sub-Saharan Africa.

The recommendations I provide are in accordance with the limitations encountered in this review (Section 4). First, for a broad picture of Sub-Saharan Africa, more research needs to be conducted in countries with no or few studies on religion, religiosity, fertility and contraceptive use. Furthermore, as observed in this review, fertility and contraceptive behaviours can differ also between areas within a country. Therefore, more research needs to be conducted in specific areas where studies are lacking. Second, religiosity needs to be considered in studies that involve religion. Surveys, including DHS surveys, should incorporate a question related to religiosity. This could be frequency of attendance of place of worship and/or a scale on the importance of religion in everyday life. Third, specific religions should not be lumped together (e.g. Shias, Sunnis, Pentecostals, etc.) as distinctions in fertility and contraceptive behaviour may be lost. Finally, sample populations need to be expanded to include men and unmarried women.

Religious leaders need to be approached, informed and educated about family planning services and their benefits so that they will spread accurate messages about family planning to their followers, and promote higher contraceptive use and low fertility. With a more religiously open stance towards family planning, population policies can be more easily implemented. Religion and religiosity need to be considered in surveys and studies on fertility and contraceptive use to inform and help policymakers, economic planners, program managers, researchers and survey specialists. In addition, this has the potential to improve environmental conditions in Sub-Saharan Africa. 


\section{References}

1. Abdi, B. Okal, J., Serour, G. \& Temmerman, M. Muslim Men's Perceptions and Attitudes on Family Planning: A Qualitative Study in Wajir and Lamu Counties in Kenya. Sexual and Reproductive Health Matters 29(1), 1-11 (2021).

2. Abdi, B., Okal, J., Serour, G. \& Temmerman, M. "Children are a Blessing from God" - A Qualitative Study Exploring the Socio-Cultural Factors Influencing Contraceptive Use in Two Muslim Communities in Kenya. Reproductive Health 17(44) (2020).

3. Adebowale, S. A. \& Palamuleni, M. E. Influence of Gender Preference and Sex Composition of Surviving Children on Childbearing Intention Among High Fertility Married Women in Stable Union in Malawi. African Health Studies 15(1), 150-160 (2015).

4. Adebowale, S. A., Adeoye, I. A. \& Palamuleni, M. E. Contraceptive Use Among Nigerian Women With No Fertility Intention: Interaction Amid Potential Causative Factors. Etude de la Population Africaine 27(2), 127 (2013).

5. Adedokun, L. A. National Survey of Fertility and Family Planning, Phase 1, Southwest Nigeria. 40-41 (Demographic Statistical Survey (DSS) Monograph No. 1 [1973-1975], 1979).

6. Adefalu, A. A., Ladipo, O. A., Akinyemi, O. O., Popoola, O. A., Latunji, O. O. \& Iyanda, O. Qualitative Exploration of Factors Affecting Uptake and Demand for Contraception and Other Family Planning Services in North-West Nigeria. African Journal of Reproductive Health 23(4), 63-74 (2019).

7. Adeleye O. A. \& Okonkwo C. A. Ideal Child Gender Preference in Men's Worldview and Their Knowledge of Related Maternal Mortality Indices in Ekiadolor, Southern Nigeria. Asian Journal of Medical Sciences 2(3), 146-151 (2010).

8. Adhikari, R., Soonthorndhada, K. \& Prasartkul, P. Correlates of Unintended Pregnancy Among Currently Pregnant Married Women in Nepal. BMC International Health and Human Rights 9(1), 17 (2009).

9. Adiri, F., Ibrahim, H. I., Ajayi, V., Sulayman, H. U., Yafeh, A. M. \& Ejembi, C. L. Fertility Behaviour of Men and Women in Three Communities in Kaduna State, Nigeria. African Journal of Reproductive Health 14(3), 97-105 (2010).

10. Adongo, P., Tapsoba, P., Phillips, J., Tabong, P., Stone, A. \& Kuffour, E. If You Do Vasectomy and Come Back Here Weak, I Will Divorce You: A Qualitative Study of Community Perceptions About Vasectomy in Southern Ghana. BMC International Health and Human Rights 14(1), (2014).

11. Adongo, P. B., Phillips, J. F. \& Binka, F. N. The Influence of Traditional Religion on Fertility Regulation Among the Kassena-Nankana of Northern Ghana. Studies in Family Planning 29(1), 23-40 (1998).

12. Afifi, M. Lactational Amenorrhoea and Modern Contraceptives Use Among Nursing Women in Egypt, 2003. Oman Medical Journal 23, 72-77 (2008).

13. Agadjanian, V. \& Yabiku, S. T. Religious Affiliation and Fertility in a Sub-Saharan Context: Dynamic and Lifetime Perspectives. Population Research and Policy Review 33, 673-691 (2014).

14. Agyei-Mensah, S. \& Owoo, N. S. Explaining Regional Fertility Variations in Ghana. Journal of Population Research 32, 157-172 (2015).

15. Ajayi, I., Adeniyi, O. \& Akpan, W. Use of Traditional and Modern Contraceptives Among Childbearing Women: Findings from a Mixed Methods Study in Two Southwestern Nigerian States. BMC Public Health 18, 604 (2018).

16. Akintunde, M. O., Lawal, M. O. \& Simeon, O. Religious Roles in Fertility Behaviour Among the Residents of Akinyele Local Government, Oyo State, Nigeria. International Journal of Economy, Management and Social Sciences 2, 455462 (2013).

17. Akinyemi, O. O., Harris, B. \& Kawonga, M. "Our Culture Prohibits Some Things": Qualitative Inquiry into How Sociocultural Context Influences the Scale-Up of Community-Based Injectable Contraceptives in Nigeria. BMJ Open 10 (2020).

18. Akpor, O., Fadare, R. \& Ekanem, E. Knowledge and Perception of Women Regarding Bilateral Tubal Ligation in Southwest Nigeria. IOSR Journal of Nursing and Health Science 5(5), 31-36 (2016).

19. Al-Mujtaba, M., Cornelius, L. J., Galadanci, H., Erekaha, S. Okundaye, J. N., Adeyemi, O. A. \& Sam-Agudu. N. A. Evaluating Religious Influences on the Utilisation of Maternal Health Services Among Muslim and Christian Women in North-Central Nigeria. Biomed Research International (2016). 
20. Alemayehu, M., Belachew, T. \& Tilahun, T. Factors Associated with Utilization of Long Acting and Permanent Contraceptive Methods Among Married Women of Reproductive Age in Mekelle Town, Tigray Region, North Ethiopia. BMC Pregnancy and Childbirth 12(1), 6 (2012).

21. Angeles, L. Demographic Transitions: Analysing the Effects of Mortality on Fertility. Journal of Population Economics 23, 99-120 (2010).

22. Ankomah, A., Anyanti, J., Adebayo, S. \& Giwa, A. Barriers to Contraceptive Use Among Married Young Adults in Nigeria: A Qualitative Study. International Journal of Tropical Disease \& Health 3(3), 267-282 (2013).

23. Aristide, C., Mwakisole, A., Mwakisole, N., Emmanuel, M., Laizer, E., Kihunrwa, A., Downs, D., Wamoyi, J. \& Downs, J. Design and Pilot Testing of a Church-Based Intervention to Address Interpersonal and Intrapersonal Barriers to Uptake of Family Planning in Rural Tanzania: A Qualitative Implementation Study. BMJ Sexual \& Reproductive Health 46, 226-233 (2020).

24. Arowolo, O. O. Determination of Fertility Among Yorubas of Nigeria: An Empirical Finding on Fertility in Korea, Nigeria, Tunisia, Venezuela and the Philippines. (Occasional Monograph Series No. 7, 1973).

25. Asare, O., Otupiri, E., Apenkwa, J. \& Odotei-Adjei, R. Perspectives of Urban Ghanaian Women on Vasectomy. Reproductive Health 14(21) (2017).

26. Atighetchi, D. The Position of Islamic Tradition on Contraception. Medical Law 13(7-8), 717-725 (1994).

27. Audu, B. M., Yahya, S., Geidam, A., Abdussalam, H., Takai, I. \& Kyari, O. Polygamy and the Use of Contraceptives. International Journal of Gynecology \& Obstetrics 101(1), 88-92 (2008).

28. Audu B. M., El-Nafaty, A. U., Bako, B. G., Melah, G. S, Mairiga, A. G \& Kullima, A. A. Attitude of Nigerian Women to Contraceptive Use by Men. Journal of Obstetrics and Gynaecology 28(6), 621-625 (2008).

29. Avogo, W. \& Agadjanian V. Men's Social Networks and Contraception in Ghana. Journal of Biosocial Science 40(3), 413-429 (2008).

30. Babalola, S., Oyenubi, O., Speizer, I. S., Cobb, L., Akiode, A. \& Odeku, M. Factors Affecting the Achievement of Fertility Intentions in Urban Nigeria: Analysis of Longitudinal Data. BMC Public Health 17(942) (2017).

31. Bankole, A. \& Singh, S. Couples' Fertility and Contraceptive Decision-Making in Developing Countries: Hearing the Man's Voice. International Family Planning Perspectives 24(1), 15-24 (1998).

32. Bawa, A. B. Muslim Women and Sharia Implementation in Northern Nigeria: An Overview of Fomwan. Unizik Journal of Arts and Humanities 18(1), 149-167 (2017).

33. Bawah, A. A. Spousal Communication and Family Planning Behaviour in Navrongo: A Longitudinal Assessment. Studies in Family Planning 33(2), 185-194 (2002).

34. Berry, L. B. Ghana: A Country Study. (GPO for the Library of Congress, 1994).

35. Beyers, J. What is Religion? An African Understanding. Theological Studies 66(1) (2010).

36. Bisika, T. Cultural Factors that Affect Sexual and Reproductive Health in Malawi. BMJ Sexual and Reproductive Health 34(2),79-80 (2008).

37. Blackstone, S. R., Nwaozuru, U. \& Iwelunmor, J. Factors Influencing Contraceptive Use in Sub-Saharan Africa: A Systematic Review. International Quarterly of Community Health Education 37(2), 79-91 (2017).

38. Bongaarts, J. Slow Down Population Growth. Nature 530, 409-412 (2016).

39. Bouvier, L. F. Catholics and Contraception. Journal of Marriage and Family 34(3), 514-522 (1972).

40. Budhwani, H, Anderson, J. \& Hearld, K. R. Muslim Women's Use of Contraception in the United States. Reproductive Health 15(1) (2018).

41. Bunce, A., Guest, G., Searing, H., Frajzyngier, V., Riwa, P., Kanama, J. \& Achwal, I. Factors Affecting Vasectomy Acceptability in Tanzania. International Family Planning Perspectives 33(1), 13-21 (2007).

42. Cahu, P., Fall, F. \& Pongou, R. Demographic Transition in Africa: The Polygyny and Fertility Nexus in Explaining Fertility Differences in Sub-Saharan Africa: Projecting the Demographic Future (eds. Mturi, A. J. \& Agyei-Mensah, S.). 95-168 (The Edwin Mellen Press, 2014).

43. Cahu, P., Fall, F. \& Pongou, R. Demographic Transition in Africa: The Polygyny and Fertility Nexus. (2011).

44. Caldwell, J. C. \& Caldwell, P. High Fertility in Sub-Saharan Africa. Scientific American 262(5), 118-125 (1990).

45. Caldwell, J. C. \& Caldwell, P. The Cultural Context of High Fertility in Sub-Saharan Africa. Population and Development Review 13(3), 409-437 (1987). 
46. Canning, D., Raja, S. \& Yazbeck, A. S. Africa's Demographic Transition: Dividend or Disaster? (The World Bank, 2015).

47. Centre for Reproductive Rights. Women of the World: Zimbabwe. (2013).

48. Chai, B. P. \& Nam-Hoon, C. Consequences of Son Preference in a Low-Fertility Society: Imbalance of the Sex Ratio at Birth in Korea. Population and Development Review 21(1) (1995).

49. Chamie, J. Religion and Fertility: Arab Christian-Muslim Differentials. (Cambridge University Press, 1981).

50. Chemhaka, G. B. \& Odimegwu, C. Individual and Community Factors Associated with Lifetime Fertility in Eswatini: An Application of the Easterlin-Crimmins Model. Journal of Population Research 37, 291-322 (2020).

51. Chimbindi, N. Z., McGrath, N., Herbst, K., Tint, K. S. \& Newell, M. L. Socio-Demographic Determinants of Condom Use Among Sexually Active Young Adults in Rural KwaZulu-Natal, South Africa. The Open AIDS Journal 4(1), 88-95 (2010).

52. Chipeta, E. K., Chimwaza, W. \& Kalilani-Phiri, L. Contraceptive Knowledge, Beliefs and Attitudes in Rural Malawi: Misinformation, Misbeliefs and Misperceptions. Malawi Medical Journal 22(2), 38-41 (2010).

53. Committee on the Elimination of Discrimination Against Women (CEDAW). Concluding Observations: Nigeria. (2008).

54. Committee on the Rights of the Child (CRC). Concluding Observations: Nigeria. (1995).

55. Croft, T. N., Marshall, A. M. J. \& Allen, C. K. Guide to DHS Statistics. (ICF International, 2018).

56. Davidson, A. S., Fabiyi, C., Demissie, S., Getachew, H. \& Gilliam, M. L. Is LARC for Everyone? A Qualitative Study of Sociocultural Perceptions of Family Planning and Contraception Among Refugees in Ethiopia. Journal of Maternal and Child Health 21, 1699-1705 (2017).

57. De Silva, W. I. Achievement of Reproductive Intentions in Sri Lanka, 1982-1985: A Longitudinal Study. Journal de la Société de Biologie 39(1-2), 123-38 (1992).

58. Degni, F., Koivusilta, L. \& Ojanlatva, A. Attitudes Towards and Perceptions About Contraceptive Use Among Married Refugee Women of Somali Descent Living in Finland. The European Journal of Contraception and Reproductive Health Care 11, 190-196 (2006).

59. Deuraseh, N. Is Birth Control Permissible by Islamic Law (Sharia)? Arab Law Quarterly 18(1), $90-97$ (2003).

60. Doctor, H. V., Phillips J. F. \& Sakeah E. The Influence of Changes in Women's Religious Affiliation on Contraceptive Use and Fertility Among the Kassena-Nankana of Northern Ghana. Studies in Family Planning 40(2), 113-122 (2009).

61. Dodoo, F. N. A. \& Seal, A. Explaining Spousal Differences in Reproductive Preferences: A Gender Inequality Approach. Population and Environment 15(5), 379-94 (1994).

62. Dodzo, M. K., Mhloyi, M., Moyo, S. \& Dodzo-Masawi, M. Praying Until Death: Apostolicism, Delays and Maternal Mortality in Zimbabwe. PLoS ONE 11(8) (2016).

63. Downs, J. A., Fuunay, L. D., Fuunay, M., Mbago, M., Mwakisole, A., Peck, R. N. \& Downs, D. J. "The Body We Leave Behind": A Qualitative Study of Obstacles and Opportunities for Increasing Uptake of Male Circumcision Among Tanzanian Christians. BMJ Open 3, (2013).

64. Downs, J. A., Mwakisole, A. H., Chandika, A. B., Lugoba, S., Kassim, R., Laizer, E., Magambo, K. A., Lee, M. H., Kalluvya, S. E., Downs, D. J. \& Fitzgerald, D. W. Educating Religious Leaders to Promote Uptake of Male Circumcision in Tanzania: A Cluster Randomised Trial. The Lancet 389, 1124-1132 (2017).

65. Dral, A. A., Tolani, M. R., Smet, E. \& van Luijn, A. Factors Influencing Male Involvement in Family Planning in Ntchisi District, Malawi: A Qualitative Study. African Journal of Reproductive Health 22(4), 35-43 (2018).

66. Dubiwak, R. \& Seme, A. Contraceptive Method Choice and Use by Married Women of Reproductive Age in Two Districts of East Harerge. Ethiopian Medical Journal 52(1), 27-35 (2014).

67. Duze, M. C. \& Mohamed, I. Z. Male Knowledge, Attitudes and Family Planning Practices in Northern Nigeria. African Journal of Reproductive Health 10(3), 53-65 (2006).

68. Dynes, M. M., Bernstein, E., Morof, D., Kelly, L., Ruiz, A., Mongo, W., Chaote, P., Bujari, R. N. \& Serbanescu, F. Client and Provider Factors Associated with Integration of Family Planning Services Among Maternal and Reproductive Health Clients in Kigoma Region, Tanzania: A Cross-Sectional Study, April-July 2016. Reproductive Health 15(152) (2018). 
69. Egeh, A. A., Dugsieh, O., Erlandsson, K. \& Osman, F. The Views of Somali Religious Leaders on Birth Spacing: A Qualitative Study. Sexual \& Reproductive Healthcare 20, 27-31 (2019).

70. Ejembi, C. L., Alti-Muazu, M., Chirdan, O., Ezeh, H. O., Sheidu, S. \& Dahiru, T. Utilisation of Maternal Health Services by Rural Hausa Women in Zaria Environs, Northern Nigeria: Has Primary Health Care Made a Difference? Journal of Community Medicine and Primary Health Care 16, 47-54 (2004).

71. Ejembi, C. L., Dahiru, T. \& Aliyu, A. A. DHS Working Papers, No. 120: Contextual Factors Influencing Modern Contraceptive Use in Nigeria. (ICF International, 2015).

72. Ekpenyong, C. E., Daniel, N. E., Uwah, A. F., Ettebong, E. O. \& Ibu, J. O. Lactational Amenorrhoea Method of Contraception: An In-Depth Study of Awareness, Knowledge and Practice by Breastfeeding Mothers with Unintended Pregnancies. International Journal of Medicine and Medical Sciences 5(1), 6-13 (2013).

73. Ezeh, A. C. Polygyny and Reproductive Behaviour in Sub-Saharan Africa: A Contextual Analysis. Demography 34(3), 355-368 (1997).

74. Faramade, I. O. Religious Sects and Fertility Preference in Socioeconomic and Behavioural Factors Affecting Ethnic Mortality (ed. Eniola, O. H.). 151-167 (Broderick Publishers Ltd., 2006).

75. Farmer, D. B., Berman, L., Ryan, G., Habumugisha, L., Basinga, P., Nutt, C., Kamali, F., Ngizwenayo, E., Fleur, J. S., Niyigena, P., Ngabo, F., Farmer, P. E. \& Rich, M. L. Motivations and Constraints to Family Planning: A Qualitative Study in Rwanda's Southern Kayonza District. Global Health: Science and Practice 3, 242-254 (2015).

76. Femininity, K. M. Sexuality and Culture: Patriarchy and Female Subordination in Zimbabwe. (ARSRC, 2006).

77. Fenske, J. African Polygamy: Past and Present [Working Paper]. (Centre for the Study of African Economies, 2013).

78. Fleming, P. J., Silverman, J., Ghule, M., Ritter, J., Battala, M., Velhal, G., Nair, S., Dasgupta, A., Donta, B., Saggurti, N. \& Raj, A. Can a Gender Equity and Family Planning Intervention for Men Change Their Gender Ideology? Results from the CHARM Intervention in Rural India. Studies in Family Planning 49, 41-56 (2018).

79. Florence, N. Bukusu (Kenya) Folktales: How Women Perpetuate Patriarchy. International Feminist Journal of Politics 15(3), 370-390 (2013).

80. Foley, F. E. Overlaps and Disconnects in Reproductive Health Care: Global Policies, National Programs and the Micro-Politics of Fertility and Contraceptive Use in Northern Senegal. Medical Anthropology 26(4), 323-354 (2007).

81. Foley, F. E. In Sickness and in Health: Responding to Disease and Promoting Health in Senegal. Doctoral Dissertation (Michigan State University, 2001).

82. Foreman, D. \& Carroll, L. Man Swarm: How Overpopulation is Killing the Wild World (2 ${ }^{\text {nd }}$ Edition). (LiveTrue Books, 2014).

83. Frajzyngier, V., Bunce, A., Lusiola, G., Searing, H., Riwa, P., Guest, G., \& Achwal, I. Factors Affecting Vasectomy Acceptability in the Kigoma Region of Tanzania. (The Acquire Project, 2006).

84. Garenne, M. DHS Analytical Studies, No. 33: Education and Fertility in Sub-Saharan Africa - A Longitudinal Perspective. (ICF International, 2012).

85. Gasca, N. C. \& Becker, S. Using Couples' Discordant Reports to Estimate Female Covert Use of Modern Contraception in Sub-Saharan Africa. Journal of Biosocial Science 50, 326-346 (2018).

86. Gebrelibanos, T. B. The Tigrean Women in the Liberation Struggle and Its Aftermath, 1975-1996: Research Report on Gender Issues. (OSSREA, 1999).

87. Global Commission on HIV and the Law. Risks, Rights and Health. (United Nations Development Programme, 2012).

88. Goodson, P. Protestants and Family Planning. Journal of Religion and Health 36(4), 353-366 (1997).

89. Götmark, F. \& Andersson, M. Human Fertility in Relation to Education, Economy, Religion, Contraception and Family Planning Programs. BMC Public Health 20, 265 (2020). https://doi.org/10.1186/s12889-020-8331-7

90. Grillo, L. S., van Klinken, A. \& Ndzovu, H. J. Religions in Contemporary Africa: An Introduction. (Routledge, 2019).

91. Gurmu, E. \& Mace, R. Fertility Decline Driven by Poverty: The Case of Addis Ababa, Ethiopia. Journal of Biosocial Science 40(3), 339-358 (2008).

92. Hargreaves, J. R., Bonell, C. P., Boler, T., Boccia, D., Birdthistle, I., Fletcher, A., Pronyk, P. M. \& Glynn, J. R. Systematic Review Exploring Time Trends in the Association Between Educational Attainment and Risk of HIV Infection in SubSaharan Africa. AIDS 22(3), 403-414 (2008). 
93. Harrington, E. K., Dworkin, S., Withers, M., Onono, M., Kwena, Z. \& Newmann, S. J. Gendered Power Dynamics and Women's Negotiation of Family Planning in a High HIV Prevalence Setting: A Qualitative Study of Couples in Western Kenya. Culture, Health \& Sexuality 18, 453-469 (2016).

94. Hartmann, M., Gilles, K., Shattuck, D., Kerner, B. \& Guest, G. Changes in Couples' Communication as a Result of a Male-Involvement Family Planning Intervention. Journal of Health Communication 17, 802-819 (2012).

95. Heaton, T. B. Does Religion Influence Fertility in Developing Countries? Population Research and Policy Review 30, 449-465 (2011).

96. Heaton, T. B. \& Darkwah, A. Religious Differences in Modernization of the Family: Family Demographics Trends in Ghana. Journal of Family Issues 32(12), 1576-1596 (2011).

97. Heise, L. \& Garcia-Moreno, C. Violence by Intimate Partners. (World Health Organisation, 2002).

98. Hubert, C., White, K., Hopkins, K., Grossman, D. \& Potter, J. E. Perceived Interest in Vasectomy Among Latina Women and Their Partners in a Community with Limited Access to Female Sterilisation. Journal of Health Care for the Poor and Underserved 27(2), 762-777 (2016).

99. Ibeji, J. U., Zewotir, T., North, D. \& Amusa, L. Modelling Fertility Levels in Nigeria Using Generalized Poisson Regression-Based Approach. Scientific African 9 (2020).

100. Ignaciuk, A. \& Kelly, L. Contraception and Catholicism in the Twentieth Century: Transnational Perspectives on Expert, Activist and Intimate Practices. Medical History 64(2), 163-172 (2020).

101. Izugbara, C. O., Ezeh, A. C. Women and High Fertility in Islamic Northern Nigeria. Studies in Family Planning 41(3), 193-204 (2010).

102. Jensen, A. M. Comparing Family Changes in Two Rural Areas of Kenya: Past Legacies and Present Realities. Development Southern Africa 34(6), 787-801 (2017).

103. Kabagenyi, A., Jennings, L., Reid, A., Nalwadda, G., Ntozi, J., \& Atuyambe, L. Barriers to Male Involvement in Contraceptive Uptake and Reproductive Health Services: A Qualitative Study of Men and Women's Perceptions in Two Rural Districts in Uganda. Reproductive Health Journal 11, 21 (2014).

104. Kabagenyi, A., Reid, A., Ntozi, J. \& Atuyambe, L. Socio-Cultural Inhibitors to Use of Modern Contraceptive Techniques in Rural Uganda: A Qualitative Study. Pan African Medical Journal 25(78) (2016).

105. Kaida, A., Kippi, W., Hessel, P., \& Konde-Lule, J. Male Participation in Family Planning: Results from a Qualitative Study in Mpigi District, Uganda. Journal of Biosocial Science 37, 18 (2005).

106. Kalmijn, M. Status Homogamy in the United States. American Journal of Sociology 97(2), 496-523 (1991).

107. Kalmijn, M. Intermarriage and Homogamy: Causes, Patterns, Trends. Annual Review of Sociology 24, 395-421 (1998).

108. Kaneka, B. \& Mturi, A. J. Young Married Women's Perceptions on the Meanings and Motivations for Their Husbands' Opposition to Their Modern Contraceptive Use in Malawi. Population Horizon 14(1), 9-17 (2017).

109. Keele J. J., Forste R. \& Flake D. F. Hearing Native Voices: Contraceptive Use in Matemwe Village, East Africa. African Journal of Reproductive Health 9(1), 32-41 (2005).

110. Kiura, A. W. Constrained Agency on Contraceptive Use Among Somali Refugee Women in the Kakuma Refugee Camp in Kenya. Gender, Technology and Development 18, 147-61 (2014).

111. Kodzi, I. A., Johnson, D. R. \& Casterline, J. B. Examining the Predictive Value of Fertility Preferences Among Ghanaian Women. Demographic Research 22(30), 965-984 (2010).

112. Kok, M., Tolani, M., Mtonga, W., Salamba, T., Mwabungulu, T., Munthali, A., Smet, E. \& Chinsakaso, B. Enabling and Hindering Factors of Health Surveillance Assistants' Roles in the Provision of Contraceptive Services in Mangochi, Malawi. Reproductive Health 17(57) (2020).

113. Korotayev, A., Zinkina, J., Goldstone, J. \& Shulgin, S. Explaining Current Fertility Dynamics in Tropical Africa from an Anthropological Perspective. Cross-Cultural Research 50(3), 251-280 (2016).

114. Kriel, Y., Milford, C., Cordero, J., Suleman, F., Beksinska, M., Steyn, P. \& Smit, J. A. Male Partner Influence on Family Planning and Contraceptive Use: Perspectives from Community Members and Healthcare Providers in KwaZuluNatal, South Africa. Reproductive Health 16(1), 89 (2019).

115. Kulczycki, A. Husband-Wife Agreement, Power Relations and Contraceptive Use in Turkey. International Family Planning Perspectives 34(3), 127-137 (2008). 
116. Kululanga, L., Sundby, J., Chirwa, E., Malata, A. \& Maluwa, A. Barriers to Husbands' Involvement in Maternal Health Care in a Rural Setting in Malawi: A Qualitative Study. Journal of Research in Nursing and Midwifery 1(1), 1-10 (2012).

117. Kwagala, B., Wandera, S. O., Ndugga, P. \& Kabagenyi, A. Empowerment, Partner's Behaviours and Intimate Partner Physical Violence Among Married Women in Uganda. BMC Public Health 13(1), 1112 (2013).

118. Lanham, M., Wilcher, R., Montgomery, E., Pool, R., Schuler, S., Lenzi, R. \& Friedland, B. Engaging Male Partners in Women's Microbicide Use: Evidence from Clinical Trials and Implications for Future Research and Microbicide Introduction. Journal of the International AIDS Society 17 (2014).

119. Larsen, U. A Comparative Study of the Levels and Differentials of Sterility in Cameroon, Kenya and Sudan in Reproduction and Social Organisation in Sub-Saharan Africa (ed. Lesthaeghe, R. J.). 167-211 (University of California Press, 1989).

120. Lawson D. W. \& Gibson, M. A. Polygynous Marriage and Child Health in Sub-Saharan Africa: What is the Evidence for Harm? Demographic Research S26(6), 177-208 (2018).

121. Lutalo, T., Gray, R., Santelli, J., Guwatudde, D., Brahmbhatt, H., Mathur, S., Serwadda, D., Nalugoda, F. \& Makumbi, F. Unfulfilled Need for Contraception Among Women with Unmet Need but with the Intention to Use Contraception in Rakai, Uganda: A Longitudinal Study. BMC Women's Health 18(1), 60 (2018).

122. Machiyama, K. \& Cleland, J. Insights into Unmet Need in Ghana. (London School of Hygiene and Tropical Medicine, 2013).

123. Maswikwa, B., Richter, L., Kaufman, J. \& Nandi, A. Minimum Marriage Age Laws and the Prevalence of Child Marriage and Adolescent Birth: Evidence from Sub-Saharan Africa. International Perspectives on Sexual and Reproductive Health 41(2), 58-68 (2015).

124. Mberu, M. B. \& Reed, H. E. Understanding Sub-Group Fertility Differentials in Nigeria. Population Review 53(2), 23-46 (2014).

125. McAndrew, S. \& Voas, D. Measuring Religiosity Using Surveys. SQB Topic Overview (2011).

126. McGovern, T., Baumont, M., Fowler, R., Parisi, V., Haerizadeh, S., Williams, E. \& Garbers, S. Association Between Plural Legal Systems and Sexual and Reproductive Health Outcomes for Women and Girls in Nigeria: A State-Level Ecological Study. PLoS ONE 14(10) (2019).

127. McKeown, J. God's Babies: Natalism and Bible Interpretation in Modern America. (Open Book Publishers, 2014).

128. Mjaaland, T. Having Fewer Children Makes It Possible to Educate Them All: An Ethnographic Study of Fertility Decline in North-Western Tigray, Ethiopia. Reproductive Health Matters 22(43), 104-112 (2014).

129. Mohsena, M. \& Kamal, N. Determinants of Contraceptive Use in Bangladesh. Ibrahim Medical College Journal 8, 34-40 (2016).

130. Mosha, I., Ruben, R. \& Kakoko, D. Family Planning Decisions, Perceptions and Gender Dynamics Among Couples in Mwanza, Tanzania: A Qualitative Study. BMC Public Health 13, 523 (2013).

131. Msoka, A. C., Pallangyo, E. S., Brownie, S. \& Holroyd, E. My Husband Will Love Me More if I Give Birth to More Children: Rural Women's Perceptions and Beliefs on Family Planning Services Utilization in a Low Resource Setting. International Journal of Africa Nursing Sciences 10, 152-158 (2019).

132. Muhoza, D. N. The Heterogeneous Effects of Socioeconomic and Cultural Factors on Fertility Preferences: Evidence from Rwanda and Kenya. Journal of Population Research 36, 347-363 (2019).

133. Muhoza, D. N., Broekhuis, A. \& Hooimeijer, P. Variations in Desired Family Size and Excess Fertility in East Africa. International Journal of Population Research (2014).

134. Mungure, E. \& Owaga, P. Family Planning in Tanzania: A Review of National and District Policies and Budgets. (Deutsche Stiftung Weltbevoelkerung [DSW], 2014).

135. Musahara, H. \& Huggins, C. Land Reform, Land Scarcity and Post Conflict Reconstruction: A Case Study of Rwanda in From the Ground Up: Land Rights, Conflict and Peace in Sub-Saharan Africa (eds. Huggins, C. \& Clover, J.). 269346 (Pretoria, 2004).

136. Musallam, B. F. Why Islam Permitted Birth Control. Arab Studies Quarterly 3(2), 181-197 (1981).

137. Mwageni, E. A., Ankomah, A. \& Powell, R. A. Attitudes of Men Towards Family Planning in Mbeya Region, Tanzania: A Rural-Urban Comparison of Qualitative Data. Journal of Biosocial Sciences 30, 381-392 (1998). 
138. Nalwadda, G., Mirembe, F., Byamugisha, J. \& Faxelid, E. Persistent High Fertility in Uganda: Young People Recount Obstacles and Enabling Factors to Use of Contraceptives. BMC Public Health 10, 530 (2010).

139. Nansubuga, E., Ojiambo, S. W. \& Fuseini, K. Who has Higher Fertility: Followers of Mohammed or Jesus? Evidence from Sub-Saharan Africa. International Population Conference (2017).

140. Nations Online Project. Political Map of Africa. https://www.nationsonline.org/oneworld/map/africa-politicalmap.htm (2019).

141. Ndulo, M. African Customary Law, Customs and Women's Rights. 87-120 (Cornell Law Faculty Publications, 2011).

142. Nsanya, M. K., Atchison, C. J., Bottomley, C., Doyle, A. M. \& Kapiga, S. H. Modern Contraceptive Use Among Sexually Active Women Aged 15-19 Years in Northwestern Tanzania: Results from the Adolescent 360 (A360) Baseline Survey. BMJ Open 9(8) (2019).

143. Ntoimo, L. F. C. \& Mutanda, N. Homogamy and Heterogamy in Sub-Saharan Africa: Implications for Couples' Fertility Behaviour. Development Southern Africa 34(6), 670-681 (2017).

144. Nyamhanga, T., Frumence, G., Mwangu, M. \& Hurtig, A. K. We Do Not Do Any Activity Until There is an Outbreak: Barriers to Disease Prevention and Health Promotion at the Community Level in Kongwa District, Tanzania. Global Health Action 7 (2014).

145. Oba, A. A. Religious and Customary Laws in Nigeria. Emory International Law Review 25(2), 881-895 (2011).

146. Obikeze, D. S. Son Preference Among Nigerian Mothers: Its Demographic and Psycho-Social Implications. International Journal of Contemporary Sociology 25(1-2), 55-63 (1988).

147. Ochako, R., Mbondo, M., Aloo, S., Kaimenyi, S., Thompson, R., Temmerman, M. \& Kays, M. Barriers to Modern Contraceptive Methods Uptake Among Young Women in Kenya: A Qualitative Study. BMC Public Health 15(1) (2015).

148. Odusina, E. K., Ayotunde, T., Kunnuji, M., Ononokpono, D. N., Bishwajit, G. \& Yaya, S. Fertility Preferences Among Couples in Nigeria: A Cross-Sectional Study. Reproductive Health 17(92) (2020).

149. Olakunde, B. O., Sam-Agudu, N. A., Patel, T. Y., Hunt, A. T., Buffington, A. M., Phebus, T. D., Onwasigwe, E. \& Ezeanolue, E. E. Uptake of Permanent Contraception Among Women in Sub-Saharan Africa: A Literature Review of Barriers and Facilitators. Contraception 99(4), 205-211 (2019).

150. Omra, P. A. R. Family Planning in the Legacy of Islam. 284 (Routledge, 1992).

151. Otoide, V. O., Oronsaye, F. \& Okonofua, F. E. Why Nigerian Adolescents Seek Abortion Rather than Contraception: Evidence from Focus Group Discussions. International Family Planning Perspectives 27(2), 77-81 (2001).

152. Oyediran, K. A. Fertility Desires of Yoruba Couples of Southwestern Nigeria. Journal of Biosocial Science 38(5), 605624 (2006).

153. Oyediran, K. A. \& Isiugo-Abanihe, U. Husband-Wife Communication and Couples Fertility Desires Among the Yoruba of Nigeria. Etude de La Population Africaine 17(2), 61-80 (2002).

154. Pallangyo, E. S., Msoka, A. C., Brownie, S. \& Holroyd, E. Religious Beliefs, Social Pressure and Stigma: Rural Women's Perceptions and Beliefs about Vasectomy in Pwani, Tanzania. PLoS ONE 15(3) (2020).

155. Patel, G. How "Universal" is the United Nations Universal Periodic Review Process? An Examination of the Discussions Held on Polygamy. Human Rights Review 18(4), 459-483 (2017).

156. Pereira, C. \& Ibrahim, J. On the Bodies of Women: The Common Ground Between Islam and Christianity in Nigeria. Third World Q 31(6), 921-937 (2010).

157. Pew Research Centre. Religion and Education around the World. (Pew Research Centre, 2016).

158. Pew Research Centre. The World's Muslims: Religion, Politics and Society. (Pew Research Centre, 2013).

159. Pew Research Centre. The Future of the Global Muslim Population. (Pew Research Centre, 2011).

160. Pew Research Centre. Tolerance and Tension: Islam and Christianity in Sub-Saharan Africa. (Pew Research Centre, 2010).

161. Plummer, M. L., Wight, D., Wamoyi, J., Mshana, G., Hayes, R. J. \& Ross, D. A. Farming with your Hoe in a Sack: Condom Attitudes, Access and Use in Rural Tanzania. Studies in Family Planning 37, 29-40 (2006).

162. Population Census Commission [Federal Democratic Republic of Ethiopia]. Summary and Statistical Report of the 2007 Population and Housing Census. (FDRE-PCC, 2008). 
163. Prata, N. Making Family Planning Accessible in Resource-Poor Settings. Philosophical Transactions of the Royal Society: Biological Sciences 364(1532), 3093-3099 (2009).

164. Protogerou, C., Flisher, A. J. \& Wild, L. G. Factors Shaping Condom Use Among South African University Students: A Thematic Analysis. Journal of Psychology in Africa 24(3), 215-224 (2014).

165. Rhine, K. A. Support Groups, Marriage and the Management of Ambiguity Among HIV-Positive Women in Northern Nigeria. Anthropological Quarterly 82(2), 369-400 (2009).

166. Robinson, D. Muslim Societies in African History. (Cambridge University Press, 2004).

167. Sadat-Hashemi, S. M., Ghorbani, R., Majdabadi, H. A. \& Farahani F. K. Factors Associated with Contraceptive Use in Tehran, Iran. The European Journal of Contraception and Reproductive Health Care 12(2), 148-153 (2007).

168. Scrivani, C. Attitudes Towards and Use of Contraception in the Muslim Refugee Population. (2018).

169. Shaikh, B. T., Azmat, S. K. \& Mazhar, A. Family Planning and Contraception in Islamic Countries: A Critical Review of the Literature. Journal of the Pakistan Medical Association 63(4), 67-72 (2013).

170. Sharan, M. \& Valente, T. W. Spousal Communication and Family Planning Adoption: Effects of a Radio Drama Serial in Nepal. International Family Planning Perspectives 28(1), 16-25 (2002).

171. Shattuck, D., Perry, B., Packer, C., \& Quee, D. A Review of 10 Years of Vasectomy Programming and Research in Low-Resource Settings. Global Health: Science and Practice 4(4), 647-660 (2016).

172. Shea, G. A., Burch, T. K., Perez, G., Ordoñez, M., van Kemanade, J., Hutjes, J. \& Hellegers, A. E. Catholic Parish Priests and Birth Control: A Comparative Study of Opinion in Colombia, the United States, and the Netherlands. Studies in Family Planning 2(6), 121-136 (1971).

173. Sinai, I., Omoluabi, E., Jimoh, A. \& Jurczynska, K. Unmet Need for Family Planning and Barriers to Contraceptive Use in Kaduna, Nigeria: Culture, Myths and Perceptions. Culture, Health \& Sexuality 22(11), 1253-1268 (2019).

174. Stark, R. The Triumph of Faith: Why the World is More Religious than Ever. (Intercollegiate Studies Institute, 2015).

175. Stark, R. \& Finke, R. Acts of Faith: Explaining the Human Side of Religion. (University of California Press, 2000).

176. Stonawski, M., Potancokova, M., Cantele, M. \& Skirbekk, V. The Changing Religious Composition of Nigeria: Causes and Implications of Demographic Divergence. Journal of Modern African Studies 54(3), 361-387 (2016).

177. Sundararajan, R., Yoder, L. M., Kihunrwa, A., Aristide, C., Kalluvya, S. E., Downs, D. J., Mwakisole, A. H. \& Downs, J. A. How Gender and Religion Impact Uptake of Family Planning: Results from a Qualitative Study in Northwestern Tanzania. BMC Women's Health 19(99) (2019).

178. Sweet, L. I. Health and Medicine in the Evangelical Tradition: "Not by Might nor Power". (Trinity Press International, 1994).

179. Thummalachetty, N., Mathur, S., Mullinax, M., DeCosta, K., Nakyanjo, N., Lutalo, T., Brahmbhatt, H. \& Santelli, J. S. Contraceptive Knowledge, Perceptions and Concerns Among Men in Uganda. BMC Public Health 17, 792 (2017).

180. Turnwait, M. \& Alfred, S. E. The Polygyny-Fertility Hypothesis: New Evidence from Nigeria. Nigerian Journal of Sociology and Anthropology 16(1), 166-181 (2018).

181. Ujuju, C., Anyanti, J., Adebayo, S. B., Muhammad, F., Oluigbo, O. \& Gofwan, A. Religion, Culture and Male Involvement in the Use of the Standard Days Method: Evidence from Enugu and Katsina States of Nigeria. International Nursing Review 58, 484-490 (2011).

182. United Nations High Commissioner for Refugees (UNHCR). Baseline Study: Family Planning Among Somali Refugees in Ali Addeh, Djibouti. (UNHCR, 2011).

183. United Nations, Department of Economic and Social Affairs, Population Division. Children Ever Born. https://www.un.org/en/development/desa/population/publications/dataset/fertility/total-children.asp (2021).

184. United Nations, Department of Economic and Social Affairs, Population Division. World Population Prospects 2019: Highlights. (United Nations, 2020).

185. United Nations Population Fund. A Decade of Change in Contraceptive Use in Ethiopia. (UNFPA, 2012).

186. Wablembo, M. S., Notzi, J., \& Kwagala, B. Does Couple Discussion Influence Unmet Need for Family Planning in Uganda? (Princeton Education Papers, 2011).

187. Wagner, G. The Bantu of North Kavirondo, Vol. 1. (Oxford University Press, 1949).

188. Walls, A. The Cross-Cultural Process in Christian History: Studies in the Transmission and Appropriation of Faith.

(Orbis, 2002). 
189. Week, J. R. Population: An Introduction to Concepts and Issues (12 ${ }^{\text {th }}$ Edition). (Wadsworth Publishing, 2015).

190. Westoff, C. F. DHS Comparative Reports, No. 25: Desired Number of Children, 2000-2008. (ICF Macro, 2010).

191. Westoff, C. F. \& Bietsch, K. DHS Analytical Studies, No. 48: Religion and Reproductive Behaviour in Sub-Saharan Africa. (ICF International, 2015).

192. Wilson, E. Reproductive Health Case Study: Senegal. (The Futures Group International, 1997).

193. World Health Organisation (WHO). Contraceptive Prevalence Rate: 2006. (World Health Organisation, 2006).

194. World Health Organisation (WHO). Task Force on Methods for the Natural Regulation of Fertility - The World Health Organisation Multinational Study of Breastfeeding and Lactational Amenorrhea: I. Description of infant feeding patterns and of the return of menses. Fertility and Sterility 70, 448-460 (1998).

195. Worldometer. African Countries by Population. http://www.worldometers.info/population/countries-in-africaby-population (2021).

196. Yeatman, S. E. \& Trinitapoli, J. Beyond Denomination: The Relationship Between Religion and Family Planning in Rural Malawi. Demographic Research 19, 1851-1882 (2008). 


\section{Appendices}

\section{Appendix A: Distribution of Population by Denomination Across Sub-Saharan Africa}

Table A. Percentage of population composition by religious denomination in Sub-Saharan African countries. [Source: United Nations, 2020] [NB: No data was available for Equatorial Guinea, Eritrea, Madagascar, Sudan and South Sudan.]

\begin{tabular}{|c|c|c|c|c|c|c|c|c|c|c|}
\hline Country & $\begin{array}{l}\text { Sub-Region } \\
\text { (UN Definition) }\end{array}$ & $\begin{array}{l}\text { Muslim } \\
\text { (\%) }\end{array}$ & $\begin{array}{l}\text { Catholic } \\
\text { (\%) }\end{array}$ & $\begin{array}{l}\text { Protestant } \\
\text { (\%) }\end{array}$ & $\begin{array}{c}\text { Other } \\
\text { Christian (\%) }\end{array}$ & $\begin{array}{c}\text { Total } \\
\text { Christian (\%) }\end{array}$ & $\begin{array}{c}\text { African } \\
\text { Indigenous } \\
\text { Religions (\%) }\end{array}$ & $\begin{array}{c}\text { Other / } \\
\text { Unspecified } \\
\text { Religions (\%) }\end{array}$ & $\begin{array}{c}\text { No Religious } \\
\text { Affiliation (\%) }\end{array}$ & $\begin{array}{l}\text { Source } \\
\text { Year }\end{array}$ \\
\hline Angola & Central Africa & & $41.1 \%$ & $38.1 \%$ & & $79.2 \%$ & & $8.6 \%$ & $12.3 \%$ & 2014 \\
\hline Benin & Western Africa & $27.7 \%$ & $25.5 \%$ & $13.5 \%$ & $9.5 \%$ & $48.5 \%$ & $14.2 \%$ & $2.6 \%$ & $5.8 \%$ & 2013 \\
\hline Botswana & Southern Africa & & & & & $79.1 \%$ & $4.1 \%$ & $1.7 \%$ & $15.2 \%$ & 2011 \\
\hline Burkina Faso & Western Africa & $61.5 \%$ & $23.3 \%$ & $6.5 \%$ & & $29.8 \%$ & $7.8 \%$ & $0.2 \%$ & $0.7 \%$ & 2010 \\
\hline Burundi & Eastern Africa & $2.5 \%$ & $62.1 \%$ & $23.9 \%$ & & $86.0 \%$ & & $11.5 \%$ & & 2008 \\
\hline Cameroon & Central Africa & $24.4 \%$ & $38.3 \%$ & $25.5 \%$ & $6.9 \%$ & $70.7 \%$ & $2.2 \%$ & $0.5 \%$ & $2.2 \%$ & 2018 \\
\hline CAR & Central Africa & $8.5 \%$ & & & & $89.5 \%$ & $1.0 \%$ & & $1.0 \%$ & 2010 \\
\hline Chad & Central Africa & $52.1 \%$ & $20.0 \%$ & $23.9 \%$ & $0.2 \%$ & $44.1 \%$ & $0.3 \%$ & $0.7 \%$ & $2.8 \%$ & $2014 / 15$ \\
\hline Congo & Central Africa & $1.6 \%$ & $33.1 \%$ & $22.1 \%$ & $23.8 \%$ & $79.0 \%$ & & $8.1 \%$ & $11.3 \%$ & 2010 \\
\hline Côte d'Ivoire & Western Africa & $42.9 \%$ & $17.2 \%$ & $13.5 \%$ & $3.2 \%$ & $33.9 \%$ & $3.6 \%$ & $0.5 \%$ & $19.1 \%$ & 2014 \\
\hline Djibouti & Eastern Africa & $94.0 \%$ & & & & $6.0 \%$ & & & & \\
\hline
\end{tabular}




\begin{tabular}{|c|c|c|c|c|c|c|c|c|c|c|}
\hline DR Congo & Central Africa & $1.3 \%$ & $29.9 \%$ & $26.7 \%$ & $39.3 \%$ & $95.9 \%$ & & $1.4 \%$ & $1.3 \%$ & 2014 \\
\hline Eswatini & Southern Africa & $2.0 \%$ & $20.0 \%$ & $40.0 \%$ & $30.0 \%$ & $90.0 \%$ & & $8.0 \%$ & & 2015 \\
\hline Ethiopia & Eastern Africa & $31.3 \%$ & $0.7 \%$ & $22.8 \%$ & $43.8 \%$ & $67.3 \%$ & $0.6 \%$ & $0.8 \%$ & & 2016 \\
\hline Gabon & Central Africa & $9.8 \%$ & $42.3 \%$ & $12.3 \%$ & $27.4 \%$ & $82.0 \%$ & $0.6 \%$ & $7.6 \%$ & & 2012 \\
\hline Gambia & Western Africa & $95.7 \%$ & & & & $4.2 \%$ & & $0.1 \%$ & & 2013 \\
\hline Ghana & Western Africa & $17.6 \%$ & $13.1 \%$ & $46.7 \%$ & $11.4 \%$ & $71.2 \%$ & $5.2 \%$ & $0.8 \%$ & $5.2 \%$ & 2010 \\
\hline Guinea & Western Africa & $89.1 \%$ & & & & $6.8 \%$ & $1.6 \%$ & $0.1 \%$ & $2.4 \%$ & 2014 \\
\hline Guinea-Bissau & Western Africa & $45.1 \%$ & & & & $22.1 \%$ & $14.9 \%$ & $15.9 \%$ & $2.0 \%$ & 2008 \\
\hline Kenya & Eastern Africa & $10.9 \%$ & $20.6 \%$ & $53.8 \%$ & $11.1 \%$ & $85.5 \%$ & & $2.0 \%$ & $1.6 \%$ & 2019 \\
\hline Lesotho & Southern Africa & & $39.3 \%$ & $47.8 \%$ & $9.1 \%$ & $96.2 \%$ & & $1.4 \%$ & $2.3 \%$ & 2014 \\
\hline Liberia & Western Africa & $12.2 \%$ & & & & $85.6 \%$ & $0.6 \%$ & $0.2 \%$ & $1.5 \%$ & 2008 \\
\hline Malawi & Eastern Africa & $13.8 \%$ & $17.2 \%$ & $33.5 \%$ & $26.6 \%$ & $77.3 \%$ & $1.1 \%$ & $5.6 \%$ & $2.1 \%$ & 2018 \\
\hline Mali & Western Africa & $93.9 \%$ & & & & $2.8 \%$ & $0.7 \%$ & & $2.5 \%$ & 2018 \\
\hline Mauritania & Western Africa & $100.0 \%$ & & & & & & & & \\
\hline Mozambique & Eastern Africa & $18.9 \%$ & $27.2 \%$ & $32.6 \%$ & & $59.8 \%$ & & $7.3 \%$ & $13.9 \%$ & 2017 \\
\hline Namibia & Southern Africa & & & & & $85.0 \%$ & $15.0 \%$ & & & \\
\hline
\end{tabular}




\begin{tabular}{|c|c|c|c|c|c|c|c|c|c|c|}
\hline Niger & Western Africa & $99.3 \%$ & & & & $0.3 \%$ & $0.2 \%$ & & $0.1 \%$ & 2012 \\
\hline Nigeria & Western Africa & $53.5 \%$ & $10.6 \%$ & & $35.3 \%$ & $45.9 \%$ & $0.6 \%$ & & & 2018 \\
\hline Rwanda & Eastern Africa & $2.0 \%$ & $43.7 \%$ & $49.5 \%$ & & $93.2 \%$ & & $2.2 \%$ & $2.5 \%$ & 2012 \\
\hline Senegal & Western Africa & $95.9 \%$ & & & & $4.1 \%$ & & & & 2016 \\
\hline Sierra Leone & Western Africa & $78.6 \%$ & & & & $20.8 \%$ & & $0.5 \%$ & & 2013 \\
\hline Somalia & Eastern Africa & $100.0 \%$ & & & & & & & & 2012 \\
\hline South Africa & Southern Africa & $1.9 \%$ & & & & $86.0 \%$ & $5.4 \%$ & $1.5 \%$ & $5.2 \%$ & 2015 \\
\hline Tanzania & Eastern Africa & $35.2 \%$ & & & & $61.4 \%$ & $1.8 \%$ & $0.2 \%$ & $1.4 \%$ & 2010 \\
\hline Togo & Western Africa & $14.0 \%$ & & & & $43.7 \%$ & $35.6 \%$ & $0.5 \%$ & $6.2 \%$ & 2010 \\
\hline Uganda & Eastern Africa & $13.7 \%$ & $39.3 \%$ & $45.1 \%$ & & $84.4 \%$ & & $1.6 \%$ & $0.2 \%$ & 2014 \\
\hline Zambia & Eastern Africa & & $20.2 \%$ & $75.3 \%$ & & $95.5 \%$ & & $2.7 \%$ & $1.8 \%$ & 2010 \\
\hline Zimbabwe & Eastern Africa & $0.5 \%$ & $7.3 \%$ & $74.8 \%$ & $5.3 \%$ & $87.4 \%$ & $1.5 \%$ & $0.1 \%$ & $10.5 \%$ & 2015 \\
\hline
\end{tabular}




\section{Appendix B: Statistical Data for Countries in Sub-Saharan Africa}

Table B. Statistical data for Sub-Saharan African nations. [Source: United Nations, 2020]

\begin{tabular}{|c|c|c|c|c|c|c|c|c|c|c|c|}
\hline Country & $\begin{array}{c}\text { Sub-Region } \\
\text { (UN } \\
\text { Definition) }\end{array}$ & $\begin{array}{c}\text { Population } \\
\text { (2020) }\end{array}$ & $\begin{array}{c}\text { Yearly } \\
\text { Change (\%) }\end{array}$ & $\begin{array}{l}\text { Population } \\
\text { Density per } \\
\text { km² (2021) }\end{array}$ & $\begin{array}{l}\text { Land Area } \\
\left(\mathbf{k m}^{2}\right)\end{array}$ & $\begin{array}{c}\text { TFR } \\
(2020)\end{array}$ & CPR (\%) & $\begin{array}{c}\text { CPR Source } \\
\text { Year }\end{array}$ & $\begin{array}{c}\text { Median } \\
\text { Age }\end{array}$ & $\begin{array}{c}\text { Urban } \\
\text { Population } \\
(\%)(2020) \\
\end{array}$ & $\begin{array}{c}\text { GDP per } \\
\text { Capita (US\$) } \\
(2019) \\
\end{array}$ \\
\hline Angola & $\begin{array}{l}\text { Central } \\
\text { Africa }\end{array}$ & $32,866,272$ & $3.27 \%$ & 26 & $1,246,700$ & 5.96 & $13.7 \%$ & $2015 / 16$ & 17 & $67 \%$ & 2,791 \\
\hline Benin & $\begin{array}{l}\text { Western } \\
\text { Africa }\end{array}$ & $12,123,200$ & $2.73 \%$ & 108 & 112,760 & 5.53 & $15.5 \%$ & $2017 / 18$ & 19 & $48 \%$ & 1,219 \\
\hline Botswana & $\begin{array}{c}\text { Southern } \\
\text { Africa }\end{array}$ & $2,351,627$ & $2.08 \%$ & 4 & 566,730 & 2.45 & $67.4 \%$ & 2017 & 24 & $71 \%$ & 7,961 \\
\hline Burkina Faso & $\begin{array}{l}\text { Western } \\
\text { Africa }\end{array}$ & $20,903,273$ & $2.86 \%$ & 76 & 273,600 & 4.51 & $32.5 \%$ & $2018 / 19$ & 18 & $31 \%$ & 787 \\
\hline Burundi & $\begin{array}{l}\text { Eastern } \\
\text { Africa }\end{array}$ & $11,890,784$ & $3.12 \%$ & 463 & 25,680 & 5.28 & $28.5 \%$ & $2016 / 17$ & 17 & $14 \%$ & 261 \\
\hline Cameroon & $\begin{array}{l}\text { Central } \\
\text { Africa }\end{array}$ & $26,545,863$ & $2.59 \%$ & 56 & 472,710 & 4.66 & $19.3 \%$ & 2018 & 19 & $58 \%$ & 1,508 \\
\hline CAR & $\begin{array}{l}\text { Central } \\
\text { Africa }\end{array}$ & $4,829,767$ & $1.78 \%$ & 8 & 622,980 & 4.14 & $15.2 \%$ & $2010 / 11$ & 18 & $42 \%$ & 468 \\
\hline Chad & $\begin{array}{l}\text { Central } \\
\text { Africa }\end{array}$ & $16,425,864$ & $3.00 \%$ & 13 & $1,259,200$ & 5.68 & $5.7 \%$ & $2014 / 15$ & 17 & $24 \%$ & 710 \\
\hline Congo & $\begin{array}{l}\text { Central } \\
\text { Africa }\end{array}$ & $5,518,087$ & $2.56 \%$ & 16 & 341,500 & 4.45 & $30.1 \%$ & $2014 / 15$ & 19 & $68 \%$ & 2,280 \\
\hline Côte d'Ivoire & $\begin{array}{l}\text { Western } \\
\text { Africa }\end{array}$ & $26,378,274$ & $2.57 \%$ & 83 & 318,000 & 3.67 & $23.3 \%$ & 2018 & 19 & $52 \%$ & 2,276 \\
\hline Djibouti & $\begin{array}{l}\text { Eastern } \\
\text { Africa }\end{array}$ & 988,000 & $1.48 \%$ & 43 & 23,180 & 2.19 & $19.0 \%$ & 2012 & 27 & $78 \%$ & 3,415 \\
\hline DR Congo & $\begin{array}{l}\text { Central } \\
\text { Africa }\end{array}$ & $89,561,403$ & $3.19 \%$ & 40 & $2,267,050$ & 5.77 & $20.4 \%$ & $2013 / 14$ & 17 & $46 \%$ & 581 \\
\hline $\begin{array}{l}\text { Equatorial } \\
\text { Guinea }\end{array}$ & $\begin{array}{l}\text { Central } \\
\text { Africa }\end{array}$ & $1,402,985$ & $3.47 \%$ & 50 & 28,050 & 4.11 & $12.6 \%$ & 2011 & 22 & $73 \%$ & 8,132 \\
\hline
\end{tabular}




\begin{tabular}{|c|c|c|c|c|c|c|c|c|c|c|c|}
\hline Eritrea & $\begin{array}{l}\text { Eastern } \\
\text { Africa }\end{array}$ & $3,546,421$ & $1.41 \%$ & 35 & 101,000 & 3.73 & $8.4 \%$ & 2010 & 19 & $41 \%$ & $\begin{array}{c}643 \\
(2011)\end{array}$ \\
\hline Eswatini & $\begin{array}{c}\text { Southern } \\
\text { Africa }\end{array}$ & $1,160,164$ & $1.05 \%$ & 67 & 17,200 & 2.52 & $66.1 \%$ & 2014 & 21 & $24 \%$ & 3,895 \\
\hline Ethiopia & $\begin{array}{l}\text { Eastern } \\
\text { Africa }\end{array}$ & $114,963,588$ & $2.57 \%$ & 115 & $1,000,000$ & 4.14 & $40.1 \%$ & 2018 & 19 & $22 \%$ & 856 \\
\hline Gabon & $\begin{array}{l}\text { Central } \\
\text { Africa }\end{array}$ & $2,225,734$ & $2.45 \%$ & 9 & 257,670 & 3.41 & $31.1 \%$ & 2012 & 23 & $90 \%$ & 7,767 \\
\hline Gambia & $\begin{array}{c}\text { Western } \\
\text { Africa }\end{array}$ & $2,416,668$ & $2.94 \%$ & 239 & 10,120 & 3.21 & $16.8 \%$ & 2018 & 18 & $63 \%$ & 778 \\
\hline Ghana & $\begin{array}{c}\text { Western } \\
\text { Africa }\end{array}$ & $31,072,940$ & $2.15 \%$ & 137 & 227,540 & 3.90 & $30.8 \%$ & 2017 & 22 & $57 \%$ & 2,202 \\
\hline Guinea & $\begin{array}{c}\text { Western } \\
\text { Africa }\end{array}$ & $13,132,795$ & $2.83 \%$ & 53 & 245,720 & 4.92 & $10.9 \%$ & 2018 & 18 & $37 \%$ & 963 \\
\hline Guinea-Bissau & $\begin{array}{c}\text { Western } \\
\text { Africa }\end{array}$ & $1,968,001$ & $2.45 \%$ & 70 & 28,120 & 4.75 & $16.0 \%$ & 2014 & 19 & $44 \%$ & 697 \\
\hline Kenya & $\begin{array}{c}\text { Eastern } \\
\text { Africa }\end{array}$ & $53,771,296$ & $2.28 \%$ & 94 & 569,140 & 3.43 & $60.5 \%$ & 2017 & 20 & $28 \%$ & 1,817 \\
\hline Lesotho & $\begin{array}{c}\text { Southern } \\
\text { Africa }\end{array}$ & $2,142,249$ & $0.80 \%$ & 71 & 30,360 & 2.50 & $64.9 \%$ & 2018 & 24 & $29 \%$ & 1,118 \\
\hline Liberia & $\begin{array}{c}\text { Western } \\
\text { Africa }\end{array}$ & $5,057,681$ & $2.44 \%$ & 53 & 96,320 & 4.90 & $31.2 \%$ & 2016 & 19 & $52 \%$ & 622 \\
\hline Madagascar & $\begin{array}{l}\text { Eastern } \\
\text { Africa }\end{array}$ & $27,691,018$ & $2.68 \%$ & 48 & 581,795 & 3.78 & $44.3 \%$ & 2018 & 20 & $39 \%$ & 523 \\
\hline Malawi & $\begin{array}{l}\text { Eastern } \\
\text { Africa }\end{array}$ & $19,129,952$ & $2.69 \%$ & 203 & 94,280 & 5.31 & $59.2 \%$ & $2015 / 16$ & 18 & $17 \%$ & 412 \\
\hline Mali & $\begin{array}{c}\text { Western } \\
\text { Africa }\end{array}$ & $20,250,833$ & $3.02 \%$ & 17 & $1,220,190$ & 5.72 & $17.2 \%$ & 2018 & 16 & $44 \%$ & 879 \\
\hline Mauritania & $\begin{array}{c}\text { Western } \\
\text { Africa }\end{array}$ & $4,649,658$ & $2.74 \%$ & 5 & $1,030,700$ & 3.65 & $17.8 \%$ & 2015 & 20 & $55 \%$ & 1,679 \\
\hline Mozambique & $\begin{array}{l}\text { Eastern } \\
\text { Africa }\end{array}$ & $31,255,435$ & $2.93 \%$ & 40 & 786,380 & 4.97 & $27.1 \%$ & 2015 & 18 & $37 \%$ & 504 \\
\hline
\end{tabular}




\begin{tabular}{|c|c|c|c|c|c|c|c|c|c|c|c|}
\hline Namibia & $\begin{array}{c}\text { Southern } \\
\text { Africa }\end{array}$ & $2,540,905$ & $1.86 \%$ & 3 & 823,290 & 3.07 & $56.1 \%$ & 2013 & 22 & $52 \%$ & 4,958 \\
\hline Niger & $\begin{array}{l}\text { Western } \\
\text { Africa }\end{array}$ & $24,206,644$ & $3.84 \%$ & 19 & $1,266,700$ & 7.00 & $11.0 \%$ & $2017 / 18$ & 15 & $17 \%$ & 554 \\
\hline Nigeria & $\begin{array}{c}\text { Western } \\
\text { Africa }\end{array}$ & $206,139,589$ & $2.58 \%$ & 226 & 910,770 & 4.72 & $16.6 \%$ & 2018 & 18 & $52 \%$ & 2,230 \\
\hline Rwanda & $\begin{array}{c}\text { Eastern } \\
\text { Africa }\end{array}$ & $12,952,218$ & $2.58 \%$ & 525 & 24,670 & 3.52 & $53.2 \%$ & $2014 / 15$ & 20 & $17 \%$ & 820 \\
\hline Senegal & $\begin{array}{c}\text { Western } \\
\text { Africa }\end{array}$ & $16,743,927$ & $2.75 \%$ & 87 & 192,530 & 4.04 & $27.8 \%$ & 2017 & 19 & $48 \%$ & 1,447 \\
\hline Sierra Leone & $\begin{array}{l}\text { Western } \\
\text { Africa }\end{array}$ & $7,976,983$ & $2.10 \%$ & 111 & 72,180 & 4.62 & $21.2 \%$ & 2019 & 19 & $43 \%$ & 528 \\
\hline Somalia & $\begin{array}{l}\text { Eastern } \\
\text { Africa }\end{array}$ & $15,893,222$ & $2.92 \%$ & 25 & 627,340 & 5.51 & & & 17 & $46 \%$ & 320 \\
\hline South Africa & $\begin{array}{l}\text { Southern } \\
\text { Africa }\end{array}$ & $59,308,690$ & $1.28 \%$ & 49 & $1,213,090$ & 2.22 & $54.6 \%$ & 2016 & 28 & $67 \%$ & 6,001 \\
\hline South Sudan & $\begin{array}{l}\text { Eastern } \\
\text { Africa }\end{array}$ & $11,193,725$ & $1.19 \%$ & 18 & 610,952 & 5.54 & $4.0 \%$ & 2010 & 19 & $20 \%$ & $\begin{array}{l}1,120 \\
(2015)\end{array}$ \\
\hline Sudan & $\begin{array}{c}\text { Eastern } \\
\text { Africa }\end{array}$ & $43,849,260$ & $2.42 \%$ & 25 & $1,765,048$ & 4.72 & $12.2 \%$ & 2014 & 20 & $35 \%$ & 442 \\
\hline Tanzania & $\begin{array}{c}\text { Eastern } \\
\text { Africa }\end{array}$ & $59,734,218$ & $2.98 \%$ & 67 & 885,800 & 4.59 & $38.4 \%$ & $2015 / 16$ & 18 & $35 \%$ & 1,122 \\
\hline Togo & $\begin{array}{c}\text { Western } \\
\text { Africa }\end{array}$ & $8,278,724$ & $2.43 \%$ & 152 & 54,390 & 4.22 & $23.9 \%$ & 2017 & 19 & $43 \%$ & 679 \\
\hline Uganda & $\begin{array}{l}\text { Eastern } \\
\text { Africa }\end{array}$ & $45,741,007$ & $3.32 \%$ & 229 & 199,810 & 5.54 & $41.8 \%$ & 2018 & 17 & $25 \%$ & 794 \\
\hline Zambia & $\begin{array}{c}\text { Eastern } \\
\text { Africa }\end{array}$ & $18,383,955$ & $2.93 \%$ & 25 & 743,390 & 5.49 & $49.5 \%$ & 2018 & 18 & $45 \%$ & 1,305 \\
\hline Zimbabwe & $\begin{array}{l}\text { Eastern } \\
\text { Africa }\end{array}$ & $14,862,924$ & $1.48 \%$ & 38 & 386,850 & 3.93 & $66.8 \%$ & 2015 & 19 & $32 \%$ & 1,464 \\
\hline
\end{tabular}




\section{Appendix C: Quantitative Papers}

Table C. Characteristics of sample populations and study design of quantitative papers of fertility.

\begin{tabular}{|c|c|c|c|c|c|c|c|c|c|c|c|c|c|}
\hline $\begin{array}{c}\text { Author \& } \\
\text { Year }\end{array}$ & $\begin{array}{c}\text { Focus } \\
\text { Region / } \\
\text { Country }\end{array}$ & $\begin{array}{c}\text { Focus } \\
\text { Religion(s) }\end{array}$ & $\begin{array}{c}\text { Focus } \\
\text { Contraception } \\
\text { Type(s) }\end{array}$ & Method & $\begin{array}{l}\text { Dependent } \\
\text { Variable }\end{array}$ & $\begin{array}{l}\text { Sample } \\
\text { Size }\end{array}$ & $\begin{array}{l}\text { Sample } \\
\text { Age } \\
\text { (Years) }\end{array}$ & $\begin{array}{l}\text { Sample } \\
\text { Gender }\end{array}$ & $\begin{array}{c}\text { Other } \\
\text { Specifics of } \\
\text { Sample } \\
\text { Population } \\
\end{array}$ & $\begin{array}{c}\text { Study } \\
\text { Location(s) }\end{array}$ & $\begin{array}{l}\text { Residential } \\
\text { Setting }\end{array}$ & $\begin{array}{l}\text { Date(s) of } \\
\text { Data } \\
\text { Collection }\end{array}$ & $\begin{array}{l}\text { Statistical } \\
\text { Approach }\end{array}$ \\
\hline $\begin{array}{l}\text { Adebowale } \\
\& \\
\text { Palamuleni } \\
\text { (2015) }\end{array}$ & Malawi & $\begin{array}{c}\text { Anglican; } \\
\text { Baptist; Catholic; } \\
\text { Muslim; } \\
\text { Presbyterian; } \\
\text { Protestant; } \\
\text { Seventh Day } \\
\text { Adventist; Other } \\
\text { Christian; Other }\end{array}$ & $\begin{array}{c}\text { Modern } \\
\text { Contraceptives }\end{array}$ & $\begin{array}{l}\text { DHS Data } \\
\text { Examination }\end{array}$ & $\begin{array}{l}\text { Fertility } \\
\text { Desires }\end{array}$ & 1,739 & $15-49$ & Females & $\begin{array}{l}\text { Married (first } \\
\text { and only } \\
\text { marriage), } \\
\text { non- } \\
\text { menopausal, } \\
\text { not sterilised, } \\
\text { fecund, and } \\
\text { have at least } \\
5 \text { children. }\end{array}$ & $\begin{array}{l}\text { Across } \\
\text { Malawi }\end{array}$ & $\begin{array}{l}\text { Rural and } \\
\text { Urban }\end{array}$ & 2010 & $\begin{array}{l}\text { Logistic } \\
\text { Regression }\end{array}$ \\
\hline $\begin{array}{l}\text { Agadjanian } \\
\text { \& Yabiku } \\
\text { (2014) }\end{array}$ & Mozambique & $\begin{array}{l}\text { Apostolic; } \\
\text { Catholic; } \\
\text { Pentecostal; } \\
\text { Protestant; } \\
\text { Zionist; No } \\
\text { Religion }\end{array}$ & $\begin{array}{c}\text { All } \\
\text { Contraceptives }\end{array}$ & Questionnaire & $\begin{array}{l}\text { Children } \\
\text { Ever Born }\end{array}$ & 2,019 & $18-50$ & Females & $\begin{array}{l}\text { Ever in a } \\
\text { union. }\end{array}$ & $\begin{array}{c}\text { Chibuto } \\
\text { District, Gaza } \\
\text { Province, } \\
\text { Mozambique }\end{array}$ & $\begin{array}{l}\text { Rural and } \\
\text { Urban }\end{array}$ & 2008 & $\begin{array}{l}\text { Logistic } \\
\text { Regression; } \\
\text { Poisson } \\
\text { Regression }\end{array}$ \\
\hline $\begin{array}{l}\text { Agyei- } \\
\text { Mensah \& } \\
\text { Owoo } \\
(2015)\end{array}$ & Ghana & $\begin{array}{c}\text { Christian; } \\
\text { Muslim; } \\
\text { Indigenous; No } \\
\text { Religion }\end{array}$ & $\begin{array}{c}\text { Modern } \\
\text { Contraceptives }\end{array}$ & $\begin{array}{l}\text { DHS Data } \\
\text { Examination }\end{array}$ & $\begin{array}{l}\text { No. of Births } \\
\text { in Last } 5 \\
\text { Years }\end{array}$ & Unspecified & $15-49$ & Females & N/A & Across Ghana & $\begin{array}{l}\text { Rural and } \\
\text { Urban }\end{array}$ & 2008 & $\begin{array}{l}\text { Poisson } \\
\text { Regression }\end{array}$ \\
\hline $\begin{array}{l}\text { Akintunde, } \\
\text { et al. } \\
\text { (2013) }\end{array}$ & Nigeria & $\begin{array}{l}\text { Christian; } \\
\text { Muslim; } \\
\text { Indigenous; } \\
\text { Other }\end{array}$ & $\begin{array}{c}\text { All } \\
\text { Contraceptives }\end{array}$ & Questionnaire & $\begin{array}{l}\text { Children } \\
\text { Ever Born }\end{array}$ & 2,197 & $15-49$ & $\begin{array}{l}\text { Males } \\
\text { and } \\
\text { Females }\end{array}$ & $\mathrm{N} / \mathrm{A}$ & $\begin{array}{l}\text { Akinyele LGA, } \\
\text { Oyo State, } \\
\text { Nigeria }\end{array}$ & Unspecified & Unspecified & $\begin{array}{c}\text { Multiple } \\
\text { Regression; } \\
\text { Chi-Square; } \\
\text { ANOVA }\end{array}$ \\
\hline $\begin{array}{l}\text { Babalola, et } \\
\text { al. (2017) }\end{array}$ & Nigeria & $\begin{array}{l}\text { Christian; } \\
\text { Muslim }\end{array}$ & $\begin{array}{c}\text { All } \\
\text { Contraceptives }\end{array}$ & $\begin{array}{l}\text { Survey (non- } \\
\text { DHS) Data } \\
\text { Examination }\end{array}$ & $\begin{array}{l}\text { Achievement } \\
\text { of Fertility } \\
\text { Desires }\end{array}$ & 1,921 & $15-49$ & Females & $\begin{array}{l}\text { In a union, } \\
\text { fecund and } \\
\text { desired no } \\
\text { more } \\
\text { children at } \\
\text { baseline. }\end{array}$ & $\begin{array}{l}\text { Abuja, Benin } \\
\text { City, Ibadan, } \\
\text { Ilorin, } \\
\text { Kaduna and } \\
\text { Zaria, Nigeria }\end{array}$ & Urban & $2010-2014$ & $\begin{array}{l}\text { Multivariable } \\
\text { Logistic } \\
\text { Regression }\end{array}$ \\
\hline $\begin{array}{l}\text { Chemhaka } \\
\& \\
\text { Odimegwu } \\
(2020)\end{array}$ & Eswatini & $\begin{array}{l}\text { Apostolic; } \\
\text { Catholic; } \\
\text { Muslim; } \\
\text { Pentecostal; } \\
\text { Protestant; } \\
\text { Indigenous; } \\
\text { Other; No } \\
\text { Religion }\end{array}$ & $\begin{array}{c}\text { All } \\
\text { Contraceptives }\end{array}$ & $\begin{array}{l}\text { DHS Data } \\
\text { Examination }\end{array}$ & $\begin{array}{l}\text { Children } \\
\text { Ever Born }\end{array}$ & 4,112 & $15-49$ & Females & $\begin{array}{c}\text { Sexually } \\
\text { experienced. }\end{array}$ & $\begin{array}{l}\text { Across } \\
\text { Eswatini }\end{array}$ & $\begin{array}{l}\text { Rural and } \\
\text { Urban }\end{array}$ & 2006-2007 & $\begin{array}{l}\text { Multilevel } \\
\text { Poisson } \\
\text { Regression }\end{array}$ \\
\hline $\begin{array}{l}\text { Garenne } \\
\text { (2012) }\end{array}$ & $\begin{array}{l}34 \text { Countries } \\
\text { in SSA } \\
\text { (including } 2 \\
\text { island } \\
\text { nations) }\end{array}$ & $\begin{array}{l}\text { Christian; } \\
\text { Muslim }\end{array}$ & $\begin{array}{c}\text { Modern } \\
\text { Contraceptives }\end{array}$ & $\begin{array}{l}\text { DHS Data } \\
\text { Examination }\end{array}$ & TFR & $\begin{array}{c}5,217- \\
60,556 \\
\text { (country } \\
\text { range) }\end{array}$ & $\begin{array}{c}20-49 \\
\text { (females); } \\
20-59 \\
\text { (males) }\end{array}$ & $\begin{array}{l}\text { Males } \\
\text { and } \\
\text { Females }\end{array}$ & N/A & $\begin{array}{c}\text { Across } \\
\text { selected } \\
\text { countries. }\end{array}$ & $\begin{array}{l}\text { Rural and } \\
\text { Urban }\end{array}$ & 1991-2009 & $\begin{array}{l}\text { Multivariat } \\
\text { e Linear } \\
\text { Regression }\end{array}$ \\
\hline
\end{tabular}




\begin{tabular}{|c|c|c|c|c|c|c|c|c|c|c|c|c|c|}
\hline $\begin{array}{l}\text { Heaton \& } \\
\text { Darkwah } \\
\text { (2011) }\end{array}$ & Ghana & $\begin{array}{l}\text { Catholic; } \\
\text { Muslim; } \\
\text { Protestant; } \\
\text { Indigenous; } \\
\text { Other Christian; } \\
\text { No Religion }\end{array}$ & $\begin{array}{c}\text { Modern } \\
\text { Contraceptives }\end{array}$ & $\begin{array}{l}\text { DHS Data } \\
\text { Examination }\end{array}$ & $\begin{array}{l}\text { Children } \\
\text { Ever Born }\end{array}$ & $\begin{array}{c}4,557 \\
(1993) ; \\
4,843 \\
(1998) ; \\
5,691 \\
(2003)\end{array}$ & $15-49$ & Females & N/A & Across Ghana & $\begin{array}{l}\text { Rural and } \\
\text { Urban }\end{array}$ & $\begin{array}{c}1993,1998 \\
2003\end{array}$ & $\begin{array}{l}\text { Cox } \\
\text { Regression; } \\
\text { Logistic } \\
\text { Regression; } \\
\text { Ordinary } \\
\text { Least } \\
\text { Squares } \\
\text { Regression }\end{array}$ \\
\hline $\begin{array}{l}\text { Heaton } \\
\text { (2011) }\end{array}$ & $\begin{array}{c}30 \\
\text { Developing } \\
\text { Countries, } \\
\text { Including } 22 \\
\text { in SSA }\end{array}$ & $\begin{array}{l}\text { Catholic; } \\
\text { Christian; } \\
\text { Muslim; } \\
\text { Protestant }\end{array}$ & $\begin{array}{c}\text { Modern } \\
\text { Contraceptives }\end{array}$ & $\begin{array}{l}\text { DHS Data } \\
\text { Examination }\end{array}$ & $\begin{array}{l}\text { No. of Births } \\
\text { in Last } 5 \\
\text { Years }\end{array}$ & $\begin{array}{c}3,223- \\
12,195 \\
\text { (country } \\
\text { range) }\end{array}$ & $15-49$ & Females & In a union. & $\begin{array}{c}\text { Across } \\
\text { selected } \\
\text { countries. }\end{array}$ & $\begin{array}{l}\text { Rural and } \\
\text { Urban }\end{array}$ & $\begin{array}{c}1995-2007 \\
\text { (across the } \\
\text { surveys) }\end{array}$ & $\begin{array}{l}\text { Poisson } \\
\text { Regression }\end{array}$ \\
\hline $\begin{array}{l}\text { Ibeji, et al. } \\
(2020)\end{array}$ & Nigeria & $\begin{array}{c}\text { Christian; } \\
\text { Muslim; Other }\end{array}$ & N/A & $\begin{array}{l}\text { DHS Data } \\
\text { Examination }\end{array}$ & $\begin{array}{l}\text { Children } \\
\text { Ever Born }\end{array}$ & $\sim 30,000$ & $15-49$ & Females & N/A & $\begin{array}{l}\text { Across } \\
\text { Nigeria }\end{array}$ & $\begin{array}{l}\text { Rural and } \\
\text { Urban }\end{array}$ & 2013 & $\begin{array}{l}\text { Negative } \\
\text { Binomial } \\
\text { Regression; } \\
\text { Poisson } \\
\text { Regression }\end{array}$ \\
\hline $\begin{array}{l}\text { Mberu \& } \\
\text { Reed } \\
(2014)\end{array}$ & Nigeria & $\begin{array}{l}\text { Catholic; } \\
\text { Muslim; } \\
\text { Protestant; } \\
\text { Other Christian; } \\
\text { Indigenous; } \\
\text { Other }\end{array}$ & $\begin{array}{c}\text { All } \\
\text { Contraceptives }\end{array}$ & $\begin{array}{c}\text { DHS Data } \\
\text { Examination }\end{array}$ & $\begin{array}{l}\text { Children } \\
\text { Ever Born }\end{array}$ & $\begin{array}{l}5,533 \\
(2003) ; \\
25,363 \\
(2008) ; \\
26,643 \\
(2013)\end{array}$ & $15-49$ & Females & $\begin{array}{l}\text { Ever } \\
\text { married. }\end{array}$ & $\begin{array}{l}\text { Across } \\
\text { Nigeria }\end{array}$ & $\begin{array}{l}\text { Rural and } \\
\text { Urban }\end{array}$ & $\begin{array}{c}2003,2008 \\
2013\end{array}$ & $\begin{array}{l}\text { Multiple } \\
\text { Linear } \\
\text { Regression }\end{array}$ \\
\hline $\begin{array}{l}\text { McGovern, } \\
\text { et al. } \\
\text { (2019) }\end{array}$ & Nigeria & $\begin{array}{l}\text { Christian; } \\
\text { Muslim }\end{array}$ & $\begin{array}{c}\text { All } \\
\text { Contraceptives }\end{array}$ & $\begin{array}{l}\text { DHS Data } \\
\text { Examination }\end{array}$ & TFR & 38,948 & $15-49$ & Females & Married. & $\begin{array}{l}\text { Across } \\
\text { Nigeria }\end{array}$ & $\begin{array}{l}\text { Rural and } \\
\text { Urban }\end{array}$ & 2013 & $\begin{array}{l}\text { Crude Linear } \\
\text { Regression; } \\
\text { Multivariate } \\
\text { Linear } \\
\text { Regression }\end{array}$ \\
\hline $\begin{array}{l}\text { Muhoza } \\
\text { (2019) }\end{array}$ & $\begin{array}{l}\text { Kenya; } \\
\text { Rwanda }\end{array}$ & $\begin{array}{l}\text { Catholic; } \\
\text { Muslim; } \\
\text { Protestant; } \\
\text { Other }\end{array}$ & $\begin{array}{c}\text { All } \\
\text { Contraceptives }\end{array}$ & $\begin{array}{l}\text { DHS Data } \\
\text { Examination }\end{array}$ & $\begin{array}{l}\text { Fertility } \\
\text { Desires }\end{array}$ & $\begin{array}{c}9,009 \\
\text { (Kenya); } \\
6,890 \\
\text { (Rwanda) }\end{array}$ & $15-49$ & Females & In a union. & $\begin{array}{l}\text { Across Kenya } \\
\text { and Rwanda }\end{array}$ & $\begin{array}{l}\text { Rural and } \\
\text { Urban }\end{array}$ & $\begin{array}{c}2014 \\
\text { (Kenya); } \\
2014 / 15 \\
\text { (Rwanda) }\end{array}$ & $\begin{array}{l}\text { Multinominal } \\
\text { Logistic } \\
\text { Regression }\end{array}$ \\
\hline $\begin{array}{l}\text { Muhoza, et } \\
\text { al. (2014) }\end{array}$ & $\begin{array}{l}\text { Kenya; } \\
\text { Rwanda; } \\
\text { Tanzania; } \\
\text { Uganda }\end{array}$ & $\begin{array}{l}\text { Catholic; } \\
\text { Muslim; } \\
\text { Protestant }\end{array}$ & N/A & $\begin{array}{l}\text { DHS Data } \\
\text { Examination }\end{array}$ & $\begin{array}{l}\text { Fertility } \\
\text { Desires }\end{array}$ & $\begin{array}{c}\text { 4,356 } \\
\text { (Kenya); } \\
6,337 \\
\text { (Rwanda); } \\
6,022 \\
\text { (Tanzania); } \\
\text { 4,868 } \\
\text { (Uganda) }\end{array}$ & $15-49$ & Females & $\begin{array}{l}\text { Married or in } \\
\text { a union with } \\
\text { at least } 1 \\
\text { child. }\end{array}$ & $\begin{array}{l}\text { Across } \\
\text { Kenya, } \\
\text { Rwanda, } \\
\text { Tanzania and } \\
\text { Uganda }\end{array}$ & $\begin{array}{l}\text { Rural and } \\
\text { Urban }\end{array}$ & $\begin{array}{c}\text { 2008/09 } \\
\text { (Kenya); } \\
2010 \\
\text { (Rwanda); } \\
2005 \\
\text { (Tanzania); } \\
\text { (2011) } \\
\text { Uganda }\end{array}$ & $\begin{array}{l}\text { Logistic } \\
\text { Regression }\end{array}$ \\
\hline $\begin{array}{l}\text { Nansubuga, } \\
\text { et al. } \\
\text { (2017) }\end{array}$ & $\begin{array}{l}22 \text { Countries } \\
\text { in SSA }\end{array}$ & $\begin{array}{l}\text { Catholic; } \\
\text { Muslim; } \\
\text { Pentecostal; } \\
\text { Protestant; } \\
\text { Major Christian } \\
\text { (country } \\
\text { specific); Other } \\
\text { Christian; } \\
\text { Indigenous; } \\
\text { Other }\end{array}$ & $\begin{array}{c}\text { All } \\
\text { Contraceptives }\end{array}$ & $\begin{array}{c}\text { DHS Data } \\
\text { Examination }\end{array}$ & TFR & $\begin{array}{c}2,891- \\
18,794 \\
\text { (country } \\
\text { range) }\end{array}$ & $15-49$ & Females & N/A & $\begin{array}{c}\text { Across } \\
\text { selected } \\
\text { countries. }\end{array}$ & Unspecified & 2010-2017 & $\begin{array}{c}\text { Poisson } \\
\text { Regression }\end{array}$ \\
\hline
\end{tabular}




\begin{tabular}{|c|c|c|c|c|c|c|c|c|c|c|c|c|c|}
\hline $\begin{array}{l}\text { Ntoimo \& } \\
\text { Mutanda } \\
\text { (2017) }\end{array}$ & $\begin{array}{l}\text { Ghana; } \\
\text { Nigeria; } \\
\text { Zambia }\end{array}$ & $\begin{array}{l}\text { Catholic; } \\
\text { Muslim; Other } \\
\text { Christian; } \\
\text { Indigenous; } \\
\text { Other }\end{array}$ & $\begin{array}{c}\text { All } \\
\text { Contraceptives }\end{array}$ & $\begin{array}{l}\text { DHS Data } \\
\text { Examination }\end{array}$ & $\begin{array}{l}\text { Children } \\
\text { Ever Born }\end{array}$ & $\begin{array}{c}1,785 \\
\text { (Ghana); } \\
3,185 \\
\text { (Nigeria); } \\
3,175 \\
\text { (Zambia) }\end{array}$ & $\begin{array}{c}35< \\
\text { (Wives) }\end{array}$ & $\begin{array}{l}\text { Males } \\
\text { and } \\
\text { Females }\end{array}$ & $\begin{array}{l}\text { Couples in } \\
\text { monogamou } \\
\text { s union. }\end{array}$ & $\begin{array}{l}\text { Across } \\
\text { Ghana, } \\
\text { Nigeria and } \\
\text { Zambia }\end{array}$ & $\begin{array}{l}\text { Rural and } \\
\text { Urban }\end{array}$ & $\begin{array}{c}2003,2008 \\
2014 \\
\text { (Ghana); } \\
2003,2008 \\
2013 \\
\text { (Nigeria); } \\
2001 / 02 \\
2007 \\
2013 / 14 \\
\text { (Zambia) }\end{array}$ & $\begin{array}{l}\text { Poisson } \\
\text { Regression }\end{array}$ \\
\hline $\begin{array}{l}\text { Odusina, et } \\
\text { al. (2020) }\end{array}$ & Nigeria & $\begin{array}{l}\text { Christian; } \\
\text { Muslim; } \\
\text { Indigenous / } \\
\text { Other }\end{array}$ & $\begin{array}{c}\text { All } \\
\text { Contraceptives }\end{array}$ & $\begin{array}{l}\text { DHS Data } \\
\text { Examination }\end{array}$ & $\begin{array}{l}\text { Fertility } \\
\text { Desires }\end{array}$ & $\begin{array}{c}\text { 6,813 } \\
\text { Couples }\end{array}$ & $15-49$ & $\begin{array}{l}\text { Males } \\
\text { and } \\
\text { Females }\end{array}$ & N/A & $\begin{array}{l}\text { Across } \\
\text { Nigeria }\end{array}$ & $\begin{array}{l}\text { Rural and } \\
\text { Urban }\end{array}$ & 2018 & $\begin{array}{c}\text { Logistic } \\
\text { Regression }\end{array}$ \\
\hline $\begin{array}{l}\text { Stonawski, } \\
\text { et al. } \\
\text { (2016) }\end{array}$ & Nigeria & $\begin{array}{l}\text { Christian; } \\
\text { Muslim (Sharia } \\
\text { / non-Sharia) }\end{array}$ & $\begin{array}{c}\text { All } \\
\text { Contraceptives }\end{array}$ & $\begin{array}{l}\text { DHS Data } \\
\text { Examination }\end{array}$ & TFR & $\begin{array}{l}8,393 \\
(1990) ; \\
32,506 \\
(2008) ; \\
38,231 \\
(2013)\end{array}$ & $15-49$ & Females & $\begin{array}{l}\text { Married or } \\
\text { cohabiting } \\
\text { and sexually } \\
\text { active. }\end{array}$ & $\begin{array}{l}\text { Across } \\
\text { Nigeria }\end{array}$ & Unspecified & $\begin{array}{l}1990,2003 \\
2008,2013\end{array}$ & Unspecified \\
\hline $\begin{array}{l}\text { Westoff \& } \\
\text { Bietsch } \\
\text { (2015) }\end{array}$ & $\begin{array}{l}17 \text { Countries } \\
\text { in SSA }\end{array}$ & $\begin{array}{l}\text { Muslim; Non- } \\
\text { Muslim }\end{array}$ & $\begin{array}{c}\text { All } \\
\text { Contraceptives }\end{array}$ & $\begin{array}{l}\text { DHS Data } \\
\text { Examination }\end{array}$ & $\begin{array}{c}\text { Fertility } \\
\text { Desires; No. } \\
\text { of Births in } \\
\text { Last } 5 \text { Years; } \\
\text { TFR }\end{array}$ & $\begin{array}{c}2,809- \\
26,163 \\
\text { (country } \\
\text { range) }\end{array}$ & $15-49$ & Females & N/A & $\begin{array}{l}\text { Across } \\
\text { selected } \\
\text { countries. }\end{array}$ & $\begin{array}{l}\text { Rural and } \\
\text { Urban }\end{array}$ & $2004-2013$ & $\begin{array}{l}\text { Multivariable } \\
\text { Logistic } \\
\text { Regression }\end{array}$ \\
\hline
\end{tabular}




\section{Appendix D: Qualitative Papers}

Table D. Results from the qualitative studies $(2010-2019+2020)$ displaying the summaries and representative quotes of themes influencing increasing fertility in Ethiopia.

\begin{tabular}{|c|c|c|c|c|c|c|c|c|c|c|c|c|}
\hline $\begin{array}{c}\text { Author \& } \\
\text { Year }\end{array}$ & Country & $\begin{array}{c}\text { Focus } \\
\text { Religion(s) }\end{array}$ & $\begin{array}{c}\text { Focus } \\
\text { Contraception } \\
\text { Type(s) } \\
\end{array}$ & $\begin{array}{l}\text { Methodological } \\
\text { Approach }\end{array}$ & Sample Size & $\begin{array}{c}\text { Sample } \\
\text { Age (Years) }\end{array}$ & $\begin{array}{l}\text { Sample } \\
\text { Gender }\end{array}$ & $\begin{array}{c}\text { Other Specifics } \\
\text { of Sample } \\
\text { Population } \\
\end{array}$ & $\begin{array}{c}\text { Study } \\
\text { Location(s) }\end{array}$ & $\begin{array}{l}\text { Residential } \\
\text { Setting }\end{array}$ & $\begin{array}{l}\text { Date(s) of } \\
\text { Data } \\
\text { Collection }\end{array}$ & $\begin{array}{l}\text { Statistical } \\
\text { Approach }\end{array}$ \\
\hline $\begin{array}{l}\text { Abdi, et al. } \\
\text { (2020) }\end{array}$ & Kenya & Muslim & $\begin{array}{c}\text { All } \\
\text { Contraceptives }\end{array}$ & $\begin{array}{c}\text { Focus Group } \\
\text { Discussions; In- } \\
\text { Depth } \\
\text { Interviews }\end{array}$ & 93 & $15-54$ & $\begin{array}{l}\text { Males and } \\
\text { Females }\end{array}$ & $\mathrm{N} / \mathrm{A}$ & $\begin{array}{l}\text { Lamu and } \\
\text { Wajir } \\
\text { Counties, } \\
\text { Kenya }\end{array}$ & Unspecified & 2018 & ATLAS.ti \\
\hline $\begin{array}{l}\text { Adefalu, et al. } \\
\text { (2019) }\end{array}$ & Nigeria & $\begin{array}{l}\text { Muslim; } \\
\text { Other }\end{array}$ & $\begin{array}{c}\text { Modern } \\
\text { Contraceptives }\end{array}$ & $\begin{array}{l}\text { Focus Group } \\
\text { Discussions; In- } \\
\text { Depth } \\
\text { Interviews }\end{array}$ & 250 & $15-45$ & Females & N/A & $\begin{array}{l}\text { Sokoto and } \\
\text { Kebbi States, } \\
\text { NW Nigeria }\end{array}$ & $\begin{array}{l}\text { Rural and } \\
\text { Urban }\end{array}$ & Unspecified & NVivo \\
\hline $\begin{array}{l}\text { Akinyemi, et } \\
\text { al. (2020) }\end{array}$ & Nigeria & Muslim & $\begin{array}{c}\text { Injectable } \\
\text { Contraceptives }\end{array}$ & $\begin{array}{l}\text { Focus Group } \\
\text { Discussions; In- } \\
\text { Depth } \\
\text { Interviews }\end{array}$ & 102 & Unspecified & $\begin{array}{l}\text { Males and } \\
\text { Females }\end{array}$ & N/A & $\begin{array}{l}\text { Gombe, } \\
\text { Nigeria }\end{array}$ & Unspecified & 2016 & NVivo \\
\hline $\begin{array}{l}\text { Aristide, et al. } \\
(2020)\end{array}$ & Tanzania & Protestant & $\begin{array}{c}\text { All } \\
\text { Contraceptives }\end{array}$ & $\begin{array}{l}\text { Focus Group } \\
\text { Discussions }\end{array}$ & 100 & $26-46$ & $\begin{array}{l}\text { Males and } \\
\text { Females }\end{array}$ & $\mathrm{N} / \mathrm{A}$ & $\begin{array}{l}\text { Rural villages } \\
\text { in NW } \\
\text { Tanzania }\end{array}$ & Rural & 2019 & NVivo \\
\hline $\begin{array}{l}\text { Davidson, et } \\
\text { al. (2017) }\end{array}$ & $\begin{array}{l}\text { Ethiopia; } \\
\text { (Eritrean \& } \\
\text { Somali } \\
\text { Refugees) }\end{array}$ & $\begin{array}{l}\text { Christian; } \\
\text { Muslim }\end{array}$ & $\begin{array}{l}\text { Long-Acting } \\
\text { Reversible } \\
\text { Contraceptives }\end{array}$ & $\begin{array}{l}\text { Focus Group } \\
\text { Discussions; In- } \\
\text { Depth } \\
\text { Interviews }\end{array}$ & $\begin{array}{c}11,000- \\
25,000 \text { (camp } \\
\text { pop. range) }\end{array}$ & $\begin{array}{c}18-44 \\
\text { (females); } \\
20-50 \\
\text { (males) }\end{array}$ & $\begin{array}{l}\text { Females } \\
\text { (IDIs); } \\
\text { Males and } \\
\text { Females } \\
\text { (FGDs) }\end{array}$ & $\begin{array}{l}\text { Refugees in } \\
\text { Ethiopia (from } \\
\text { Eritrea and } \\
\text { Somalia); } \\
\text { Married (males } \\
\text { and females), } \\
\text { non-pregnant } \\
\text { (females), and } \\
\text { residence of } 6+ \\
\text { months (males). }\end{array}$ & $\begin{array}{l}2 \text { Eritreans } \\
\text { and } 2 \text { Somali } \\
\text { refugees } \\
\text { camps in } \\
\text { Northern and } \\
\text { Eastern } \\
\text { borders of } \\
\text { Ethiopia }\end{array}$ & Unspecified & 2014 & ATLAS.ti \\
\hline $\begin{array}{l}\text { Egeh, et al. } \\
\text { (2019) }\end{array}$ & Somalia & Muslim & $\begin{array}{c}\text { All } \\
\text { Contraceptives }\end{array}$ & $\begin{array}{l}\text { In-Depth } \\
\text { Interviews }\end{array}$ & 17 & $28-59$ & Unspecified & $\begin{array}{l}\text { Islamic religious } \\
\text { leaders. }\end{array}$ & $\begin{array}{l}\text { Somaliland, } \\
\text { Somalia }\end{array}$ & Unspecified & Unspecified & $\begin{array}{l}\text { Transcript- } \\
\text { Based } \\
\text { Analysis }\end{array}$ \\
\hline $\begin{array}{l}\text { Izugbara \& } \\
\text { Ezeh (2010) }\end{array}$ & Nigeria & Muslim & $\begin{array}{c}\text { All } \\
\text { Contraceptives }\end{array}$ & $\begin{array}{l}\text { Focus Group } \\
\text { Discussions; In- } \\
\text { Depth } \\
\text { Interviews }\end{array}$ & 336 & $14-64$ & Females & $\begin{array}{l}\text { Married; also } \\
\text { included health } \\
\text { care providers, } \\
\text { NGO workers, } \\
\text { and community } \\
\text { leaders. }\end{array}$ & $\begin{array}{l}\text { Jigawa and } \\
\text { Kano States, } \\
\text { Nigeria }\end{array}$ & $\begin{array}{l}\text { Rural and } \\
\text { Urban }\end{array}$ & $2007-2008$ & $\begin{array}{l}\text { Transcript- } \\
\text { Based } \\
\text { Analysis }\end{array}$ \\
\hline Jensen (2017) & Kenya & $\begin{array}{l}\text { Christian, } \\
\text { Muslim }\end{array}$ & $\begin{array}{c}\text { All } \\
\text { Contraceptives }\end{array}$ & $\begin{array}{l}\text { Focus Group } \\
\text { Discussions; In- } \\
\text { Depth } \\
\text { Interviews }\end{array}$ & $\begin{array}{l}\text { FGDs: } 170 . \\
\text { IDIs: } 219 \\
\text { women (132 } \\
\text { first round; } 87 \\
\text { second } \\
\text { round) and } 25\end{array}$ & Irrespective & $\begin{array}{l}\text { Males and } \\
\text { Females }\end{array}$ & $\begin{array}{l}\text { FGDs: } \\
\text { Randomly } \\
\text { selected. } \\
\text { Second round, } \\
\text { descendants } \\
\text { were also }\end{array}$ & $\begin{array}{l}\text { Rural villages } \\
\text { in Coast and } \\
\text { Western } \\
\text { Provinces, } \\
\text { Kenya }\end{array}$ & Rural & $\begin{array}{c}1988 \\
\text { (Western } \\
\text { Province); } \\
1990 \text { (Coast } \\
\text { Province); } \\
2011\end{array}$ & $\begin{array}{l}\text { ATLAS.ti; } \\
\text { SPSS }\end{array}$ \\
\hline
\end{tabular}




\begin{tabular}{|c|c|c|c|c|c|c|c|c|c|c|c|c|}
\hline & & & & & $\begin{array}{l}\text { men (20 first } \\
\text { round; } 25 \\
\text { second } \\
\text { round). }\end{array}$ & & & $\begin{array}{l}\text { supplemented. } \\
\text { IDIs: Randomly } \\
\text { selected. In } \\
\text { addition, health } \\
\text { personnel, } \\
\text { teachers, } \\
\text { community and } \\
\text { religious } \\
\text { leaders were } \\
\text { interviewed. }\end{array}$ & & & & \\
\hline $\begin{array}{l}\text { Kabagenyi, et } \\
\text { al. (2016) }\end{array}$ & Uganda & $\begin{array}{l}\text { Catholic; } \\
\text { Muslim; } \\
\text { Pentecostal; } \\
\text { Protestant; } \\
\text { Other }\end{array}$ & $\begin{array}{c}\text { Modern } \\
\text { Contraceptives }\end{array}$ & $\begin{array}{c}\text { Focus Group } \\
\text { Discussions; In- } \\
\text { Depth } \\
\text { Interviews }\end{array}$ & 154 & $15-64$ & $\begin{array}{c}\text { Males and } \\
\text { Females }\end{array}$ & N/A & $\begin{array}{l}\text { Bugiri and } \\
\text { Mpigi } \\
\text { Districts, } \\
\text { Uganda }\end{array}$ & Rural & 2012 & ATLAS.ti \\
\hline $\begin{array}{l}\text { Kok, et al. } \\
(2020)\end{array}$ & Malawi & $\begin{array}{l}\text { Catholic; } \\
\text { Muslim; } \\
\text { Other }\end{array}$ & $\begin{array}{c}\text { Modern } \\
\text { Contraceptives }\end{array}$ & $\begin{array}{l}\text { Focus Group } \\
\text { Discussions; In- } \\
\text { Depth } \\
\text { Interviews }\end{array}$ & 123 & Unspecified & $\begin{array}{c}\text { Males and } \\
\text { Females }\end{array}$ & $\mathrm{N} / \mathrm{A}$ & $\begin{array}{c}\text { Makanjira, } \\
\text { Katuli, and } \\
\text { Namkumba } \\
\text { TAs in } \\
\text { Mangochi } \\
\text { District, } \\
\text { Malawi }\end{array}$ & Unspecified & 2019 & NVivo \\
\hline $\begin{array}{l}\text { Mjaaland } \\
\text { (2014) }\end{array}$ & Ethiopia & $\begin{array}{l}\text { Muslim; } \\
\text { Orthodox; } \\
\text { Protestant }\end{array}$ & $\begin{array}{c}\text { Modern } \\
\text { Contraceptives }\end{array}$ & $\begin{array}{l}\text { In-Depth } \\
\text { Interviews }\end{array}$ & $\begin{array}{c}25 \text { (women } \\
\text { from three } \\
\text { generations); } \\
270 \\
\text { (household } \\
\text { women); } 200 \\
\text { (students) }\end{array}$ & Unspecified & $\begin{array}{l}\text { Females } \\
\text { (non- } \\
\text { students); } \\
\text { Males and } \\
\text { Females } \\
\text { (students) }\end{array}$ & N/A & $\begin{array}{c}\text { Northwestern } \\
\text { Tigray, } \\
\text { Ethiopia }\end{array}$ & $\begin{array}{l}\text { Rural and } \\
\text { Suburban }\end{array}$ & 2008-2012 & $\begin{array}{c}\text { Unspecifie } \\
\text { d }\end{array}$ \\
\hline $\begin{array}{l}\text { Msoka, et al. } \\
\text { (2019) }\end{array}$ & Tanzania & $\begin{array}{l}\text { Christian; } \\
\text { Muslim }\end{array}$ & $\begin{array}{c}\text { All } \\
\text { Contraceptives }\end{array}$ & $\begin{array}{l}\text { Focus Group } \\
\text { Discussions }\end{array}$ & 20 & $20-50$ & Females & $\begin{array}{l}\text { Married with } 2 \\
\text { or more } \\
\text { children. }\end{array}$ & $\begin{array}{l}\text { Bagamoyo } \\
\text { and Kisarawe } \\
\text { in Pwani, } \\
\text { Tanzania }\end{array}$ & Rural & 2017-2018 & NVivo \\
\hline $\begin{array}{l}\text { Pallangyo, et } \\
\text { al. (2020) }\end{array}$ & Tanzania & $\begin{array}{l}\text { Christian; } \\
\text { Muslim }\end{array}$ & Vasectomy & $\begin{array}{l}\text { In-Depth } \\
\text { Interviews }\end{array}$ & 20 & $20-50$ & Females & $\begin{array}{l}\text { Married or } \\
\text { cohabiting with } \\
2 \text { or more } \\
\text { children. }\end{array}$ & $\begin{array}{l}\text { Bagamoyo } \\
\text { and Kisarawe } \\
\text { in Pwani, } \\
\text { Tanzania }\end{array}$ & Rural & 2017-2018 & NVivo \\
\hline $\begin{array}{l}\text { Protogerou, } \\
\text { et al. (2014) }\end{array}$ & $\begin{array}{l}\text { South } \\
\text { Africa }\end{array}$ & Christian & Condom & $\begin{array}{l}\text { In-Depth } \\
\text { Interviews }\end{array}$ & 20 & $18-25$ & $\begin{array}{c}\text { Males and } \\
\text { Females }\end{array}$ & $\begin{array}{l}\text { Undergraduate } \\
\text { students. }\end{array}$ & $\begin{array}{l}\text { Cape Town, } \\
\text { South Africa }\end{array}$ & Unspecified & Unspecified & NVivo \\
\hline $\begin{array}{l}\text { Sinai, et al. } \\
\text { (2019) }\end{array}$ & Nigeria & $\begin{array}{l}\text { Christian; } \\
\text { Muslim }\end{array}$ & $\begin{array}{c}\text { All } \\
\text { Contraceptives }\end{array}$ & $\begin{array}{l}\text { Focus Group } \\
\text { Discussions }\end{array}$ & 81 & $15-49$ & Females & $\begin{array}{l}\text { Married, non- } \\
\text { pregnant, } \\
\text { sexually active, } \\
\text { no intention of } \\
\text { pregnancy in } \\
\text { the next year, } \\
\text { and not using } \\
\text { any FP method. }\end{array}$ & $\begin{array}{l}\text { Northern, } \\
\text { Central and } \\
\text { Southern } \\
\text { Zones of } \\
\text { Kaduna, } \\
\text { Nigeria }\end{array}$ & $\begin{array}{l}\text { Rural and } \\
\text { Urban }\end{array}$ & 2016 & NVivo \\
\hline
\end{tabular}




\begin{tabular}{|c|c|c|c|c|c|c|c|c|c|c|c|c|}
\hline $\begin{array}{l}\text { Sundararajan, } \\
\text { et al. (2019) }\end{array}$ & Tanzania & $\begin{array}{l}\text { Muslim; } \\
\text { Protestant }\end{array}$ & $\begin{array}{c}\text { Modern } \\
\text { Contraceptives }\end{array}$ & $\begin{array}{l}\text { Focus Group } \\
\text { Discussions }\end{array}$ & 206 & $18<$ & $\begin{array}{l}\text { Males and } \\
\text { Females }\end{array}$ & $\begin{array}{l}\text { Villages that } \\
\text { had both a } \\
\text { Church and a } \\
\text { Mosque. }\end{array}$ & $\begin{array}{c}\text { Mwanza, NW } \\
\text { Tanzania }\end{array}$ & Rural & 2016-2017 & NVivo \\
\hline $\begin{array}{l}\text { Ujuju, et al. } \\
\text { (2011) }\end{array}$ & Nigeria & $\begin{array}{l}\text { Catholic; } \\
\text { Muslim }\end{array}$ & $\begin{array}{l}\text { Standard Days } \\
\text { Method }\end{array}$ & $\begin{array}{l}\text { Focus Group } \\
\text { Discussions; In- } \\
\text { Depth } \\
\text { Interviews }\end{array}$ & 113 & $29-42$ & $\begin{array}{l}\text { Males and } \\
\text { Females }\end{array}$ & $\begin{array}{l}\text { In a union and } \\
\text { cohabiting, and } \\
\text { used SDM for at } \\
\text { least } 6 \text { months; } \\
\text { FP providers } \\
\text { and users of } \\
\text { SDM. }\end{array}$ & $\begin{array}{l}\text { Enugu and } \\
\text { Katsina } \\
\text { States, } \\
\text { Nigeria }\end{array}$ & $\begin{array}{c}\text { Rural and } \\
\text { Urban }\end{array}$ & Unspecified & $\begin{array}{c}\text { Transcript- } \\
\text { Based } \\
\text { Analysis }\end{array}$ \\
\hline
\end{tabular}




\section{Appendix E1: Increasing Fertility (Ethiopia)}

Table E1. Results from the qualitative studies (2010-2019 + 2020) displaying the summaries and representative quotes of themes influencing increasing fertility in Ethiopia.

\begin{tabular}{|c|c|c|c|}
\hline Study & Theme & Summary & Representative Quote(s) \\
\hline \multirow[t]{3}{*}{$\begin{array}{l}\text { Davidson, et al. } \\
\text { (2017) }\end{array}$} & $\begin{array}{l}{ }^{*} \text { Religion } \\
\text { [Somalis] }\end{array}$ & $\begin{array}{l}\text { Somalis' desire for large family sizes } \\
\text { was influenced by the Islamic } \\
\text { religion to have many children. } \\
\text { Somalis felt that religious beliefs } \\
\text { outweighed economic concerns as } \\
\text { they believed Allah would provide } \\
\text { them with protection. }\end{array}$ & $\begin{array}{l}\text { "Our Somali community wishes in having birth with many children. Our culture and our } \\
\text { religion both are encouraging in having birth of more children." Somali (gender unspecified) } \\
\text { "Our religion and culture allows in having lot of children, and we do not worry about } \\
\text { economy because Allah guarantee all the economic aspects whatsoever, therefore, I interest } \\
\text { in having many children." Somali Male }\end{array}$ \\
\hline & $\begin{array}{l}\text { Child Mortality / } \\
\text { Financial } \\
\text { Security / Social } \\
\text { Security } \\
\text { [Somalis] }\end{array}$ & $\begin{array}{l}\text { Somalis saw having many children as } \\
\text { necessary due to the possibility of a } \\
\text { child dying, as well being a source of } \\
\text { financial and social support in the } \\
\text { future. }\end{array}$ & $\begin{array}{l}\text { "I personally interest to birth a lot of children...if someone interest in having } 1 \text { to } 2 \text { children, } \\
\text { he does not know their children's live endurance, as well as his live endurance but only Allah } \\
\text { knows it. Having a lot of children is helpful in many different aspects. For example, when the } \\
\text { parent become old they support their parents and among themselves they will bring up their } \\
\text { younger brothers and sisters and they also provide support to the society at large." } \\
\text { Somali Male }\end{array}$ \\
\hline & $\begin{array}{l}\text { Fertility Desires } \\
\text { [Somalis] }\end{array}$ & $\begin{array}{l}\text { Both Eritreans and Somalis desired } \\
\text { high family size, however, Somalis } \\
\text { desired larger family sizes of } 15 \text { to } 20 \\
\text { children, despite their refugee } \\
\text { status. }\end{array}$ & $\begin{array}{l}\text { "I like to have 15, up to } 20 . " \text { Somali Male } \\
\text { "I do not agree using contraception methods, because I need to have a lot of children." } \\
\text { Somali Male }\end{array}$ \\
\hline Mjaaland (2014) & $\begin{array}{l}\text { Financial } \\
\text { Security }\end{array}$ & $\begin{array}{l}\text { When children are more educated } \\
\text { and economic situation improves, } \\
\text { fertility would increase again } \\
\text { (causality - when economic } \\
\text { considerations are central to their } \\
\text { reasoning). }\end{array}$ & (None presented.) \\
\hline
\end{tabular}




\section{Appendix E2: Increasing Fertility (Kenya)}

Table E2. Results from the qualitative studies $(2010-2019+2020)$ displaying the summaries and representative quotes of themes influencing increasing fertility in Kenya.

\begin{tabular}{|c|c|c|c|}
\hline Study & Theme & Summary & Representative Quote(s) \\
\hline \multirow[t]{5}{*}{$\begin{array}{l}\text { Abdi, et al. } \\
(2020)\end{array}$} & *Religion & $\begin{array}{l}\text { Most respondents from Wajir } \\
\text { County referred to the Quranic } \\
\text { recommendation that mothers } \\
\text { breastfeed their children for } 2 \text { years } \\
\text { to restore their physical and } \\
\text { psychological health before } \\
\text { continuing with another pregnancy, } \\
\text { up until menopause. }\end{array}$ & $\begin{array}{l}\text { "In our religion in the Quran we were told for the woman who gives birth she should breast } \\
\text { feed her child for } 2 \text { years so that both the mother and the baby's health will not be affected } \\
\text { but if what you are talking about is child spacing more than those two years unless it is for } \\
\text { medical reason then the religion does not allow, even ALLAH says in his book give birth and } \\
\text { do not think about poverty because he is the provider." FGD, Religious Leader, Wajir } \\
\text { "In our community we want our wives to give birth until the menopause stage that is what } \\
\text { I want personally... My reason is am following the practice of the prophet and the prophet } \\
\text { said I want my followers to reproduce and fill the earth." FGD, Male, Wajir }\end{array}$ \\
\hline & Child Mortality & $\begin{array}{l}\text { Families in both Lamu and Wajir } \\
\text { Counties had larger families to take } \\
\text { into account that some children may } \\
\text { die in their childhood. }\end{array}$ & $\begin{array}{l}\text { "We prefer many children so that when some die at least you will still have some. For } \\
\text { example, when you have only one or two and God takes them what will you do? So it's wise } \\
\text { you bear as many children as you can." FGD, Female, Lamu } \\
\text { "Many people have that perception that I rather have many children so that when some die, } \\
\text { still you have other children." IDI, Female Leader, Wajir }\end{array}$ \\
\hline & $\begin{array}{l}\text { Fertility Desires } \\
\text { (preference for } \\
\text { large family size) }\end{array}$ & $\begin{array}{l}\text { Men from Wajir County desired up } \\
\text { to } 15 \text { children as children provide } \\
\text { wealth and labour force. }\end{array}$ & $\begin{array}{l}\text { "In our community we want our wives to give birth until the menopause stage that is what } \\
\text { I want personally. If you ask a number, I can tell you personally I need many children, around } \\
15, \text { because nobody wants few number when it comes to children." FGD, Male, Wajir }\end{array}$ \\
\hline & $\begin{array}{l}\text { Gender } \\
\text { Preference }\end{array}$ & $\begin{array}{l}\text { Having a boy was culturally } \\
\text { preferred, more so in Wajir County } \\
\text { than in Lamu County, therefore } \\
\text { women would keep giving birth until } \\
\text { they get a boy (or reach } \\
\text { menopause). }\end{array}$ & $\begin{array}{l}\text { "...the other one is cultural bias towards the male... you will see a mother has } 4 \text { girls she sees } \\
\text { this is a good number but her wanting to get a boy child, she will keep trying to get pregnant } \\
\text { until she is able to get a boy or until menopause." IDI, Health Worker, Wajir } \\
\text { "The society values boys more than girls, so if you don't have a boy you keep giving birth } \\
\text { until you are able to get [one]." FGD, Female, Wajir }\end{array}$ \\
\hline & Polygyny & $\begin{array}{l}\text { Polygyny fuelled competition } \\
\text { between co-wives. The more } \\
\text { children each co-wife had, the more } \\
\text { financial support they would inherit. } \\
\text { This was reported more by }\end{array}$ & $\begin{array}{l}\text { "In polygamous marriage when a woman is married to a rich man many children will help } \\
\text { her to inherit more wealth." IDI, Female Leader, Wajir }\end{array}$ \\
\hline
\end{tabular}




\begin{tabular}{|c|c|c|c|}
\hline & & $\begin{array}{l}\text { respondents in Wajir County than in } \\
\text { Lamu County. }\end{array}$ & \\
\hline \multirow[t]{5}{*}{ Jensen (2017) } & $\begin{array}{l}\text { Age at First } \\
\text { Marriage } \\
\text { [Coast Villages] }\end{array}$ & $\begin{array}{l}\text { Relatively lower fertility was likely } \\
\text { due to women marrying later and } \\
\text { therefore being exposed less to } \\
\text { pregnancy. }\end{array}$ & (None presented.) \\
\hline & $\begin{array}{l}\text { Gender Attitudes } \\
\text { [Western } \\
\text { Villages] }\end{array}$ & $\begin{array}{l}\text { In a highly polygynous and } \\
\text { patriarchal society, risky behaviour } \\
\text { such as drinking and prostitution led } \\
\text { to risky sexual behaviour which led } \\
\text { to higher fertility. }\end{array}$ & (None presented.) \\
\hline & $\begin{array}{l}\text { Gender } \\
\text { Preference } \\
\text { [Western } \\
\text { Villages] }\end{array}$ & $\begin{array}{l}\text { Boys were preferred, therefore } \\
\text { women continued to have many } \\
\text { children until they got a son. }\end{array}$ & $\begin{array}{l}\text { "In Bukusu (Kenya)... a woman... must at least give birth to a son, otherwise you are useless } \\
\text { as a person in the family. Children are men's possessions: Children belong to the man... } \\
\text { because he is the one who planted the seed." FGD, Western Villages, Young Female (18- } \\
35 \text { Years) }\end{array}$ \\
\hline & $\begin{array}{l}\text { Marital Security / } \\
\text { Social Status } \\
\text { [Coast and } \\
\text { Western } \\
\text { Villages] }\end{array}$ & $\begin{array}{l}\text { Overall, having many children } \\
\text { provides security for women and } \\
\text { prestige for men in both provinces, } \\
\text { but on varying levels. }\end{array}$ & (None presented.) \\
\hline & $\begin{array}{l}\text { Medical } \\
\text { Improvements } \\
\text { [Coast Villages] }\end{array}$ & $\begin{array}{l}\text { In the past, untreated reproductive } \\
\text { health problems (venereal diseases } \\
\text { and Muslim cultural practices) } \\
\text { resulted in a sub-fertility belt } \\
\text { stretching across central Africa } \\
\text { which left Muslims with lower } \\
\text { fertility than Christians. The Digo } \\
\text { women in this study had fewer } \\
\text { children in their desires. Women } \\
\text { now have access to medical } \\
\text { treatments for STls, and are now } \\
\text { able to achieve their fertility desires, } \\
\text { which explains the slight increase in } \\
\text { fertility. }\end{array}$ & (None presented.) \\
\hline
\end{tabular}




\begin{tabular}{|c|c|c|}
\hline $\begin{array}{l}\text { Polygyny } \\
\text { [Coast Villages] }\end{array}$ & $\begin{array}{l}\text { The power of polygyny is moderate } \\
\text { as women have higher autonomy } \\
\text { and the option to leave their } \\
\text { husbands. }\end{array}$ & $\begin{array}{l}\text { "Just leave the man to live his life and I live mine." Young Female, Early 20s, Mother of Two } \\
\text { (In response to what she would do if her husband took another wife.) }\end{array}$ \\
\hline $\begin{array}{l}\text { Polygyny } \\
\text { [Western } \\
\text { Villages] }\end{array}$ & $\begin{array}{l}\text { Women have many children to } \\
\text { prevent husbands from taking on } \\
\text { additional wives. }\end{array}$ & (None presented.) \\
\hline $\begin{array}{l}\text { Social Status } \\
\text { (Men) } \\
\text { [Western } \\
\text { Villages] }\end{array}$ & $\begin{array}{l}\text { Having many children enhances a } \\
\text { man's prestige, ensures his property } \\
\text { and is a sign of wealth. }\end{array}$ & (None presented.) \\
\hline $\begin{array}{l}\text { Social Status } \\
\text { (Women) } \\
\text { [Western } \\
\text { Villages] }\end{array}$ & $\begin{array}{l}\text { A woman's status depends on the } \\
\text { number of children she bears as "a } \\
\text { prolific wife will command more } \\
\text { respect from her husband and his } \\
\text { kinsmen" (Wagner, 1949). }\end{array}$ & $\begin{array}{l}\text { "I only have one child, who happens to be a girl. People do not value girls as much as boys. } \\
\text { So I feel that I am much inferior if I do not have children just like my co-wife who has eight } \\
\text { children. Thus many people look down upon me just because I do not have many children." } \\
\text { IDI, Female, Early 30s, Western Villages, Has High Status in Terms of Education and } \\
\text { Income, Second Wife of a Man of Rank }\end{array}$ \\
\hline
\end{tabular}




\section{Appendix E3: Increasing Fertility (Malawi)}

Table E3. Results from the qualitative studies (2010-2019 + 2020) displaying the summaries and representative quotes of themes influencing increasing fertility in Malawi.

\begin{tabular}{l|ll|l}
\hline \multicolumn{1}{c|}{ Study } & \multicolumn{1}{c}{ Theme } & \multicolumn{1}{c}{ Summary } & \multicolumn{1}{c}{ Representative Quote(s) } \\
\hline Kok, et al. (2020) & $\begin{array}{l}\text { Polygyny (more } \\
\text { attention with } \\
\text { more children) }\end{array}$ & $\begin{array}{l}\text { Women who have many children get } \\
\text { more attention from husbands when } \\
\text { competing with co-wives. This was } \\
\text { reported by participants in Katuli and } \\
\text { Makanjira where the culture is } \\
\text { predominantly Yao, which is } \\
\text { predominantly Muslim and practice } \\
\text { polygyny. }\end{array}$ & "Give their husbands more children." Married Female \\
& Social Status & $\begin{array}{l}\text { Culturally, having many children } \\
\text { brings men high esteem among their } \\
\text { peers. }\end{array}$ & (None presented.) \\
\hline
\end{tabular}




\section{Appendix E4: Increasing Fertility (Nigeria)}

Table E4. Results from the qualitative studies $(2010-2019+2020)$ displaying the summaries and representative quotes of themes influencing increasing fertility in Nigeria.

\begin{tabular}{|c|c|c|c|}
\hline Study & Theme & Summary & Representative Quote(s) \\
\hline \multirow[t]{3}{*}{$\begin{array}{l}\text { Adefalu, et al. } \\
\text { (2019) }\end{array}$} & *Religion & $\begin{array}{l}\text { In Islam it is forbidden to stop having } \\
\text { children. }\end{array}$ & $\begin{array}{l}\text { "In Islam, they say it is forbidden for a woman to stop herself from getting pregnant or } \\
\text { people from getting more children. So, that is how they see it." } \\
\text { FP Coordinator, Sokoto North LGA } \\
\text { "Islam said woman should not be stopped from getting pregnant and deliver babies which } \\
\text { our religion focuses on." Community Representative, Sokoto North LGA }\end{array}$ \\
\hline & $\begin{array}{l}\text { Age at First } \\
\text { Marriage }\end{array}$ & $\begin{array}{l}\text { Women who married at a younger } \\
\text { age were more likely to have more } \\
\text { children. }\end{array}$ & $\begin{array}{l}\text { "Many women get married at young age when they are in their mid-twenties above and } \\
\text { they already have about six especially when they need male children. When they have many } \\
\text { already, they go to the facility for contraceptives." } \\
\text { Community Representative, Sokoto South LGA }\end{array}$ \\
\hline & $\begin{array}{l}\text { Gender } \\
\text { Preference }\end{array}$ & $\begin{array}{l}\text { Having boys offers a sense of } \\
\text { security in their husband's house, } \\
\text { therefore women will continue to } \\
\text { give birth until they get a boy. }\end{array}$ & (As above.) \\
\hline $\begin{array}{l}\text { Akinyemi, et al. } \\
\text { (2020) }\end{array}$ & ${ }^{*}$ Religion & $\begin{array}{l}\text { Community members believed that } \\
\text { children are a "divine blessing" from } \\
\text { God and families should have as } \\
\text { many children as possible. }\end{array}$ & $\begin{array}{l}\text { "...there will always be resistance to this use of contraceptives, because here, we are people } \\
\text { that believe that children are a blessing, so you give birth to as many as possible. ...The } \\
\text { resistance may not be as a group, but when you come to individual levels... as a government, } \\
\text { they might not show you the resistance, but when it comes to the actual usage, that's where } \\
\text { you start having problems." IDI, Male Doctor, SMoH }\end{array}$ \\
\hline \multirow[t]{2}{*}{$\begin{array}{l}\text { Izugbara, \& Ezeh } \\
\text { (2010) }\end{array}$} & $\begin{array}{l}\text { * Religion } \\
\text { (having children } \\
\text { is a way to } \\
\text { worship God) }\end{array}$ & $\begin{array}{l}\text { Children are a gift from God so } \\
\text { having several children is a way to } \\
\text { worship God and secure the future } \\
\text { of Islam. Those serving one's fertility } \\
\text { to Allah and helping the religion of } \\
\text { Islam are considered good Muslims. }\end{array}$ & (None presented.) \\
\hline & $\begin{array}{l}\text { Age at First } \\
\text { Marriage }\end{array}$ & $\begin{array}{l}\text { Early marriage led to many children. } \\
\text { One respondent stated that she was } \\
\text { only } 12 \text { when she got married, and } \\
\text { by the time she was } 20 \text {, she had had }\end{array}$ & (None presented.) \\
\hline
\end{tabular}




\begin{tabular}{|c|c|c|}
\hline & $\begin{array}{l}6 \text { pregnancies. Men preferred to } \\
\text { take young girls and virgins as wives } \\
\text { for reason related to power, prestige } \\
\text { and status. }\end{array}$ & \\
\hline Child Mortality & $\begin{array}{l}\text { Having a high number of children } \\
\text { was a strategy to take into account if } \\
\text { a child dies during childhood. }\end{array}$ & (None presented.) \\
\hline $\begin{array}{l}\text { Contraceptive } \\
\text { Use (covert use) }\end{array}$ & $\begin{array}{l}\text { Many women used contraceptives } \\
\text { secretly from their husbands which } \\
\text { made adhering to the products' } \\
\text { correct usage difficult, resulting in } \\
\text { risk of pregnancy. Covert use was to } \\
\text { prevent husbands from taking on } \\
\text { more wives if he was to find out } \\
\text { about his wife's limited childbearing. }\end{array}$ & $\begin{array}{l}\text { "It is not easy for women here to use contraceptives with their husbands' knowledge. If men } \\
\text { know..., you cannot tell what they will do. They can tell you to go ahead and then marry } \\
\text { another wife. So, many of us use them secretly..., with poor results." Female } \\
\text { "Many us do not want our husbands to know that we are using contraceptives... so we are } \\
\text { extremely careful. Sometimes you have to hide whatever you are using, and doing this } \\
\text { makes it difficult to use them as prescribed." Female }\end{array}$ \\
\hline $\begin{array}{l}\text { Contraceptive } \\
\text { Use / } \\
\text { Misconceptions }\end{array}$ & $\begin{array}{l}\text { Respondents believed that modern } \\
\text { contraceptives would cause } \\
\text { "mahaifan kulle" (locked womb) and } \\
\text { halt childbearing. Respondents also } \\
\text { believed that modern methods were } \\
\text { laced with substances that could } \\
\text { cause cancer, loss of fertility, birth } \\
\text { defects and STIs. These } \\
\text { misconceptions are enforced by } \\
\text { political and religious campaigns } \\
\text { against modern methods. Many } \\
\text { respondents resorted to traditional } \\
\text { methods, despite knowing that they } \\
\text { are less effective than modern } \\
\text { methods. These traditional methods } \\
\text { involved concoctions, amulets or } \\
\text { charms. The calendar method was } \\
\text { also used, though women found } \\
\text { excuses to not have sex with their }\end{array}$ & $\begin{array}{l}\text { Contraceptives "gradually eat up women's fertility." } \\
\text { Female Participants in Jigawa and Kano } \\
\text { "Even when we don't want to have more children and we make efforts to prevent } \\
\text { [pregnancy] by going for traditional family planning, it usually fails and we continue to have } \\
\text { many children. Many fear using modern methods because of the things we hear about them: } \\
\text {...that they are not good." Kairo, } 38 \text { Years Old, Housewife, Jigawa }\end{array}$ \\
\hline
\end{tabular}


husbands on ovulating days, such as

pretending to be ill or picking a

quarrel.

Financial Having many children provides

Security financial security and labour for the

Polygyny (to

receive more

wealth)

Polygyny (to

prevent

husbands from

taking on more

wives) future, and security and care for

parents in their old age.

(None presented.)

"Here, husbands give things to their wives based on the number of children [the wives] have... To get more of your husband's wealth, you have to give birth to many children."

with more children get a higher

share of the husband's daily earnings

as well as inheritance at death

(Islamic inheritance system). Even

when there is not much to be

inherited, husbands do not ask their

wives to stop giving birth and

competing (perhaps due to their

elevated social status and power

from having many children).

Women give birth to more children

to prevent husbands from taking on

more wives. More children mean

more responsibility for the husband.

\section{Nasirat, Female, 34 Years Old}

"Men here, when they have some money, continue to marry, and when the women begin to compete to have more children, the men do not say anything, even when they know there isn't much to be inherited." Female

"Men always say we need children to inherit from us. When wives hear it, they begin to compete to see who will have more children, especially when the man has some wealth." Female

"If you go there (to my sister's house, aged 40), you won't believe it. When one wife gets pregnant, the others follow immediately; they don't want to be left behind." Female

"Often cowives do not want their mates to have more children than they do. You either match them or outpace them. So they often continue to give birth until the whole place is full of children... If you don't compete, you get less from maigida [the husband]. He will give your mates 10,000 naira because they have many children and give you 3,000 naira or less because you have three children. The problem is there because husbands do not often ask their wives to stop when they notice this happening."

\section{Safinatu, Mother of Seven, Second Wife (of Four)}

"Women here, when they want to prevent their husbands from marrying more wives will continue to give birth. By the time the house is full of children, the man will not want to bring in another wife." Asana, 27 Years Old, Housewife, Kano 


\section{Polygyny (threat} of divorce)

Social Security

Social Security

(survival of

family names,

heritages and

lineages)

"I know men here... If you want to stop them from getting new wives, give them more responsibilities, and don't talk about family planning. Big responsibility is the key thing that prevents them from marrying so many women. When they remember that the responsibility for these children will be theirs alone... they rethink."

\section{Hafsat, 42 Years Old, Mother of Eight, Kano}

"If we had four children each, it would be easy for him to take a third or even a fourth wife. He could even decide to throw one of us out of his house and then redistribute her children among the other wives, but now it is difficult for him to do this." Maimuna, Female, Jigawa (Conspired with her co-wife to each become pregnant in alternate years to prevent their husband from taking on a third wife. They each have 7 children as of this study.)

A strategy to deal with the threat of divorce is to have many children especially when Muslim men have reached their allowed limit of having 4 wives. In northern Nigeria, divorced women do not leave with their children, but rather, they are left with the husbands. Therefore, having many children will put husbands off from divorce.

Childless women can be vulnerable to mistreatment and disrespect, consequently leaving her unhappy. Having children is a form of social protection.

High fertility guarantees the surviva of family names, heritage and

lineages. Childlessness is fatal for the family line.

\section{"A wife with many children is not easily divorced."}

FGD Female Participants in Jigawa and Kano

"One way to prevent a man from divorcing you is to bear him many children."

\section{FGD Female Participants in Jigawa and Kano}

"A wife can prevent divorce by bearing her husband many children."

\section{FGD Female Participants in Jigawa and Kano}

"I heeded this advice, and in five years I had four children. It is difficult for him to ask me to go now because I will leave the children with him. He can't send another four children to his mother." Jamima, Female (Husband was notorious for divorcing his wives over flimsy excuses and sent his 4 children to live with his mother.)

"If you don't have children, people will not respect you." Female, Jigawa

"Children bring you respect; a childless woman can be mistreated by her co-wives and even by her husband... That's why it is good to have many children, so that you are sure nobody will laugh at you." Female, Kano

"Haifuwa maganin mutuwa." ["Only birth cures death."]

Female Participants in Jigawa and Kano 


\begin{tabular}{|c|c|c|c|}
\hline & $\begin{array}{l}\text { Social Security } \\
\text { (survival of } \\
\text { ethnic groups, } \\
\text { faiths and } \\
\text { regions) }\end{array}$ & $\begin{array}{l}\text { High fertility sustains the strength } \\
\text { and relevance of ethnic groups, } \\
\text { faiths and regions, as well as } \\
\text { promotes greater political influence } \\
\text { and representation. }\end{array}$ & $\begin{array}{l}\text { "Without giving birth to many people, we will not have many people and many Muslims." } \\
\text { FGD, Female, Jigawa } \\
\text { "A large population is good...; it guarantees our people a strong place in Nigeria and helps } \\
\text { the religion to flourish." Female, Kano }\end{array}$ \\
\hline & Social Status & $\begin{array}{l}\text { Large families symbolise fame, } \\
\text { influence, respect and wealth, and } \\
\text { serve to expand men and women's } \\
\text { social networks and potentially } \\
\text { elevate families up the social } \\
\text { hierarchy. Furthermore, some of the } \\
\text { many children could marry into } \\
\text { wealthy and powerful households, } \\
\text { bringing parents wealth and social } \\
\text { standing. }\end{array}$ & $\begin{array}{l}\text { "You don't really know, [but a] child may be married by an emir or may marry a governor's } \\
\text { daughter and bring you honour and wealth." Female, Urban Jigawa }\end{array}$ \\
\hline \multirow[t]{4}{*}{$\begin{array}{l}\text { Sinai, et al. } \\
\text { (2019) }\end{array}$} & *Religion & $\begin{array}{l}\text { Both Christian and Muslim } \\
\text { participants believed that children } \\
\text { are a gift from God and should not } \\
\text { be declined. }\end{array}$ & $\begin{array}{l}\text { "We have to thank God who gives us the children and pray to Him to give us good health } \\
\text { and strength to care for them." Rose, } \mathbf{3 1} \text { Years Old, Mother of Five, Only Wife, Christian } \\
\text { "It is God who gives it to you, and you cannot do anything about it." } \\
\text { Zahra, } 36 \text { Years Old, Mother of Seven, Second Wife (of Three), Muslim }\end{array}$ \\
\hline & Child Mortality & $\begin{array}{l}\text { Having a high number of children } \\
\text { was a strategy to take into account if } \\
\text { a child dies during childhood. This } \\
\text { was viewed by most participants in } \\
\text { the } 20-29 \text { age group only. }\end{array}$ & (None presented.) \\
\hline & $\begin{array}{l}\text { Contraceptive } \\
\text { Use }\end{array}$ & $\begin{array}{l}\text { Failure in a FP method resulted in } \\
\text { high number of children. This was } \\
\text { stronger among women in 30-49 age } \\
\text { group than 20-29. }\end{array}$ & (None presented.) \\
\hline & $\begin{array}{l}\text { Financial } \\
\text { Security }\end{array}$ & $\begin{array}{l}\text { High number of children was viewed } \\
\text { as future social and financial } \\
\text { security. }\end{array}$ & (None presented.) \\
\hline
\end{tabular}


Preference

Misconceptions

women continued to have many

children until they got a son.

Some women believed that they

wouldn't be able to conceive easily

because their eggs are far.

Misconceptions

Some women believed that they must have as many children as they

have eggs, and that they must finish their eggs.

Misconceptions Some women believed that only preejaculate liquids could make them pregnant.

Polygyny (share of inheritance)

Polygyny (more attention with more children)

Social

Expectations

Social Status
When co-wives are involved, having many children increases the share of inheritance from the husband.

Many women perceived men to view women more beautifully and love them more if they had more children, especially if competition between co-wives is involved. This view was stronger among women in 30-49 age group than 20-29.

Women felt pressure from relatives and in-laws to have a greater number of children.

Limiting the number of children causes men to appear weak and submissive to their wives.
(None presented.)

"There are some people that say that their egg is far, and they can reach four to five years before they conceive. So, some people are comfortable with it because it is suiting their births and the spacing between their children."

\section{Felicia, 28 Years Old, Mother of One, Only Wife, Christian}

"Some women think that if they do not give birth to all their eggs, it can lead to diseases or make her to become sick, so they try as much as possible to see that they deliver all the eggs." Favour, 29 Years Old, Mother of One, Only Wife, Christian

"Yes, the male sperm that comes at the beginning of the intercourse is what makes women pregnant not the one that comes at the end of long intercourse that only makes the couples feel the pleasure of having sex."

\section{Huseina, 30 Years Old, Mother of Three, Third Wife (of Three), Muslim}

(None presented.)

(None presented.)

(None presented.)

(None presented.) 


\section{Appendix E5: Increasing Fertility (Somalia)}

Table E5. Results from the qualitative studies $(2010-2019+2020)$ displaying the summaries and representative quotes of themes influencing increasing fertility in Somalia.

\begin{tabular}{|c|c|c|c|}
\hline Study & Theme & Summary & Representative Quote(s) \\
\hline $\begin{array}{l}\text { Egeh, et al. } \\
\text { (2019) }\end{array}$ & *Religion & $\begin{array}{l}\text { The Islamic religion encourages } \\
\text { giving birth to as many children as } \\
\text { possible. Limiting the number of } \\
\text { children is considered a sin. }\end{array}$ & $\begin{array}{l}\text { "Using birth control is not only forbidden but is considered a deadly sin and a violation of } \\
\text { Islamic law." Religious Leader }\end{array}$ \\
\hline
\end{tabular}




\section{Appendix E6: Increasing Fertility (Tanzania)}

Table E6. Results from the qualitative studies $(2010-2019+2020)$ displaying the summaries and representative quotes of themes influencing increasing fertility in Tanzania.

\begin{tabular}{|c|c|c|c|}
\hline Study & Theme & Summary & Representative Quote(s) \\
\hline $\begin{array}{l}\text { Aristide, et al. } \\
\text { (2020) }\end{array}$ & ${ }^{*}$ Religion & $\begin{array}{l}\text { Church-goers believed that being } \\
\text { provided with eggs was God's plan } \\
\text { and that they should multiply as } \\
\text { much as they can. Some respondents } \\
\text { were unsure whether their faith } \\
\text { allowed to control the number of } \\
\text { children they give birth to. }\end{array}$ & $\begin{array}{l}\text { "I don't know if the Bible says it but as I recognise even God said he allows us to go and } \\
\text { multiply. I don't know if there is another passage which says you should give birth according } \\
\text { to [FP]." Female, Church Attender } \\
\text { "There is no using FP because I want [to give birth] until the eggs that God planned [have } \\
\text { been used up]." Female, Church Attender }\end{array}$ \\
\hline \multirow[t]{2}{*}{$\begin{array}{l}\text { Msoka, et al. } \\
\text { (2019) }\end{array}$} & $\begin{array}{l}\text { Husband's Age / } \\
\text { No. of Living } \\
\text { Children / } \\
\text { Polygyny }\end{array}$ & $\begin{array}{l}\text { Men are unwilling to limit the } \\
\text { number of children they have until } \\
\text { they reach a certain age and have a } \\
\text { certain number of children (between } \\
\text { multiple wives). }\end{array}$ & $\begin{array}{l}\text { "Vasectomy can be done after a man is above } 45 \text { years and has six or more children. He will } \\
\text { be willing to practice vasectomy because the number of children is so big." } \\
\text { FGD } 3, R 5 \text {, Kisarawe }\end{array}$ \\
\hline & Social Status & $\begin{array}{l}\text { The more children a man had, the } \\
\text { more respected he was in the } \\
\text { community. Men with many children } \\
\text { were viewed as powerful, proud and } \\
\text { rich. Children were seen as assets for } \\
\text { future wealth and labour. }\end{array}$ & (None presented.) \\
\hline \multirow[t]{2}{*}{$\begin{array}{l}\text { Pallangyo, et al. } \\
(2020)\end{array}$} & *Religion & $\begin{array}{l}\text { Some women said limiting births (by } \\
\text { vasectomy) was against "God's } \\
\text { plan". This was particularly relevant } \\
\text { in rural settings. }\end{array}$ & $\begin{array}{l}\text { "Why are you correcting God who planned for the birth? You are contrary to His wish, you } \\
\text { are against good values of the religion... In town, you will be seen as a cunning person, but } \\
\text { for people like us from rural areas it is an issue." Woman 1, Kisarawe }\end{array}$ \\
\hline & Social Status & $\begin{array}{l}\text { Men with many children were } \\
\text { regarded as powerful, proud and } \\
\text { respected in the community. Those } \\
\text { who practice contraception are seen } \\
\text { as weak and submissive to women. }\end{array}$ & (None presented.) \\
\hline
\end{tabular}




\begin{tabular}{|c|c|c|c|}
\hline $\begin{array}{l}\text { Sundararajan, et } \\
\text { al. (2019) }\end{array}$ & $\begin{array}{l}\text { *Religion } \\
\text { (against limiting } \\
\text { number of } \\
\text { children) }\end{array}$ & $\begin{array}{l}\text { Direct statements regarding fertility } \\
\text { within religious scriptural texts were } \\
\text { vague and lacking, leading to varied } \\
\text { and ambiguous interpretations on } \\
\text { religious stances on the number of } \\
\text { children acceptable. A number of } \\
\text { Christian and Muslim respondents } \\
\text { viewed limiting the number of } \\
\text { children as opposed to their religious } \\
\text { beliefs, that their religion states that } \\
\text { they should multiply and fill the land. }\end{array}$ & $\begin{array}{l}\text { "In our religion, we are forbidden to use family planning, because we are told to go and } \\
\text { multiply, and fill the land." Female, Christian } \\
\text { "The Quran does not allow us because the prophet he says he will be proud on that day } \\
\text { when he stands to see the multitude of people is big." Male, Muslim }\end{array}$ \\
\hline
\end{tabular}




\section{Appendix E7: Increasing Fertility (Uganda)}

Table E7. Results from the qualitative studies $(2010-2019+2020)$ displaying the summaries and representative quotes of themes influencing increasing fertility in Uganda.

\begin{tabular}{|c|c|c|c|}
\hline Study & Theme & Summary & Representative Quote(s) \\
\hline \multirow{3}{*}{$\begin{array}{l}\text { Kabagenyi, et al. } \\
\text { (2016) }\end{array}$} & Attitudes & $\begin{array}{l}\text { There is a belief that when there is a } \\
\text { twin birth, it should be followed by } \\
\text { another birth and that it is } \\
\text { abominable to stop at twins. }\end{array}$ & $\begin{array}{l}\text { "For me what I hear people saying is that "Nalongo or Salongo" parents of twins do not stop } \\
\text { giving birth at twins. There should be a follower to the twins called "KIIZA", therefore if } \\
\text { someone bears twins, they have to get another child to follow the twins." } \\
\text { Female, FGD, 25-34 Years, Mpigi }\end{array}$ \\
\hline & $\begin{array}{l}\text { Gender Attitudes } \\
\text { / Domestic } \\
\text { Violence }\end{array}$ & $\begin{array}{l}\text { Some women fear domestic violence } \\
\text { and being chased away if they don't } \\
\text { produce many children. Men are } \\
\text { perceived as the decision-makers } \\
\text { and decide how many children they } \\
\text { want; women are perceived to grant } \\
\text { the number of children a man wants } \\
\text { and does not have any say in the } \\
\text { matter. }\end{array}$ & $\begin{array}{l}\text { "Men are difficult and always say they are the decision makers. For instance, I had twins } \\
\text { with my husband, however when I conceived again, they (health workers) called my } \\
\text { husband to talk to him because I had complications. They (health workers) wanted me to } \\
\text { stop giving birth but my husband did not want." Female, IDI, Bugiri }\end{array}$ \\
\hline & $\begin{array}{l}\text { Gender Attitudes } \\
\text { / Social } \\
\text { Expectations }\end{array}$ & $\begin{array}{l}\text { Married women are expected to give } \\
\text { birth to as many children as possible. } \\
\text { If a woman does meet the marital } \\
\text { expectations, she can be chased }\end{array}$ & $\begin{array}{l}\text { "...in our society every married woman is expected to have as many children as possible. } \\
\text { Those who cannot bear children are given undesirable names. Occasionally, some married } \\
\text { women with few or no children are threatened by their partners to retrieve bride price from } \\
\text { their families." Female, IDI, Bugiri }\end{array}$ \\
\hline
\end{tabular}




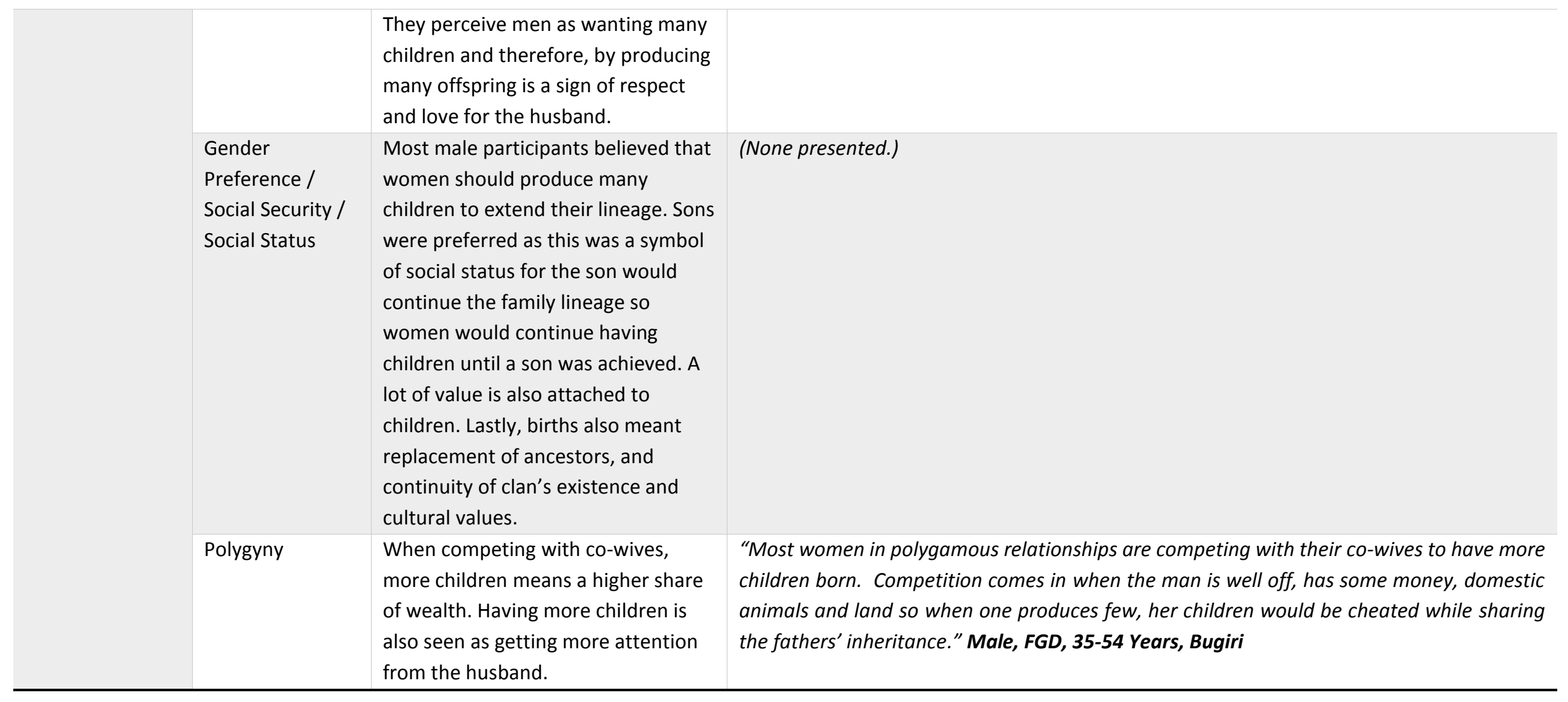




\section{Appendix F1: Limiting Fertility (Ethiopia)}

Table F1. Results from the qualitative studies $(2010-2019+2020)$ displaying the summaries and representative quotes of themes influencing limiting fertility in Ethiopia.

\begin{tabular}{|c|c|c|c|}
\hline Study & Theme & Summary & Representative Quote(s) \\
\hline \multirow[t]{3}{*}{$\begin{array}{l}\text { Davidson, et al. } \\
\text { (2017) }\end{array}$} & $\begin{array}{l}\text { Access to } \\
\text { Education / } \\
\text { Quality of Life } \\
\text { [Eritreans] }\end{array}$ & $\begin{array}{l}\text { Having fewer children can allow for } \\
\text { education and better quality of life. } \\
\text { The following quote may also imply } \\
\text { that having fewer children is also } \\
\text { beneficial for the environment, and } \\
\text { that by benefitting the environment, } \\
\text { quality of life is also benefitted. }\end{array}$ & $\begin{array}{l}\text { "...The world is getting more developed; the soil is not as in the past. It is being polluted. So } \\
\text { that you cannot have children as in the past. You have to see in quality not quantity. Being } \\
\text { educated and healthy, he can benefit the community and can be a citizen that can benefit } \\
\text { his country." Eritrean Male }\end{array}$ \\
\hline & $\begin{array}{l}\text { Fertility Desires } \\
\text { [Eritreans] }\end{array}$ & $\begin{array}{l}\text { Both Eritreans and Somalis desired } \\
\text { high family size, however, Eritreans } \\
\text { preferred to limit their family size to } \\
3 \text { to } 5 \text { children due to economic } \\
\text { constraints and their refugee status. }\end{array}$ & $\begin{array}{l}\text { "I say generally it should not exceed from three." Eritrean Female } \\
\text { "My husband and I do not want to have child here, since we are migrants we do not want } \\
\text { any more." Eritrean Female }\end{array}$ \\
\hline & $\begin{array}{l}\text { Financial } \\
\text { Constraints / } \\
\text { Refugee Status } \\
\text { [Eritreans] }\end{array}$ & $\begin{array}{l}\text { Eritreans preferred to limit their } \\
\text { family size due to economic } \\
\text { constraints and their refugee status. }\end{array}$ & $\begin{array}{l}\text { "You have to get children with plan since we are in migration; economy can restrict you. If } \\
\text { you get more children you can be pressured due to the poverty." Eritrean Male }\end{array}$ \\
\hline Mjaaland (2014) & $\begin{array}{l}\text { Financial } \\
\text { Constraints }\end{array}$ & $\begin{array}{l}\text { Participants from rural and suburban } \\
\text { areas stated that if they could not } \\
\text { afford children, then they should not } \\
\text { have any. Limiting fertility helped } \\
\text { with escaping poverty and hunger, } \\
\text { improved living conditions, improved } \\
\text { their and their children's health, and } \\
\text { be able to provide all their children } \\
\text { (rather than just their cleverest boys) } \\
\text { with an education. }\end{array}$ & $\begin{array}{l}\text { "We want to give our children a good upbringing. If they are too many how can we } \\
\text { manage?" Female, } 30 \text { Years Old, Non-Literate, Peasant } \\
\text { "Since we were rich [then], there was no reason to reduce the births." } \\
\text { Female, } 58 \text { Years Old, Non-Literate, Peasant }\end{array}$ \\
\hline
\end{tabular}




\section{Appendix F2: Limiting Fertility (Kenya)}

Table F2. Results from the qualitative studies $(2010-2019+2020)$ displaying the summaries and representative quotes of themes influencing limiting fertility in Kenya.

\begin{tabular}{|c|c|c|c|}
\hline Study & Theme & Summary & Representative Quote(s) \\
\hline $\begin{array}{l}\text { Abdi, et al. } \\
(2020)\end{array}$ & $\begin{array}{l}\text { Fertility Desires } \\
\text { (preference for } \\
\text { modest family } \\
\text { size) }\end{array}$ & $\begin{array}{l}\text { Both men and women from Lamu } \\
\text { County and Women from Wajir } \\
\text { County desired modest family sizes } \\
\text { of } 4-6 \text { children due to the economic } \\
\text { burden of sustaining large families. }\end{array}$ & $\begin{array}{l}\text { "I would say four is enough. Many women in this current time, they are employed women } \\
\text { and the economy doesn't favour one having many children. Some say they want four, others } \\
\text { even seven children, but most prefer four because it is manageable." } \\
\text { IDI, Female Leader, Lamu }\end{array}$ \\
\hline \multirow[t]{5}{*}{ Jensen (2017) } & $\begin{array}{l}\text { Contraceptive } \\
\text { Use } \\
\text { [Coast }+ \text { Western } \\
\text { Villages] }\end{array}$ & $\begin{array}{l}\text { Widespread access to modern } \\
\text { contraceptives decreased fertility in } \\
\text { Western Villages and kept it low and } \\
\text { stable in Coast Villages. }\end{array}$ & (None presented.) \\
\hline & $\begin{array}{l}\text { Financial } \\
\text { Constraints } \\
\text { [Western } \\
\text { Villages] }\end{array}$ & $\begin{array}{l}\text { Western Villages are more } \\
\text { agricultural therefore needing more } \\
\text { children. But fertility fall of the } \\
\text { Western Villages could be the result } \\
\text { of weak economic development. }\end{array}$ & (None presented.) \\
\hline & $\begin{array}{l}\text { Gender Attitudes } \\
\text { [Coast Villages] }\end{array}$ & $\begin{array}{l}\text { Father's involvement in their } \\
\text { children likely influences keeping } \\
\text { fertility relatively low and stable. }\end{array}$ & (None presented.) \\
\hline & $\begin{array}{l}\text { Gender Attitudes } \\
\text { [Coast and } \\
\text { Western } \\
\text { Villages] }\end{array}$ & $\begin{array}{l}\text { Discontent in gender roles and signs } \\
\text { of change in attitudes may play a } \\
\text { part in fertility trends changing in } \\
\text { Western Villages, and maintaining } \\
\text { relatively low in Coast Villages. }\end{array}$ & (None presented.) \\
\hline & $\begin{array}{l}\text { Gender } \\
\text { Preference } \\
\text { [Coast Villages] }\end{array}$ & $\begin{array}{l}\text { There appears to be no preference } \\
\text { for boys or girls, therefore keeping } \\
\text { fertility relatively low and stable. }\end{array}$ & $\begin{array}{l}\text { "All kids are equal... sex doesn't matter, a kid is a kid." } \\
\text { FGD, Coast Villages, Young Males (18-35 Years) } \\
\text { "I regard all children as equal. We cannot ignore their rights." } \\
\text { IDI, Coast Villages, Young Female }\end{array}$ \\
\hline
\end{tabular}




\section{Appendix F3: Limiting Fertility (Malawi)}

Table F3. Results from the qualitative studies (2010-2019 + 2020) displaying the summaries and representative quotes of themes influencing limiting fertility in Malawi.

\begin{tabular}{|c|c|c|c|}
\hline Study & Theme & Summary & Representative Quote(s) \\
\hline \multirow[t]{3}{*}{ Kok, et al. (2020) } & $\begin{array}{l}\text { Financial } \\
\text { Constraints }\end{array}$ & $\begin{array}{l}\text { Having many children is costly and } \\
\text { keeps the woman stuck in poverty. }\end{array}$ & $\begin{array}{l}\text { "A woman who doesn't follow family planning is always busy with children at home and } \\
\text { poverty is always on her because of the many children. You also appear attractive to your } \\
\text { husband when you practice family planning because you don't get old quickly." } \\
\text { FGD, Married Females 19+ Years, Makanjira }\end{array}$ \\
\hline & $\begin{array}{l}\text { Polygyny (more } \\
\text { attention with } \\
\text { less children) }\end{array}$ & $\begin{array}{l}\text { Contrary to the above, some women } \\
\text { from the same areas stated that } \\
\text { having fewer children helped them } \\
\text { remain attractive to their husbands } \\
\text { thereby avoiding them taking on a } \\
\text { younger second wife. }\end{array}$ & (As above.) \\
\hline & Time Consuming & $\begin{array}{l}\text { Having many children is time } \\
\text { consuming and eliminate women of } \\
\text { their free time. }\end{array}$ & (As above.) \\
\hline
\end{tabular}




\section{Appendix F4: Limiting Fertility (Nigeria)}

Table F4. Results from the qualitative studies $(2010-2019+2020)$ displaying the summaries and representative quotes of themes influencing limiting fertility in Nigeria.

\begin{tabular}{|c|c|c|c|}
\hline Study & Theme & Summary & Representative Quote(s) \\
\hline \multirow[t]{4}{*}{$\begin{array}{l}\text { Izugbara \& Ezeh } \\
\text { (2010) }\end{array}$} & $\begin{array}{l}\text { *Religion (God } \\
\text { and people both } \\
\text { control fertility) }\end{array}$ & $\begin{array}{l}\text { Respondents believed that both God } \\
\text { and the people had the power to } \\
\text { control fertility. }\end{array}$ & $\begin{array}{l}\text { "Allah (God) gives and controls fertility, but people can also do something about it." } \\
\text { FGD Female Participants in Kano } \\
\text { "Allah gives us fertility, but people can also affect it... We can try and fail, but Allah does not } \\
\text { fail." Female, Kano } \\
\text { "It is only Allah that makes people fertile and gives children, but people can also decide to } \\
\text { have a particular number." Amina, } 40 \text { Years Old, Jigawa }\end{array}$ \\
\hline & Fertility Desires & $\begin{array}{l}\text { Most women desired } 5 \text { children or } \\
\text { fewer, however, most women had } \\
\text { far more than their desired number, } \\
\text { exceeding } 6 \text { children. Those who had } \\
\text { not yet achieved their fertility } \\
\text { desires predicted that they would } \\
\text { likely overshoot their desired mark } \\
\text { as a results of co-wife competition. }\end{array}$ & $\begin{array}{l}\text { "I decided then that if I ever married, I wouldn't want more than five or six children." } \\
\text { However, her husband, married a second and third wife, and left them to compete among } \\
\text { themselves concerning the number of children to have. } \\
\text { Halima, } 47 \text { Years Old, Mother of Eight }\end{array}$ \\
\hline & $\begin{array}{l}\text { Financial } \\
\text { Constraints }\end{array}$ & $\begin{array}{l}\text { Despite the influences of wanting to } \\
\text { have many children, most } \\
\text { respondents did not support } \\
\text { unregulated childbearing. Having too } \\
\text { many children can be costly and lead } \\
\text { to poverty, which reduces the quality } \\
\text { of life and opportunities available for } \\
\text { the children. }\end{array}$ & $\begin{array}{l}\text { "Having a house full of children can bring you wealth, good luck, and happiness, but it can } \\
\text { also be difficult. You need to train them and cater for them, and if you are poor, this is not } \\
\text { easy." } 35 \text { Years Old, Mother of Four }\end{array}$ \\
\hline & Maternal Health & $\begin{array}{l}\text { Most respondents acknowledged } \\
\text { that limiting fertility would be } \\
\text { beneficial towards their health, and } \\
\text { avoid illness and suffering. }\end{array}$ & (None presented.) \\
\hline
\end{tabular}




\section{Appendix F5: Limiting Fertility (Tanzania)}

Table F5. Results from the qualitative studies $(2010-2019+2020)$ displaying the summaries and representative quotes of themes influencing limiting fertility in Tanzania.

\begin{tabular}{|c|c|c|c|}
\hline Study & Theme & Summary & Representative Quote(s) \\
\hline $\begin{array}{l}\text { Msoka, et al. } \\
\text { (2019) }\end{array}$ & $\begin{array}{l}\text { Financial } \\
\text { Security }\end{array}$ & $\begin{array}{l}\text { Some women raised concerns that } \\
\text { having fewer children would be } \\
\text { easier financially. }\end{array}$ & (None presented.) \\
\hline \multirow[t]{2}{*}{$\begin{array}{l}\text { Pallangyo, et al. } \\
\text { (2020) }\end{array}$} & $\begin{array}{l}\text { Access to } \\
\text { Education / } \\
\text { Financial } \\
\text { Constraints / } \\
\text { Quality of Life }\end{array}$ & $\begin{array}{l}\text { Some women commented that a } \\
\text { large number of children results in } \\
\text { poor living standards and quality of } \\
\text { life, and that having too many } \\
\text { children meant that families couldn't } \\
\text { pay school fees, leaving children } \\
\text { uneducated as a consequence and } \\
\text { not improving living conditions in the } \\
\text { future. }\end{array}$ & (None presented.) \\
\hline & $\begin{array}{l}\text { Access to } \\
\text { Education / } \\
\text { Quality of Life }\end{array}$ & $\begin{array}{l}\text { Educated men desired smaller family } \\
\text { sizes so that they can provide a } \\
\text { better quality family life. }\end{array}$ & $\begin{array}{l}\text { "Some people will see [a man] as breaching customs (if he uses vasectomy), but those who } \\
\text { are ahead of us those who are well educated see him as a clever person. Educated people } \\
\text { give birth to two, three, or four children, but for us who did not go to school, we go for eight } \\
\text { children or ten. You're competing: my neighbour has six kids so I also need six kids." } \\
\text { Female 1, Chalinze }\end{array}$ \\
\hline $\begin{array}{l}\text { Sundararajan, } \\
\text { et al. (2019) }\end{array}$ & $\begin{array}{l}\text { * Religion (for } \\
\text { limiting number } \\
\text { of children) }\end{array}$ & $\begin{array}{l}\text { Contrary to the above, some } \\
\text { respondents believed that limiting } \\
\text { the number of children was } \\
\text { acceptable by citing moral lessons } \\
\text { derived from religious texts, such as } \\
\text { caring for children and living within } \\
\text { one's means. }\end{array}$ & $\begin{array}{l}\text { "When God says that you should fill the earth, he did not mean we should just give birth, } \\
\text { that we should just give birth haphazardly. He meant that you give birth to those children } \\
\text { you should be able to feed them with your income... You should give birth to the children } \\
\text { that you can take care of in your life... If you do not take care of them, you just leave them? } \\
\text { That is also a sin." Female, Christian } \\
\text { "God has started this question. He has seen it-yes indeed -because he said first when you } \\
\text { want to marry, you marry in accordance with your position. God has admonished us, first } \\
\text { even if you want to marry, marry the women you are able to keep. But, you must fulfil their } \\
\text { needs. There we came to look, and in this question of children, the religion is also involved } \\
\text { to tell us we should give birth in relation to our capacity. It has admonished us we should }\end{array}$ \\
\hline
\end{tabular}




\begin{tabular}{|c|c|c|}
\hline & & $\begin{array}{l}\text { give birth in accordance to our economic capacity, the way we are. Yes, indeed that is how } \\
\text { religion tries to be involved." Male, Muslim }\end{array}$ \\
\hline Maternal Health & $\begin{array}{l}\text { Having fewer children leads to lower } \\
\text { risk of maternal mortality. }\end{array}$ & $\begin{array}{l}\text { "Another reason which women... follow family planning is the deaths of mother and child... } \\
\text { if you look a high percentage of families who do not follow family planning, the mother gets } \\
\text { negative effects. First there is exhaustion, exhaustion brings deaths. The mother gives birth } \\
\text { one year, she gives birth to a child one year, she hasn't rested those cells.... She has a child. } \\
\text { The following year she has a child. It means it leads even to death." Male, Christian }\end{array}$ \\
\hline Quality of Life & $\begin{array}{l}\text { Having fewer children allows more } \\
\text { attention and better quality to be } \\
\text { given to each child. This was } \\
\text { generally agreed upon regardless of } \\
\text { gender or religion. }\end{array}$ & $\begin{array}{l}\text { "We give them a chance of being... [A young child] still needs the mother's love and you give } \\
\text { birth to another child, that means you desert the previous one and you don't give him/her } \\
\text { the same rights equal to the ones of the small child. [By using family planning] we are having } \\
\text { ample time to take care of the children we already have with more love and bringing them } \\
\text { up better." Female, Muslim }\end{array}$ \\
\hline $\begin{array}{l}\text { Quality of Life } \\
\text { (Hygiene) }\end{array}$ & $\begin{array}{l}\text { Having fewer children results in } \\
\text { better hygiene. Husbands also want } \\
\text { clean living conditions otherwise } \\
\text { they may look for additional wives } \\
\text { that are cleaner. }\end{array}$ & $\begin{array}{l}\text { "Now the man sees the children reach even three, four inside. Now I, the woman, will be } \\
\text { unable even to wash clothes, to sweep the house. When he comes in he finds it just dirty. } \\
\text { Now it is necessary that he finds a [girlfriend outside of the marriage] because... he'll find } \\
\text { that woman is clean. Maybe she has children, she has only one child. He'll find the lady there } \\
\text { is clean. She washes the clothes. But if he comes to you with five or six children, it just smells } \\
\text { of urine inside, so he just has to run away and leave you with this family." Female, Christian }\end{array}$ \\
\hline
\end{tabular}




\section{Appendix G1: Lower Acceptance of Family Planning (Ethiopia)}

Table G1. Results from the qualitative studies $(2010-2019+2020)$ displaying the summaries and representative quotes of themes influencing lower acceptance of family planning in Ethiopia.

\begin{tabular}{|c|c|c|c|}
\hline Study & Theme & Summary & Representative Quote(s) \\
\hline \multirow[t]{2}{*}{$\begin{array}{l}\text { Davidson, et al. } \\
\text { (2017) }\end{array}$} & *Religion & $\begin{array}{l}\text { Many Muslim Somalis chose not to } \\
\text { use FP because it was against their } \\
\text { religious beliefs. Religion was also a } \\
\text { deterrent to use of the contraceptive } \\
\text { implant for Somalis. }\end{array}$ & $\begin{array}{l}\text { "My religion doesn't allow me to control the birth." Somali Woman } \\
\text { "I meet other who have different idea than me; they say to me, "What do you need implant? } \\
\text { If you die while implant is with you then you will be in the hell." However, my husband and } \\
\text { I agreed to use this method." Somali Woman }\end{array}$ \\
\hline & Attitudes & $\begin{array}{l}\text { Somali views on modern FP were } \\
\text { more negative. However, when it } \\
\text { came to the Intrauterine Device, } \\
\text { both Eritreans and Somalis held } \\
\text { negative attitudes due to its long- } \\
\text { acting nature. One Eritrean man } \\
\text { believed it was used by sex workers. }\end{array}$ & $\begin{array}{l}\text { "You can use birth control, but you had better use natural methods not artificial methods." } \\
\text { Somali Woman } \\
\text { "We hate them [contraceptives]." Somali Woman } \\
\text { "We heard it, but it is impossible to us because it [IUD] is a long term." } \\
\text { Somali Men and Women } \\
\text { "I do not know the time of intrauterine device takes, so I may die before having any child." } \\
\text { Somali Men and Women } \\
\text { "This [IUD] is very difficult contraception method to use, besides waiting } 10 \text { years; people } \\
\text { cannot accept waiting in } 3 \text { years, particularly in the Somali community. I do not belief that } \\
\text { refugee women in this camp will accept this kind of birth control ever." Somali } \\
\text { "They did not choose it [IUD] because it stays for a long time and they need before that time } \\
\text { to give birth." Somali } \\
\text { It [IUD] is very effective as informed by health professionals. You can take it out whenever } \\
\text { you want baby, but every one cannot remove it. But in our community it is not acceptable; } \\
\text { because if she is going to stay for } 10 \text { years without child she may be sterile." } \\
\text { Male (despite knowing that IUD can be removed for childbearing) }\end{array}$ \\
\hline
\end{tabular}




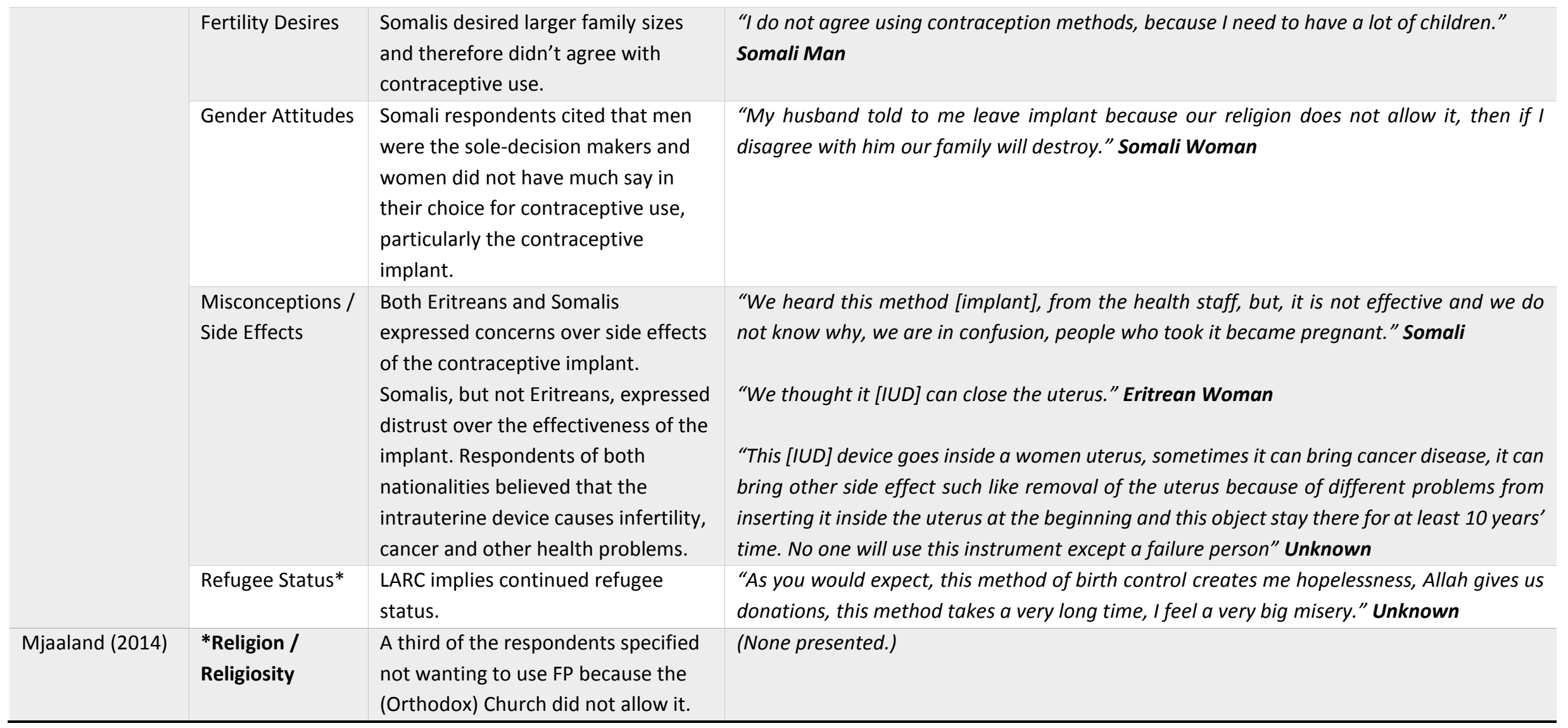




\section{Appendix G2: Lower Acceptance of Family Planning (Kenya)}

Table G2. Results from the qualitative studies $(2010-2019+2020)$ displaying the summaries and representative quotes of themes influencing lower acceptance of family planning in Kenya.

\begin{tabular}{|c|c|c|c|}
\hline Study & Theme & Summary & Representative Quote(s) \\
\hline \multirow[t]{4}{*}{$\begin{array}{l}\text { Abdi, et al. } \\
(2020)\end{array}$} & *Religion & $\begin{array}{l}\text { Some respondents form both Lamu } \\
\text { and Wajir counties stated that Islam } \\
\text { does not support the use of FP at all } \\
\text { and that children are a blessing from } \\
\text { God. }\end{array}$ & $\begin{array}{l}\text { "Family planning is haram because you are preventing a living creature from coming to the } \\
\text { world." FGD, Male, Lamu } \\
\text { "Because they have the belief that God is the one who provides and sustains so family } \\
\text { planning is a sin to them even when we are giving them health talk some say we the health } \\
\text { workers are irrational, they ask why do you want us to kill the unborn child, they tell us } \\
\text { taking the pill is to kill the child." IDI, Health Provider, Wajir }\end{array}$ \\
\hline & $\begin{array}{l}\text { Access to } \\
\text { Education / } \\
\text { Spousal } \\
\text { Communication }\end{array}$ & $\begin{array}{l}\text { In Wajir, communication on } \\
\text { contraceptive use was rare or non- } \\
\text { existent and often depended on the } \\
\text { level of education of the couples. In } \\
\text { both Lamu and Wajir, lack of } \\
\text { communication or opposition from } \\
\text { husband or other family member } \\
\text { often led women to resort to covert } \\
\text { use of contraceptives, risking their } \\
\text { marriage. }\end{array}$ & $\begin{array}{l}\text { "At the family level discussing family planning is an issue [for only the few] who are educated } \\
\text { because there is mass which are over } 80 \text { percent of uneducated people the issue of a family } \\
\text { planning it is not a topic of discussion... "IDI, Health Manger, Wajir } \\
\text { "There are some who say they hide the pills because if their husbands find out they end up } \\
\text { getting divorced but there are those who are clever enough they come for injection that way } \\
\text { the husband will not know." IDI, Female Leader, Wajir } \\
\text { "In cases where men don't support, this forces the woman to practice family planning in } \\
\text { secrecy. This can also lead to relationship wrangles and [divorce]." FGD, Females, Lamu }\end{array}$ \\
\hline & Child Mortality & $\begin{array}{l}\text { Many respondents from both Lamu } \\
\text { and Wajir counties considered the } \\
\text { risk that some children would die } \\
\text { during childhood, which influenced } \\
\text { their lower uptake of contraception. } \\
\text { Furthermore, when a child dies, a } \\
\text { woman was less likely to use FP. }\end{array}$ & $\begin{array}{l}\text { "We prefer many children so that when some die at least you will still have some. For } \\
\text { example, when you have only one or two and God takes them what will you do? So it's wise } \\
\text { you bear as many children as you can." FGD, Female, Lamu } \\
\text { "...many people have that perception that I rather have many children so that when some } \\
\text { die, still you have other children." IDI, Female Leader, Wajir }\end{array}$ \\
\hline & Gender Attitudes & $\begin{array}{l}\text { In both Lamu and Wajir counties, } \\
\text { most women believed that men had } \\
\text { full authority in FP decision making. }\end{array}$ & $\begin{array}{l}\text { "In many cases, the decision of how many children the family needs lies with the husband. } \\
\text { In some instance[s], the decision is made by the couple. In few instances, advice from the } \\
\text { doctor due to the health of the mother." FGD, Male, Lamu }\end{array}$ \\
\hline
\end{tabular}




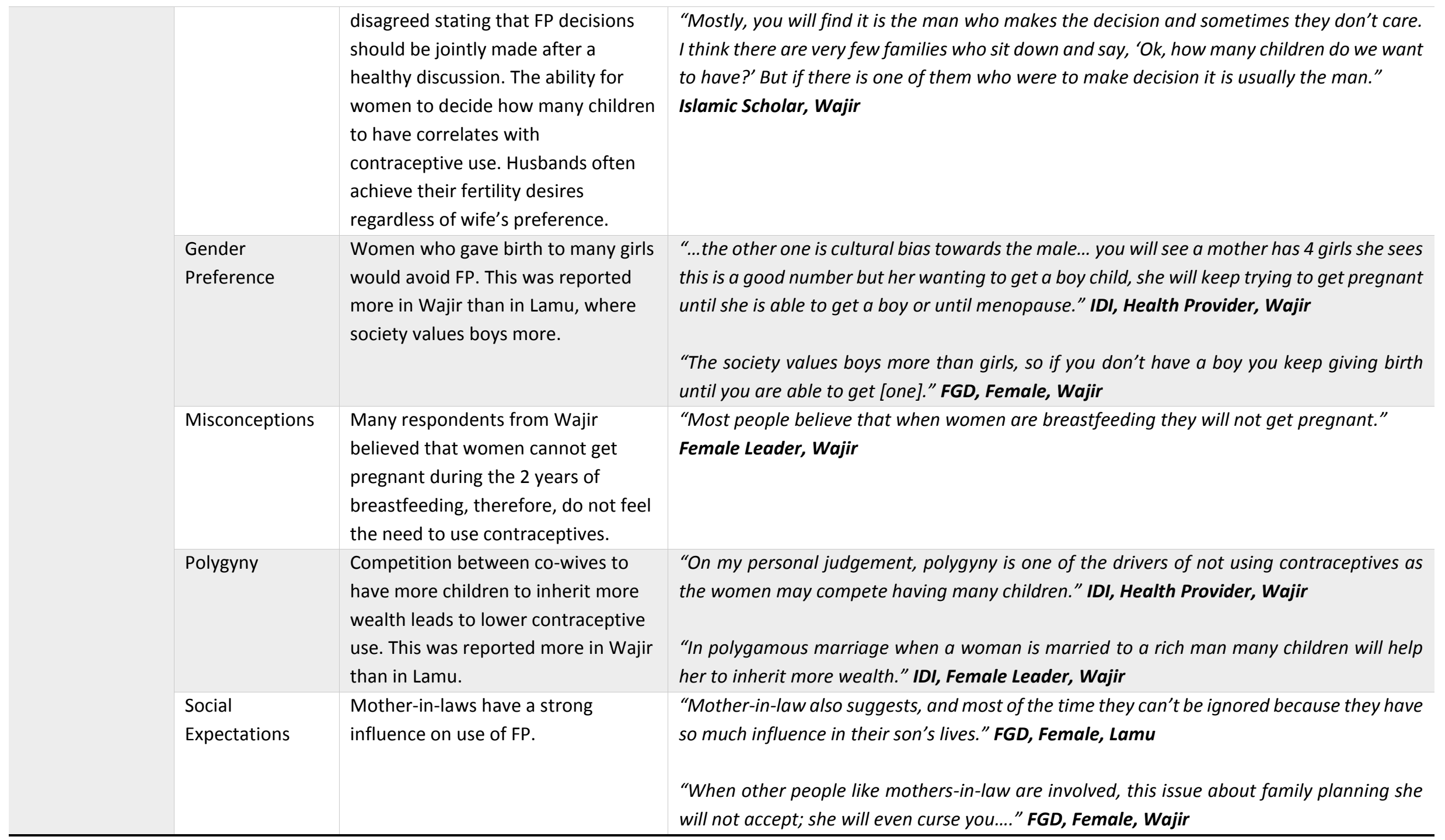




\section{Appendix G3: Lower Acceptance of Family Planning (Malawi)}

Table G3. Results from the qualitative studies $(2010-2019+2020)$ displaying the summaries and representative quotes of themes influencing lower acceptance of family planning in Malawi.

\begin{tabular}{|c|c|c|c|}
\hline Study & Theme & Summary & Representative Quote(s) \\
\hline \multirow[t]{3}{*}{ Kok, et al. (2020) } & Accessibility & $\begin{array}{l}\text { Although there is a high availability } \\
\text { of contraceptives, the most popular } \\
\text { methods such as Depo Provera were } \\
\text { often out of stock. This is because } \\
\text { district hospitals and health centres } \\
\text { can only order according to the } \\
\text { number of commodities used in the } \\
\text { last consignment. As a result of stock } \\
\text { outs, women were often encouraged } \\
\text { to use another method, which } \\
\text { sometimes made them terminate } \\
\text { their contraceptive uptake, and led } \\
\text { to mistrust against HSAs. }\end{array}$ & $\begin{array}{l}\text { "The methods are not there, it's now six months without contraceptives and many [people] } \\
\text { like the Depo but it's not there. And now the people have lost hope in family planning." } \\
\text { FGD, HSAs, Lugola }\end{array}$ \\
\hline & Attitudes & $\begin{array}{l}\text { Sex is seen as for those who are } \\
\text { married, therefore, social stigma } \\
\text { exists for young people who used } \\
\text { contraceptives, particularly young } \\
\text { females who are seen as } \\
\text { promiscuous. Although HSAs kept } \\
\text { young people's contraceptive use } \\
\text { confidential and were overall } \\
\text { comfortable supply young people } \\
\text { with contraceptives, they did not } \\
\text { seem to know how to face possible } \\
\text { resistance when discussing teenage } \\
\text { pregnancy prevention with parents. }\end{array}$ & (None presented.) \\
\hline & Gender Attitudes & $\begin{array}{l}\text { Both male and female participants } \\
\text { agreed that child upbringing is more }\end{array}$ & (None presented.) \\
\hline
\end{tabular}


the woman's responsibility and

therefore, contraceptive uptake was seen as the woman's responsibility. However, husbands hold authority and if husbands did not support the use of contraceptives, women would resort to covert use. Most women preferred Depo-Provera and would visit the health clinic at night to get the injection. Some women feared that their husbands would divorce them should they find out. On the other hand, most male participants claimed that they would not feel uncomfortable if their wives were using contraceptives covertly.

Misconceptions

Many participants, particularly men

believed that contraceptives would

reduce sexual desire and

performance, and cause body

deformations. These misconceptions

were either experienced first-hand

or heard from others in the

community.

Polygyny (more

attention with

more children) more attention from husbands when

competing with co-wives. This was
"The contraceptives have weakened our men. They could sleep with us three times a day, but not now, they can't perform..." FGD, Married Females 19+ Years, Makanjira

\section{"Give their husbands more children." Married Female}

reported by participants in Katuli and

Makanjira where the culture is

predominantly Yao, which is

predominantly Muslim and practice

polygyny. These women don't use

contraceptives. 
Quality of Family

Planning and

Services

(training)

Social Status
About half of the HSAs that took part

in the study were trained in the

provision of Depo Provera. This

caused confusion and mistrust

among clients when untrained HSAs

had to refer to trained HSAs.

More children gave men high esteem

within the community.
"Number 6 [referring to a colleague HSA] and I come from very far villages, and when we tell the people to come here at the hospital to get the Depo, they find the nurse busy and they go back home, 26 to 28 kilometres without any help. If we were trained, we would help them in the outreach clinics." FGD, HSAs, Namkumba

(None presented.) 


\section{Appendix G4: Lower Acceptance of Family Planning (Nigeria)}

Table G4. Results from the qualitative studies $(2010-2019+2020)$ displaying the summaries and representative quotes of themes influencing lower acceptance of family planning in Nigeria.

\begin{tabular}{|c|c|c|c|}
\hline Study & Theme & Summary & Representative Quote(s) \\
\hline \multirow[t]{3}{*}{$\begin{array}{l}\text { Adefalu, et al. } \\
\text { (2019) }\end{array}$} & $\begin{array}{l}\text { *Religion / } \\
\text { Gender Attitudes }\end{array}$ & $\begin{array}{l}\text { According to Islam, use of FP is } \\
\text { forbidden, even if the woman has } \\
\text { medical issues. This view has a } \\
\text { strong influence on husbands' } \\
\text { rejection of FP. Men are seen as the } \\
\text { decision makers of the household. }\end{array}$ & $\begin{array}{l}\text { "We are bound by religion... they say family planning is Haram that means it is forbidden... } \\
\text { If she even has some medical issues she cannot, she will say no, it is Haram." } \\
\text { FP Coordinator, Sokoto North LGA } \\
\text { "Islam said woman should not be stopped from getting pregnant and deliver babies which } \\
\text { our religion focuses on." Community Representative, Sokoto North LGA } \\
\text { "Here, whatever your husband says is the final, so for some women, their husband will not } \\
\text { allow them." FP Coordinator, Argungu LGA } \\
\text { "So the men will stop their women, they will already tell you as you are getting married that } \\
\text { it is Haram. Some will even make them to vow, they will make them to swear even before } \\
\text { you marry, that you will not do family planning." FP Coordinator, Sokoto North } \\
\text { "Everything here is all about your husband. You can't do anything without your husband } \\
\text { here, so knowledge is very limited." Community Representative, Aliero LGA } \\
\text { "...some men do not still allow their wives." FP Coordinator, Sokoto South LGA }\end{array}$ \\
\hline & Accessibility & $\begin{array}{l}\text { All LGAs, with the exception of } \\
\text { Sokoto North, have experienced } \\
\text { stock-out of contraceptives. }\end{array}$ & $\begin{array}{l}\text { "We do experience stock-out sometimes. Even now, we have no commodity and our } \\
\text { providers are complaining that they do not have any commodity." } \\
\text { FP Coordinator, Sokoto South LGA }\end{array}$ \\
\hline & $\begin{array}{l}\text { Age at First } \\
\text { Marriage / } \\
\text { Financial } \\
\text { Security / } \\
\text { Gender } \\
\text { Preference }\end{array}$ & $\begin{array}{l}\text { Marrying at an early age and having } \\
\text { lots of children, some of which are } \\
\text { boys, offers financial security in the } \\
\text { husband's house, thus many women } \\
\text { do not use contraceptives until this } \\
\text { goal has been achieved. }\end{array}$ & $\begin{array}{l}\text { "Many women get married at young age when they are in their mid-twenties above and } \\
\text { they already have about six especially when they need male children. When they have many } \\
\text { already, they go to the facility for contraceptives." } \\
\text { Community Representative, Sokoto South LGA }\end{array}$ \\
\hline
\end{tabular}




\begin{tabular}{|c|c|c|c|}
\hline & Attitudes & $\begin{array}{l}\text { With the exception to Sokoto South, } \\
\text { unmarried women were less } \\
\text { comfortable obtaining FP due to the } \\
\text { social stigma attached. }\end{array}$ & $\begin{array}{l}\text { "Anybody can demand for contraceptive... some that are not married, their boyfriend will } \\
\text { buy the drug for them in the chemist." Community Representative, Aliero LGA } \\
\text { "Anybody can demand for contraceptive and family planning but if you are not married, } \\
\text { people will gossip about it especially all these young ones." } \\
\text { Community Representative, Sokoto North LGA }\end{array}$ \\
\hline & $\begin{array}{l}\text { Knowledge of } \\
\text { Family Planning }\end{array}$ & $\begin{array}{l}\text { Level of knowledge of FP was } \\
\text { generally poor. }\end{array}$ & $\begin{array}{l}\text { "...knowledge is very limited. Enlightenment is very poor." } \\
\text { Community Representative, Aliero LGA }\end{array}$ \\
\hline & $\begin{array}{l}\text { Social } \\
\text { Expectations }\end{array}$ & $\begin{array}{l}\text { The older generation is able to } \\
\text { influence young, uneducated women } \\
\text { against contraceptive use. }\end{array}$ & $\begin{array}{l}\text { "The problem is those old people and women, they are the ones that have the problems and } \\
\text { influence young uneducated women against contraceptive use." } \\
\text { FP Coordinator, Sokoto North, KII }\end{array}$ \\
\hline \multirow[t]{3}{*}{$\begin{array}{l}\text { Akinyemi, et al. } \\
\text { (2020) }\end{array}$} & *Religion & $\begin{array}{l}\text { Children are 'divine blessings' from } \\
\text { God and procreation should not be } \\
\text { regulated. }\end{array}$ & $\begin{array}{l}\text { "...There will always be resistance to this use of contraceptives, because here, we are people } \\
\text { that believe that children are a blessing, so you give birth to as many as possible. ...The } \\
\text { resistance may not be as a group, but when you come to individual levels... as a government, } \\
\text { they might not show you the resistance, but when it comes to the actual usage, that's where } \\
\text { you start having problems." IDI, Male, Doctor, SMoH }\end{array}$ \\
\hline & ${ }^{*}$ Religiosity & $\begin{array}{l}\text { Strong religiosity is a hindrance to } \\
\text { contraceptive uptake. }\end{array}$ & (None presented.) \\
\hline & $\begin{array}{l}\text { Gender Attitudes } \\
\text { / Knowledge of } \\
\text { Family Planning }\end{array}$ & $\begin{array}{l}\text { Gombe is largely a society where } \\
\text { men are the sole decision-makers } \\
\text { and may not allow contraceptive } \\
\text { use. Many men are also ill-informed } \\
\text { about contraceptives. }\end{array}$ & $\begin{array}{l}\text { "Some men will not accept it (contraceptive) because they want plenty children... she (the } \\
\text { wife) should continue begging the husband until he agrees if she wants to use } \\
\text { contraceptives." FGD, Women Not Using Contraceptives } \\
\text { "...Some of the men don't know much about family planning commodities and some } \\
\text { (people) are telling them some of the side effects. So, they prevent the women from using } \\
\text { them...that's why we need more sensitization to the men and the youths." } \\
\text { IDI, Female, Nurse } \\
\text { "The perception of men (about contraceptives) is lower than that of women. The women } \\
\text { know the implications better than the men. The men in the rural areas don't mind having } \\
\text { any number of children..." FGD, Married Men } \\
\text { "Honestly, we need to do more in carrying them [men] along. Male involvement is very } \\
\text { important because you know they are our superiors. We in the North, it is only the educated } \\
\text { that may be sometimes at loggerhead (with their husbands)... but these illiterates and }\end{array}$ \\
\hline
\end{tabular}




\begin{tabular}{|c|c|c|c|}
\hline & & & $\begin{array}{l}\text { native people, it is always the man that is superior. So, it is very important for us to consider } \\
\text { male involvement, it will help a lot." IDI, Female, Nurse }\end{array}$ \\
\hline & Side Effects & $\begin{array}{l}\text { Adverse effects of injectable } \\
\text { contraceptives have led to } \\
\text { reluctance to take up or continue } \\
\text { with the contraceptive. }\end{array}$ & "Severe bleeding during menstruation." IDI, Female, CHEW \\
\hline
\end{tabular}




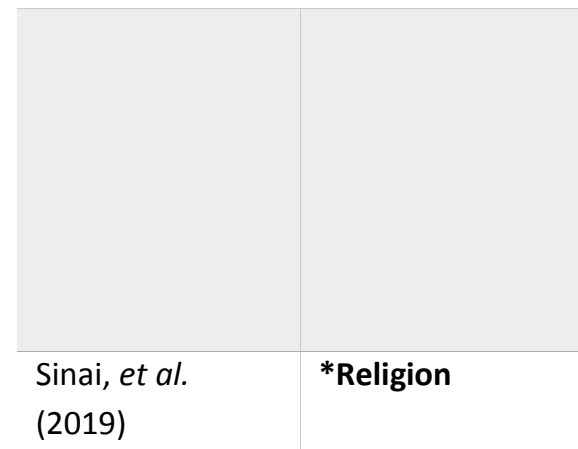

(2019)

Affordability

Attitudes

Gender Attitudes involved concoctions, amulets or charms. The calendar method was also used, though women found excuses to not have sex with their husbands on ovulating days, such as pretending to be ill or picking a quarrel.

Both Christian and Muslim participants believed that children are a gift from God and should not be declined. Therefore, many women do not feel empowered to make contraceptive decisions.

Participants showed concerns that contraception was not always instock at health facilities.

Although commodities are free, clients often have to pay for tests, consumables, and insertion and removal of LARC.

Women who use contraception are viewed as promiscuous and men who let their wives use

contraception are considered weak.

Many women felt they did not have the power to make contraceptive decisions as husbands were seen as the decision-makers of the household. Most men, and their
"We have to thank God who gives us the children and pray to Him to give us good health and strength to care for them." Rose, 31 Years Old, Mother of Five, Only Wife, Christian

"It is God who gives it to you, and you cannot do anything about it."

Zahra, 36 Years Old, Mother of Seven, Second Wife (of Three), Muslim

"Injection and implant are not always available in the hospitals, so they use drugs [emergency contraception]."

Huseina, 30 Years Old, Mother of Three, Third Wife (of Three), Muslim

"It can prevent because I don't know the reality of the cost of the commodity. I just relied on the false information that some women are spreading. So, if I don't have the money I can be scared to go to the hospital for the method."

\section{Blessing, 27 Years Old, Mother of Four, Only Wife, Christian}

"Some people see the women who use family planning as promiscuous. This is because they think that such women are engaged in extra-marital sexual activities. That is why they are using the methods to prevent them from getting pregnant."

Thabita, 25 Years Old, Mother of Three, Only Wife, Christian

"In my area if a woman uses a family planning method, people think that her husband does not have control over [her] and that she is not submissive to her husband, and in most cases the woman encounters problems with her husband's relatives."

\section{Rita, 28 Years Old, Mother of Three, Only Wife, Christian}

"In my area if a woman uses a family planning method, people think that her husband does not have control over [her] and that she is not submissive to her husband, and in most cases the woman encounters problems with her husband's relatives."

Rita, 28 Years Old, Mother of Three, Only Wife, Christian 
relatives, were against contraceptive use. Many participants perceived that their husbands did not understand the burden of childbearing and that child-rearing was solely the mother's responsibility. Participants perceived that some health providers will only prescribe FP if they are accompanied by their husbands or if they have already given birth to at least 3 children.

Some women covertly use contraceptives as they fear their husbands will divorce them should they find out. Although this means contraceptive uptake, it could potentially result in incorrect usage.

\section{Misconceptions Many folkloric contraceptive} methods were also mentioned, such as drinking various concoctions after sex, including water mixed with Quranic verses. Others included smoking of spider web and herbs, and wearing beads around the waist. Information about these methods was circulated by religious and traditional leaders, as well as by men and women in the community.

Misconceptions Participants believe women need to have as many children as possible or they become sick, and that they can
"If you come to the hospital to get a method, they will not attend to you if you don't come with your husband. So, they will tell you to come back with your husband and until he agrees before you can get a method."

\section{Aziza, 30 Years Old, Mother of Five, First Wife (of Two), Muslim}

"I went to collect a method, but the provider asks me how many children do I have? I replied only one and he said they only give method to a woman after she delivered three times."

\section{Thabita, 25 Years Old, Mother of Three, Only Wife, Christian}

"Yes, there are situations whereby the husbands don't want their wives to use the methods, so if they use the methods secretly it can lead the husbands to divorce them once they realise that their wives are using the methods."

\section{Favour, 29 Years Old, Mother of One, Only Wife, Christian}

"There is one religious method that is called rubutu. In this case you write some [Quranic] verses on a piece of paper, cut the paper into tiny pieces and then you swallow the pieces of paper bit by bit depending on the duration of the safe period [from pregnancy] you want to have." Unidentified, 15-29 Age Group

"We get the information about the traditional methods from the elderly members of the community. I have used the guru [sacred rope] tied round the waist and Laya [sacred band]." Bintu, 40 Years Old, Mother of Seven, First Wife (of Two), Muslim

"Some women think that if they do not give birth to all their eggs, it can lead to diseases or make her to become sick, so they try as much as possible to see that they deliver all the eggs." Favour, 29 Years Old, Mother of One, Only Wife, Christian 
get pregnant from pre-ejaculate

fluids, not sperm. These

misconceptions lead participants to

believe that they do not require

contraception.

Misconceptions Most participants had the

misconception that health providers would not prescribe a form of FP without undergoing tests.

Misconceptions / Most participants believed there was Side Effects a major risk to using modern contraceptives, including bleeding, infertility and miscarriage. The source of this information was often from family and friends rather than from health facilities.

Polygyny (more attention with more children
Many women perceived men to view women more beautifully and love them more if they had more children, especially if competition between co-wives is involved. Therefore, women in these situations are less inclined to use contraception. This view was stronger among women in 30-49 age group than 20-29.
"Yes, the male sperm that comes at the beginning of the intercourse is what makes women pregnant not the one that comes at the end of long intercourse that only makes the couples feel the pleasure of having sex."

\section{Huseina, 30 Years Old, Mother of Three, Third Wife (of Three), Muslim}

"We know that one is supposed to be tested and the people who go there are not usually tested, and the results have been bad. So how can we go, since we see women who use [the methods without test] suffer the side effect?"

\section{Elizabeth, 29 Years Old, Mother of Three, Only Wife, Christian}

"Some women want to use the methods but are scared of the excessive bleeding that usually accompanies the use of the methods. I know of a woman who bled for more than two weeks after using a method of delaying pregnancy."

Laraba, 45 Years Old, Mother of Seven, Third Wife (of Three), Muslim

"I see many women after using it and they want to have children, they usually don't conceive when they want [...] for a very long time. I observed that in most cases when they eventually conceive, they either lose the child after birth or sometimes even lose their lives during delivery." Rita, 28 Years Old, Mother of Three, Only Wife, Christian

"Any woman that has used a method and benefited from it always informs her friends about the methods she has used. If her friends complain to her about problems related to childbirth, she directs them to the hospital where they also obtain the methods and counsels on how the method works."

Bintu, 40 Years Old, Mother of Seven, First Wife (of Two), Muslim

(None presented.) 
Polygyny (share

of inheritance)

Quality of Family

Planning \&

Services

Social

Expectations

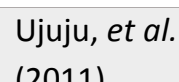

*Religion

(2011)

\section{*Religion /}

Gender Attitudes

with the husband is against the

religious ethics of marriage. In

marriages where the husband

refused to cooperate on fertile days,

women would have to stop using

SDM.

Attitudes

Fear of Sexual

Dissatisfaction

Gender Attitudes

\section{Condoms were perceived to}

encourage promiscuity.

Condoms were perceived to have

reduced sexual satisfaction and

performance.

In Enugu state, some women

covertly use modern contraceptives

to not anger their husband nor be

ostracised from the community.
(None presented.)

"The provider was kind to me, she was polite in her response. It was a nice experience meeting that woman." Julie, 28 Years Old, Mother of Five, Only Wife, Christian

"Some men are not against it, because when the woman looks good because she is resting from childbirth, it makes the man proud. But the instigation from the husband's relatives makes the man to be against it, sometimes beating the woman."

\section{Joy, 27 Years Old, Mother of Three, Only Wife, Christian}

"Some religion is against pills but this one (CycleBeads), our Priest encouraged us to use it."

Female

(None presented.)

(None presented.)

(None presented.)

"They (women) will come and take injectables so that the husband will not know about it or take pills (they) remove pill from the sachet and put it in an envelope... (this is because) if the husband hears that the wife is taking pills, he'll be furious." Health Provider 


\section{Knowledge of}

Family Planning

Although no misconceptions were

mentioned, some users stated that

they did not fully understand the

instructions of SDM and CycleBeads.

Misconceptions

Some respondents believe that the use of modern contraceptives can prevent future pregnancy and that some methods cause abortion.

Self-Control A big drawback of SDM is the long fertile period and having to have strong sexual self-control.

Participants who had stopped using injectable contraceptives

complained of side effects including irregular bleeding, menorrhagia,

headaches and stiffness.

Subsequently they took up SDM.
"The red indicates the start of the period, the white possibility of conception and the brown no conception." Male

"I have used condoms but each time I meet my wife I don't enjoy it, then I used Billing's Method but I don't understand its instructions." Male

(None presented.)

"When I take injection it is for 2 months I and my husband meet at anytime but now it needs a lot of self-control on his side." Female

"One of my friends is also using it but her initial complaint was that the white bead days are too long. They are practicing the withdrawal method during the white bead days." Female

"They told me they would stop using it because of the white bead days." Health Provider "For me I had a problem, I was using injectable and I was menstruating 2 times in a month." Female 


\section{Appendix G5: Lower Acceptance of Family Planning (Somalia)}

Table G5. Results from the qualitative studies $(2010-2019+2020)$ displaying the summaries and representative quotes of themes influencing lower acceptance of family planning in Somalia.

\begin{tabular}{|c|c|c|c|}
\hline Study & Theme & Summary & Representative Quote(s) \\
\hline \multirow[t]{3}{*}{$\begin{array}{l}\text { Egeh, et al. } \\
\text { (2019) }\end{array}$} & *Religion & $\begin{array}{l}\text { Use of FP is only acceptable for the } \\
\text { purpose of birth spacing, but only } \\
\text { when used in compliance with } \\
\text { Islamic religious beliefs. Using FP for } \\
\text { the purpose of limiting is considered } \\
\text { a sin in Islam. }\end{array}$ & $\begin{array}{l}\text { "Using birth control is not only forbidden but is considered a deadly sin and a violation of } \\
\text { Islamic law." Religious Leader } \\
\text { "Allah makes the ultimate decision regarding creation; withdrawal can prevent the woman } \\
\text { from becoming pregnant. Thus, a distinction is drawn between whether the withdrawal } \\
\text { method was used with the intention to limit the number of children or to space the births. } \\
\text { This distinction is important when making the choice to use the withdrawal method." } \\
\text { Religious Leader }\end{array}$ \\
\hline & $\begin{array}{l}\text { Birth Spacing - } \\
\text { Condom }\end{array}$ & $\begin{array}{l}\text { Condoms are also prohibited as this } \\
\text { practice would likely promote sexual } \\
\text { activity outside of marriage. }\end{array}$ & $\begin{array}{l}\text { "I am totally against condoms. I believe that condoms cause diseases when they are used } \\
\text { by young people without control. I don't trust the idea that condoms prevent sexually } \\
\text { transmitted diseases. In my opinion, it leads instead to negative use and in that sense } \\
\text { condoms are disgusting, insecure products used by the young and unmarried." } \\
\text { Religious Leader }\end{array}$ \\
\hline & Misconceptions & $\begin{array}{l}\text { Religious leaders stated that } \\
\text { breastfeeding before intercourse will } \\
\text { decrease the chances of pregnancy, } \\
\text { even though it is still possible to } \\
\text { become pregnant while } \\
\text { breastfeeding. }\end{array}$ & $\begin{array}{l}\text { "Continuing with breastfeeding most probably disrupts women from menstruating. This } \\
\text { gives them a break before another pregnancy, which means that if the women continue } \\
\text { breastfeeding, they will most probably not become pregnant." Religious Leader } \\
\text { "There is no need to give women contraceptive pills to achieve birth spacing because } \\
\text { breastfeeding the child correctly by emptying the breasts of milk before having sex is enough } \\
\text { to achieve the desired results." Religious Leader }\end{array}$ \\
\hline
\end{tabular}




\section{Appendix G6: Lower Acceptance of Family Planning (South Africa)}

Table G6. Results from the qualitative studies (2010-2019 + 2020) displaying the summaries and representative quotes of themes influencing lower acceptance of family planning in South Africa.

\begin{tabular}{|c|c|c|c|}
\hline Study & Theme & Summary & Representative Quote(s) \\
\hline \multirow[t]{4}{*}{$\begin{array}{l}\text { Protogerou, et } \\
\text { al. (2014) }\end{array}$} & *Religion & $\begin{array}{l}\text { The Catholic Church prohibits } \\
\text { contraceptive use as well as } \\
\text { premarital sex. Participants felt } \\
\text { conflicted and uncertain about how } \\
\text { their religious beliefs might impact } \\
\text { sex and condom use. Some } \\
\text { participants also felt that they did } \\
\text { not need condom protection as God } \\
\text { would protect them. }\end{array}$ & $\begin{array}{l}\text { "...the Catholic Church apparently is against the use of contraceptive measures, so that } \\
\text { basically means first of all you should have sex after marriage according to the religion and } \\
\text { if you are engaging in sexual intercourse you shouldn't use any contraceptive } \\
\text { measures...that would make it impossible to wear a condom in those circumstances." } \\
\text { Ryan, Black Xhosa, Christian, } 20 \text { Years Old } \\
\text { "I believe in God, I believe that He is protecting me cause even now like I always attribute } \\
\text { the fact that I haven't contracted any diseases at the moment, it's pure luck and the fact } \\
\text { that He's watching over me..." Alice, Black Zulu, Christian, } 25 \text { Years Old }\end{array}$ \\
\hline & $\begin{array}{l}\text { *Religion / } \\
\text { Attitudes }\end{array}$ & $\begin{array}{l}\text { Stigma was attached to the sexual } \\
\text { act itself, and that discussing } \\
\text { condom use or carrying a condom } \\
\text { around implies that the sexual act } \\
\text { was planned. Several female } \\
\text { participants felt embarrassed when } \\
\text { buying condoms. It seemed that the } \\
\text { Church is responsible for } \\
\text { stigmatising the sexual act. }\end{array}$ & $\begin{array}{l}\text { "I don't think it's quite natural to just talk about sex because talking about condom use could } \\
\text { also mean you're talking about sex and things like that, usually sex happens spontaneously, } \\
\text { so usually it [condom use] will be just spontaneous." Kali, White, } 18 \text { Years Old } \\
\text { "Firstly, I'd be a bit taken aback if they were sort of planning for it [sex], which I don't really } \\
\text { agree with... I'm hoping that their intentions are not like a plan..." } \\
\text { Lydia, White, } 21 \text { Years Old } \\
\text { "...it sounds like you are a loose cannon, it looks like you are just a loose person who's just } \\
\text { ready for sex wherever." Adam, Black Zulu, } 19 \text { Years Old }\end{array}$ \\
\hline & & & $\begin{array}{l}\text { "I think condoms are the easiest, I mean you can find them on campus, they hand them out, } \\
\text { it's easy enough to provide over the counter, you don't need a prescription... but for me } \\
\text { going to a pharmacy to get the pill is maybe a little easier, emotionally, because I can say } \\
\text { it's for my hormones." Ella, Black Xhosa, } 20 \text { Years Old }\end{array}$ \\
\hline & $\begin{array}{l}\text { Affordability / } \\
\text { Quality of Family } \\
\text { Planning \& } \\
\text { Services }\end{array}$ & $\begin{array}{l}\text { Participants complained of the high } \\
\text { costs of brand-name condoms. } \\
\text { While government-provided } \\
\text { condoms were cheaper or free, }\end{array}$ & $\begin{array}{l}\text { "...we used to buy condoms and it was like a hundred rand a box [of 3] and we just think like } \\
\text { they should be cheap, but they're not, they charge so much and the government ones are } \\
\text { fine but if they really wanna make sure people keep using them they should make a higher } \\
\text { quality I mean, they break." Brett, Coloured, } 21 \text { Years Old }\end{array}$ \\
\hline
\end{tabular}


Emotional

Distress

Female participants cited negative emotions, such as sadness,

depression and anger, could lead to risky sexual behaviour as this was an outlet of emotional distress, often resulting in unprotected sex. Nonuse of condom was exchanged for affection.

All male participants reported that the decision to use condoms were up to men. Half of the female participants were unsure who decides to use a condom, and the other half stated that either the man decides or it's a shared decision, but none said it was entirely the woman's decision. It was often difficult for women to persuade men to put on a condom, if they mentioned it at all. Most participants, however, felt their peers would approve of a female friend asking a man to use a concern, though concerns were raised about the stigma attached. Participants also said men feared strong, empowered women and would “...you're sort of disturbed about certain things, like you're quite sad about something, maybe somebody close to you died and you're feeling very emotional, and you're irrational about decision-making and things like that, so you might end up being sexually interacting with this person... and you probably will engage in sexual activity but not even think about the consequences." Tasmin, Black Xhosa, 19 Years Old

"If I had a huge fight with my parents or with someone I know...or some of my friends, they have a huge fight with their parents or they've failed a test and they feel really bad about something and then they go see one of their guy friends and then they're [the guy friends] consoling them and comforting them, and... he is obviously looking after you caring for you, if there's no condom, well it's ok because you feel bad and he's trying to cheer you up."

\section{Eva, White, 20 Years Old}

"...based on my religion, I'm firstly waiting for marriage to have sex... so, ja my body it's not actually mine and it belongs to my future husband, basically, so it's not mine to just go and use it like that really." Rosie, Black Sotho, Christian; 18 Years Old

"I would say my partner most of times [decides on condom use] like, I tried to avoid being the one to say "can we use a condom", I'd wait for them to make the decision first... if they decided not to [not use a condom], let's say if we were in the moment I wouldn't rip out the condom and say let's use one, I'd see whether he did first... if the guy didn't want to, it would be hard to use it." Libby, Coloured, 19 Years Old

"It's something that I'm struggling with really [negotiating condom use], one time, he said "let's put a condom on" but he didn't, and I wanted to see...I was so mad afterwards because sometimes you can't even feel the condom as a woman, so afterwards, I wanted to see the condom the one that he ejaculated in, the semen, there was nothing."

\section{Alice, Black Zulu, 25 Years Old}

"...if it's someone you really like but you're nervous around and he now wants to have sex with you, then you think you don't want to chase him away or you don't want to put him off, so to now ask for condoms you know, "should I, shouldn't I", and then usually whilst 
therefore feel intimidated by a woman who carried a condom around.

Intimacy (heat of the moment)

Intimacy (trust)
Values, personal choice and

responsibility were often overridden by emotions experienced in the heat of the moment.

Most female participants linked condom use in intimate relationships to lack of trust and infidelity. you're thinking things end up happening and you kind of like, oh well, can't do anything about it now." Eva, White, 20 Years Old

"...I think it would be kind of weird if a girl did that [ask a man to use a condom] in our group of friends because we are, as a group of friends, quite judgmental of such things, you know, a woman isn't supposed to do that but she's still supposed to be safe."

\section{Ryan, Black Xhosa, 20 Years Old}

"Yes, yes it's acceptable, even though me and my friends don't really talk about such things, but I think it would be acceptable." Kali, White, 20 Years Old

"...maybe it [carrying condoms] will have repercussions on her, the way people view her, the way people interact with her... I mean I think many guys are quite intimidated by strong empowered women and also they fear them, and this may lead to some form of hostility, so I think I think these are some of the dangers that women face."

\section{Brett, Coloured, 21 Years Old}

"...you are so wrapped up in the heat of the moment you actually want to complete whatever it is that's going on there..." Ryan, Black Xhosa, 20 Years Old

"...I actually would try to avoid using condoms if I could... I guess it feels more intimate for both of us if we don't use them... the pill has basically been the thing that's made a difference because before we used to use condoms quite religiously, because I really don't wanna be pregnant. For some reason, for me pregnancy is more of a scare than sexually transmitted diseases because of the trust that we have." Libby, Coloured, 19 Years Old

"...the man is probably sleeping around...the men is always out there doing some funny things... so I guess, partly, they would've found out something, some features about each other... so it [condom use in exclusive relationships] is lack of trust, but it can also be trying to take care of one another..." Tasmin, Black Xhosa, 19 Years Old 


\section{Appendix G7: Lower Acceptance of Family Planning (Tanzania)}

Table G7. Results from the qualitative studies $(2010-2019+2020)$ displaying the summaries and representative quotes of themes influencing lower acceptance of family planning in Tanzania.

\begin{tabular}{|c|c|c|c|}
\hline Study & Theme & Summary & Representative Quote(s) \\
\hline \multirow[t]{4}{*}{$\begin{array}{l}\text { Aristide, et al. } \\
\text { (2020) }\end{array}$} & *Religion & $\begin{array}{l}\text { Religious leaders are strongly } \\
\text { influential figures and have the } \\
\text { power to spread FP message. } \\
\text { However, most respondents had } \\
\text { never heard their Church leaders } \\
\text { discuss FP, and were unsure whether } \\
\text { FP use was acceptable with their } \\
\text { faith. Their main understanding } \\
\text { about the association between FP } \\
\text { and their faith is through their } \\
\text { understanding of the Bible, which is } \\
\text { that God's eggs are "unborn } \\
\text { children" and that God allows them } \\
\text { to multiply. }\end{array}$ & $\begin{array}{l}\text { "Many communities believe the pastor a lot and the pastor has a great influence in the } \\
\text { community -- therefore when they... explain a matter like [FP] it is easy to be understood." } \\
\text { Male Church Attender } \\
\text { "I don't know if the Bible says it but as I recognise even God said he allows us to go and } \\
\text { multiply. I don't know if there is another passage which says you should give birth according } \\
\text { to [FP]." Female Church Attender } \\
\text { "There is no using FP because I want [to give birth] until the eggs that God planned [have } \\
\text { been used up]." Female Church Attender }\end{array}$ \\
\hline & Attitudes & FP is perceived as taboo. & (None presented.) \\
\hline & $\begin{array}{l}\text { Fear of Sexual } \\
\text { Dissatisfaction / } \\
\text { Marital Security }\end{array}$ & $\begin{array}{l}\text { Some women feared that } \\
\text { contraceptives would cause sexual } \\
\text { dissatisfaction for their husbands, } \\
\text { and that use of the calendar method } \\
\text { would lead men to seek other sexual } \\
\text { partners. Some men feared that } \\
\text { contraceptives would decrease their } \\
\text { wives' libidos. }\end{array}$ & $\begin{array}{l}\text { "Maybe some women fail to use FP due to the fact that when she uses the calendar the man } \\
\text { gets another woman, he marries, she has a child, now the woman can't do anything, she } \\
\text { decides to continue giving birth." Female Church Attender }\end{array}$ \\
\hline & Gender Attitudes & $\begin{array}{l}\text { Men are considered household } \\
\text { heads and bear decision-making } \\
\text { authority, including over FP, which } \\
\text { many men oppose to. }\end{array}$ & $\begin{array}{l}\text { "Their husbands are usually very harsh. They don't want them to use FP, they just want... } \\
\text { well, a child. Now if the woman goes for FP, it brings isolation in the marriage." } \\
\text { Female Church Attender }\end{array}$ \\
\hline
\end{tabular}




\begin{tabular}{|c|c|c|c|}
\hline & $\begin{array}{l}\text { Gender Attitudes } \\
\text { / Marital Security }\end{array}$ & $\begin{array}{l}\text { Many respondents stated that it was } \\
\text { a wife's duty to give birth to many } \\
\text { children, and that men did not } \\
\text { support the use of FP. }\end{array}$ & "If you stop giving birth, your marriage is over." Female \\
\hline & $\begin{array}{l}\text { Knowledge of } \\
\text { Family Planning }\end{array}$ & $\begin{array}{l}\text { Lack of knowledge on FP led to } \\
\text { reluctance of FP uptake. And } \\
\text { because men are considered } \\
\text { household decision-makers, they } \\
\text { need to be educated about FP. }\end{array}$ & $\begin{array}{l}\text { "The reasons that cause some not to use FP is lack of education. If you were given education } \\
\text { as to what FP means, some would know that it cannot harm you if you use it the healthy } \\
\text { way." Female Church Attender } \\
\text { "[The man] has no such education [about FP]... the main decision maker is the man, he } \\
\text { should have education of knowing FP." Male Church Attender }\end{array}$ \\
\hline & Misconceptions & $\begin{array}{l}\text { Women were often fed } \\
\text { misinformation from neighbours, } \\
\text { friends and other family members. }\end{array}$ & $\begin{array}{l}\text { "In my community, some say that FP has side effects... you find the child, you can give birth } \\
\text { to it with an implant in the eye... others are saying that when they use FP, they get cancer } \\
\text { of the uterus, you bleed for even a whole month! That is why they are scared of FP." } \\
\text { Female Church Attender } \\
\text { "The reason which causes a woman not to use FP is because she is afraid[it] is dangerous, } \\
\text { and at times there is excessive bleeding during her days." Male Church Attender } \\
\text { "If you use these [contraceptive] pills, [babies] can be born without intelligence." } \\
\text { Male Church Attender }\end{array}$ \\
\hline & $\begin{array}{l}\text { Social } \\
\text { Expectations }\end{array}$ & $\begin{array}{l}\text { Women are often pressured by their } \\
\text { own and their husband's families to } \\
\text { bear many children. }\end{array}$ & $\begin{array}{l}\text { "She cannot use FP, she says, 'My mother did not use FP so how can I?" } \\
\text { Female Church Attender } \\
\text { "Maybe she was forbidden by her husband or his relatives. She should not use FP." } \\
\text { Female Church Attender }\end{array}$ \\
\hline \multirow[t]{2}{*}{$\begin{array}{l}\text { Msoka, et al. } \\
\text { (2019) }\end{array}$} & *Religion & $\begin{array}{l}\text { Women saw religion as one of their } \\
\text { biggest barriers and perceived use of } \\
\text { FP as against their religious } \\
\text { teachings. They also stated that most } \\
\text { men see male contraception as } \\
\text { religious taboo. }\end{array}$ & $\begin{array}{l}\text { "...But honest, according to [the] Muslim religion, it is not easy to sit with my husband and } \\
\text { talk [about] issues concerning family planning, he will not agree at all; taking him to the } \\
\text { clinic will be difficult for him, and it is the same case for all Muslim men from coastal region." } \\
\text { FGD 3, R 2, Kisarawe }\end{array}$ \\
\hline & Accessibility & $\begin{array}{l}\text { Attending health clinics for } \\
\text { vasectomy required the whole day. } \\
\text { Many men saw attending the clinic }\end{array}$ & $\begin{array}{l}\text { "My husband is not employed; he is a day worker, so if you want to take him to the clinic he } \\
\text { is supposed to stop working for the whole day." FGD 4, R 4, Masaki }\end{array}$ \\
\hline
\end{tabular}


as a "waste of time" as they could be working instead.

Fear of Sexual

Dissatisfaction /

Misconceptions

Some women feared vasectomy

could make their husbands sexually

dysfunctional, or that men with

vasectomy are unable to satisfy their wives.

Financial

Security / Social

Security / Social

Status

Misconceptions

Men were disinterested in taking up

FP as having a large number of

children brought them good

reputation in the community.

Children also brought financial and

social security for the future. Men

are not keen to take up FP until they had a certain number of children.

Many men had misconceptions on vasectomy, which many women urged on the importance of spreading accurate knowledge to educate men on vasectomy.

\begin{tabular}{|l|l|l|}
\hline $\begin{array}{l}\text { Pallangyo, et al. } \\
\text { (2020) }\end{array}$ & *Religion & $\begin{array}{l}\text { Some women believed vasectomy } \\
\text { was against their religion and that } \\
\text { men who had vasectomy were living } \\
\text { against "God's plan". Particularly in } \\
\text { rural settings, FP was seen as "killing } \\
\text { living things". }\end{array}$ \\
\hline *Religion & $\begin{array}{l}\text { In Islam, men are permitted to have } \\
\text { multiple wives. Having a vasectomy } \\
\text { could be problematic for co-wives } \\
\text { who may be competing over number } \\
\text { of children. }\end{array}$ \\
\hline
\end{tabular}

You mean he has to attend clinic and what about our food? He should go to work to get money for meals, because you can go to the clinic and find that there is a long queue.

\section{FGD 4, R 2, Masak}

"Men with vasectomy cannot satisfy their wives, women find it a pleasure and feel to have sex frequently and have kids; if the men will practice vasectomy, some of their needs will not be fulfilled, and hence no more children." FGD 1, R 5, Bagamoyo

"Vasectomy can be done after a man is above 45 years and has six or more children. He will be willing to practice vasectomy because the number of children is so big."

\section{FGD 3, R 5, Kisarawe}

"I cannot advise him because he is not yet more than 45 years and where he came from he used to have many kids; for example, I'm the third wife, I have three children, the second wife has five, the first one has six children, and the last wife has two. It is not easy to advise him for vasectomy." FGD 2, R 2, Chalinze

"I am very sorry to say that he will never assist me in any of the reproductive health issues; for example, my husband has wrong beliefs regarding the effect of vasectomy on both physical and sexual ability." FGD 3, R 3, Kisarawe

"Before starting using family planning you should involve your partner so as to get his/her thoughts, and attend the clinic together, and it is a good idea because each one gets firsthand information from the service provider." FGD 1, R 3, Bagamoyo

"Why are you correcting God who planned for the birth? You are contrary to His wish, you are against good values of the religion... In town, you will be seen as a cunning person, but for people like us from rural areas it is an issue." Female 1, Kisarawe

"There might be a problem between a man and his wives because one wife or two wives may have children, whereas others don't have. It might happen that one wife want a child and not becoming pregnant [after vasectomy]. This may cause the marriage to break up because of conflict and misunderstandings in the family." Woman 2, Bagamoyo 


\begin{tabular}{|c|c|c|}
\hline & Attitudes & $\begin{array}{l}\text { Men who had received a vasectomy } \\
\text { were seen in the community as } \\
\text { "idiots", "powerless to their wives", } \\
\text { "half men" and "bushmen". }\end{array}$ \\
\hline & Gender Attitudes & $\begin{array}{l}\text { Men believe that FP is the woman's } \\
\text { responsibility and most men did not } \\
\text { play a role in FP uptake. Some } \\
\text { women also believed FP is the } \\
\text { woman's responsibility and would } \\
\text { prefer female over male sterilisation. } \\
\text { However, most women preferred } \\
\text { shared responsibility, but found it } \\
\text { difficult to approach their husbands. }\end{array}$ \\
\hline & $\begin{array}{l}\text { Knowledge of } \\
\text { Family Planning }\end{array}$ & $\begin{array}{l}\text { Some women described vasectomy } \\
\text { as an unsafe procedure. }\end{array}$ \\
\hline & Social Status & $\begin{array}{l}\text { Men with many children were seen } \\
\text { in the community as powerful, proud } \\
\text { and respected. }\end{array}$ \\
\hline $\begin{array}{l}\text { Sundararajan, et } \\
\text { al. (2019) }\end{array}$ & *Religion & $\begin{array}{l}\text { A number of Christian and Muslim } \\
\text { participants saw FP as against their } \\
\text { religious beliefs. There is the belief } \\
\text { that God gave them a finite number } \\
\text { of eggs (also referred to as "unborn } \\
\text { children") and it was their moral } \\
\text { duty to "finish" the eggs and not } \\
\text { interfere with God's plan by denying } \\
\text { children the right to be born. Despite } \\
\text { many participants overall desiring } \\
\text { more information on FP, some } \\
\text { participants did not feel it was }\end{array}$ \\
\hline
\end{tabular}

"The community cannot agree with this issue (vasectomy), they can look at you as a "bush man", meaning you can be ignored. They will say, "for which reasons is this person practicing family planning?" If you practice it [vasectomy], you do it secretly; maybe a man could only inform his wife." Woman 2, Masaki

"A lot of people judge men for having a vasectomy because it's such an absurd thing to be done by a man." Woman 2, Kisarawe

(None presented.)

"He will be despicable eeh! People will see him doing something [vasectomy] which is nonexisting... They [the community] are not well educated about practicing vasectomy."

\section{Woman 1, Masaki}

(None presented.)

"In our religion, we are forbidden to use family planning, because we are told to go and multiply, and fill the land." Female, Christian

"The Quran does not allow us because the prophet he says he will be proud on that day when he stands to see the multitude of people is big." Male, Muslim

"If we go back even to our teachings of the Islamic religion, the lesson of family planning, we don't have it. Refer even to the teachings of the Prophet Mohammed. This question is not there. Our prophets have given birth to very many children." Muslim Man 
appropriate that FP was discussed in

a religious setting.
Some women believed that women should be the primary decision makers on FP as they are the ones physically affected by pregnancies. However, despite this, men are seen as the household heads and make the ultimate decision. Sometimes, women will employ deceptive negotiation to get their husbands to agree with FP.
"There are eggs which you are stopping. It is possible that child would have come to be born and been of help to the community. Now, when you take those medicines, you are going to kill that egg, and you kill God's plan." Christian Man

"A woman can tell you, 'We at our home don't close [use family planning]. I shall give birth until my eggs do what? They finish the ones allocated to me.' Now you find this woman has a brain. She tells you that, "I have already been born with eggs, so I will give them out according to what was given to me by God'." Muslim Man

"Questions of family planning? Those are completely different from the topic of religion." Muslim Man

"You see, [the Imam] will have opened our ears... so that we get the exemplification that family planning is ok. But on the other side, some people will contradict him, because he is not allowed to tell us in the mosque." Muslim Woman

"If my leaders tell me about family planning, I wouldn't feel good because the word of God says 'Go into the world. Fill this country, and what belongs to Caesar leave it to Caesar'. Therefore, it will be good to get this education on the side of Caesar." Christian Man

"The hardship and problems connected to giving birth are upon the woman. That is why she will make the big decisions herself, according to her health." Muslim Woman

"The one who decides to use family planning is the woman, not the man. Men often don't agree because he doesn't have a heavy load. He does not carry the pregnancy. He doesn't breastfeed." Christian Woman

"As I understand family planning, the one with the main decision is the man. He is the one who prescribes for you, 'Now, my wife, we should use family planning. It is necessary that we go to the clinic, this and that. Indeed, we should use family planning.'" Christian Woman

"For example, we women, it is possible that you... have a man, he does not want you to practice family planning... as for you, that is your husband. You must follow his laws the way he wants." Muslim Woman 
"The one who gets hurt first is the woman. She reaches the conclusion to tell her husband, 'Sir, my husband, I want to start family planning.'...Now, if the husband has understanding, the man can receive it directly that it is good. Because the one who gets trouble is the woman. I-the man-don't get any trouble at the time of giving birth. She is the one who gets the pain, I am just enjoying." Christian Man

"The father gets concerned after being told by the mother about family planning. First, he evaluates himself, the situation he is in in life and economically and...this pace [of rapidly having children]... he sees this idea that his wife brought. If it is useful, then he supports his wife. Therefore, they are both together for the purpose of continuing with family planning."

\section{Christian Man}

"We [women] have the ability to confuse the man until he agrees... you convince him until he agrees, so that you join family planning." Christian Woman

"You must use extra intelligence - how will you bring this question to him? You will present it. He will find it is now necessary that you use your brain if he is stubborn - because husbands are stubborn. They absolutely don't agree with this [family planning]. It is necessary that you use an alternative approach, and you see. At what time should I present this question? Which should I use so that I can obtain an agreement more quickly?"

\section{Muslim Woman}

"Clearly the one with the major decision making, it's the man. That is why at times even women reach the point of using these ways of family planning secretly without informing their men. Some men do absolutely not want to hear something like this, and they have the final say in this matter, which concerns everything regarding marriage." Christian Woman

Knowledge of Family Planning
Women had higher knowledge of FP as they received information during antenatal and postnatal visits to health clinics. Men, on the other hand, did not receive such information and therefore lack knowledge on FP, causing conflict
"We men don't have that education: the benefit of family planning are these, and the negative impacts are these. That is why the woman, as a woman, she looks at the level of the life which she leads... now it is necessary that the woman uses it [family planning] in secret." Muslim Man

"It is necessary that first education must be given so he knows the benefit of family planning. What are the benefits? If he does not use family planning, what are the negative effects? 
being the main decision-maker of

the household.

Misconceptions

There are many misconceptions

circulating around the community

about FP causing cancer, alteration

of menstrual cycle and infertility.

Many participants also believed that

women are born with a limited

number of eggs and that they must

give birth to all the eggs or the

remaining eggs will make them ill.

These beliefs are shared by

Christians and Muslims, males and

females.
Once he recognizes this, he will be easily involved in implementing family planning. But, if he is not educated, he will not be involved." Christian Man

"Some believe this family planning has side effects, because if you use the pill you can give birth to a child who has maybe not even fingers. They are not fully developed, maybe they are just half. Maybe the head is twisted sideways, maybe s/he has no legs, maybe handicapped." Christian Man 


\section{Appendix G8: Lower Acceptance of Family Planning (Uganda)}

Table G8. Results from the qualitative studies $(2010-2019+2020)$ displaying the summaries and representative quotes of themes influencing lower acceptance of family planning in Uganda.

\begin{tabular}{|c|c|c|c|}
\hline Study & Theme & Summary & Representative Quote(s) \\
\hline \multirow[t]{3}{*}{$\begin{array}{l}\text { Kabagenyi, et al. } \\
\text { (2016) }\end{array}$} & $\begin{array}{l}\text { *Religion / } \\
\text { Religiosity }\end{array}$ & $\begin{array}{l}\text { Male and female respondents } \\
\text { mentioned that children are a gift } \\
\text { from God and that all children come } \\
\text { with a blessing. Respondents } \\
\text { believed that they have to produce } \\
\text { until all eggs are finished and that } \\
\text { God will provide for all children. } \\
\text { According to religions like } \\
\text { Catholicism and Islam, the use of } \\
\text { contraception is likened to the killing } \\
\text { of children and only God will decide } \\
\text { when it's time to limit. }\end{array}$ & $\begin{array}{l}\text { "When it comes to religion, for example, the Muslims have to produce until the eggs are } \\
\text { finished in the womb. However not only the Muslims, the Bible says go produce and fill the } \\
\text { world. Muslims also have a belief that every child comes with his or her blessing." } \\
\text { Male, IDI, Mpigi }\end{array}$ \\
\hline & $\begin{array}{l}\text { Gender } \\
\text { Preference / } \\
\text { Social Security / } \\
\text { Social Status }\end{array}$ & $\begin{array}{l}\text { Most male participants believed that } \\
\text { women should produce many } \\
\text { children to extend their lineage. Sons } \\
\text { were preferred as this was a symbol } \\
\text { of social status for the son would } \\
\text { continue the family lineage so } \\
\text { women would continue having } \\
\text { children until a son was achieved. A } \\
\text { lot of value is also attached to } \\
\text { children. Lastly, births also meant } \\
\text { replacement of ancestors, and } \\
\text { continuity of clan's existence and } \\
\text { cultural values. Therefore, many } \\
\text { participants opted out of using FP. }\end{array}$ & (None presented.) \\
\hline & Misconceptions & $\begin{array}{l}\text { Traditional methods believed to } \\
\text { regulate fertility was used in both }\end{array}$ & $\begin{array}{l}\text { "Yes, I heard that women usually go to traditional doctors who make them sit in herbs mixed } \\
\text { with water for about an hour or so. Once these herbs enter inside the woman's womb, she }\end{array}$ \\
\hline
\end{tabular}


districts. This included tying

traditional herbs around the waist or inserted into the woman's vagina,

mixing of herbs with a woman's

menstrual blood, drinking

concoctions, using calendar or

withdrawal methods, and tying an

umbilical cord around the waist.

Misconceptions

(fear of

perceived side

effects)
Perceived side effects of modern methods contraceptives are prolonged bleeding, birth deformities, infertility, cancer, bodily pains, and weight gain or loss.

Hormonal methods were thought to cause dizziness, lack of sexual libido and impromptu bleeding. cannot conceive. The traditional doctor may give a woman a duration of 2 or 3 years when one would not conceive." Male, IDI, Mpigi

"Yes, people here say that if a woman gets the child's umbilical cord and mixes it with some traditional medicine then ties them together and keep them in a secret place or around the waist then this woman would not conceive until she unties the concoction in future."

\section{Female, IDI, Mpigi}

"Yes, using my menstrual blood after delivery, I can tie it with herbs in a piece of paper and put it in the kitchen chimney where the smoke gets out. That method can easily prevent one from conceiving." Female, FGD, 35-49 Years, Bugiri

"Not only here in Mpigi but in the whole of Uganda most people are still mainly using traditional / cultural practices like consulting their ancestral spirits. There is no where you can go more than 3-4 steps without finding a traditional healer / witch doctor in this community." Male, FGD, 35-54 Years, Mpigi

"We have elderly women who are knowledgeable about the traditional methods that can be used to space births. These are respected in our communities for their expertise and advice. Many women in need of traditional methods do consult them."

\section{Female, FGD, 35-49 Years, Mpigi}

"If women use cultural practices or herbs or evoke spirits, with these they don't get side effects because these can be untied and one's fertility restored. It won't be like pills that will pile up in her stomach and bring harm. For instance, traditional herbs like "mumbwa" luganda word meaning (clay) are easy for her to use since they are not harmful to her. Most women if they go in for cultural practices at the end of their reproductive period, they remain looking good, but pills treat them badly. Sometimes you find them (women) losing or gaining unnecessary weight which is not the case with traditional methods."

\section{Male, FGD, 25-34 Years, Mpigi}

"...the modern methods have some side effects. People say that modern methods are bad, they have a belief that if you stop using the modern contraceptive methods and want a child, you will never get pregnant." Male, IDI, Mpigi 


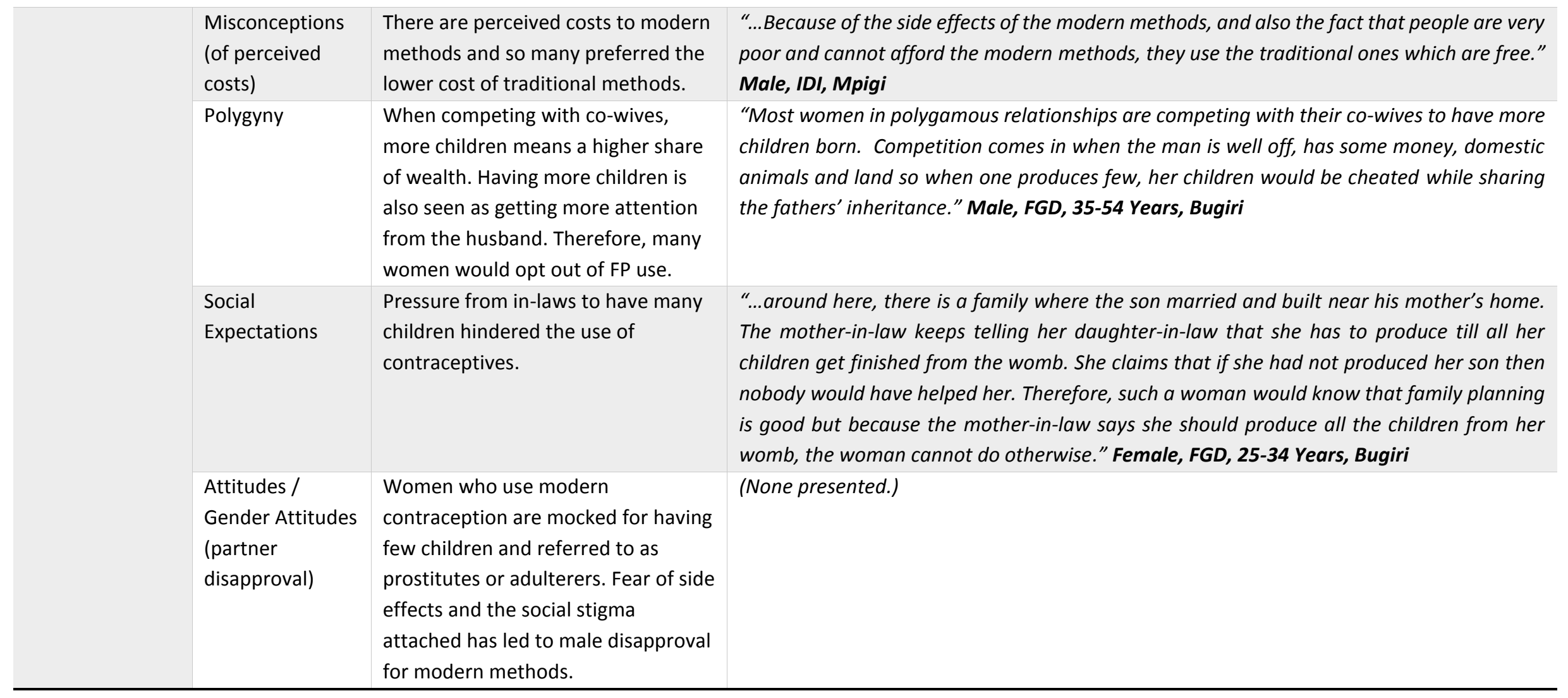




\section{Appendix H1: Higher Acceptance of Family Planning (Ethiopia)}

Table H1. Results from the qualitative studies $(2010-2019+2020)$ displaying the summaries and representative quotes of themes influencing higher acceptance of family planning in Ethiopia.

\begin{tabular}{|c|c|c|c|}
\hline Study & Theme & Summary & Representative Quote(s) \\
\hline \multirow[t]{4}{*}{$\begin{array}{l}\text { Davidson, et al. } \\
\text { (2017) }\end{array}$} & $\begin{array}{l}\text { *Religion / Birth } \\
\text { Spacing }\end{array}$ & $\begin{array}{l}\text { Both Eritreans and Somalis were in } \\
\text { support of FP for birth spacing, as it } \\
\text { is supported by Islam, though } \\
\text { Eritreans cited } 3 \text { to } 5 \text { years as ideal } \\
\text { whereas Somalis cited } 2 \text { years. }\end{array}$ & $\begin{array}{l}\text { "Our religion says } 2 \text { years is the best, to have healthier mother and child." Somali Woman } \\
\text { "Religion leaders (Sheikhs) say it is good to have a time interval between two children... they } \\
\text { preach us to use the oral contraceptive pills and injection." Somali } \\
\text { "Family planning is spacing children from three to } 4 \text { years difference. We can say this is } \\
\text { family planning." Eritrean Woman } \\
\text { "Now we have... this family planning... we would like to have family planning at this time. } \\
\text { So people in this camp need/want to have children with plan. Everything is told to us, so we } \\
\text { know it. This is the present situation of the camp." Eritrean Woman }\end{array}$ \\
\hline & Attitudes & $\begin{array}{l}\text { Eritreans had positive views about FP } \\
\text { in general. When it came to } \\
\text { contraceptive implants, Eritreans } \\
\text { admitted they had less experience, } \\
\text { however, they still expressed } \\
\text { positive attitudes. }\end{array}$ & $\begin{array}{l}\text { "They like it. All women took injection or pills. No one hate it." Eritrean Woman } \\
\text { "I hear that it [implant] is the best while they were telling us; I mean it is preferable." } \\
\text { Eritrean Woman }\end{array}$ \\
\hline & $\begin{array}{l}\text { Knowledge of } \\
\text { Family Planning / } \\
\text { Promotion of } \\
\text { Family Planning }\end{array}$ & $\begin{array}{l}\text { FP campaigns had increased the } \\
\text { participants' knowledge and } \\
\text { awareness, and dispelled myths of } \\
\text { contraception for both Eritreans and } \\
\text { Somalis. }\end{array}$ & $\begin{array}{l}\text { "I, myself, did not know it until the IRC social worker came and teach us. After that I knew it } \\
\text { and went to the center." Eritrean Woman } \\
\text { "As they were saying there should have more education on women. There are many who do } \\
\text { not have knowledge... There are many who overlap children. This is because of lack of } \\
\text { education... if they believe that they can be sterile, this is lack of knowledge." Eritrean Man }\end{array}$ \\
\hline & $\begin{array}{l}\text { Modern } \\
\text { Development }\end{array}$ & $\begin{array}{l}\text { Eritreans and Somalis were happy to } \\
\text { take up FP as they saw this as being } \\
\text { a part of modern development. }\end{array}$ & $\begin{array}{l}\text { "I have two children the first one exceeds one year than the other, now there is a } \\
\text { development because we use pills or injection. Thanks for IRC." Somali Woman }\end{array}$ \\
\hline Mjaaland (2014) & $\begin{array}{l}\text { *Religion / } \\
\text { Religiosity }\end{array}$ & $\begin{array}{l}\text { Although women were much more } \\
\text { religious than men in this study, }\end{array}$ & $\begin{array}{l}\text { "...According to our religion it [contraceptive use] is not allowed. To use medicines [to } \\
\text { prevent childbirth] is not allowed by our religion. But, we don't respect our religion that }\end{array}$ \\
\hline
\end{tabular}


Financial

Constraints many women ignored religious

disapproval of contraceptive use

(mostly Orthodox women). A third of

the respondents interpreted the

Church's silence on the issue to

mean they were allowed to use FP.

Another third believed the Church

was against contraceptive use, but

they felt it was necessary. they still decided to use it anyway as

much [on this issue], so we use it. I, myself use it now. Meaning, to avoid unwanted pregnancy and other things [diseases]; so far, I have taken care of myself properly. Otherwise, it's prohibited by our religion; it doesn't say take the [contraceptive] injection. According to our religion it's said to be a sin...(laughs). But I keep quiet. I use it by my own choice. If I want to give birth, if I want it, I will stop it...I don't tell the priests. That's it, they tell [us] this, this and that. Then we say okay, and listen to them. But in practice it's not done...it means...if we follow what they say it might not be good for our lives. But... we tell God and say, Lord forgive us, and do what we want (laughs)."

Female, Late 20s, Married Housewife, Suburban Area, 10 Years of Education

"What about it; it's good to give birth, but if you don't want to, you can prevent it. The priests don't have knowledge about this; it's the doctors who know. Who will tell them about it?" Female, 70 Years Old, Non-Literate, Living Alone, Suburban Area

"We don't ask the priests' [permission]." Female, 40s, Peasant, Non-Literate

"Who will tell the priests?" Female, 30s, Peasant, Non-Literate

"I will take it from now on, I have enough children now." Female, 30s, Non-Literate

"I don't know if it's allowed or not. We will allow it ourselves!" Female, 30s, Non-Literate

"The government follows science, scientific education, the clergy only religion; so there is a difference... My opinion and the priests' opinion are different. They say it is sin; that it's not allowed. From the point of view of science, it's allowed, I think." Female, 30 Years Old, Suburban Area, Divorced Day-Labourer of a Peasant with 4 Years Formal Education

"[Giving birth] must not become a problem for us; if we become too many it will be a problem... The priests say it's a sin, but we will use it anyway. There is not enough land now, what shall we eat if we bear too many children?" Female, 22 Years Old, Peasant, Pregnant with Third Child, Taken Out of School in Fourth Grade, Married to a Deacon at 15 Years

Participants from rural and suburban areas stated that if they could not afford children, then they should not
"If you don't have enough means to raise many children, it's the right thing to do." Female, 30 Years Old, Suburban Area, Divorced Day-Labourer of a Peasant with 4 Years Formal Education 
have any. Using contraceptives was

seen positively as it helped with

escaping poverty and hunger,

improved living conditions, improved

their and their children's health, and

be able to provide all their children

(rather than just their cleverest boys)

with an education. 


\section{Appendix H2: Higher Acceptance of Family Planning (Kenya)}

Table H2. Results from the qualitative studies $(2010-2019+2020)$ displaying the summaries and representative quotes of themes influencing higher acceptance of family planning in Kenya.

\begin{tabular}{|c|c|c|c|}
\hline Study & Theme & Summary & Representative Quote(s) \\
\hline \multirow[t]{4}{*}{$\begin{array}{l}\text { Abdi, et al. } \\
(2020)\end{array}$} & *Religion & $\begin{array}{l}\text { Most religious leaders and scholars } \\
\text { in both Lamu and Wajir counties } \\
\text { believe the use of FP is supported by } \\
\text { Islam (especially for child spacing) } \\
\text { and that nowhere in the Quran or } \\
\text { Sunnah prohibits the use. The } \\
\text { respondents also referred to the } \\
\text { Sunnah saying that it specifically } \\
\text { states that FP is allowed, especially } \\
\text { the withdrawal method. }\end{array}$ & $\begin{array}{l}\text { "The Sunnah does not directly talk about child spacing as such but it talks about the prophet } \\
\text { (PBUH) noticing that his companions doing practicing coitus interruptus (Al azl) and when } \\
\text { he heard about it he did not forbid this practice therefore his followers concluded that if it } \\
\text { was anything that is not allowed in Islam he could have stopped it immediately. The } \\
\text { intention of Al azl was to prevent pregnancy just like the modern temporary methods." } \\
\text { IDI, Islamic Scholar, Wajir } \\
\text { "Our religion says that God is the one who gives us children, but on another perspective, we } \\
\text { are not allowed to burden ourselves. To do family planning is okay, what is wrong is } \\
\text { abortion. Its better you have a child that you can take care of." IDI, Female Leader, Lamu }\end{array}$ \\
\hline & $\begin{array}{l}{ }^{*} \text { Religion / Birth } \\
\text { Spacing }\end{array}$ & $\begin{array}{l}\text { However, most respondents from } \\
\text { Wajir mentioned that according to } \\
\text { Islam, use of FP should be exclusively } \\
\text { used for the purpose of child spacing } \\
\text { (about } 2 \text { years to restore physical } \\
\text { and psychological health) and that } \\
\text { women should keep giving birth until } \\
\text { menopause. }\end{array}$ & $\begin{array}{l}\text { "In our religion in the Quran we were told for the woman who gives birth she should breast } \\
\text { feed her child for } 2 \text { years so that both the mother and the baby's health will not be affected } \\
\text { but if what you are talking about is child spacing more than those two years unless it is for } \\
\text { medical reason then the religion does not allow, even ALLAH says in his book give birth and } \\
\text { do not think about poverty because he is the provider." FGD, Religious Leader, Wajir } \\
\text { "Islam allows family planning only if it's child spacing and not stopping the women from } \\
\text { giving birth completely and also the other reason is that if a doctor recommends family } \\
\text { planning for a woman for a reason related to her health and the baby, the religion has no } \\
\text { objection." FGD, Religious Leader, Wajir }\end{array}$ \\
\hline & $\begin{array}{l}\text { *Religion / } \\
\text { Maternal Health }\end{array}$ & $\begin{array}{l}\text { Respondents in Wajir stated that in } \\
\text { addition to child spacing, FP can only } \\
\text { be used if the woman's health is at } \\
\text { risk, according to Islam. }\end{array}$ & $\begin{array}{l}\text { "Islam allows family planning only if it's child spacing and not stopping the women from } \\
\text { giving birth completely and also the other reason is that if a doctor recommends family } \\
\text { planning for a woman for a reason related to her health and the baby, the religion has no } \\
\text { objection." FGD, Religious Leader, Wajir }\end{array}$ \\
\hline & $\begin{array}{l}\text { *Religion / } \\
\text { Financial } \\
\text { Constraints }\end{array}$ & $\begin{array}{l}\text { Despite the belief that Islam does } \\
\text { not support the use of } \\
\text { contraception, especially for limiting } \\
\text { births, many still justify their use of }\end{array}$ & $\begin{array}{l}\text { "Islam doesn't allow family planning, it is haram, (forbidden) we are just practicing because } \\
\text { of the difficult economic times, even the Prophet said fill the world with children so that I } \\
\text { have a big ummah (society) in the day of judgement." FGD, Female, Lamu }\end{array}$ \\
\hline
\end{tabular}




\begin{tabular}{|l|l|l|l|l}
\hline & $\begin{array}{l}\text { contraception as a result of } \\
\text { economic constraints preventing a } \\
\text { large family size access to a good } \\
\text { quality of life, particularly in Lamu. }\end{array}$ & \\
\hline $\begin{array}{l}\text { Spousal } \\
\text { Communication }\end{array}$ & $\begin{array}{l}\text { In Lamu, there is some } \\
\text { communication between couples on } \\
\text { contraceptive use. }\end{array}$ & $\begin{array}{l}\text { "We talk to our husbands, some support the idea while others don't support the idea." } \\
\text { Famu }\end{array}$ \\
\hline
\end{tabular}




\section{Appendix H3: Higher Acceptance of Family Planning (Malawi)}

Table H3. Results from the qualitative studies $(2010-2019+2020)$ displaying the summaries and representative quotes of themes influencing higher acceptance of family planning in Malawi.

\begin{tabular}{|c|c|c|c|}
\hline Study & Theme & Summary & Representative Quote(s) \\
\hline \multirow[t]{4}{*}{ Kok, et al. (2020) } & *Religion & $\begin{array}{l}\text { Although Catholics and Bible } \\
\text { believers do not support the use of } \\
\text { modern contraceptives because of } \\
\text { the importance of reproduction and } \\
\text { avoiding the sin of 'killing the child', } \\
\text { the majority of participants (HSAs } \\
\text { and community members) said that } \\
\text { religion did not influence their need } \\
\text { and decision-making for } \\
\text { contraceptives. Churches also } \\
\text { seemed to tolerate the use of } \\
\text { modern contraceptives silently. }\end{array}$ & $\begin{array}{l}\text { "I am a church leader and the Bible says we should multiply like the sand. For the people to } \\
\text { go to the hospital for family planning methods we cannot condone that, but since the way } \\
\text { the organizations are lined up these days, we encourage some people that the way the } \\
\text { world is these days, it's good for them to go to the hospital and follow family planning, but } \\
\text { according to the bible, it is unacceptable." KII, Christian Religious Leader, Namkumba }\end{array}$ \\
\hline & Accessibility & $\begin{array}{l}\text { Although contraceptives were not } \\
\text { provided by the Catholic CHAM } \\
\text { facility in Makanjira, long-lasting } \\
\text { contraceptives were still highly } \\
\text { available throughout Mangochi } \\
\text { District and provided by HSAs. In } \\
\text { Namkumba, community-based } \\
\text { distribution agents also existed. }\end{array}$ & (None presented.) \\
\hline & $\begin{array}{l}\text { Financial } \\
\text { Constraints }\end{array}$ & $\begin{array}{l}\text { Having many children is costly and } \\
\text { keeps the woman stuck in poverty. }\end{array}$ & $\begin{array}{l}\text { "A woman who doesn't follow family planning is always busy with children at home and } \\
\text { poverty is always on her because of the many children. You also appear attractive to your } \\
\text { husband when you practice family planning because you don't get old quickly." } \\
\text { FGD, Married Females 19+ Years, Makanjira }\end{array}$ \\
\hline & $\begin{array}{l}\text { Knowledge of } \\
\text { Family Planning }\end{array}$ & $\begin{array}{l}\text { All participants were aware of } \\
\text { different types of modern } \\
\text { contraceptives and their advantages } \\
\text { (though knowledge didn't }\end{array}$ & (None presented.) \\
\hline
\end{tabular}




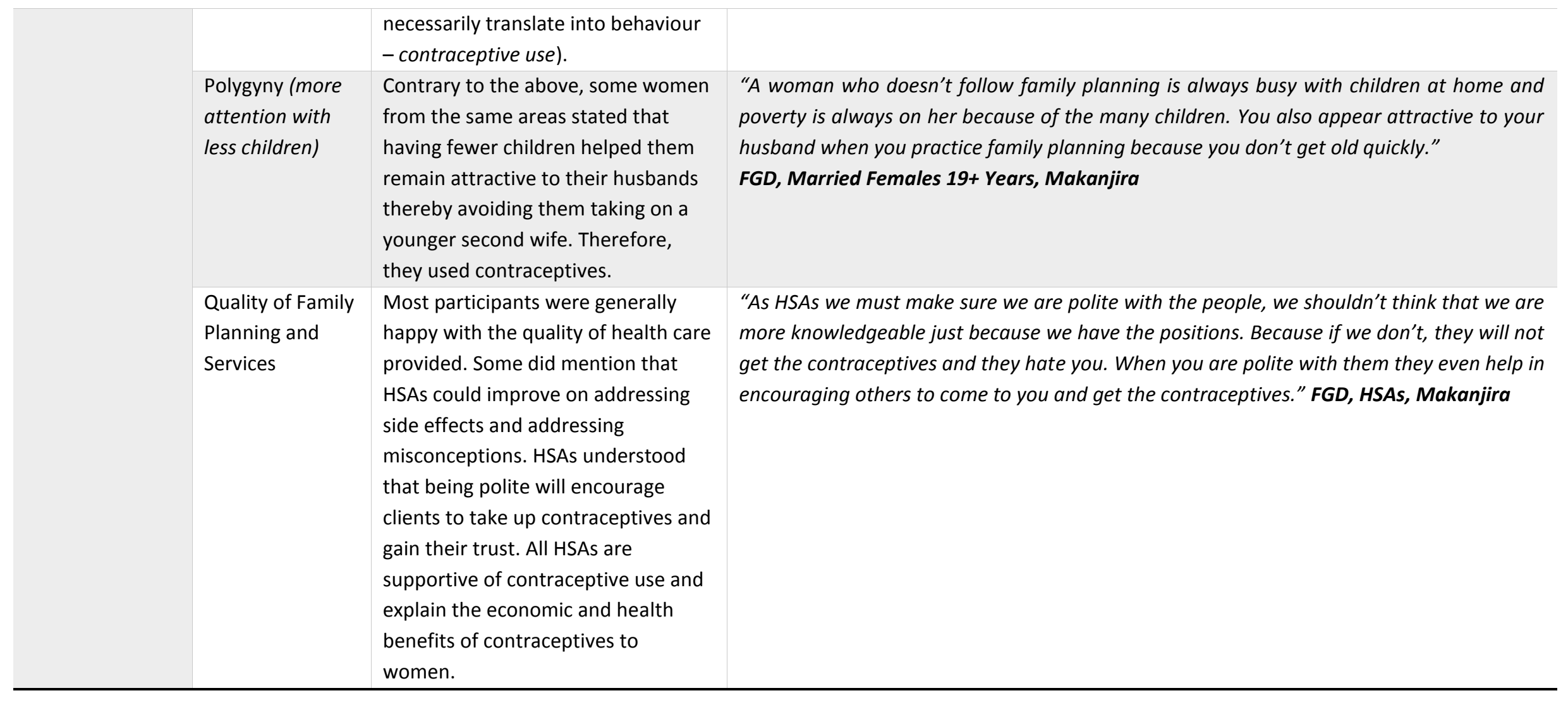




\section{Appendix H4: Higher Acceptance of Family Planning (Nigeria)}

Table H4. Results from the qualitative studies $(2010-2019+2020)$ displaying the summaries and representative quotes of themes influencing higher acceptance of family planning in Nigeria.

\begin{tabular}{|c|c|c|c|}
\hline Study & Theme & Summary & Representative Quote(s) \\
\hline \multirow[t]{4}{*}{$\begin{array}{l}\text { Adefalu, et al. } \\
\text { (2019) }\end{array}$} & $\begin{array}{l}\text { Increasing Trend } \\
\text { of FP Acceptance }\end{array}$ & $\begin{array}{l}\text { Overall, there is an increasing } \\
\text { demand for FP. }\end{array}$ & $\begin{array}{l}\text { "The demand is increasing now unlike before." Community Representative, Argungu LGA } \\
\text { "The people trained by the Association for Reproductive and Family Health (ARFH) have } \\
\text { been moving around so uptake has increased gradually. They are coming, especially this } \\
\text { new Sayana Press, it has gotten through, and they are coming." } \\
\text { FP Coordinator, Sokoto North LGA } \\
\text { "It is free of charge everywhere." Community Representative, Argungu LGA }\end{array}$ \\
\hline & $\begin{array}{l}\text { *Religion / } \\
\text { Knowledge of } \\
\text { Family Planning }\end{array}$ & $\begin{array}{l}\text { Health education on religious leaders } \\
\text { has meant that religious leaders are } \\
\text { now supporting the use of FP, which } \\
\text { has a strong influence on followers } \\
\text { of that religion. }\end{array}$ & $\begin{array}{l}\text { "Because of health education (of the religious leaders), the religious leaders are now } \\
\text { supporting for child spacing." Community Representative, Argungu LGA } \\
\text { "Health education from house to house and community dialogue with men and religious } \\
\text { leaders in the community." Community Representative, Argungu LGA } \\
\text { "...community dialogue, invite our religious leaders. Here in Sokoto, the opinions of religious } \\
\text { leader especially the sultanate council are more followed and respected than that of even } \\
\text { the governor or senator or anybody so invite them to the dialogue with health education." } \\
\text { Community Representative, Sokoto South LGA }\end{array}$ \\
\hline & $\begin{array}{l}\text { Access to } \\
\text { Education }\end{array}$ & $\begin{array}{l}\text { Increased access to education is } \\
\text { increasing FP knowledge and usage. }\end{array}$ & $\begin{array}{l}\text { "...now, with more education, more younger generation coming up, with more training, } \\
\text { more sensitization more everything, so things are getting better honestly, and we are } \\
\text { getting there and I think I am sure in another couple of years, when you come around again, } \\
\text { it (perception towards contraceptive use) is going to be } 70-80 \% . " \\
\text { FP Coordinator, Sokoto North }\end{array}$ \\
\hline & Accessibility & $\begin{array}{l}\text { Sokoto North was the only LGA to } \\
\text { claim to not have experienced any } \\
\text { stock-out of contraceptives. }\end{array}$ & $\begin{array}{l}\text { "For the past five years, there has been no out of stock of any commodity. Thanks to [donor } \\
\text { agencies]. They provide all the commodity, they go to our clinics they go there with their } \\
\text { vans." FP Coordinator, Sokoto North LGA }\end{array}$ \\
\hline
\end{tabular}




\begin{tabular}{|c|c|c|}
\hline & Attitudes & $\begin{array}{l}\text { Sokoto South is the only LGA in the } \\
\text { study where respondents felt there } \\
\text { was no social stigma attached to } \\
\text { unmarried women obtaining FP. }\end{array}$ \\
\hline & Gender Attitudes & $\begin{array}{l}\text { Although men are still the dominant } \\
\text { decision makers, gender attitudes of } \\
\text { the role of women is changing and } \\
\text { women are increasingly able to make } \\
\text { their own decisions. }\end{array}$ \\
\hline & $\begin{array}{l}\text { Knowledge of } \\
\text { Family Planning }\end{array}$ & $\begin{array}{l}\text { An exception where level of } \\
\text { knowledge of FP was very high was } \\
\text { in Sokoto South. }\end{array}$ \\
\hline & $\begin{array}{l}\text { Knowledge of } \\
\text { Family Planning }\end{array}$ & $\begin{array}{l}\text { Another exception where level of } \\
\text { knowledge of FP was very high was } \\
\text { in Sokoto North. }\end{array}$ \\
\hline & $\begin{array}{l}\text { Promotion of } \\
\text { Family Planning }\end{array}$ & $\begin{array}{l}\text { Family planning campaigns through } \\
\text { house to house and mass media } \\
\text { exposures have educated people } \\
\text { about FP and gradually increased FP } \\
\text { uptake. It is also to integrate } \\
\text { religious leaders (above) and men } \\
\text { into the target of these campaigns as } \\
\text { they are strong influential figures } \\
\text { and sole decision-makers, } \\
\text { respectively. }\end{array}$ \\
\hline $\begin{array}{l}\text { Akinyemi, et al. } \\
\text { (2020) }\end{array}$ & $\begin{array}{l}\text { Overall Support } \\
\text { for Scale-Up }\end{array}$ & $\begin{array}{l}\text { Overall, there is support from both } \\
\text { the community and religious leaders } \\
\text { for the scale-up programme to }\end{array}$ \\
\hline
\end{tabular}

"Now, since people are educated, not only married people accept family planning, even school girls, highly educated girls in the university even secondary schools come for contraceptives." FP Coordinator, Sokoto South

"Things are getting better now, before women are meant to stay home, get pregnant, deliver children and take care of them." FP Coordinator, Argungu LGA

"Here in Sokoto South, knowledge about family planning is very high. People are aware of different methods." Community Representative, Sokoto South LGA

"I will give them $80 \% .$. When a woman comes to you for service; she already knows most of the methods with advantages and disadvantages, the side effect etc. They are very knowledgeable about [family planning] here." FP Coordinator, Sokoto South LGA

"The reason [for the high level of knowledge] is that Sokoto North is the heart of Sokoto."

Unknown, FGD (Session 3), Sokoto State

"The urban area of Sokoto caliphate, people here are more educated and enlightened compared to other part of Sokoto [Sokoto North] ." Community Representative

"The community volunteers trained have been moving from house to house so knowledge is increasing gradually." FP Coordinator, Argungu LGA

"We can continue to increase awareness especially on the television and radio."

FP Coordinator, Sokoto South LGA

"It is also important to involve the men, since they are the one that have the final say once the men are involved, the whole problem of family planning will be solved. They will also be able to talk to their fellow men about it. Community dialogue and compound meeting involving men to discuss the benefits of family planning are very important."

\section{Community Representative, Sokoto North LGA}

"In fact, the support our community gives to this programme, without exaggeration, I will say maybe $80 \%-90 \%$. They (the community) have been very supportive of the programme." IDI, Male, Traditional Ruler, Yamaltu/Deba 
Programme /

*Religion

Accessibility /

Confidentiality /

Gender Attitudes injectable contraceptives. However

some respondents cautioned that

some supporters did not have

adequate knowledge about

injectable contraceptives.
Most female and male respondents preferred community-based

approaches over facility-based approaches to distribution of contraceptives due to convenience, affordability and focused attention from health worker. For men, convenience meant giving women more time for domestic issues.
"Definitely, you have 70\% support from the communities. From the religious leaders, traditional rulers and even of ward heads in the community we get $100 \%$ support."

\section{IDI, Male, Traditional Leader, Gombe}

"...Really, people have supported the program but I know some people do not have the knowledge (about injectable contraceptives) but those that have the knowledge are really in support of the program... [you know] the Northern culture prohibits some things, that's why I said the support for it (injectable contraceptives scale up) is not as much as we expect." IDI, Male, Christian Religious Leader

"Whenever the need arises, we normally call the kingmakers, district head kingmakers, they are about seven, and we have at least 54 ward heads, we use to call them from time to time and enlighten them on the programme. In fact, almost all the community leaders are fully aware of the programme." IDI, Male, Traditional Leader

"There are so many traditional rulers that were involved in this program; that is the reason why it has been accepted 100\%, especially in Gombe State now."

\section{IDI, Male, Traditional Leader, Gombe}

"...My involvement is... passive involvement. Of course, we preachers, you can push people, encourage them in your own little way... We preach it, we tell people about it..."

\section{IDI, Male, Christian Religious Leader}

"...During home visit, it's between you and the woman (health worker) and she can explain it very well to you since she is not in a hurry; although in the hospital they can also explain but the home visit is better since the health worker will explain until you understand."

\section{FGD, Female, Current User}

"...Maybe the time the wife wants to go (to the health facility) the husband needed her for something else... Sometimes some husbands want all these things to be confidential, but when you now tell them to release their wives to the hospital, they will think you are exposing the family issues." FGD, Married Men 


\section{Financial}

Constraints /

Marital Security /

Quality of Life allows women to stay attractive in order to prevent husbands from

'straying'. Quality of life and hygiene is improved with fewer children and fewer financial constraints.

\begin{tabular}{|c|c|c|}
\hline \multirow[t]{3}{*}{$\begin{array}{l}\text { Sinai, et al. } \\
\text { (2019) }\end{array}$} & Attitudes & $\begin{array}{l}\text { Despite the social stigma associated } \\
\text { with contraceptive use, attitudes } \\
\text { towards FP are changing and being } \\
\text { viewed in a more positive light. }\end{array}$ \\
\hline & $\begin{array}{l}\text { Birth Spacing / } \\
\text { Polygyny } \\
\text { (attractiveness) }\end{array}$ & $\begin{array}{l}\text { Despite some women believing that } \\
\text { they appeared more beautiful with } \\
\text { more children, others felt that if they } \\
\text { spaced their children, the effect of } \\
\text { repeated deliveries would have less } \\
\text { of an effect on their bodies and they } \\
\text { would look more attractive, } \\
\text { healthier and youthful to their } \\
\text { husbands (especially if there was } \\
\text { competition between co-wives). } \\
\text { Therefore, these women were more } \\
\text { inclined to use contraceptives. This } \\
\text { sentiment resonated more with } \\
\text { women in their forties than in their } \\
\text { twenties. }\end{array}$ \\
\hline & $\begin{array}{l}\text { Financial } \\
\text { Constraints }\end{array}$ & $\begin{array}{l}\text { People are starting to realise that it } \\
\text { is difficult to support many children } \\
\text { and are therefore open to } \\
\text { contraceptive use. }\end{array}$ \\
\hline
\end{tabular}

"...If we space our children well, we will enjoy our lives because our husbands will always desire us since we are always looking attractive. He will not stay out late because he will be thinking of you at home." FGD, Female, Current User

"...You will be able to take care of yourself as well as your house, your husband will also desire you as you will look good as well as your children. Flies will not follow you around and anyone that comes to your house will be able to eat and drink because everywhere is clean and attractive." FGD, Female, Current User

"We viewed them as women who enjoyed their lives, because there is no comparison between women who use that method and those who do not. What is more interesting in this community is that people are beginning to rethink about the use of family planning methods. I really adore women who use family planning methods; I'd really love to use it if my husband would allow it."

\section{Asabe, 49 Years Old, Mother of Nine, First Wife (of Three), Muslim}

"Those using the [contraceptive] methods are much healthier in looks than those who do not. If you would see my age mate who is using the methods, you would think I am older than her because she rests after every delivery before another."

\section{Fatima, 31 Years Old, Mother of Six, Second Wife (of Two), Muslim}

"God gives us these children and He provides us with what to sustain them. On the other hand, people are now complaining about the number of children. People now don't want to take responsibility. In fact, people are saying the number of children women give birth to is too much" Asabe, 49 Years Old, Mother of Nine, First Wife (of Three), Muslim 


\begin{tabular}{|c|c|c|}
\hline & $\begin{array}{l}\text { Knowledge of } \\
\text { Family Planning }\end{array}$ & $\begin{array}{l}\text { Information about FP is widely } \\
\text { available and all could name modern } \\
\text { contraceptive methods. }\end{array}$ \\
\hline & $\begin{array}{l}\text { Quality of Family } \\
\text { Planning \& } \\
\text { Services }\end{array}$ & $\begin{array}{l}\text { Participants overall found quality of } \\
\text { health care to be friendly, } \\
\text { informative and helpful. }\end{array}$ \\
\hline \multirow[t]{3}{*}{$\begin{array}{l}\text { Ujuju, et al. } \\
\text { (2011) }\end{array}$} & *Religion & $\begin{array}{l}\text { Billing's Method was preferred as } \\
\text { this was the method approved by } \\
\text { the Catholic Church. Community and } \\
\text { religious leaders also helped } \\
\text { expanding access of SDM and } \\
\text { CycleBeads which helped alleviate } \\
\text { fears in the communities about the } \\
\text { methods. Withdrawal method is also } \\
\text { accepted. }\end{array}$ \\
\hline & $\begin{array}{l}\text { Birth Spacing } \\
\text { (short term) }\end{array}$ & $\begin{array}{l}\text { SDM was accepted for those } \\
\text { intending for short term birth } \\
\text { spacing or those breastfeeding to } \\
\text { prevent pregnancy. It is also best for } \\
\text { women with regular menstrual } \\
\text { cycles. }\end{array}$ \\
\hline & $\begin{array}{l}\text { Male } \\
\text { Involvement }\end{array}$ & $\begin{array}{l}\text { Male participants who introduced } \\
\text { the SDM and CycleBeads to their } \\
\text { wives were more likely to ensure } \\
\text { that their wives remember to move } \\
\text { the ring, and abstain or use condoms } \\
\text { during the fertile periods as they } \\
\text { took pregnancy prevention more } \\
\text { seriously. Abstinence for men in } \\
\text { polygynous marriages is easier as }\end{array}$ \\
\hline
\end{tabular}

"Most of the time they use injections or implants, but injection is mostly used."

Amina, 31 Years Old, Mother of Two, First Wife (of Two), Muslim

"They told me that I will experience a small change, but it is normal and after some time I be fine." Huseina, 30 Years Old, Mother of Three, Third Wife (of Three), Muslim

"Some religion is against pills but this one (CycleBeads), our Priest encouraged us to use it." Female

"Islamic clerics have been asked to comment on the Islamic relevance of the CycleBeads which they said is allowed for health reasons and spacing." Male

"For me I would say that any woman who has lots of children and gives birth at a close range should use the CycleBeads." Female

"Women who don't want to use pills to prevent pregnancy." Female

"Those women that their cycle length is 26-32 days." Female

"It could be used by a woman who wants to space her children for three years or more because some women who are breastfeeding can get pregnant." Male

"I monitor it on a daily basis to ensure she (my wife) moves the ring." Male

"The health provider gives me condoms to use because I had complained to him that I cannot abstain for the 12 days." Male

"Some abstain, some use condom but majority abstain." Provider

"You can't start using CycleBeads without the consent of your husband. You can't do it alone except your husband agrees. The problem is not with the women, but usually with the men. 
they can be with a different wife

during the fertile period.

The absence of side effects was a big reason for using SDM.

Most users of SDM obtained

information from health care

providers.
I suggested to my husband and he gave me his consent. If he did not agree, I wouldn't have used it, frankly." Female

"We only spend two days in a wife's room and move to the next... The man with one (wife) is the one with that problem (managing the white bead days)." Male

"You see, rotation allows the man to have sexual intercourse with all the wives. It is easier because it is rare for all the women to be on white bead days at the same time."

Health Provider

(None presented.)

(None presented.)
Source of

Information 


\section{Appendix H5: Higher Acceptance of Family Planning (Somalia)}

Table H5. Results from the qualitative studies $(2010-2019+2020)$ displaying the summaries and representative quotes of themes influencing higher acceptance of family planning in Somalia.

\begin{tabular}{|c|c|c|c|}
\hline Study & Theme & Summary & Representative Quote(s) \\
\hline \multirow[t]{6}{*}{$\begin{array}{l}\text { Egeh, et al. } \\
\text { (2019) }\end{array}$} & $\begin{array}{l}\text { * Religion / Birth } \\
\text { Spacing - } \\
\text { Breastfeeding }\end{array}$ & $\begin{array}{l}\text { Breastfeeding is the most accepted } \\
\text { form of birth spacing and is } \\
\text { mentioned } 14 \text { times in the Quran. }\end{array}$ & $\begin{array}{l}\text { "We [my wife and I] used } 2 \text { consecutive years of breastfeeding to space the births of our } \\
\text { children... that helped us and there is a 2-year interval between the birth of my children." } \\
\text { Religious Leader }\end{array}$ \\
\hline & $\begin{array}{l}\text { * Religion / Birth } \\
\text { Spacing - Oral } \\
\text { Contraceptives }\end{array}$ & $\begin{array}{l}\text { Oral contraceptives are prohibited in } \\
\text { Islam. However, religious leaders } \\
\text { agreed that is was permissible for } \\
\text { birth spacing only if it did not have } \\
\text { any health problems for women. }\end{array}$ & $\begin{array}{l}\text { "There is no need to give women contraceptive pills to achieve birth spacing because } \\
\text { breastfeeding the child correctly by emptying the breasts of milk before having sex is enough } \\
\text { to achieve the desired results." Religious Leader }\end{array}$ \\
\hline & $\begin{array}{l}\text { Birth Spacing - } \\
\text { Condom }\end{array}$ & $\begin{array}{l}\text { Despite the negative attitudes, one } \\
\text { religious leader supported condoms. }\end{array}$ & $\begin{array}{l}\text { "I think that married couples can use condoms if they so desire. Condoms are not a big deal, } \\
\text { and it is just like the withdrawal method." Religious Leader }\end{array}$ \\
\hline & $\begin{array}{l}\text { Birth Spacing - } \\
\text { Withdrawal }\end{array}$ & $\begin{array}{l}\text { Withdrawal is an accepted form of } \\
\text { FP, so long as it is used for the } \\
\text { purpose of birth spacing. }\end{array}$ & $\begin{array}{l}\text { "Allah makes the ultimate decision regarding creation; withdrawal can prevent the woman } \\
\text { from becoming pregnant. Thus, a distinction is drawn between whether the withdrawal } \\
\text { method was used with the intention to limit the number of children or to space the births. } \\
\text { This distinction is important when making the choice to use the withdrawal method." } \\
\text { Religious Leader }\end{array}$ \\
\hline & Maternal Health & $\begin{array}{l}\text { If pregnancy is risky to the woman's } \\
\text { health, a Muslim doctor can } \\
\text { recommend contraception to extend } \\
\text { birth spacing. }\end{array}$ & $\begin{array}{l}\text { "If the mother does not have or eat a balanced diet that will build her body and prepare her } \\
\text { for having another baby, birth spacing is an option for her because the Islamic religion } \\
\text { always protects the women and children and does not want to harm anybody." } \\
\text { Religious Leader }\end{array}$ \\
\hline & $\begin{array}{l}\text { Spousal } \\
\text { Communication }\end{array}$ & $\begin{array}{l}\text { Most religious leaders believe } \\
\text { healthy discussion and fair decision- } \\
\text { making between couples for FP } \\
\text { needs is prudent for birth spacing } \\
\text { and avoids problems caused by lack } \\
\text { of communication. }\end{array}$ & $\begin{array}{l}\text { Decision making that is fair and shared is the best way to make decisions on birth spacing. } \\
\text { However, sometimes this may not be the case (e.g. sometimes the woman may express false } \\
\text { complaints, telling the husband that she is sick and unable to have another pregnancy when } \\
\text { in fact she is physically fit). The couples should be open and honest to build a strong and } \\
\text { lasting relationship." Religion Leader } \\
\text { "...shared decision making is not a matter of quarrelling but it is like sitting together to } \\
\text { discuss what is good for both of them, both the man and the woman." Religious Leader }\end{array}$ \\
\hline
\end{tabular}




\section{Appendix H6: Higher Acceptance of Family Planning (South Africa)}

Table H6. Results from the qualitative studies $(2010-2019+2020)$ displaying the summaries and representative quotes of themes influencing higher acceptance of family planning in South Africa.

\begin{tabular}{|c|c|c|c|}
\hline Study & Theme & Summary & Representative Quote(s) \\
\hline \multirow[t]{5}{*}{$\begin{array}{l}\text { Protogerou, et al. } \\
(2014)\end{array}$} & *Religion & $\begin{array}{l}\text { Some participants were able to } \\
\text { disassociate their religious beliefs } \\
\text { from sex and condom use. }\end{array}$ & $\begin{array}{l}\text { "...you know when having sex, it's not a relief bringing religion into it, I guess when in that } \\
\text { space, when I am about to have sex I kind of dissociate the religion and because of the clashes } \\
\text { with the religion and what I'm doing, so there's no religious influence in condom use." } \\
\text { Nicole, White, Roman Catholic, } 22 \text { Years Old }\end{array}$ \\
\hline & $\begin{array}{l}\text { Accessibility / } \\
\text { Affordability }\end{array}$ & $\begin{array}{l}\text { Government condoms were free of } \\
\text { charge and were "everywhere" } \\
\text { (though of low quality). Hormonal } \\
\text { contraception was also easily } \\
\text { accessible and more affordable than } \\
\text { brand-name condoms. }\end{array}$ & $\begin{array}{l}\text { "You can either get the pill for free from, I know at UCT [the University's initials], they will } \\
\text { provide you with the pill for free, but I think it's best to go to a doctor, however they won't be } \\
\text { free but it's really easy to get it, currently I go to my doctor and she just gives me three months } \\
\text { for it and I don't have to keep coming back for it, it's just a case of making an appointment." } \\
\text { Libby, Coloured, } 19 \text { Years Old }\end{array}$ \\
\hline & $\begin{array}{l}\text { Domestic } \\
\text { Violence }\end{array}$ & $\begin{array}{l}\text { Four female participants reported } \\
\text { experiencing intimate partners } \\
\text { violence (with one being physical } \\
\text { violence). All participants cited } \\
\text { increased condom use and increased } \\
\text { precaution due to lack of trust. }\end{array}$ & $\begin{array}{l}\text { "...now [after experiencing verbal and physical violence] we no longer want to try that whole } \\
\text { adventurous thing, you just wanna keep it safe all the time, I told him, now I don't wanna } \\
\text { trust you..." Zoe, Black Tsonga, } 24 \text { Years Old }\end{array}$ \\
\hline & $\begin{array}{l}\text { Family and } \\
\text { Educational } \\
\text { Values }\end{array}$ & $\begin{array}{l}\text { Condom use appeared to be heavily } \\
\text { influenced by family and school } \\
\text { values (schools were selected based } \\
\text { on family values). }\end{array}$ & $\begin{array}{l}\text { "The only thing that would really influence me is just my parents, what they have told me and } \\
\text { said to me and made sure that I understand what could happen... so it's just my parents } \\
\text { drilling morals into me really." Lydia, White, } \mathbf{2 1} \text { Years Old } \\
\text { "I went to a Jewish school...it was quite a liberal school I think in terms of safe sex education } \\
\text { and they were quite open about that, but I think, you know, my mother, I'm quite open with } \\
\text { my mother about my sexual history so... I think it's just the fact that they've educated me } \\
\text { enough is enough." Megan, White, } 23 \text { Years Old }\end{array}$ \\
\hline & & & $\begin{array}{l}\text { "My family's a kind of a very alternative "diluted" form, we are proud of who we are and we } \\
\text { do some of the cultural things but we have added our own sort of, some would say western, } \\
\text { I would say more advanced things to the culture... we've added on some values that really }\end{array}$ \\
\hline
\end{tabular}




\begin{tabular}{|c|c|c|}
\hline & & $\begin{array}{l}\text { would help preserve our family and ourselves so, condoms, it's something that we really } \\
\text { endorse." Ryan, Black Xhosa, } 20 \text { Years Old } \\
\text { "...from experience and friends and just general family, I think it's down to the person. I don't } \\
\text { think it's about culture because I think of people from all [South African] cultures who make } \\
\text { stupid decisions and people that are very safe." Libby, Coloured, } 19 \text { Years Old }\end{array}$ \\
\hline $\begin{array}{l}\text { Pregnancy and } \\
\text { Disease } \\
\text { Prevention }\end{array}$ & $\begin{array}{l}\text { Male participants did not feel } \\
\text { condoms threatened intimacy. Male } \\
\text { and female participants agreed that } \\
\text { condoms would be appropriate in } \\
\text { intimate relationships if the intention } \\
\text { was to prevent pregnancy and } \\
\text { HIV/STIs. }\end{array}$ & $\begin{array}{l}\text { "I do agree with married couples wearing the condoms sometimes if they're not taking any } \\
\text { other precautionary methods, but I'd like to think that the condom is rather to avoid } \\
\text { unexpected pregnancies ... or if one of the partners is indeed infected with a disease, it's not } \\
\text { the end of the world, then it's good... you're still giving your partner pleasure and you're still } \\
\text { getting pleasure from your partner." Tyler, Black Zulu, } 19 \text { Years Old } \\
\text { "I know people would think about the issue of trust, I maybe do trust the person but it's not } \\
\text { about trusting, I think, it's just that we live in a time where HIV especially in South Africa is } \\
\text { such a huge thing, and you can't really afford to slip up anywhere, you know, even when I get } \\
\text { married, I've decided, I think, I'm going to have to use them [condoms] so, I think exclusive or } \\
\text { not exclusive, condoms all the way." Ryan, Black Xhosa, } 20 \text { Years Old }\end{array}$ \\
\hline
\end{tabular}




\section{Appendix H7: Higher Acceptance of Family Planning (Tanzania)}

Table H7. Results from the qualitative studies $(2010-2019+2020)$ displaying the summaries and representative quotes of themes influencing higher acceptance of family planning in Tanzania.

\begin{tabular}{|c|c|c|c|}
\hline Study & Theme & Summary & Representative Quote(s) \\
\hline $\begin{array}{l}\text { Aristide, et al. } \\
(2020)\end{array}$ & *Religion & $\begin{array}{l}\text { Some respondents did say that it was } \\
\text { their belief that using FP was a moral } \\
\text { responsibility. }\end{array}$ & (None presented.) \\
\hline $\begin{array}{l}\text { Msoka, et al. } \\
\text { (2019) }\end{array}$ & $\begin{array}{l}\text { Source of } \\
\text { Information }\end{array}$ & $\begin{array}{l}\text { More and more women are getting } \\
\text { reproductive health information from } \\
\text { health facilities and their phones. } \\
\text { Women saw health facilities as } \\
\text { providing credible sources of } \\
\text { information. }\end{array}$ & $\begin{array}{l}\text { "I do get information from [the] health center, but sometimes I receive messages through my } \\
\text { phone; there are some questions that am being asked about my health." FGD 4, R 5, Masaki } \\
\text { "What I know due to poor economy, it is important you plan before giving birth; therefore, you } \\
\text { need to sit with your husband in the clinic and decide." FGD 1, R 2, Bagamoyo }\end{array}$ \\
\hline \multirow[t]{3}{*}{$\begin{array}{l}\text { Pallangyo, et al. } \\
\text { (2020) }\end{array}$} & $\begin{array}{l}\text { Access to } \\
\text { Education / } \\
\text { Financial Security } \\
\text { / Quality of Life }\end{array}$ & $\begin{array}{l}\text { Women believed that men with } \\
\text { higher education and from well- } \\
\text { educated communities were more } \\
\text { likely to take up vasectomy as they } \\
\text { are aware that FP allows them to save } \\
\text { money and have better quality of life. }\end{array}$ & $\begin{array}{l}\text { "Some people will see [a man] as breaching customs (if he uses vasectomy), but those who are } \\
\text { ahead of us those who are well educated see him as a clever person. Educated people give birth } \\
\text { to two, three, or four children, but for us who did not go to school, we go for eight children or } \\
\text { ten. You're competing: my neighbor has six kids so I also need six kids." Woman 1, Chalinze }\end{array}$ \\
\hline & $\begin{array}{l}\text { Fertility Desires / } \\
\text { Financial } \\
\text { Constraints / } \\
\text { Quality of Life }\end{array}$ & $\begin{array}{l}\text { A key reason for accepting vasectomy } \\
\text { was that a small family size meant } \\
\text { that it was possible to save money, } \\
\text { educate each of their children and } \\
\text { have better quality of life. }\end{array}$ & (None presented.) \\
\hline & $\begin{array}{l}\text { Gender Attitudes } \\
\text { / Promotion of } \\
\text { Family Planning }\end{array}$ & $\begin{array}{l}\text { Most women believed that promoting } \\
\text { FP to men would increase their uptake } \\
\text { as they are the decision-makers in the } \\
\text { household, therefore, it is easier if the } \\
\text { man contributed to FP decisions. } \\
\text { Many women feel they are more } \\
\text { educated that men on FP as they get } \\
\text { information when visiting health }\end{array}$ & $\begin{array}{l}\text { "Encourage men to use contraceptive methods using community health workers, or maybe you } \\
\text { could announce seminars or meetings about family planning in villages. Through these } \\
\text { meetings, you may encourage men to attend clinics." Woman 4, Bagamoyo } \\
\text { "The [woman's] main role is to educate the father so he can understand it (vasectomy) through } \\
\text { action and words too. We [women] get this education when visiting clinics with our children." } \\
\text { Woman 4, Masaki }\end{array}$ \\
\hline
\end{tabular}


clinics. They then educate their

husbands. However, men who receive

information from a health

professional is more likely to take FP

seriously. Women also stated that

supporting men in their decision-

making would encourage them to take up vasectomy.

Knowledge of Some women believed vasectomy Family Planning / protected against HIV and other STIs. Misconceptions

\section{*Religion}

\section{Contrary to the above, some}

respondents believed that limiting the number of children was acceptable by citing moral lessons derived from religious texts, such as caring for children and living within one's means. Using FP was consistent with these moral standards. Other respondents supported the view that FP is against their religion, however, they are also in support of the use of FP due to current hardships in life including economical and the spread of diseases. Although some participants did not feel it was appropriate that FP was discussed in a religious setting, others were open to it.
"A woman's role is to accept and not ignore him, because he will continue with sexual acts as normal. You should not ignore your husband, saying he is no longer a man because he practiced vasectomy. You need to be humble and respect him so that your marriage will last."

\section{Woman 1, Bagamoyo}

\section{"Vasectomy should prevent both pregnancy and HIV/AIDS." Woman 3, Kisarawe}

"When God says that you should fill the earth, he did not mean we should just give birth, that we should just give birth haphazardly. He meant that you give birth to those children you should be able to feed them with your income... You should give birth to the children that you can take care of in your life... If you do not take care of them, you just leave them? That is also a sin."

\section{Female, Christian}

"God has started this question. He has seen it-yes indeed-because he said first when you want to marry, you marry in accordance with your position. God has admonished us, first even if you want to marry, marry the women you are able to keep. But, you must fulfil their needs. There we came to look, and in this question of children, the religion is also involved to tell us we should give birth in relation to our capacity. It has admonished us we should give birth in accordance to our economic capacity, the way we are. Yes, indeed that is how religion tries to be involved." Male, Muslim

"The Bible is clear, and God has ordered us that we go and give birth, and fill the world. Except, because the way of life has changed for now, the human being enters into the challenge of life. It is better to at least use family planning because life is difficult." Christian Man

"There are diseases the woman may have, like diabetes, high blood pressure. These are among all the things that can cause her to use family planning. Even though in our religion of Islam, these things are not there; in our faith there is no family planning. It is not there at all, but according to the situation right now, it has to be done." Muslim Man 
Female

Independence

FP allows women to pursue their own income-generating ambitions.

Financia

Constraints

Maternal Health /

Quality of Life
Both Christians and Muslims showed interest in FP due to economic constraints and stresses caused by large family sizes.

Taking up FP is beneficial to the health of both mother and child and allows the mother to give more attention to each child when there are fewer children, giving each child a better quality childhood. This was reported by Christians and Muslims, males and females.
"It would be a good thing [if religious leaders provided family planning education] because indeed... it will be easy. Men for men. Therefore, if they [male religious leaders] deliver it [family planning education] it will indeed be better because we ourselves [women] we are taught and then the man is at home. The woman cannot teach the man at home, and some men don't listen at all." Muslim Woman

"If... in church they talk about this matter...you must feel good because they give quality education to the believers and the whole society, not only in church. It means once you are taught in church straight away even outside you will provide it, you will teach others."

\section{Christian Man}

"Family planning helps me with very many issues because it helps me that I can have a business. Many children in short intervals [means] you cannot do your business. But you plan reproduction, your business goes well, those big children; you give them space and things go very well." Muslim Woman

"What causes us men to agree to be advised early to practice family planning is mainly due to the economic situation. If you look at it right now, the economy is already very bad. Men agree easily to family planning because of the life, and low life, you see. I have to reduce the poverty because I am the one to look out for everything, therefore I must be involved so that I bring up few children." Male, Christian

"It comes like this; you get a family. At times it is too much for you... to give it the important needs. For example, education, a place to sleep, and the needs of food." Male, Muslim

"We give them a chance of being... [a young child] still needs the mother's love and you give birth to another child, that means you desert the previous one and you don't give him/her the same rights equal to the ones of the small child. [By using family planning] we are having ample time to take care of the children we already have with more love and bringing them up better."

\section{Muslim Woman}

"Another reason which women... follow family planning is the deaths of mother and child... if you look a high percentage of families who do not follow family planning, the mother gets negative effects. First there is exhaustion, exhaustion brings deaths. The mother gives birth one year, she gives birth to a child one year, she hasn't rested those cells.... She has a child. The following year she has a child. It means it leads even to death." Christian Man 

necessary that he finds a [girlfriend outside of the marriage] because... he'll find that woman is clean. Maybe she has children, she has only one child. He'll find the lady there is clean. She washes the clothes. But if he comes to you with five or six children, it just smells of urine inside, so he just has to run away and leave you with this family." Female, Christian 


\section{Appendix H8: Higher Acceptance of Family Planning (Uganda)}

Table H8. Results from the qualitative studies $(2010-2019+2020)$ displaying the summaries and representative quotes of themes influencing higher acceptance of family planning in Uganda.

\begin{tabular}{|c|c|c|c|}
\hline Study & Theme & Summary & Representative Quote(s) \\
\hline $\begin{array}{l}\text { Kabagenyi, et al. } \\
\text { (2016) }\end{array}$ & Attitudes & $\begin{array}{l}\text { Younger adults (15-24 years) claim to } \\
\text { be in a modern generation and do } \\
\text { not know about the older } \\
\text { generation's traditional methods and } \\
\text { are less likely to practice it. }\end{array}$ & $\begin{array}{l}\text { "Those were methods uses a long time ago. Such traditional contraception methods of using } \\
\text { herbs and cultural practices are no longer efficient. The elderly people who knew these herbs } \\
\text { are no longer there as they died." Male, FGD, 15-24 Years, Mpigi } \\
\text { "We hear our elders were using traditional medicine, I do not know them. I doubt whether } \\
\text { they still use them because every generation has its practices but what I know is that they } \\
\text { give you herbs for drinking. Also, there are women who cannot get pregnant when } \\
\text { breastfeeding. A woman can spend } 3 \text { years breastfeeding her baby and when she chooses to } \\
\text { stop, she can immediately conceive." Female, FGD, 15-24 Years, Bugiri } \\
\text { "Those were for a long time ago, the contraception methods of using herbs and cultural } \\
\text { practices. The elderly people who knew these herbs are no longer there as they died." } \\
\text { Male, FGD, 19-24 Years, Mpigi }\end{array}$ \\
\hline
\end{tabular}

